archives-ouvertes

\title{
Functionalized Benzazines as Luminescent Materials and Components for Optoelectronics
}

\author{
Emiliya V. Nosova, Sylvain Achelle, Galina N. Lipunova, Valery N. \\ Charushin, Oleg N. Chupakhin
}

\section{To cite this version:}

Emiliya V. Nosova, Sylvain Achelle, Galina N. Lipunova, Valery N. Charushin, Oleg N. Chupakhin. Functionalized Benzazines as Luminescent Materials and Components for Optoelectronics. Russian Chemical Reviews, Turpion, 2019, 88 (11), pp.1128-1178. 10.1070/RCR4887 . hal-02493304

HAL Id: hal-02493304

\section{https://hal-univ-rennes1.archives-ouvertes.fr/hal-02493304}

Submitted on 27 Feb 2020

HAL is a multi-disciplinary open access archive for the deposit and dissemination of scientific research documents, whether they are published or not. The documents may come from teaching and research institutions in France or abroad, or from public or private research centers.
L'archive ouverte pluridisciplinaire HAL, est destinée au dépôt et à la diffusion de documents scientifiques de niveau recherche, publiés ou non, émanant des établissements d'enseignement et de recherche français ou étrangers, des laboratoires publics ou privés. 


\title{
Functionalized Benzazines as Luminescent Materials and Components for Optoelectronics
}

\author{
E.V. Nosova ${ }^{1,2 *}$, S. Achelle ${ }^{3}$, G.N. Lipunova ${ }^{1,2}$, V.N. Charushin ${ }^{1,2}$, O.N. Chupakhin ${ }^{1,2}$ \\ ${ }^{1}$ I. Ya. Postovsky Institute of Organic Synthesis, Ural Branch of the Russian Academy of Sciences, \\ Ekaterinburg, Russian Federation.E-mail: lipunova@ios.uran.ru \\ ${ }^{2}$ Ural Federal University, Ekaterinburg, Russian Federation.E-mail: emily74@rambler.ru \\ ${ }^{3}$ Univ. Rennes, CNRS, Institut des Sciences Chimiques de Rennes - UMR 6226, F35000 Rennes, \\ France
}

\begin{abstract}
Extensive research on the synthesis and application of benzazine derivatives for electronic devices, luminescent elements, photoelectric conversion elements, and image sensors has been published recently. In the frames of this review article data obtained within the period 2012-2018 on the synthesis and optical properties of functionalized quinolines, quinoxalines and quinazolines are considered. Arylvinyl-, arylethynyl- and (het)arylderivatives of these benzazines, their photoluminescence and photoisomerisation are discussed. Examples of photosensitive annelated, oligo- and polymeric benzazines and also coordination compounds with benzazine ligands are reviewed.

Bibliography 267 references.
\end{abstract}

\section{Content}

I. Introduction

II. Arylvinyl-, arylethynyl- and (het)arylbenzazines

III. Annelated benzazines

IV. Polymer benzazines

V. Coordination compounds of benzazines

VI. Conclusion

\section{Introduction}

Organic photosensitive materials have attracted much attention during the past two decades due to their applications in electronic and optoelectronic devices such as organic light-emitting diodes (OLEDs), organic field-effect transistors (OFETs), organic solar cells (OSCs), sensors and many others, as indicated by numerous publications, including recent monographs. ${ }^{1-5}$ In themed issue of Journal of Materials Chemistry dedicated to novel organic optoelectronic materials ${ }^{6}$ it is noted that the research and development of these materials belong to the cross-disciplinary science 
uniting chemistry, physics, materials science, electronics, nanotechnology and biology. Numerous reviews are devoted to separate aspects in the field of creation and use of new photosensitive materials. So, researches of luminescent materials, including organic, for semiconductor lighting have been presented in recent review article. ${ }^{7}$ Authors of work $^{8}$ analyzed organic electroluminescent materials, including metalloorganic and coordination compounds, and also the devices radiating in UV and IR ranges. Data on coordination compounds of lanthanides with the organic ligands applied in design of electroluminescent diodes are systematized in another work of the same group of authors. ${ }^{9}$ Recent advances in creation of the white light-emitting diodes (WOLEDs) having a number of advantages are presented. ${ }^{10,11}$ New design of WOLEDs which allows to decrease the number of photolithographic cycles and to reduce the production cost is discussed in work. ${ }^{12}$ Materials for highly effective phosphorescent OLEDs with low working voltage are described in the review. ${ }^{13}$ Organic materials with nonlinear optical properties are presented. ${ }^{14}$ Fundamental processes in organic photo cells are discussed. ${ }^{15}$ Data on the physical mechanisms defining optoelectronic properties of high-performance organic materials, materials for organic solar cells and semiconductors are summarized. ${ }^{16}$

Organic compounds with expanded $\pi$-electronic system represent the basis of photosensitive materials. Among them the important place is taken by the structures including the electron donating and electron withdrawing groups connected through $\pi$-conjugated spacer, so-called pushpull systems. Molecular properties of such chromophores are defined by the ability of both donating and withdrawing fragments to participate in intramolecular charge transfer (ICT). Aromatic nitrogen-containing $\pi$-deficient heterocycles, such as pyridine, quinoline and their aza-analogs, are widely used as electron withdrawing part in the systems with ICT. ${ }^{13}$ The ability of these heterocycles to protonation and complexation at nitrogen atoms, as well as incorporation of groups capable to polymerization expands the application of such compounds for the creation of light sensitive materials. ${ }^{10}$

Six-membered heterocycles with two nitrogen atoms - diazines (pyridazine, pyrimidine and pyrazine) and their benzoanalogs (quinazoline and quinoxaline) have already proved to be the key structural fragments in functionalized $\pi$-conjugated systems, and they are presented in a number of reviews. ${ }^{17-22}$ Aryl, arylvinyl and arylethenyl derivatives of pyrimidines and coordination compounds based on them are most studied, optical, electrochemical properties, photoluminescence, scopes of application are discussed. ${ }^{17-19}$ As for similar derivatives of quinoxaline and quinazoline, some data are provided in reviews ${ }^{19,20,22,23}$, mainly such compounds are described in articles and patents. Taking into account that intensive researches of organic compounds as key components for OLEDs have begun with derivatives of quinoline, ${ }^{24}$ which properties are close to quinoxaline and 
quinazoline, it was of interest to carry out the comparative analysis of derivatives of these three heterocycles. Other benzo(di)azines such as isoquinoline, cinnoline and phtalazine have been much less used in the field of chromophores for optoelectronic.

In the present review we tried to summarize the data on the synthesis and optical properties of functionalized benzazines (quinolines, quinoxalines and quinazolines) as luminescent materials and components of optoelectronic devices. This review focuses on arylvinyl- arylethynyl- and aryl(hetaryl)benzazines, their metal complexes, annulated derivatives as well are oligomer and polymer structures bearing these moieties for the period of 2012-2018. Non aromatic benzazinones and structures bearing extra cycles will not be discussed here.

The following abbreviations are used in the current review:

AACC -activtion/ alkynylation/ cyclocendensation,

acac - acetylacetonate,

AIE -aggregation-induced emission,

$\mathrm{Alq}_{3}$ - complex of aluminium with 8-hydroxyquinoline,

BAZnP - butylaminozirconium phosphate,

biimquin - bis(imidazol-1-yl)quinoxaline,

bpy - 2,2-bipyridine,

$\mathrm{Bz}$ - benzoyl,

bzq - benzo[ $h]$ quinoline,

cd - candela,

CPDT - cyclopentadithiophene,

CPL - circularly polarized luminescence,

Cy - cyclohexyl,

D-A-D - donor-acceptor-donor,

dbm - dibenzoylmethane,

DBU - 1,8-diazabicyclo[5.4.0]undec-7-ene,

dca - dicyanamide,

DCM- dichloromethane,

dfppy - difluorophenylpyridine,

DFT -density functional theory,

dmp - дипивалоилметан;

DNA - deoxyribonucleic acid,

DPEPO - [bis(2-diphenylphosphoryl)]phenyl ester

dpquin - dipyrido[3,2-f:2,3- $h$ ]quinoxaline,

dpquin $(\mathrm{COOH})_{2}-6,7-$ dicarboxypyrido[3,2-f:2,3-h]quinoxaline, 
DSSC - dye-sensitized solar cell,

EFISH -electric field induced second harmonic,

ESIPT - excited state intramolecular proton transfer,

EQE -external quantum efficiency,

FRET -Förster resonance energy transfer,

FTO - fluorine-doped tin oxide,

GM - units of Goeppert-Mayer, characterizing two-photon absorption $\left(1 \mathrm{GM}=1 \cdot 10^{-50} \mathrm{~cm}^{4} \cdot \mathrm{s}\right.$ $\cdot$ photon $^{-1}$ )

HEPES - 4-(2-hydroxyethyl)-1-piperazine-ethanesulphonic acid,

hip - deprotonated 5-hydroxyisophthalic acid,

HOMO - highest occupied molecular orbital,

$\mathrm{H}_{2}$ qldc - quinolin-2,3-dicarboxylic acid,

3-Hqlc - quinolin-3-carboxylic acid,

ICT - intramolecular charge transfer,

${ }^{3}$ MLCT -triplet metal-to-ligand charge transfer,

${ }^{3} \mathrm{LC}$ - triplet ligand-centred,

LLCT - ligand-ligand charge transfer,

LUMO - lowest unoccupied molecular orbital,

MTPP-Br - methyltriphenylphosphonium bromide,

MW - microwave irradiation,

Naph - naphthyl,

NLO - non-linear optics,

OFET - organic field-effect transistor,

OLED - organic light-emitting diode,

OPV - organic photovoltaics,

OSC - organic solar cell,

OTFT - organic thin film transistor,

ITO - indium tin oxide,

P3HT - poly(3-hexylthiophene),

PBS - sodium phosphate buffer,

PCE - power conversion efficiency,

PEDOT - poly(3,4-ethylenedioxythiophene),

phen - 1,10-phenanthroline,

PhOLED - phosphorescent light-emitting diode,

PMMA - polymethylmetacrylate, 
PPi - pyrophosphate,

ppq1 - 2,4-diphenylquinoline,

PSC - polymer solar cell,

PSS - polystyrolsulphonate,

Py - pyridyl,

PVC - photovoltaic cell,

q-8-hydroxyquinoline,

ql - quinolone,

qnz - quinazoline,

qox - quinolin- $N$-oxide,

quin - quinoxaline,

RISC - reverse intersystem crossing,

rt - room temperature,

SMM - single molecule magnet,

TADF - thermally activated delayed fluorescence,

TCE - 1,1,1-trichloroethane,

TDDFT - time-dependent DFT,

Th - thienyl,

TFA - trifluoroacetic acid,

TIPS - triisopropylsilyl,

TMS - trimethylsilyl,

TPA -two-photon absorption,

TPEF - two-photon-excited fluorescence,

Vs - volatile solids,

WOLED -white organic light-emitting diode,

$\Phi_{\mathrm{F}}$ - luminescence quantum yield.

\section{Arylvinyl-, arylethynyl- and (het)arylbenzazines}

\section{II.1. Synthesis, photoluminescence and photoisomerization of arylvinylbenzazines}

Condensation of 2-methylsubstituted benzazines $\mathbf{1}$ with arylcarboxaldehydes $\mathbf{2}$ or arylcarboxdialdehydes $\mathbf{4}$ under basic or acidic conditions represent traditional, synthetic approaches to arylvinylbenzazines 3, 5 (Scheme 1 ). ${ }^{22}$

Scheme 1 


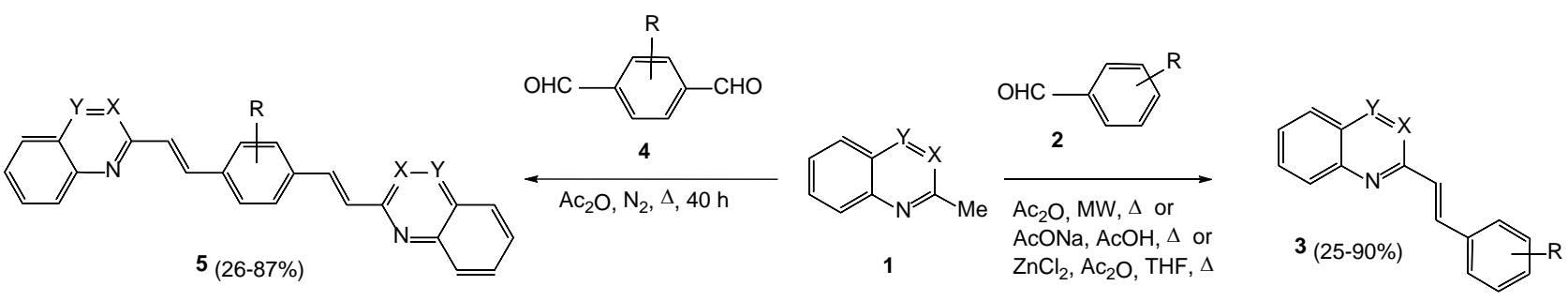

1, 3, 5: $\mathrm{X}=\mathrm{CH}, \mathrm{N} ; \mathrm{Y}=\mathrm{CH}, \mathrm{N}$

\section{II.1.1. Arylvinylquinolines}

2-Arylvinylquinoline chromophores are generally obtained exclusively as their $E$ stereoisomer. Most of the time, they are obtained by functionalization of already formed quinoline fragment. 2-Arylvinylquinoline derivatives 7 can be easily prepared by condensation of arylcarboxaldehydes and 2-methylquinoline derivatives (6) (Scheme 2, top reaction). This reaction can be performed either in basic media, ${ }^{25}$ in acetic anhydride ${ }^{26-28}$ or even in water without the presence of any catalyst. ${ }^{29}$ These derivatives can be also obtained in two steps from 2quinolinecarboxaldehyde (8) (Scheme 2 , bottom reaction). ${ }^{30}$ The first step consists in a Wittig reaction with methyltriphenylphosphonium bromide to obtain 2-vinylquinoline $\mathbf{9}$. This intermediate can be involved in a palladium catalyzed Heck cross-coupling reaction with aryliodides to yield $(E)$ 2-arylvinylquinolines 7.

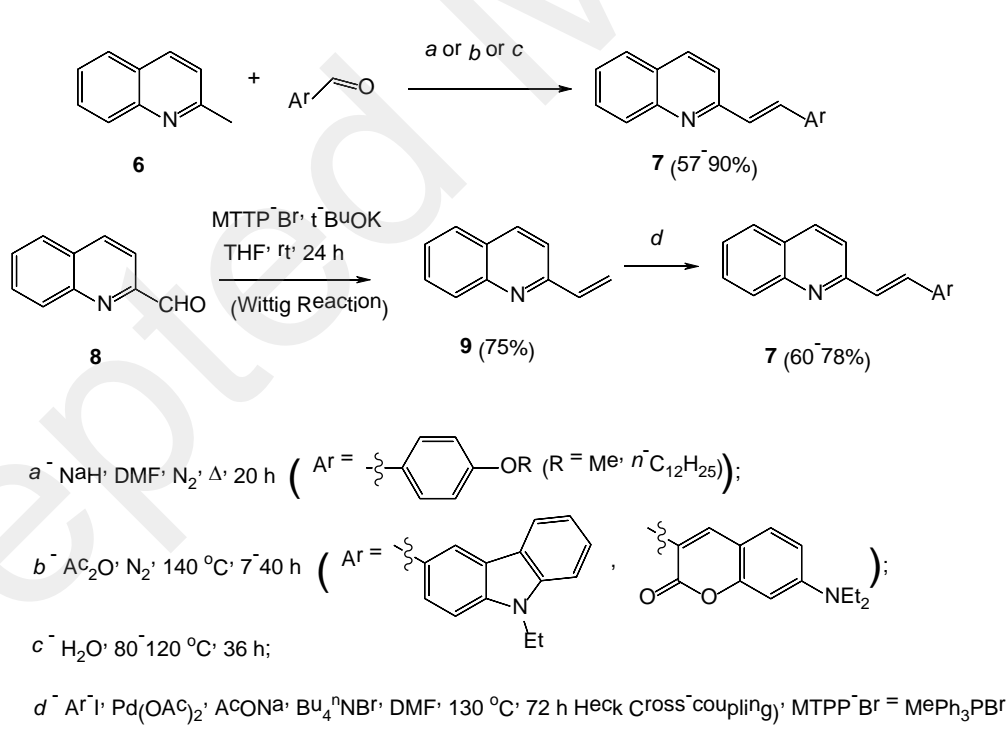

2-Styrylquinoline derivatives 12 can be also obtained from ortho-iodo anilines 10 and 2trans-styryl propargyl alcohols $\mathbf{1 1}$ by domino synthesis initiated by a Sonogashira couping and concluded by a base catalyzed propargyl alcohol-enone isomerization (Scheme 3, top reaction). ${ }^{31}$ Sukuzi cross coupling reaction with styrylboronic acids on 6,8-dibromo-4-chloroquinoline derivative 13 affords 4,6,8-tristyrylquinoline chromophores 14 (Scheme 3, bottom reaction). ${ }^{32}$ 


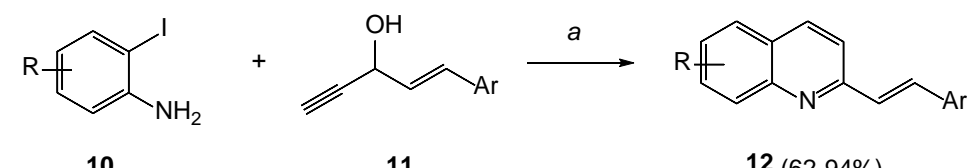

10

11

$12(62-94 \%)$

a - $\mathrm{Pd}\left(\mathrm{PPh}_{3}\right)_{2} \mathrm{Cl}_{2}$ (2 mol\%), Cul (1 mol\%), DBU (2 equiv), THF, MW

120-150 ${ }^{\circ} \mathrm{C}, 30 \mathrm{~min} ; \mathrm{R}=\mathrm{H}, \mathrm{CF}_{3}, \mathrm{CN} ; \mathrm{Ar}=\mathrm{C}_{6} \mathrm{H}_{4} \mathrm{NMe}_{2}-4$;

$\mathrm{MW}$ - microwave irradiation
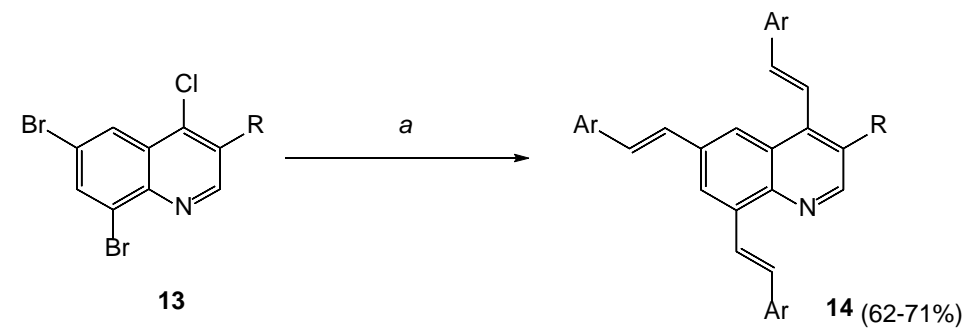

a - $\mathrm{ArCH}=\mathrm{CHB}(\mathrm{OH})_{2}$ (3.5 equiv), $\mathrm{Pd}\left(\mathrm{PPh}_{3}\right)_{2} \mathrm{Cl}_{2}, \mathrm{PCy}_{3}, \mathrm{~K}_{2} \mathrm{CO}_{3}$,

dioxane-water (4:1 v/v), $90{ }^{\circ} \mathrm{C}, 3 \mathrm{~h}$; $\mathrm{Ar}=\mathrm{Ph}, \mathrm{C}_{6} \mathrm{H}_{4} \mathrm{~F}-4, \mathrm{C}_{6} \mathrm{H}_{4} \mathrm{OMe}-4$;

Cy ${ }^{-}$cyclohexyl

As shown before, the majority of synthetic methods of 2-arylvinylquinoline leads to the $E$ isomer. However reversible $E \rightarrow Z$ photoisomerization of compounds $\mathbf{1 5}$ is generally possible (Scheme 4). ${ }^{33-35}$ The photoisomerizable 2-styrylquinoline fragment can be incorporated into methacrylic polymers as side chain with potential photonic applications. ${ }^{36,37}$

Scheme 4

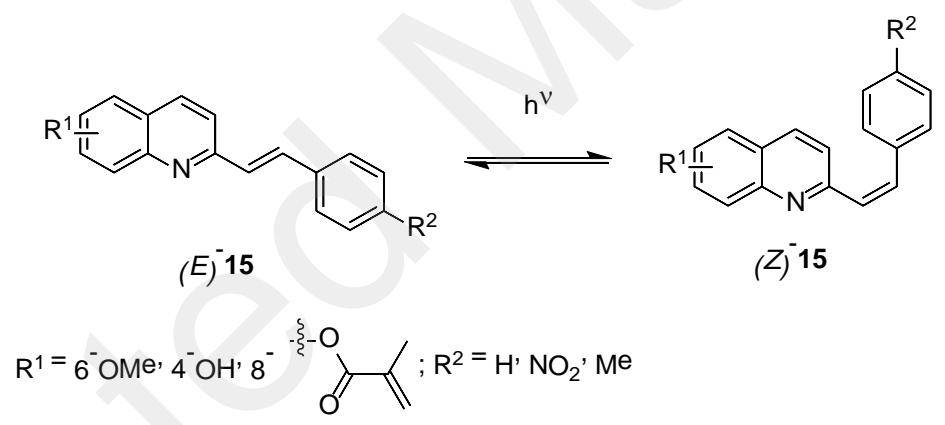

Budyka and coworkers have designed bichromophoric dyads 16 bearing 2-stryrylquinoline and 2-naphthol chromophoric groups as photonic molecular switches. ${ }^{38}$ Whereas no significant interactions between chromophores are observed in ground state, Forster resonance energy transfer (FRET) occurs from the naphthol to the styrylquinoline fragment, quenching the emission of the naphthol fragment. In this structure, the E/Z photoisomerization of the styrylquinoline fragment in the dyads 16 occurs with the same quantum yield $(\sim 0.5)$ as in model methoxystyrylquinoline 17 independently of the methylene bridge length. The photoisomerization into the non-emissive $\mathrm{Z}$ isomer leads to enhancement of the naphthol fragment emission.

Structures 16, 17 


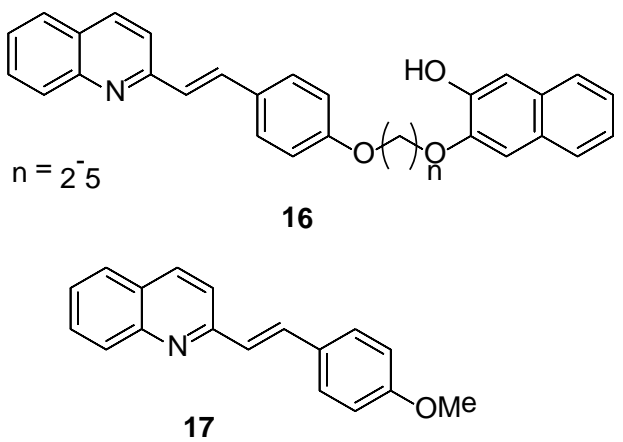

The same team ${ }^{39}$ has designed also a monochromophoric dyad 18 bearing two 2stryrylquinoline fragments leading to $\mathbf{1 9}$ possible isomers: $E E, E Z, Z E$ and $Z Z$. When the polyethylene linker incorporate an o-xylylene bridge (compound 20), along with photoisomerization, [2+2]-photocycloaddition occurs affording tetrasubstituted cyclobutane (Scheme 5). ${ }^{40}$ When one of the two 2-stryrylquinoline is replaced by a styrylquinolinium fragment (dyad 19), ${ }^{41-43}$ photoisomerization of the styrylquinoline fragment occurs only on one-way: it goes in $c$ is $\rightarrow$ trans direction whereas trans $\rightarrow$ cis isomerization is quenched because of competing FRET to the styrylquinolinium fragment. Nevertheless, trans $\rightarrow$ cis photoisomerization can be observed upon protonation of the styrylquinoline fragment. Therefore, the cycle protonation $\rightarrow$ trans-cis photoisomerization (reversible) $\rightarrow$ deprotonation $\rightarrow$ cis-trans photoisomerization (one-way) - can be repeated and used for design of controlled molecular photoswitches.

Structures 18, 19<smiles>CC=Cc1ccc(OCCCOc2ccc(C=Cc3ccc4ccccc4n3)cc2)cc1</smiles>

18' 19<smiles>[R7]c1ccc2ccccc2n1</smiles>

(18)'<smiles></smiles>

Scheme 5
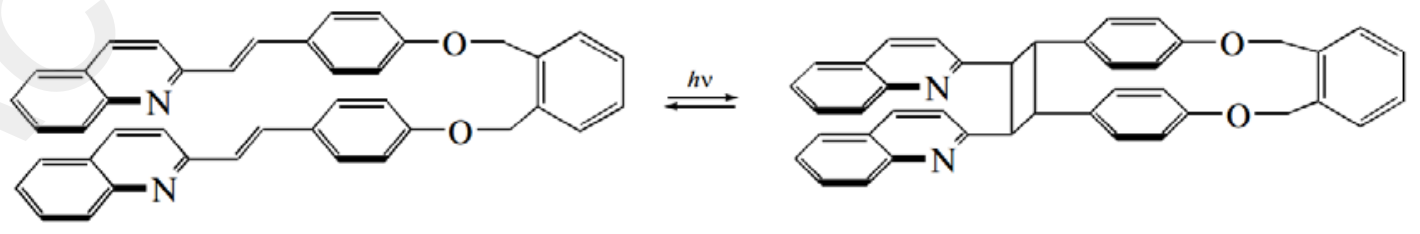

20

The particular attention was paid to heterogeneous catalysis when styrylquinolinium fragment has been grafted on quantum dot via isothiouronium anchor (compound 21, Figure 1). ${ }^{44,45}$ 
Compared to the free fragment, $E-Z$ photoisomerization of the styrylquinolinium fragment grafted on quantum dot was suppressed and its photodestruction was accelerated.

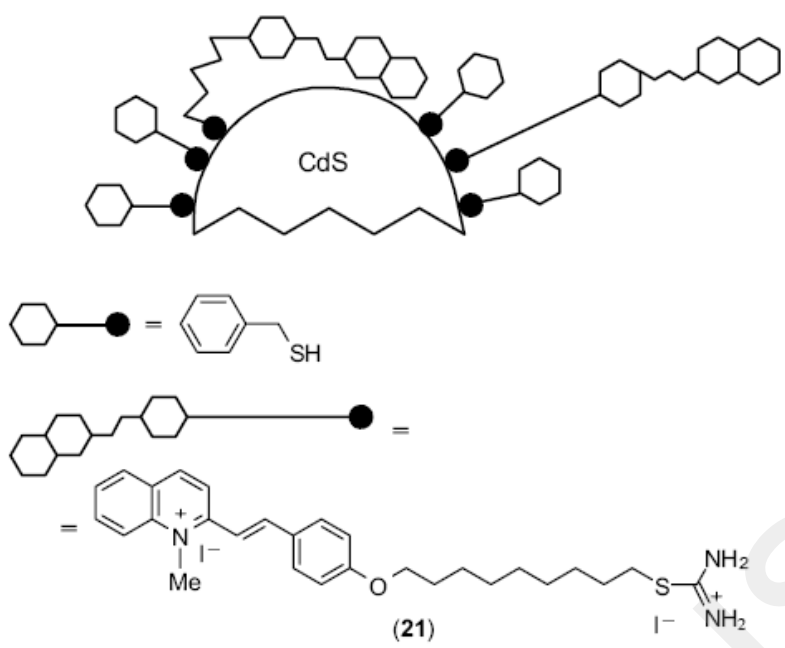

Figure 1. Styrylquinoline 21 grafted on quantum $\operatorname{dot}^{45}$

Xiong and coworkers have designed two styrylquinoline chromophores 22 and 23 bearing tetraphenylethene and anthracene fragments. ${ }^{26}$ These compounds, nearly non emissive in DMSO/water system with low water content $\left(f_{\mathrm{w}}<30 \%\right)$, exhibit aggregation induced emission (AIE). These compounds have been used as selective fluorescent probes of $\mathrm{Cu}^{2+}$ in aqueous solution and test strips (ON-OFF probe).

Structures 22-24

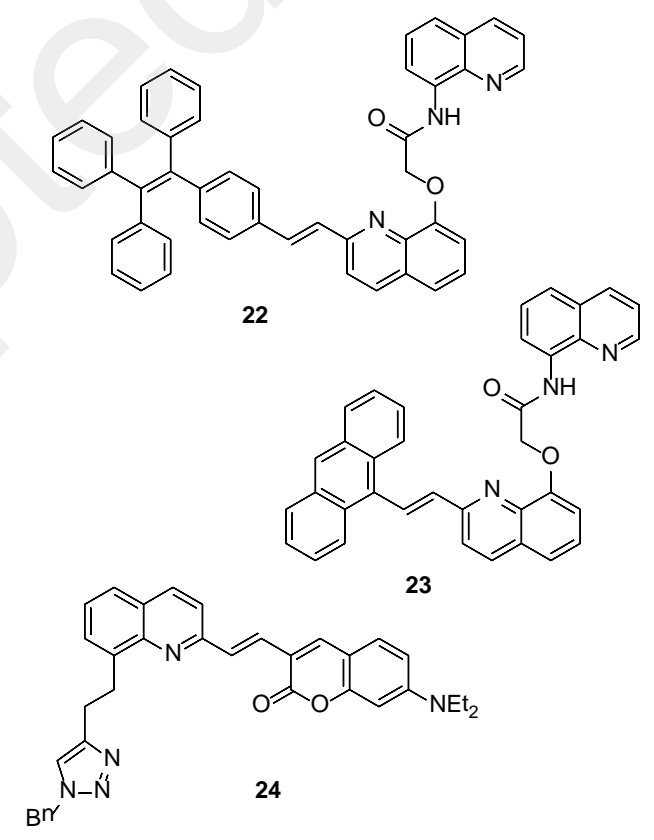

$\mathrm{Wu}$ and coworkers have designed a styrylquinoline chromophore $\mathbf{2 4}$ bearing a coumarin fragment. ${ }^{46}$ This compound exhibits an emission at $516 \mathrm{~nm}$ in MeCN/water mixture and was used as selective ratiometric probe for $\mathrm{Zn}^{2+}$ in living cells. 
$\mathrm{Li}$ and coworkers have designed carbazole derivatives 25 and $26 .^{28}$ These compounds exhibit two-photon absorption in DMF solution (25: $\sigma_{\mathrm{TPA}}=81 \mathrm{GM}, 26$ : $\sigma_{\mathrm{TPA}}=364 \mathrm{GM}$ measured by the two-photon excitation fluorescence (TPEF) method) and in doped polymethylmethacrylate (PMMA) thin film (25: $\sigma_{\mathrm{TPA}}=470 \mathrm{GM}, 26: \sigma_{\mathrm{TPA}}=621 \mathrm{GM}$ measured by the Z-Scan method). ${ }^{47}$ Three-dimensional optical data storage experiments have been performed proving that these chromophores are well-suited as high-density optical information storage.

Structures 25, 26

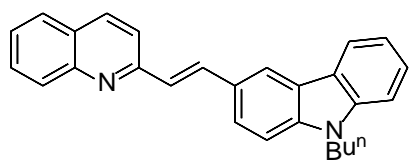

25

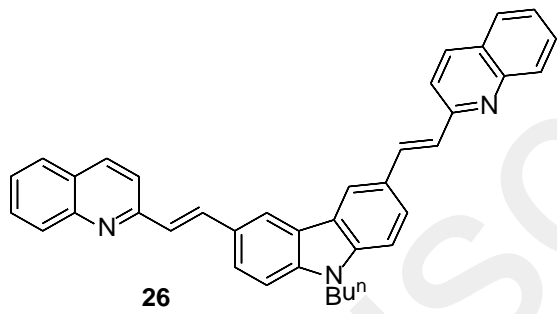

26

Yuang and coworkers have reported the solid state emission of alkoxy substituted styrylquinoline derivatives 17 and 27 (Scheme 6). ${ }^{25}$ These compounds remain emissive upon reversible protonation with a remarquable red-shift $\left(\lambda_{\mathrm{em}}=570-574 \mathrm{~nm}\right)$. Whereas the neutral forms exhibit negligible emission change upon mechanical force, remarkable piezochromism is observed for the protonated chromophores.

Scheme 6
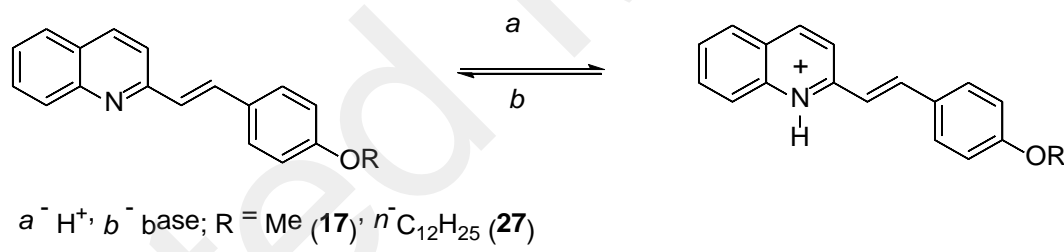

Flores-Noria and coworkers have designed phenylenevinylenequinoline derivatives 28a-c. These compounds are highly luminescent in $\mathrm{CHCl}_{3}$, THF and toluene. ${ }^{30} \mathrm{~A}$ push-pull effect is only observed for compound 28a, whereas for $\mathbf{2 8 b}$ and 28c no significant effects of the quinoline fragment are observed neither spectroscopically, electrochemically nor theoretically. Compound 28a is the most emissive (in $\mathrm{CHCl}_{3} \lambda_{\mathrm{em}}=499 \mathrm{~nm} \Phi_{\mathrm{F}}=0.64$ ) making it suitable for optoelectronic devices.

Structures 28, 29 


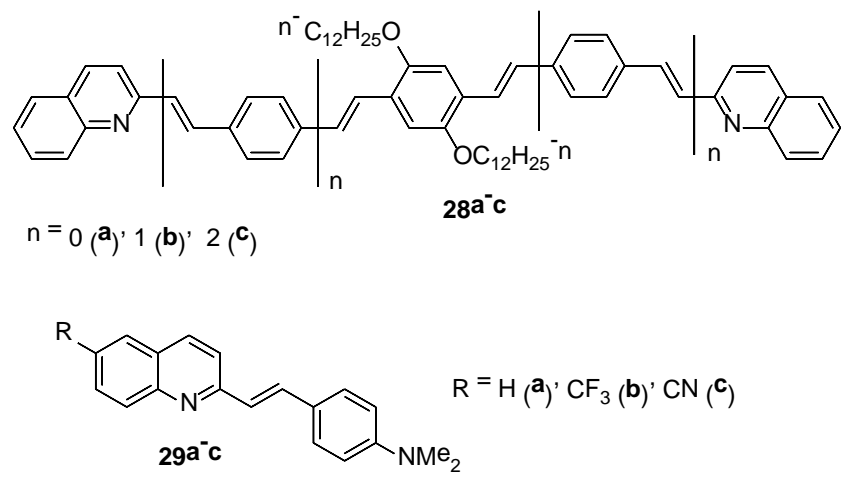

Cinar et al have designed dimethylamino substituted styrylquinoline chromophores 29a-c. In addition to strong emission solvatochromism characteristic of push-pull luminophores, these compounds exhibit a pH-sensibility and "ON-OFF-ON" emission profiles. ${ }^{31}$ Indeed the emission of these compounds can be quenched by addition of one proton (protonation of the quinoline ring) and blue shifted with respect of the free base upon a second protonation (amino group).

Tzeli and coworkers have designed theoretically a styrylquinoline derivative $\mathbf{3 0}$ bearing a benzo-18-crown-6-ether fragment. ${ }^{48}$ Due to the reversible sensibility of photophysical properties (absorption and emission) to the presence of $\mathrm{H}^{+}, \mathrm{Ca}^{2+}$ and the possibility of reversible photoisomerization, the author suggest the use of this chromophore to build logic gates.

Structures 30-32

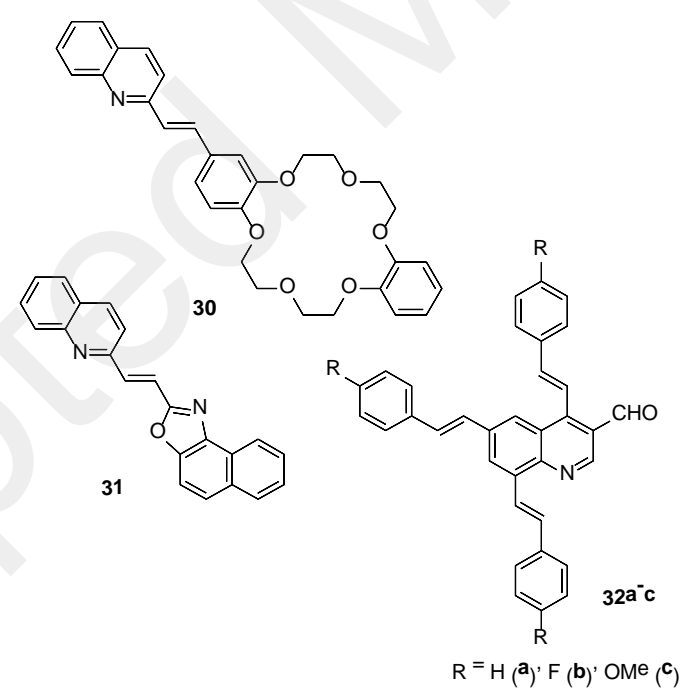

Zanocco et al have designed chromophore 31. This compound exhibits intense white light emission based on proton transfer in solvent mixture including at least a strong hydrogen-bonding solvent such as $\mathrm{MeOH}$ (for 17\% of DMSO, the chromacity coordinates are 0.33, 0.35 and quantum yield is 0.31$)^{49}$

Mphahlele et al have designed 4,6,8-tristyrylquinoline derivatives 32a-c. ${ }^{32}$ Whereas chromophore 32a exhibits yellow-green luminescence $\left(\lambda_{\mathrm{em}}=529 \mathrm{~nm}, \Phi_{\mathrm{F}}=0.06\right)$ in $\mathrm{DCM}$ solutions, the subtitution by electron-donating fluorine or methoxy group leads to blue shifted 
emission with enhanced quantum yield (32b: $\lambda_{\text {em }}=420,430 \mathrm{~nm}, \Phi_{\mathrm{F}}=0.17$ and 32c: $\lambda_{\text {em }}=370,470$ $\left.\mathrm{nm}, \Phi_{\mathrm{F}}=0.21\right)$.

Styrylquinolines $\mathbf{3 3}$ and $\mathbf{3 4}$ with expanded $\pi$-electronic system, bearing quinolinmalonodinitryl as new building block were symthesized and studied as fluorophores with aggregation-induced emission (AIE) in red and near IR ranges. ${ }^{50}$ Authors summarized recent advances and discussed potential application of such derivatives containing donating groups as agents for optical biovisualisation in vivo. Incorporation of different substituents $\left(\mathrm{R}, \mathrm{R}^{1}, \mathrm{R}^{2}\right)$, including sulphonate groups, allows to apply compounds 33, 34 both for preparation of AIE-active nanoparticles, and for drug delivery using nanoparticles. New strategy of molecular design for generation of nanoagregates of different forms of these compounds possessing longwave emission was presented.

Structures 33-35

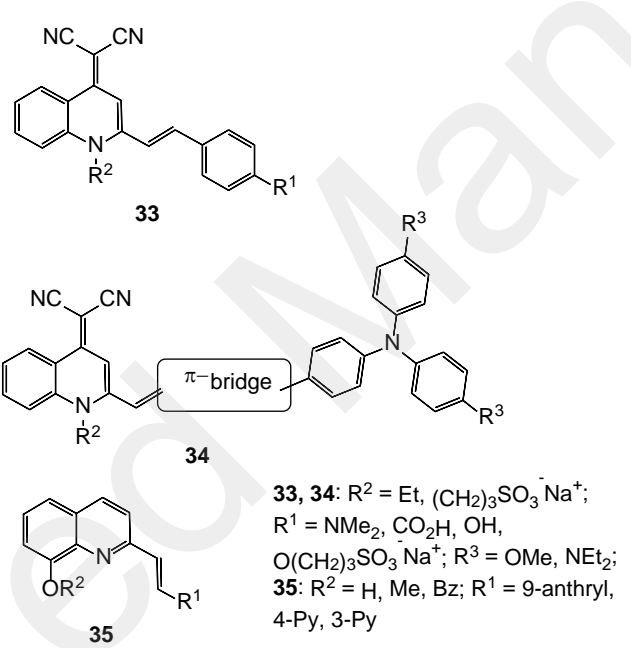

In continuation of research on 8-hydroxyquinoline derivatives the synthesis and photoluminescence of styrylquinolines 35, bearing ether groups at position 8 of quinoline unit and anthracene or pyridine fragments $\left(\mathrm{R}^{1}\right)$ was described. ${ }^{51-53}$ It was shown that substitution of phenol hydrogen with methoxy group leads to the increase in fluorescence quantum yield from 0.067 to 0.25 for $35\left(\mathrm{R}^{1}=9\right.$-anthryl), to 0.41 for $35\left(\mathrm{R}^{1}=4\right.$-Py) and to 0.37 for $35\left(\mathrm{R}^{1}=3-\mathrm{Py}\right)$.

\section{II.1.2. Arylvinylquinazolines}

Only few examples of arylvinylquinazoline chromophores have been described so far in the literature. 2- and 4-Arylvinylquinazolines 38a-d and 40a-d as well as 2,4-diarylvinylquinazoline 41a,b can be obtained by Knoevenagel condensation from the corresponding methylquinazoline and benzaldehyde derivative exclusively as $E$ isomers (Scheme 7). ${ }^{54}$ The reaction can be performed with electron-donating substituted benzaldehyde and it should be noted that 4-bromobenzaldehyde reacts 
only with 2-methylquinazoline. Bromo derivative 38d can be involved in a Suzuki cross coupling reaction to obtain biphenylenevinylene derivative 39. The methylquinazoline intermediates 36 are not commercially available but can be obtained either from chloro derivatives by palladium catalyzed coupling with trimethylaluminium (4-methylquinazoline (36b) and 2,4dichloroquinazoline (36c) $)^{55}$ or by cyclization reaction from 2-bromobenzaldehyde and acetamidine hydrochloride (2-methylquinazoline (36a)). ${ }^{56}$

Scheme 7

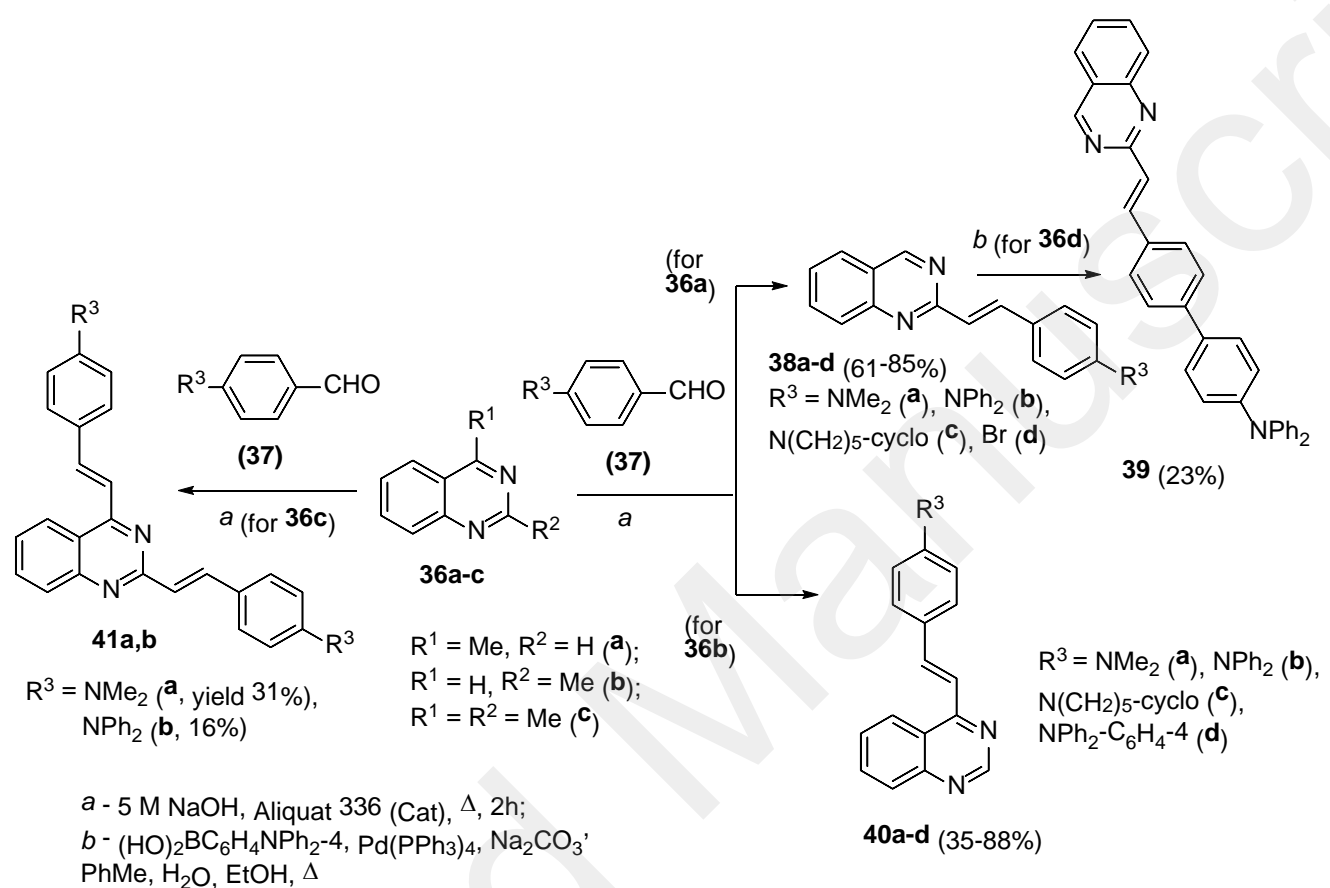

2-Arylvinylquinazolines 38a-c and 39 exhibit green emission in $\mathrm{CH}_{2} \mathrm{Cl}_{2}\left(\lambda_{\mathrm{em}}=520-545\right.$ $\mathrm{nm}$ ), diphenylamino derivatives exhibit the highest fluorescence quantum yield (38b: $\Phi_{\mathrm{F}}=0.61$, 39: $\Phi_{\mathrm{F}}=0.65$ ). It should be noted that biphenylenevinylene derivative 39 shows a significantly increased Stokes shifts $\left(\Delta v=7796 \mathrm{~cm}^{-1}\right)$ with regard to its phenylenevinylene analogue 38. 4Arylvinylquinazoline analogues 40a-d exhibit significantly red-shifted emission $\left(\lambda_{\text {em }}=548-610\right.$ $\mathrm{nm}$ ) but reduced quantum yield (up to 0.25 for 40b). 4,6-Diarylvinylquinazolines 41a,b exhibit redshifted emission maxima with regard to their 2-arylvinylquinazoline analogues but blue-shifted in comparison with their 4-arylvinylquinazoline analogues but with low emission quantum yield $\left(\Phi_{\mathrm{F}}=\right.$ 0.02-0.09). All of these compounds exhibits strong emission solvatochromism, halochromism and are potential NLOphores.

Dhuguru and coworkers have described 6-arylvinyl- and 6-arylbutadienylquinazoline chromophores $\mathbf{4 2 a - e}$ and $\mathbf{4 3 a - e}$ obtained by Heck cross coupling reaction from 6-iodoquinazoline precursors. ${ }^{57}$ Bromopyridines were involved into Suzuki cross-coupling reaction for the arylalkenylation of cycle. ${ }^{58}$ All the compounds are luminescent in $\mathrm{CHCl}_{3}$ with good to moderate 
quantum yield $\left(\Phi_{\mathrm{F}}=0.02-0.57\right)$. In the arylvinylquinazoline series 42a-e, the most red shifted absorption and emission are observed for the dimethylamino derivative 42a $\left(\lambda_{\text {abs }}=381 \mathrm{~nm}\right.$ and $\lambda_{\text {em }}$ $=495 \mathrm{~nm})$ and the nitro chromophore $42 \mathrm{e}\left(\lambda_{\mathrm{abs}}=372 \mathrm{~nm}\right.$ and $\left.\lambda_{\mathrm{em}}=539 \mathrm{~nm}\right)$. A red shift in absorption and emission is observed for butadiene derivatives 43a-e with regards to their vinyl analogues 42a-e. For all these compounds emission is attributed to ICT (from electron donating group to the quinazoline fragment in case of 42a-c and 43a-c and from the amino group to the electron-withdrawing substituent in for 42d,e and 43d,e where the quinazoline fragment acts as a $\pi$ conjugated linker).

Structures 42, 43

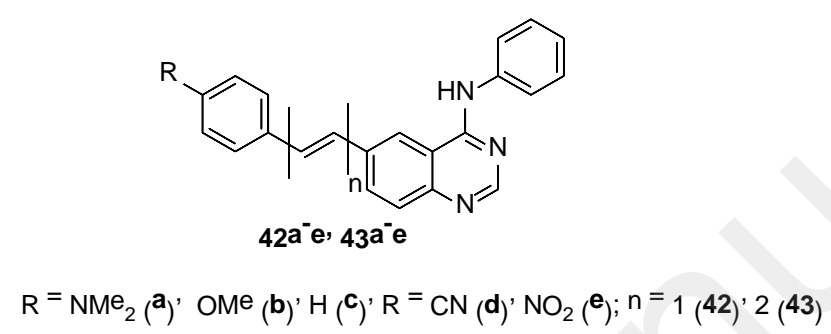

\section{II.1.3. Arylvinylquinoxalines}

Various methods can be used to obtain 2-arylvinyl- and 2,6-diarylvinylquinoxaline derivatives, all leading exclusively to the E-isomers. The first one consists in Knoevenagel condensation between commercially available 2-methyl or 2,4-dimethylquinoxaline $\mathbf{4 4}$ and the corresponding arylcarboxaldehyde (Scheme 8, top reaction). Various conditions have been described; aqueous sodium hydroxyde with Aliquat 336 as phase transfer catalyst, ${ }^{59} \mathrm{NaH}^{60}$ or $t \mathrm{BuOK}^{61}$ in THF. Another strategy consists in the condensation of a butanedione $\mathbf{4 7}$ bearing two arylvinyl substituents with an $o$-phenylenediamine derivative 46 (Scheme 8, bottom reaction). ${ }^{62}$ Recently arylvinylquinoxalines 52 have been obtained by palladium-catalyzed C-H alkenylation of quinoxaline $N$-oxide intermediates $\mathbf{5 0}$ and subsequent reduction of derivatives $\mathbf{5 1}$. $^{63,64}$ Compound $\mathbf{5 2}$ was synthesized from $N$-oxide $\mathbf{5 0}$ by iodine-catalyzed direct alkenylation of ethanedione $\mathbf{4 7}$ with styrol (Scheme 9). Direct arylalkenylation of furazan[3,4-b]pyrazines was presented as new approach to $\mathrm{CH}$-functionalization. ${ }^{65}$ Synthesis of 6-styryl-substituted 1,6-dihydropyrazine derivatives by reaction of 6-hydroxy adducts with styrylboronic acid was presented. ${ }^{66}$ 


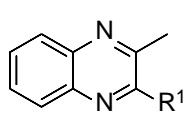

44

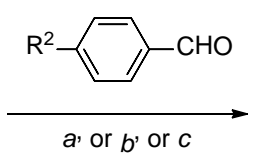

a. or $b$, or $c$

$\mathrm{R}^{1}=\mathrm{R}^{3}=\mathrm{H} ; \mathrm{R}^{1}=\mathrm{Me}, \mathrm{R}^{3}=$<smiles>[R]c1ccc(C=C)cc1</smiles>

$\mathrm{a}^{-}$Aliquat 336 (Cat)' $5 \mathrm{M} \mathrm{NaOH}^{\prime} \Delta^{\prime} 15 \mathrm{~h}$; R = Cl' Br' SMe' $\mathrm{NMe}_{2}$, $\mathrm{NPh}_{2}, \mathrm{CyClO}^{-} \mathrm{N}\left(\mathrm{CH}_{2}\right) 5$ (yields $24^{-} 78 \%$ );

$b^{-} \mathrm{NaH}^{\prime}$ THF' $\mathrm{N}_{2} \mathrm{rt}^{\prime} 2 \mathrm{~h}\left(\mathrm{R}=\mathrm{NMe}_{2}(83 \%) \mathrm{NPh}_{2}(78 \%)\right.$;

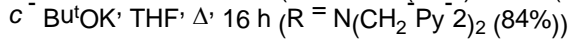

46

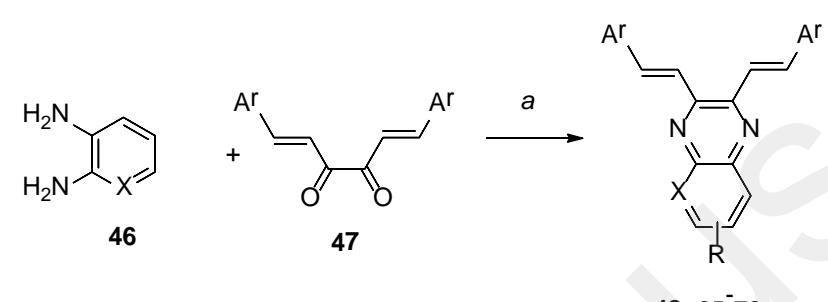

47

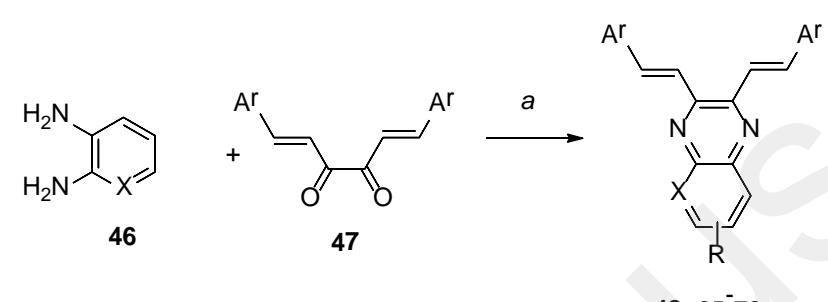

$a^{-} \mathrm{ACOH}^{\prime}$ PhMe, $\Delta^{\prime} 12 \mathrm{~h} ; \mathrm{X}=\mathrm{CH}^{\prime} \mathrm{N}$<smiles>[R]c1ccc(/C=C/c2cnc3ccccc3n2)cc1</smiles>

$45\left(24^{-} 81 \%\right)$

$48\left(65^{-} 72 \%\right)$

Scheme 9

$c_{(R}=H^{\prime}$ yield $\left.48 \%\right)$

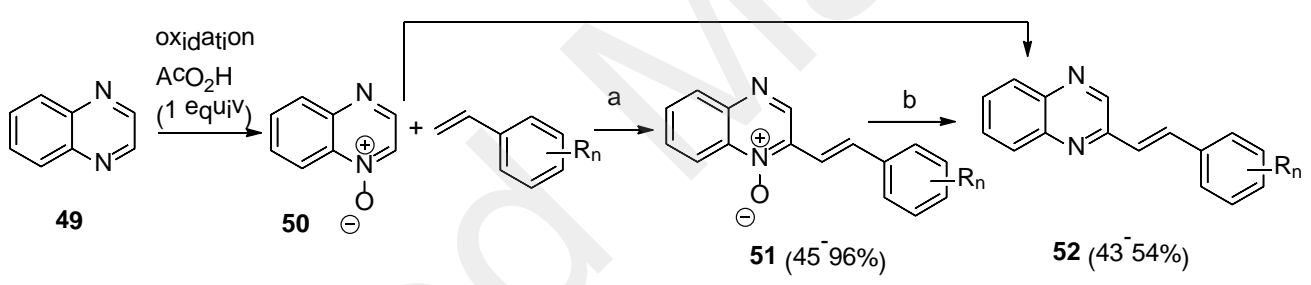

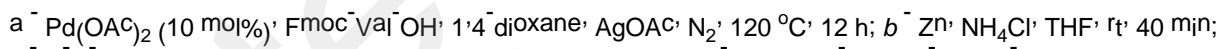

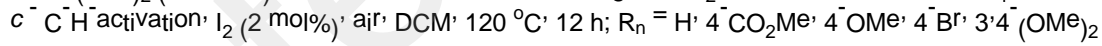

6-Bromo-, 7-bromo- and 5,8-dibromoquinoxaline derivatives 53a-c can be involved in Heck cross coupling reaction to yield the corresponding arylvinylquinoxalines 54a-c (Scheme 10). ${ }^{67,68}$

Scheme 10

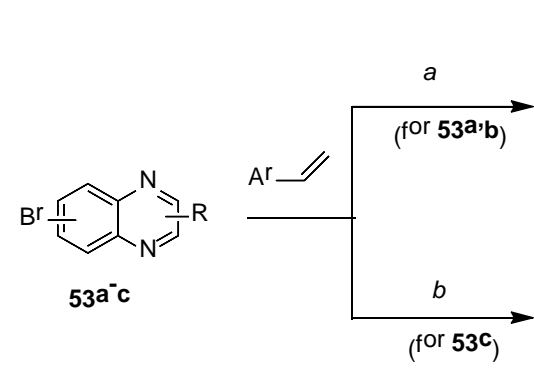

$a^{-} \mathrm{Pd}\left(\mathrm{OAC}_{2}\right)^{\prime} \mathrm{DMF}{ }^{\prime} \mathrm{P}\left(\mathrm{TOl}_{3}\right)_{3} \mathrm{NEt}_{3}, 100{ }^{\circ} \mathrm{C}^{\prime} 24 \mathrm{~h}$;<smiles>Cc1nc2ccccc2nc1-c1ccccc1</smiles>

$\mathrm{Ar}^{\mathrm{r}}=\mathrm{C}_{6} \mathrm{H}_{4}\left(\mathrm{NMe}_{2}\right)^{-}$;

$b^{-} \mathrm{Pd}\left(\mathrm{OAC}_{2}\right)_{2} \mathrm{Bu}_{4} \mathrm{NB}^{\mathrm{r}} \cdot \mathrm{K}_{2} \mathrm{CO}_{3}, \mathrm{DMF} \cdot 90^{\circ} \mathrm{C}^{\prime} 48 \mathrm{~h}$;

$\mathrm{Ar}^{\mathrm{r}=} \mathrm{C}_{6} \mathrm{H}_{4} \mathrm{~N}\left(\mathrm{C}_{6} \mathrm{H}_{4}\right)\left(\mathrm{OC}_{6} \mathrm{H}_{13}{ }^{4}\right)_{2}$

53: $\mathrm{R}^{1}=\mathrm{Me} \cdot \mathrm{R}^{2}=\mathrm{Ph}$; isomers: $6 \mathrm{~B}^{\mathrm{r}}(\mathbf{a}) \cdot 7^{-} \mathrm{B}^{\mathrm{r}}(\mathbf{b})$

$\mathrm{R}^{1}=\mathrm{R}^{2}=\mathrm{Ph}: 5,8^{-} \mathrm{Br}_{2}(\mathbf{c})$;

54: 6 ' isomer (' ' yield 48\%)' 7 ¡ ¡somer (b' 46\%) 
Achelle and coworkers have described a series of 2-arylvinyl quinoxalines 55-59. 59,69,70 Compounds 58a-c and 59a-d have been obtained respectively by Suzuki and Sonogashira cross coupling reaction from compound 55b. Amino derivatives 55d-f exhibit yellow emission with high fluorescence quantum yield $\left(\Phi_{\mathrm{F}}=0.59-0.70\right)$ in DCM with strong positive emission solvatochromism in aprotic solvent of increasing polarity. Upon addition of trifluoroacetic acid, on solution of 55d,e, a dramatic hypsochromic shift of the emission band is observed due to the protonation of the amino electron-donating group. In the case of compounds 56, 58a and 59b, on the other hand, a progressive emission quenching attributed to the protonation of the quinoxaline fragment is observed. Biphenylenevinylene derivatives 58b,c exhibit orange luminescence in DCM with lower fluorescence quantum yield $\left(\Phi_{\mathrm{F}}=0.14-0.35\right)$ but extended emission solvatochromic range with regards to their phenylenevinylene analogues 55d,e. Compound 58a exhibits blue luminescence with high fluorescence quantum yield $\left(\Phi_{\mathrm{F}}=0.42\right)$. In compounds 59b-d the addition of a triple bound between the two phenylene linker lead to a red shift of absorption and emission with regards to their analogues 58a,b, and red emission was observed for 59c $\left(\lambda_{\text {em }}=647 \mathrm{~nm}, \Phi_{\mathrm{F}}=\right.$ 0.07). The second order NLO response of compounds $\mathbf{5 5 b}$ and $\mathbf{5 9 c , d}$ have been measured by the electric field induced second harmonic generation method (EFISH) and moderate $\mu \beta$ values (respectively 300,280 and $200 \cdot 10^{-48}$ esu) have been measured in $\mathrm{CHCl}_{3}$. The $\mathrm{NLO}$ response of compound 55d has been also calculated theoretically by means of quantum chemical first principles calculations and calculated NLO response reproduce well the experimental value. ${ }^{71}$

Structures 55-60

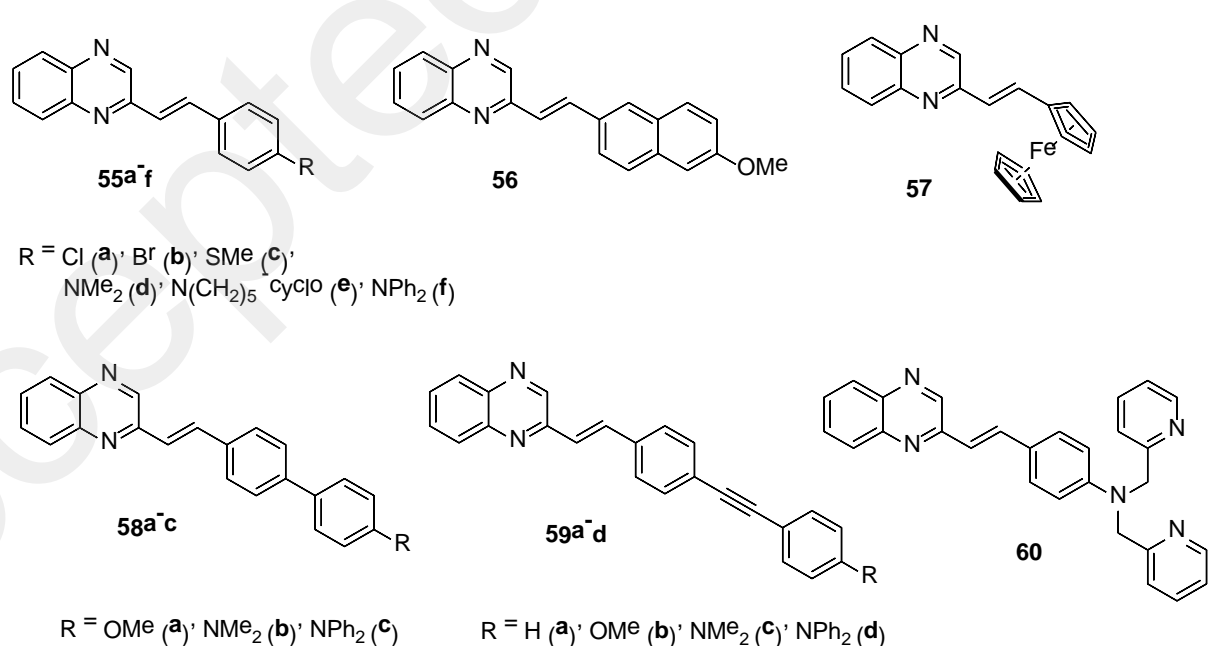

When comparing the photophysical properties of quinolin-2-yl, quinoxalin-2-yl, quinoxalin4-yl and quinazolin-2-yl derivatives 29a, 38a, 40a and 55d, all bearing $N, N$-dimethylaminostyryl fragments (Table 1), it appears that the quinazoline derivarive 55d exhibits the most red-shifted emission and the highest fluorescence quantum yield in $\mathrm{CH}_{2} \mathrm{Cl}_{2}$. 
Table 1. Photophysical properties of $N, N$-dimethylamino- and $N, N$ diphenylaminostyrylbenzo(di)azine derivatives in $\mathrm{CH}_{2} \mathrm{Cl}_{2}$

\begin{tabular}{lllll}
\hline Compound & $\lambda_{\text {abs }} / \mathrm{nm}\left(\varepsilon / \mathrm{mM}^{-1} \mathrm{~cm}^{-1}\right)$ & $\lambda_{\text {em }} / \mathrm{nm}$ & $\Phi_{\mathrm{F}}$ & References \\
\hline 29a & $392(27.0)$ & 512 & 0.12 & 31 \\
38a & $395(26.6)$ & 536 & 0.21 & 54 \\
40a & $433(18.0)$ & 548 & 0.07 & 54 \\
55d & $427(22.4)$ & 570 & 0.59 & 59 \\
55f & $421(25.4)$ & 565 & 0.67 & 59 \\
58c & $393(36.4)$ & 632 & 0.35 & 59 \\
59d & $403(35.7)$ & 630 & 0.37 & 68 \\
\hline
\end{tabular}

On the other hand, comparing the photophysical properties of $N, N$-diphenylamino substituted quinoxaline derivatives, the extension of the conjugation by adding a second phenylene fragment in the $\pi$-conjugated fragment results in a significant blue-shift of absorption and red-shift in emission associated with a reduction of quantum yield. The incorporation of a triple bond between the two phenylene fragment (compounds 58c, 59d) does not significantly modify the photophysical properties.

The same group has designed dipicolylamine fluorophore 60. This compound exhibits yellow emission in MeCN $\left(\lambda_{\text {em }}=593 \mathrm{~nm}, \Phi_{\mathrm{F}}=0.15\right) .{ }^{55}$ As shown by the previous series of compounds positive emission solvatochromism is observed in aprotic solvent as well as $\mathrm{pH}$ sensibility with a dramatic red shift on absorption band and emission quenching. Moreover a significant blue shift of the emission has been observed in the presence of $\mathrm{Zn}^{2+}$ (and to a lesser extend with $\mathrm{Cd}^{2+}$ ) due to complexation of the dipicolylamine fragment reducing its electrondonating character and consequently the ICT into the chromophore.

Zhu and coworkers have designed 2-arylvinylquinazolines $61, \quad 62$ and arylbutadienequinoxaline $\mathbf{6 4} .^{72}$ In $\mathrm{EtOH}, \mathbf{6 1}$ exhibits green luminescence with moderate fluorescence quantum yield $\left(\lambda_{\mathrm{em}}=568 \mathrm{~nm}, \Phi_{\mathrm{F}}=0.22\right)$. In the same solvent, the emission quantum yield is much lower for 55d, 62 and 63. As far as 62 and 63 are compared, a significant red shift is observed for the butadiene derivative $63\left(\lambda_{\mathrm{em}}=583 \mathrm{~nm}\right)$. These compounds have been used for in vivo florescence detection of cerebral tau angles in Alzheimer's models.

Structures 61-65 


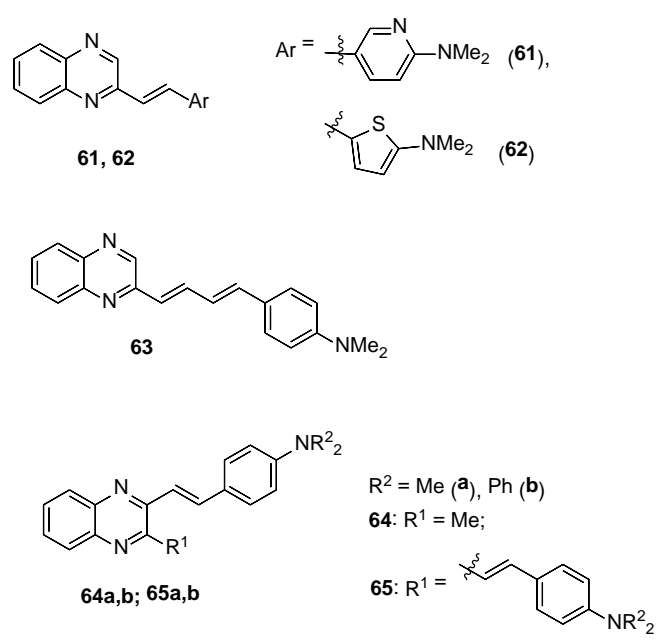

Zhao and coworkers have described aminostyrylquinoxaline chromophores 64, 65 exhibiting yellow emission in DCM with a bathochromic shift of around $20 \mathrm{~nm}$ for disbustituted compounds 65 with regards to their monosubstituted analogues $64 .^{59}$ As shown in other series of compounds, strong emission solvatochromsim and $\mathrm{pH}$ sensibility has been described. In addition, the chromophore 65b exhibits reversible mechanofluorochromism: crystals exhibit yellow emission at $542 \mathrm{~nm}$, red shifted to carmine emission at $592 \mathrm{~nm}$ upon grinding. Yellow emission can be recovered after fuming with DCM vapors.

Independently, Chauhan and cowokers ${ }^{73}$ and Senthilkumar et $a l^{74}$ have described a series of 2,3-di(ferrocenylstyryl)quinoxalines 66, 67. Compounds 66a,c,f,g were exploited as photosensitizers in $\mathrm{TiO}_{2}$-based dye-sensitized solar cells and compounds $\mathbf{6 6} \mathbf{c}$,g revealed to be the most efficient with overall conversion efficiency of $3.38 \%$ and $4.42 \%$ respectively. The second order NLO properties of chromophores 66a-e and $\mathbf{6 7}$ have been also studied by the EFISH method and negative $\mu \beta$ values up to $-960 \cdot 10^{-48}$ esu have been measured. Surprisingly high and stable second harmonic generation response in composite polymeric film has been also reported for $\mathbf{6 6 \mathbf { b }}$ $\left(\mathrm{d}_{33}=5.27 \mathrm{pm} \mathrm{V}^{-1}\right.$ in PMMA).

Structures 66, 67

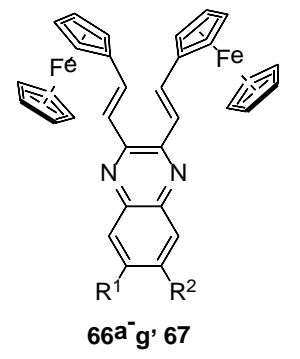

66: $\mathrm{R}^{2}=\mathrm{H}^{\mathrm{R}} \mathrm{R}^{1}=\mathrm{H}(\mathrm{a})^{\prime} \mathrm{CF}_{3}(\mathrm{~b})^{\prime}$

$\mathrm{NO}_{2}\left({ }^{\mathrm{C}}\right)^{\prime} \mathrm{CN}(\mathrm{d})^{\prime} \mathrm{OMe}^{(\mathrm{e})}$ '

$\mathrm{Cl}\left(f^{\prime} \mathrm{CO}_{2} \mathrm{H}(\mathrm{g})\right.$

67: $\mathrm{R}^{1}=\mathrm{R}^{2}=\mathrm{OMe}$

Cvejn and coworkers have designed the tripodal chromophores 68 and 69 with peripherical vinylquinazoline fragments (Scheme 11). ${ }^{75}$ These compounds have been obtained with moderate yield by triple Sonogashira cross coupling reaction between tris(4-ethynylphenyl)amine and 
bromoarylvinylquinoxaline intermediates. Compounds 68, 69 exhibit orange-red photoluminescence with high Stokes shifts $\left(>6700 \mathrm{~cm}^{-1}\right)$ in DCM $\left(\mathbf{6 8}: \lambda_{\mathrm{em}}=630 \mathrm{~nm}, \Phi_{\mathrm{F}}=0.37, \mathbf{6 9}\right.$ : $\lambda_{\text {em }}=617 \mathrm{~nm}, \Phi_{\mathrm{F}}=0.38$ ), strong emission solvatochromism and two-photon absorption properties with interesting two photon cross section (68: $\sigma=239$ GM at $780 \mathrm{~nm}, \mathbf{6 9}: \sigma=416 \mathrm{GM}$ at $760 \mathrm{~nm}$ ).

Scheme 11

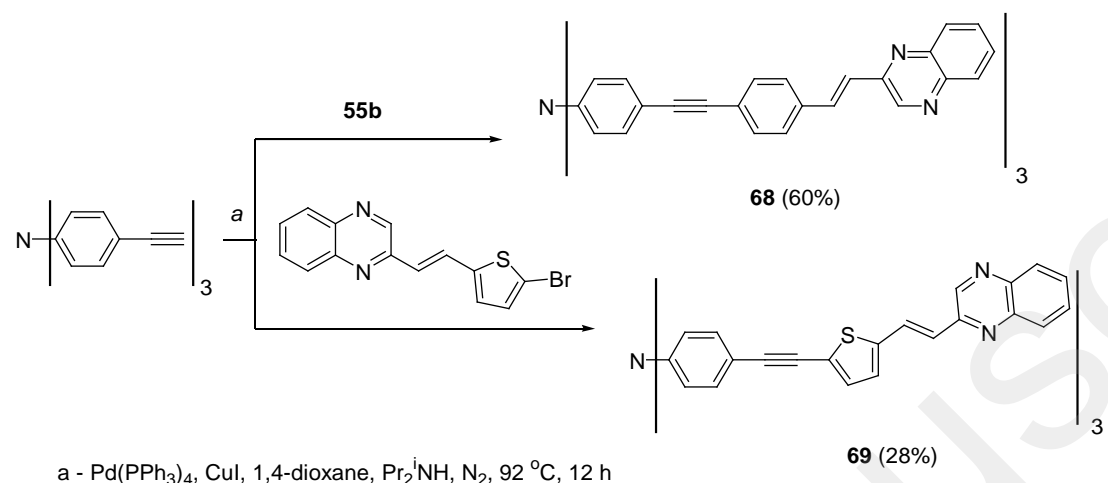

Achelle and coworkers ${ }^{76}$ have described the pyranylidene derivative 70. This compound described as a potential $2^{\text {nd }}$ order NLO chromophore, exhibits a significantly enhanced blue shifted emission upon protonation $\left(\lambda_{\mathrm{em}}=479 \mathrm{~nm}, \Phi_{\mathrm{F}}=0.25\right)$.

Structures 70-72

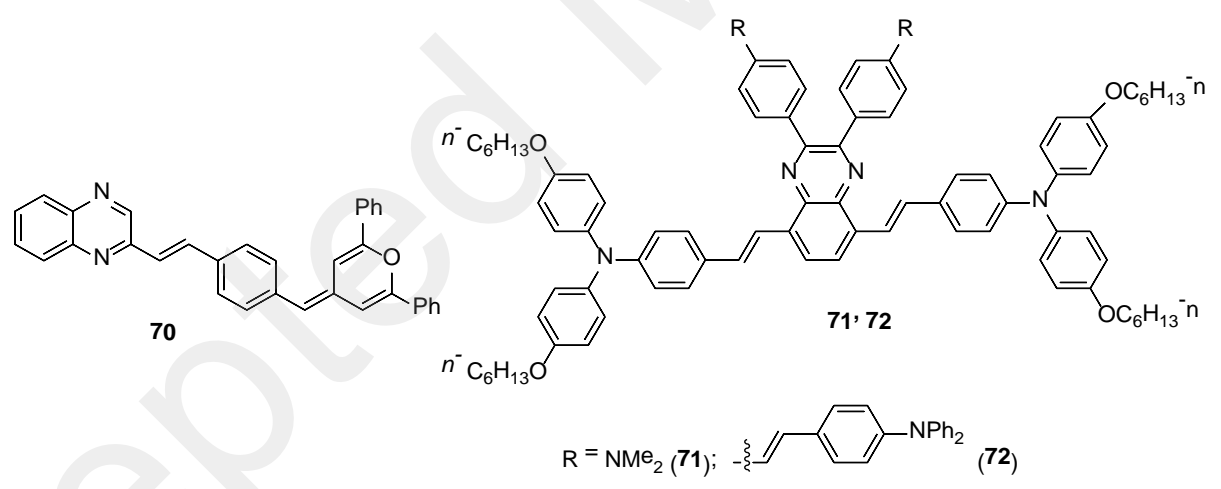

Chang and coworkers have designed multisubstituted quinoxaline chromophores $\mathbf{7 1}$ and $\mathbf{7 2}$, chloroform solutions and thin films of these compounds exhibit yellow photoluminescence. ${ }^{68}$ Photovoltaic cells (PVCs) and OLEDs were fabricated from $\mathbf{7 1}$ and by solution processing. While PVCs with a structure of ITO/PEDOT:PSS/71 or 72:PC ${ }_{71} \mathrm{BM} / \mathrm{Al}$ show the power conversion efficiencies of $0.31 \%$ and $0.45 \%$, respectively, OLEDs with a structure of ITO/PEDOT:PSS/71 or 72/LiF/Al exhibit a maximum luminance (efficiency) of $7.42 \mathrm{~cd} / \mathrm{m}^{2}(0.034 \mathrm{~cd} / \mathrm{A})$ and $48.84 \mathrm{~cd} / \mathrm{m}^{2}$ $(0.032 \mathrm{~cd} / \mathrm{A})$ with a turn-on voltage of 3.6 and $2.4 \mathrm{~V}$, respectively.

Lin and coworkers have described three other multibranched quinoxaline chromophores 74a-c. 6-Bromoquinoxaline 53d is capable to react with tributylvinyltin in conditions of Stille cross-coupling reaction leading to 6-vinylquinoline 73, which was used in Heck cross-coupling with 
arylbromide for the synthesis of styrylderivatives 74a-c (Scheme 12). ${ }^{77}$ These compounds exhibit cyan luminescence in toluene as well as two-photon absorption with high cross section (74a: $\sigma$ 1250 GM, 74b: $\sigma \sim 1680$ GM, 74c: $\sigma \sim 2300$ GM). Optical power limiting properties of compound 74b have been also demonstrated.

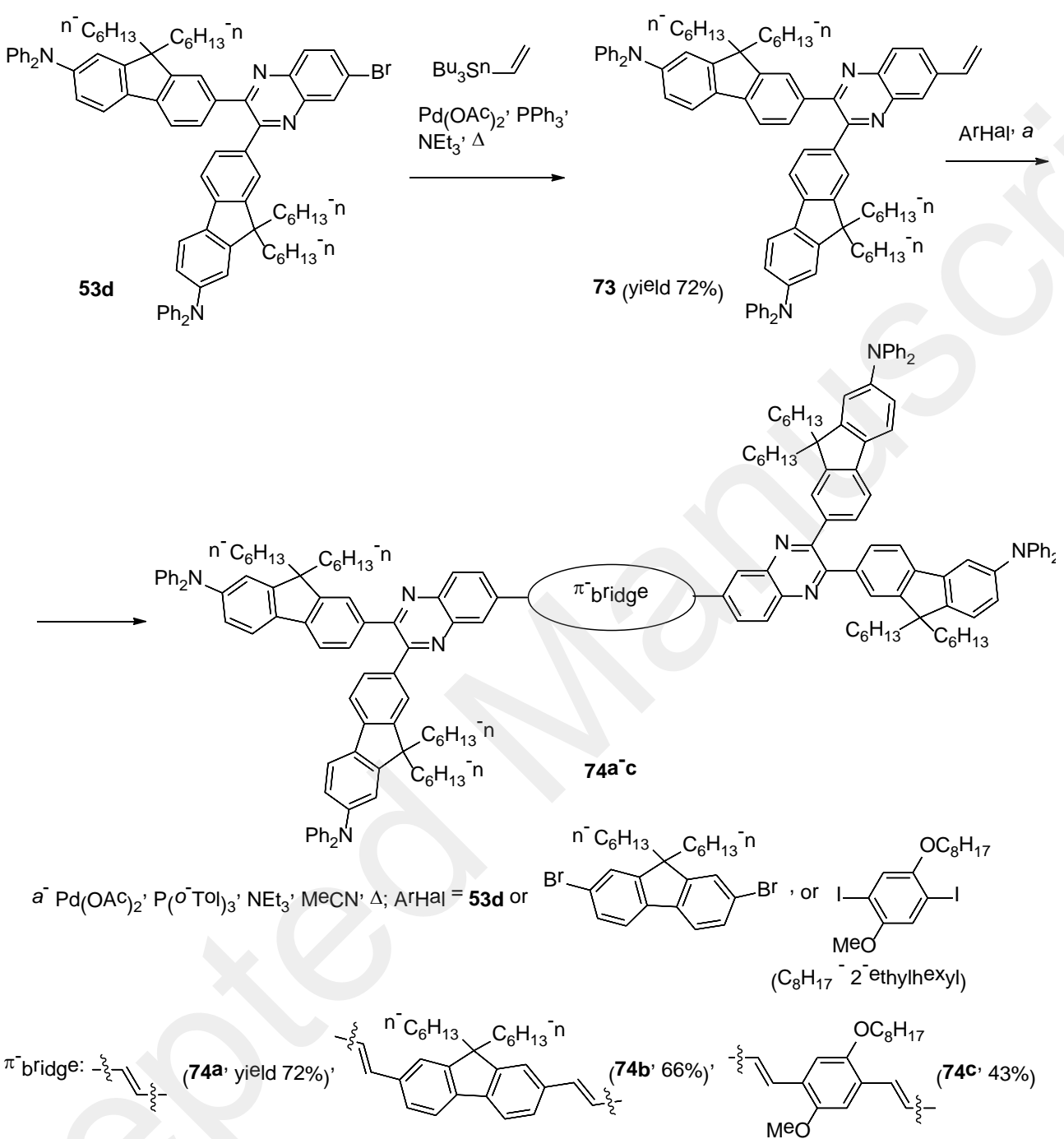

Kalinin and coworkers have proposed two push-pull chromophores 75 and 76 in which the quinoxaline linker plays the role of $\pi$-conjugated linker. ${ }^{67}$ Red shifted absorption is observed for the isomer $76\left(\lambda_{\mathrm{abs}}=600 \mathrm{~nm}\right)$. DFT calculation has shown that this chromophore can be considered as a promising candidate for the development of $2^{\text {nd }}$ order NLO materials.

Structures 75, 76<smiles>CN(C)c1ccc(/C=C/c2ccc3nc(-c4ccccc4)c(/C=C/C4=C(C#N)/C(=C(/[14CH2])C#N)OC4(C)C)nc3c2)cc1</smiles> 
As shown with these examples, arylvinylbenzo(di)azine derivatives have been extensively studied for their luminescence, NLO and photovoltaic properties.

\section{II.2. Synthesis and photoluminescence of arylethynyl- and aryl(hetaryl)benzazines}

\section{II.2.1. (Het)arylquinolines}

2,4-Diarylquinoline chromophores 77 are generally obtained by condensation reaction leading to the construction of the quinoline core. Various methods have been proposed including Friedländer condensation, ${ }^{78}$ condensation of arylalkynes and $o$-aminobenzophenone derivatives, ${ }^{79}$ or multicompoment reaction between arylaldehyde, anilines and arylalkynes (Scheme 13). ${ }^{80}$ The Suzuki cross coupling reaction has been commonly used to afford 2-aryl-, 2,4-diaryl- or 4,6,8triarylquinolines from 2-bromo, 2,4-dibromo and 6,8-dibromo-4-chloroquinoline derivatives respectively. ${ }^{32,78,81}$ quinoline boronic ester have been also involved in Suzuki cross coupling to obtain 5/6-arylquinoline chromophores. ${ }^{82}$

Scheme 13

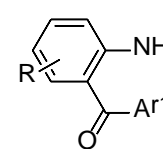

$a$ or $b$ or $c$
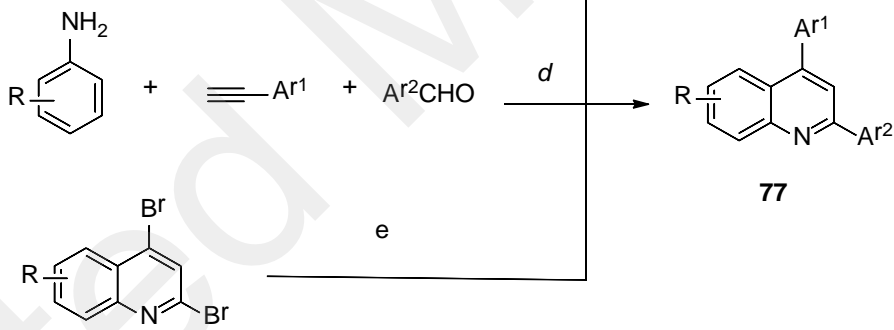

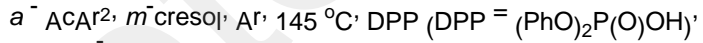
yield 68 99\%' (Frie dlander reaction

$b^{-} \mathrm{A}^{2}-\mathrm{C} \equiv \mathrm{CH} \cdot \mathrm{Ru}_{3}\left(\mathrm{CO}_{12}{ }^{\prime} \mathrm{HBF}_{4}\left(1^{\prime} 5 \mathrm{~mol} \%\right)^{\prime} \mathrm{PhMe}, 150^{\circ} \mathrm{C}^{\prime} 2 \mathrm{~h}\left(50^{-} 63 \%\right)\right.$

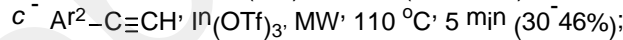

$d^{-} \mathrm{NbCl}_{5}$ (0`5 equiv), MeCN' rt' $96 \mathrm{~h}$ (54 $98 \%$;

$e^{-} \mathrm{A}^{\mathrm{r}} \mathrm{B}(\mathrm{OH})_{2}{ }^{\prime} \mathrm{Pd}\left(\mathrm{PPh}_{3}\right)_{2} \mathrm{Cl}_{2}{ }^{\prime} \mathrm{PCy}_{3}, \mathrm{~K}_{2} \mathrm{CO}_{3}$ ' dioxane ${ }^{-} \mathrm{H}_{2} \mathrm{O}(4: 1)\left(60^{-} 70 \%\right)$
}

Carvalho dos Santos et al have described a series of 6-nitro- and 6-aminoquinolines $\mathbf{7 8}$ and 79. ${ }^{83}$ In EtOH, nitro derivatives $\mathbf{7 8}$ exhibit purple emission with low fluorescence quantum yield $\left(\Phi_{\mathrm{F}}<0.03\right)$ whereas amino analogues 79 exhibit blue emission with much stronger quantum yield $\left(\Phi_{\mathrm{F}}=0.14-0.83\right)$. As expected, nitro substituents on the $\mathrm{C} 2$ phenyl ring of 6-aminoquinolines significantly reduce emission quantum yield.

Structures 78-80 


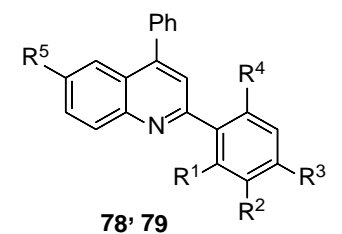

$\mathrm{R}^{5}=\mathrm{NO}_{2}(78) \cdot \mathrm{NH}_{2}(79$ :

$\mathrm{R}^{1,} \mathrm{R}^{2}, \mathrm{R}^{3,} \mathrm{R}^{4}=\mathrm{H}^{\prime} \mathrm{F} ; \mathrm{Cl}^{\prime} \mathrm{Br}$,

Me' tвu' OMe' $\mathrm{NMe}_{2}, \mathrm{SMe}^{\prime} \mathrm{NO}_{2}$

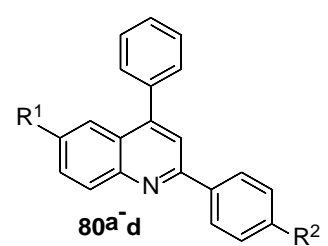

$\left.\mathrm{R}^{1}=\mathrm{H}_{(} \mathbf{a}\right) ; \mathrm{Cl}_{\left(\mathbf{b}^{-} \mathbf{d}\right) ;}$

$\mathrm{R}^{2}=\mathrm{H}\left(\mathbf{a}^{\mathbf{a}} \mathbf{b}\right) \cdot \mathrm{Cl}(\mathbf{c}) ; \mathrm{CN}(\mathbf{d})$

Kumar et al have studied the solid state (powder) emission of 2,4-diphenylquinoline $\mathbf{8 0 a - c .}{ }^{84}$ For 80a,b emission peak appears at $492 \mathrm{~nm}$ together with a weak shoulder at $536 \mathrm{~nm}$, in case of $\mathbf{8 0 c}$, emission maximun is observed at $478 \mathrm{~nm}$ with a shoulder at $536 \mathrm{~nm}$. For compounds $\mathbf{8 0 a}, \mathbf{b}$ the emission spectra are significantly broad due to $\pi-\pi^{*}$ interaction and/or conformational rigidity in the solid state, leading to chromacity coordinates not far from white light $(0.28,0.35)$.

Ghate and coworkers have synthesized cyano substituted quinoline derivative $\mathbf{8 0 d}{ }^{85}$ This compound exhibits purple luminescence $\left(\lambda_{\mathrm{em}}=374-376 \mathrm{~nm}\right.$ with a shoulder at $\left.395 \mathrm{~nm}\right)$ in various solvent (THF, DCM, $\left.\mathrm{CHCl}_{3}\right)$ with high emission quantum yield $\left(\Phi_{\mathrm{F}}=0.69-0.75\right)$ and blue emission $\left(\lambda_{\text {em }}=434 \mathrm{~nm}\right)$ in solid state (powder).

Mphahlele et al have described a series of 4,6,8-triarylquinoline derivatives 81-83. These compounds exhibit purple-blue luminescence in $\mathrm{CHCl}_{3}{ }^{32}$ Imines 82a-c and methanol derivatives 83a-c exhibit reduced emission intensity compared to the carbaldehyde analogues 81a-c. The presence of methoxy substituents in compounds $\mathbf{8 1}$ and $\mathbf{8 3}$ leads to a significantly red-shifted emission (81c: $\lambda_{\mathrm{em}}=470 \mathrm{~nm}$ and 83c: $\left.\lambda_{\mathrm{em}}=461 \mathrm{~nm}\right)$.
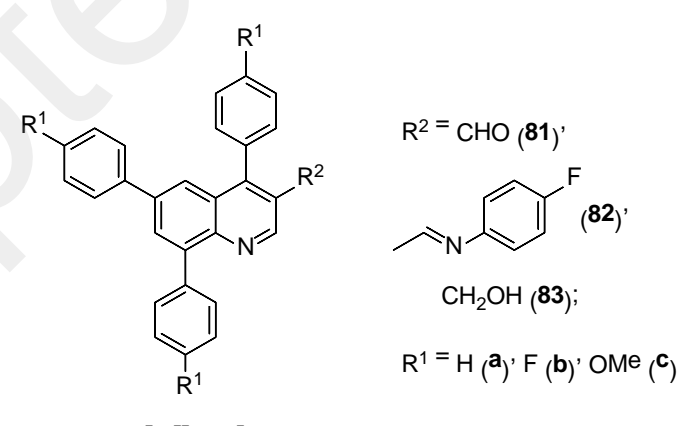

$81 a^{-c}{ }^{--} 83 a^{\top} c$

More et al and Han and coworkers have described the quinoline chromophores 84 and 85 respectively as $\mathrm{Cu}^{2+}$ fluorescent sensors. ${ }^{86,87}$ Both compounds exhibit blue photoluminescence in solution (84 in MeCN/HEPES buffer, 85 in the mixture EtOH- $\mathrm{H}_{2} \mathrm{O}$ ). The presence of $\mathrm{Cu}^{2+}$ ion caused selectively a great fluorescence quenching of this compound (ON-OFF probe) whereas, the addition of $\mathrm{Cd}^{2+}$ caused a weak reduction of emission intensity with a red-shift $\left(\lambda_{\mathrm{em}}=380 \mathrm{~nm}\right)$. 

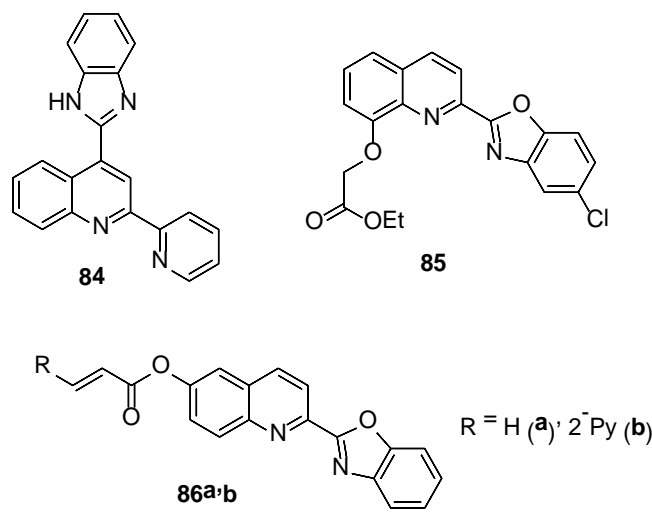

$\mathrm{Wu}$ and coworkers have designed chromophores $\mathbf{8 6 a}, \mathbf{b}$ as selective probe for cystein for bioimaging in living cell. ${ }^{88}$ These probes can discriminate cystein over other biothiol. Compound 86a exhibits emission at $383 \mathrm{~nm}$ and quantum yield of 0.41 in EtOH/PBS 1:3. A ratiometric fluorescence response of $\mathbf{8 6 a}$ toward cystein with big peak-shifting to $518 \mathrm{~nm}$ is observed leading to detection limit below $1 \mu \mathrm{M}$. Compound $\mathbf{8 6} \mathbf{b}$ acts as an OFF-ON probe for cystein.

Bonacorso and coworkers have designed a series of amine-substituted 2-aryl-4trifluoromethylquinolines $\mathbf{8 7 - 8 9} .^{89}$ These compounds that show blue luminescence $\left(\lambda_{\text {em }}=468-482\right.$ $\mathrm{nm})$ with moderate emission quantum yield $\left(\Phi_{\mathrm{F}}=0.05-0.18\right)$ in chloroform, exhibit strong interaction with ct-DNA and can be used for DNA titration.
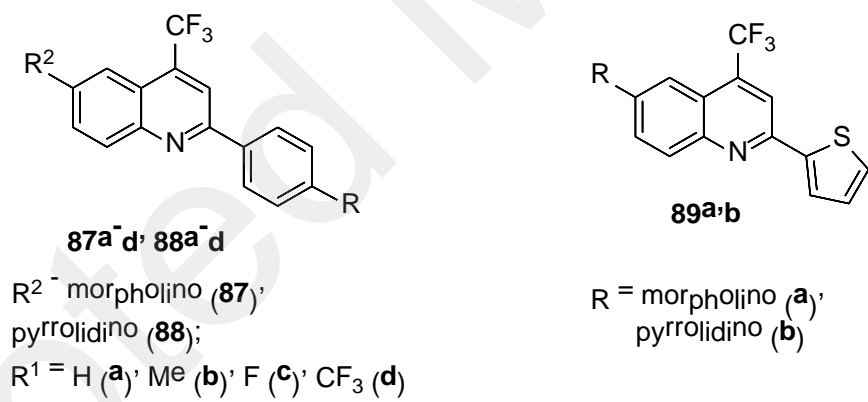

Tran et al have described 8-dimethylaminoquinoline-derived quadrupolar two-photon absorption chromophores 90 and $91 .{ }^{82}$ These compounds that exhibit low luminescence $\left(\Phi_{\mathrm{F}}=\right.$ 0.04-0.12) and moderate two-photon cross section (90: $\sigma=25 \mathrm{GM}$ at $680 \mathrm{~nm}$ and 91: $\sigma=10 \mathrm{GM}$ at $700 \mathrm{~nm}$ ), have been designed for two-photon acetyl uncaging application.

Structures 90, 91 

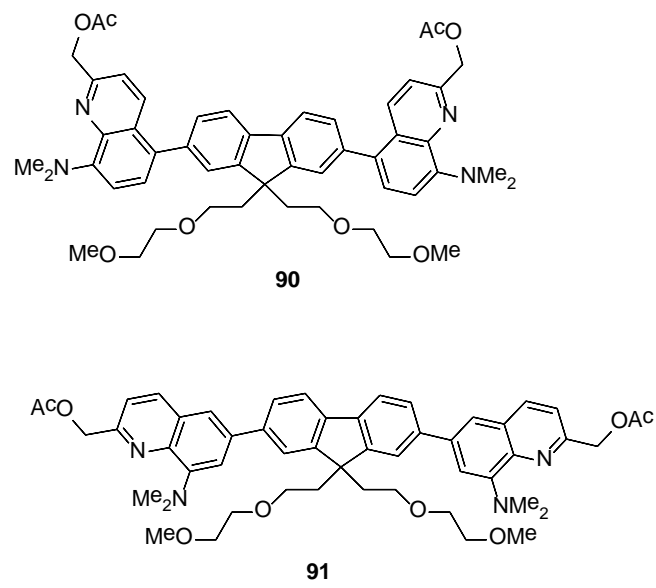

Cao and coworkers have designed chromophore 92. ${ }^{81}$ This compound forms organogel in various solvents. When self-assembled into organogel in MeCN, 92 exhibits two emission peaks at $385 \mathrm{~nm}$ and $495 \mathrm{~nm}$ due to $\pi-\pi$ stacking interactions in the gel state are observed. Solution and organogel of $\mathbf{9 2}$ in MeCN selectively and reversibly respond to volatil acid and organic amine vapors.

In addition to compound 31, Zanocco et al have described an analogue 93 without vinyl linker. ${ }^{49}$ As expected, 93 exhibits blue shifted emission with regards to 31 (410 nm for 93 and 450 $\mathrm{nm}$ for 31) but the quantum yield remains close to 1 in benzene. As for 31, compound 93 exhibits intense white light emission in $\mathrm{MeOH}$ (for $15 \%$ of DMSO, the chromacity coordinates are 0.28 , 0.35) with higher emission quantum yield than 31 (0.42 vs 0.31).

Lee and coworkers have designed diphenylamino substituted quinoline chromophores 9499. ${ }^{78}$ These compounds exhibit blue photoluminescence in toluene with high quantum yield (>90\%) attributed to charge transfer from the diphenylamino group to the quinoline ring. OLEDs have been fabricated with these chromophores with external quantum efficiency in the range of $1.2-2.3 \%$.

Structures 92-99 

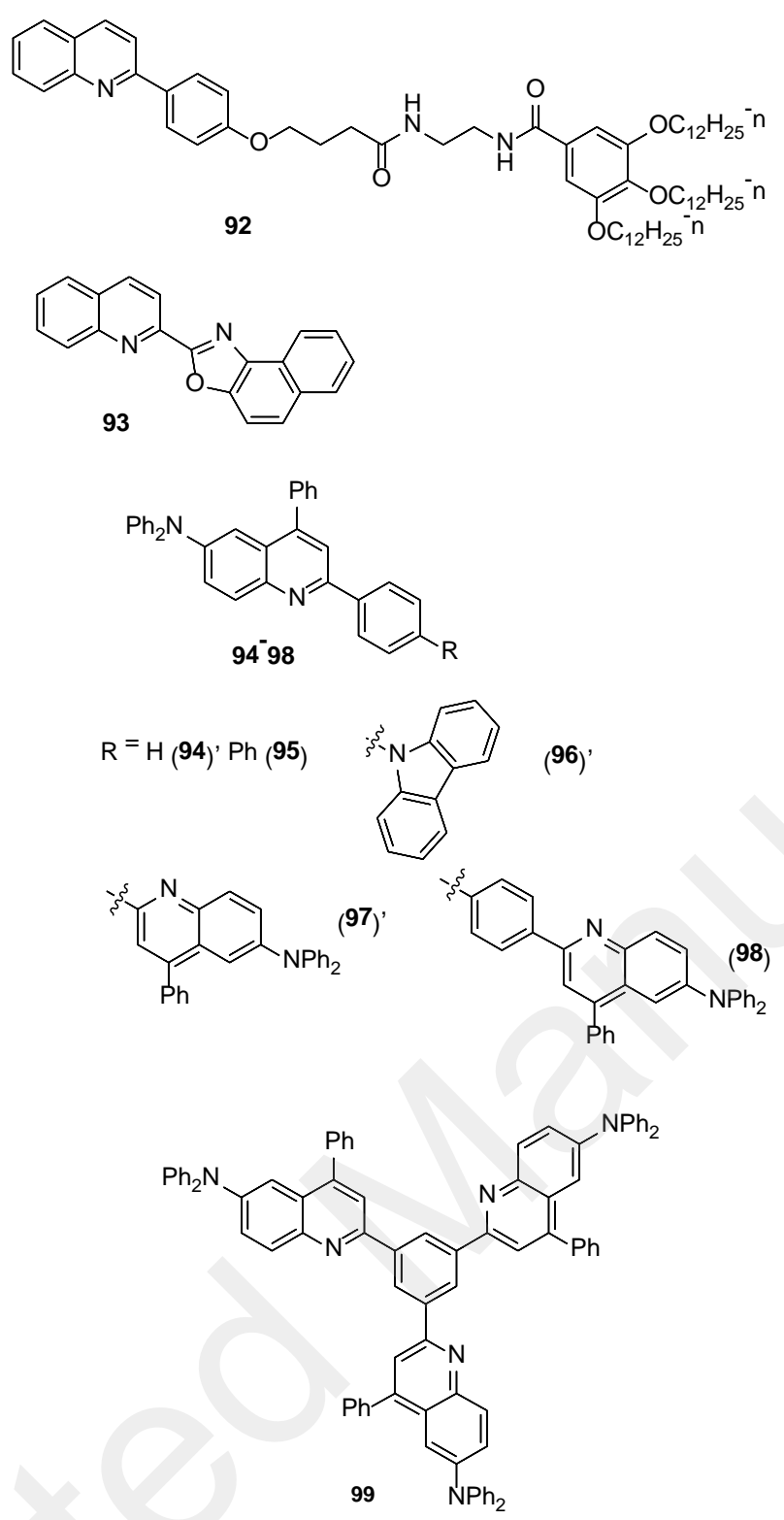

Slodek and coworkers $^{79}$ have designed quinoline chromophores with a 2,2'-bithiophene fragment 100a-e, 101. Compounds 100 and 101 exhibit blue-green emission in DCM $\left(\lambda_{\text {em }}=\right.$ 444-479 nm) with moderate Stokes shifts and microsecond lifetime whereas orange-red fluorescence is observed for 100c $\left(\lambda_{\mathrm{em}}=595 \mathrm{~nm}\right)$ with a larger Stokes shift $\left(7465 \mathrm{~cm}^{-1}\right)$. Starting from 100d, the same team has described a series of Schiff bases 102a-c. ${ }^{90}$ The compounds 102 exhibit moderately strong blue emission in solution as well as in PMMA blend whereas green emission is observed in polyvinylcarbazole matrix. When mixed with silver nanowires, these compounds exhibit strong electroluminescence due to plasmonic enhancement.

The same team ${ }^{91}$ has also compared bithiophene quinoline chromophores $\mathbf{1 0 0}$ with their carbazyl analogues 103a. Stronger ICT occurs in carbazyl substituted quinoline 103a with regards to 100, and the carbazyl substituent leads to higher quantum yield and lifetime (respectively up to 0.7 and 5.72 ns for 103a). Applications as fluorescent cellular probes have been proposed. 


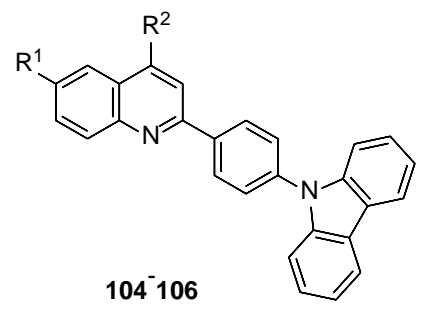

$R^{1}=H: R^{2}=P h(104)$,
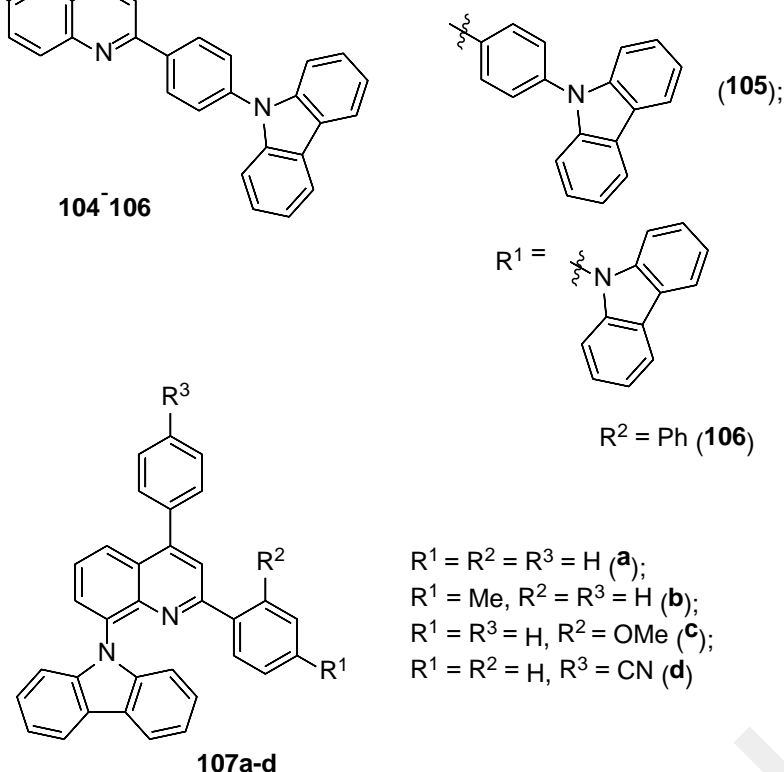

\section{II.2.2. Arylethynylquinolines}

5-, 6- and 8-Arylethynylquinolines 108 can be easily obtained by Sonogashira cross coupling reaction from the corresponding iodoquinolines (Scheme 14, top reaction). ${ }^{82,95}$ The same strategy can be used to obtain 4-arylethynylquinoline from the corresponding chloro intermediate. ${ }^{96}$ 6-Arylethynylquinolines $\mathbf{1 0 9}$ have been also obtained by Friedländer condensation from arylethynyl substituted aminobenzaldehyde (Scheme 14 , bottom reaction). ${ }^{97}$

\section{Scheme 14}

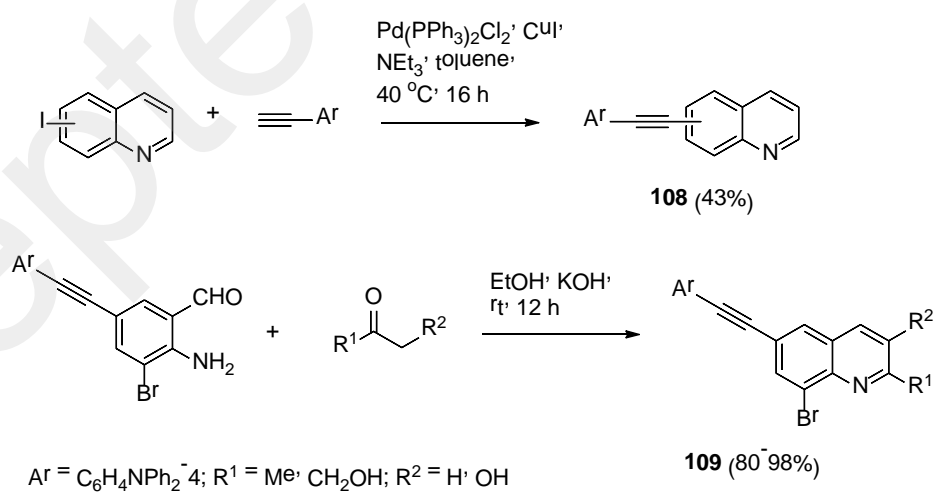

Alapour et al have designed a series of trifluoromethyl substituted 4-arylethynylquinolines chromophores 110. These compounds exhibit blue luminescence in MeCN solution and in solid state. ${ }^{96}$ In solid state, the addition of $\mathrm{CF}_{3}$ substituents was found to result in increased flexibility of the structure with a decrease in the number of intermolecular interactions and the authors stated that it could result in enhancement their emission in solid state. 

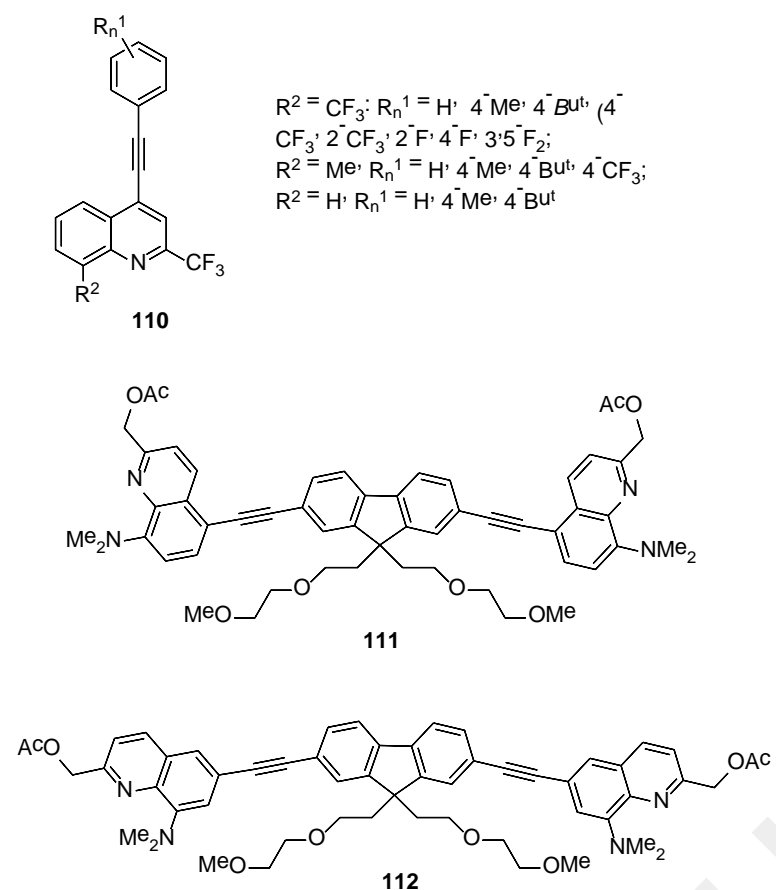

In addition to arylquinolines 90 and 91, Tran and coworkers ${ }^{82}$ have designed their arylethynyl analogues 111 and 112 as two-photon absorption chromophores for acetyl uncaging. In comparison with their analogues 90, 91, compounds 111, 112 exhibit enhanced two-photon cross section (111: $\sigma=160 \mathrm{GM}$ at $720 \mathrm{~nm}$ and 112: $\sigma=70 \mathrm{GM}$ at $710 \mathrm{~nm})$.

The same team has also developed the chromophores 113-117 for the same application. ${ }^{95}$ These compounds exhibit blue emission in THF with high emission quantum yield $\left(\Phi_{\mathrm{F}}=\right.$ 0.59-0.68). Quadripolar compound 117 exhibit the lowest two-photon cross section ( $\sigma=75$ GM at $\lambda=710 \mathrm{~nm})$ whereas the higher value is observed for $116(\sigma=480 \mathrm{GM}$ at $\lambda=730 \mathrm{~nm})$.

Structures 113-117
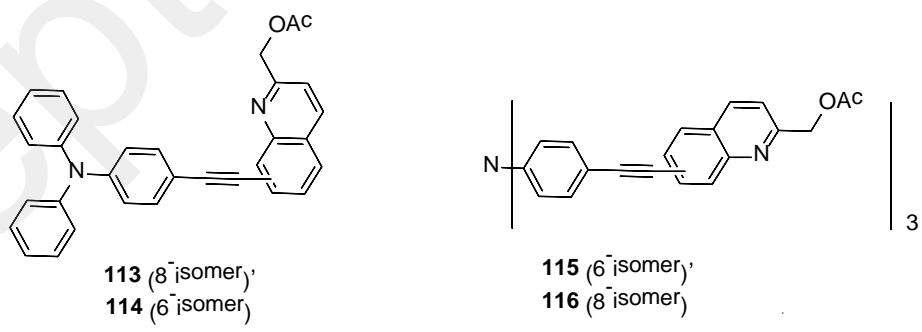

115 ( $6{ }^{-}$isomer $)$ 116 (8 isomer)

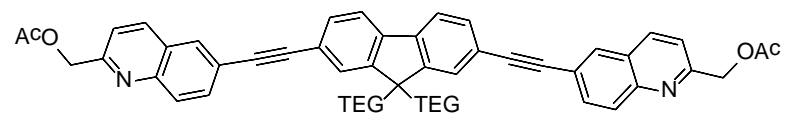

117

TEG $=\left[{ }_{\left[\left(\mathrm{CH}_{2) 2} \mathrm{O}\right]_{3} \mathrm{Me}\right.}\right.$

Picard and coworkers have designed a series of diphenylamino-substituted 6-arylethynyl,8bromoquinolines 118. ${ }^{97}$ These chromophores combine in toluene significant two photon absorption cross section $\left(\sigma=116-265\right.$ GM) in the NIR region, good photosensitization ability $\left(\Phi_{\Delta}=0.4-0.6\right)$ and fluorescence properties $\left(\Phi_{\mathrm{F}}=0.2-0.6\right)$. The authors described these compounds as promissing 
dyes for combining two-photon imaging and photodynamic therapy. Compound 118c has been used as precursor to obtain $\mathbf{1 1 9}$ that can be graphted on mesoporous silica nanoparticles via click chemistry for two-photon photodynamic therapy. ${ }^{98}$

Ning and coworkers have designed chromophore 120 as two-photon viscosity probe. ${ }^{99}$ It was shown that increasing the water/glycerol mixture viscosity, which blocking the rotation of the dicyanovinyl group, leads to strong enhancement of emission intensity of compound 120 upon twophoton excitation. The effectiveness of application of this compound as fluorescent probe depending on the environment viscosity was shown in vivo on cervical tumor cells HeLa.

Structures 118-120

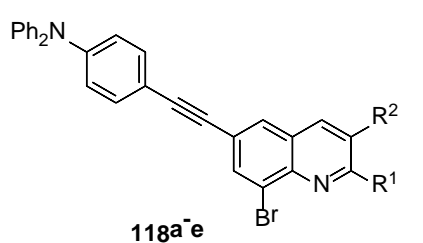

$\mathrm{R}^{1}=\mathrm{Me}_{\left({ }^{2}\right)}{ }^{\prime} \mathrm{CHO}(\mathbf{b})^{\prime}$

$\mathrm{CH}_{2} \mathrm{OH}$ (c', e' $\mathrm{Me}$ (d)

$\mathrm{R}^{2}=\mathrm{H}\left(\mathbf{a}^{-} \mathbf{c}\right) \cdot \mathrm{OH}\left(\mathbf{d}^{\prime} \mathbf{e}^{\mathrm{e}}\right)$

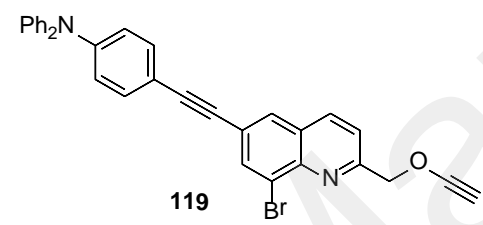

Meo

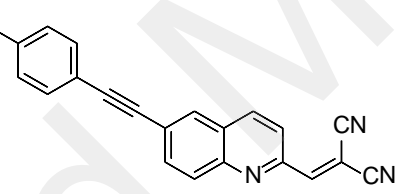

120

Yang et al have designed a two-photon fluorescent probe $\mathbf{1 2 1}$ for selective detection of endogenous formaldehyde via Aza-Cope reaction (Scheme 15). ${ }^{100}$ In PBS buffer, compound 121 shows an emisison maxima at $405 \mathrm{~nm}\left(\Phi_{\mathrm{F}}=0.03, \sigma=185 \mathrm{GM}\right)$, upon addition of formaldehyde, emission maxima is red shifted at $490 \mathrm{~nm}\left(\Phi_{\mathrm{F}}=0.10, \sigma=275 \mathrm{GM}\right)$.

Scheme 15

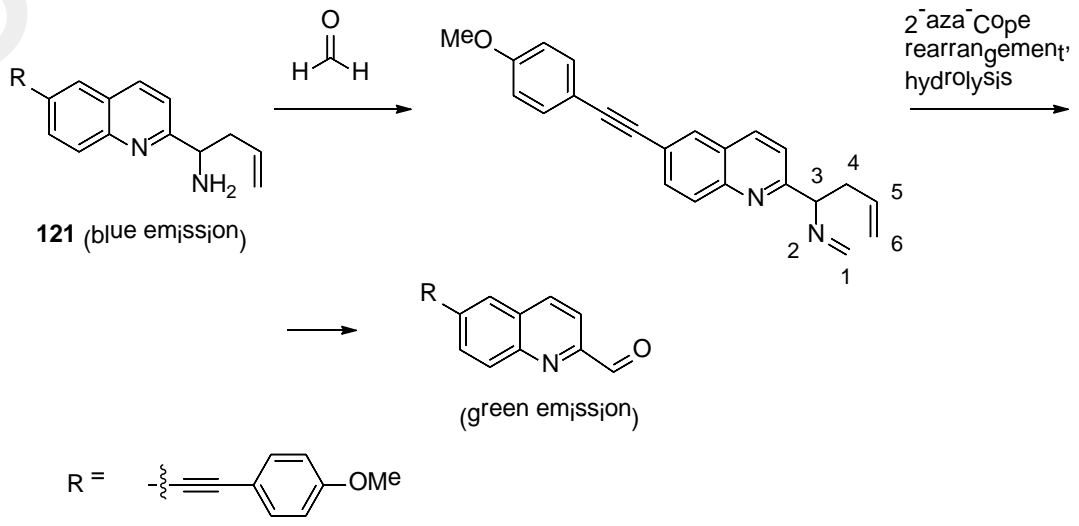

\section{II.2.3. (Het)arylquinazolines}


Two main methods have been used to synthesize arylquinazoline derivatives. The $1^{\text {st }}$ one consists in condensation reactions to build the quinazoline core and the second one in Suzuki cross coupling reaction from halogenoquinazolines. 2-Arylquinazolines can be obtained by reaction of 2aminobenzamide with arylcarboxaldehyde. ${ }^{101}$ 4-Arylquinazoline can be obtained by Suzuki cross coupling reaction from chlorine intermediates ${ }^{54}$ or by iodine-catalyzed oxidative $\mathrm{C}-\mathrm{H}$ amination from ortho-carbonyl-substituted anilines and amonia. ${ }^{102}$ 2,4-Diarylquinazolines can be obtained either by double Suzuki cross coupling (the C4 position being more reactive than the C2 one), ${ }^{54}$ by condensation reaction from 2-cyanoaniline ${ }^{103}$ or by condensation of 2-aminobenzophenone with arylcarboxaldehyde. ${ }^{104}$ 6-Arylquinazoline can be also obtained from 6-bromo or 6-iodoquinaline by Suzuki cross-coupling. ${ }^{57,101}$

Achelle and coworkers have synthesized 4-aryl and 2,4-diarylquinazolines 122, $123 .{ }^{54,105}$ In DCM, compound 122a exhibits blue photoluminescence whereas compounds 122b and 123a,b exhibit green luminescence and 122c emits yellow-orange light. 4-Arylquinazolines 123a,b exhibit significantly higher quantum yield $\left(\Phi_{\mathrm{F}}=0.8-0.93\right)$ than their 2,4 -diarylquinazoline $123\left(\Phi_{\mathrm{F}}=0.30\right.$ $0.34)$ and 4-arylvinylquinazoline $\left(\Phi_{\mathrm{F}}=0.02-0.25\right)$ analogues. As expected with regards to their arylvinyl analogues $\mathbf{4 0}$ and $\mathbf{4 1}$, compounds 122, 123 show blue shifted emission. ${ }^{54}$

Structures 122, 123

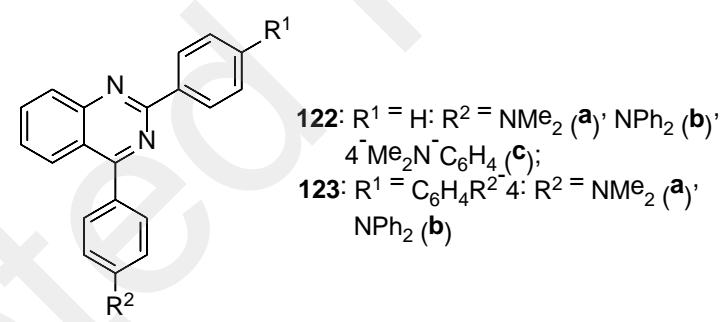

$122 a^{-} \mathrm{c}, 123 \mathrm{a}_{\mathrm{b}}$

Nosova and coworkers have designed a series of 4-morpholin-4-yl substituted quinazoline 124-127. These compounds have been obtained by bromination of 124 followed by palladium catalyzed Suzuki/Sonogashira cross coupling reaction. ${ }^{106}$ Compounds 125d,e exhibit green photoluminescence in MeCN whereas compounds 125b,c and 126, 127 show blue photoluminescence. $\mathrm{pH}$ sensibility with significant red-shifted emission has been demonstrated. Cyano analogue $125 \mathbf{e}$ is poorly emissive $\left(\lambda_{\text {em }}=471 \mathrm{~nm}, \Phi_{\mathrm{F}}<0.01\right) .^{107}$

Structures 124-127 


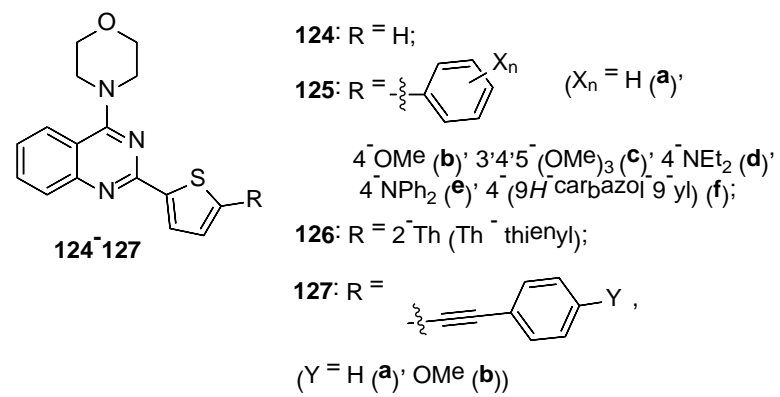

The same group has described a series of 2,4-diarylquinazoline derivatives $\mathbf{1 2 8 - 1 3 0}{ }^{108}$ These compounds exhibit blue luminescence in toluene $\left(\lambda_{\mathrm{em}}=431-459 \mathrm{~nm}\right)$ with emission quantum yield up to 0.82 for $\mathbf{1 2 8 a}$ whereas orange emission is observed for the same compounds in MeCN with lower quantum yield $\left(\Phi_{\mathrm{F}}=0.05-0.28\right)$.

Structures 128-130

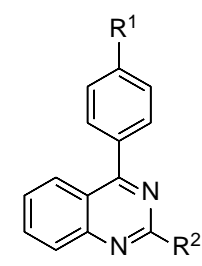

$128 a \cdot b ; 129 a \cdot b$

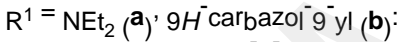
$\mathrm{R}^{2}=\mathrm{Ph}(\mathbf{1 2 8})$, fluoren ${ }^{-}{ }^{-} \mathrm{yl}^{\prime}(\mathbf{1 2 9})$

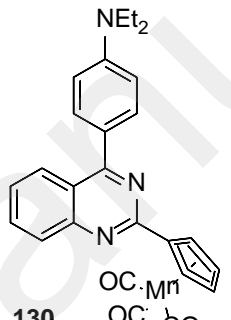

$130 \mathrm{OC}$ CO

Wang and coworkers have designed a series of 2-arylquinazolines-substituted ethene derivatives including chromophores 131a-d. ${ }^{109}$ These compounds exhibit typical aggregation induced emission properties. As a typical example, compound 131b exhibits green emission $\left(\lambda_{\mathrm{em}}=\right.$ $530 \mathrm{~nm})$ in thin film with high quantum yield $\left(\Phi_{\mathrm{F}}=0.52\right)$.

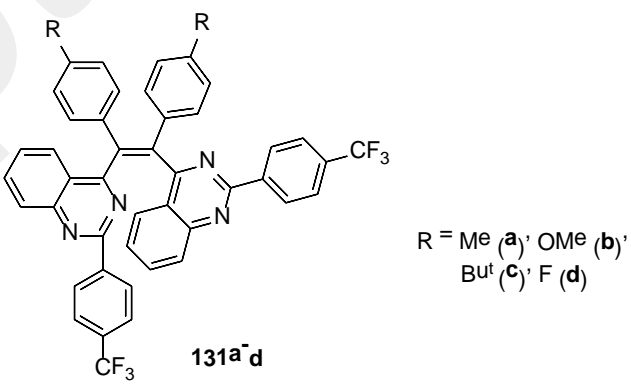

Structures 131, 132

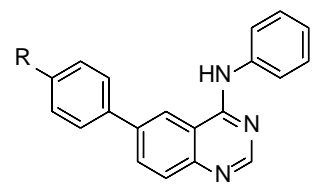

$\mathrm{R}=\mathrm{NMe}_{2}\left(\stackrel{\mathbf{a}}{)^{\prime}} \mathrm{OMe}_{(\mathbf{b})}\right)^{\prime}$

$\mathrm{H}\left(\mathbf{c}^{2}\right), \mathrm{CN}(\mathbf{d}) \mathrm{NO}_{2}\left(\mathbf{e}^{\mathrm{e}}\right)$

$132 \mathrm{a}^{\mathrm{e}}$

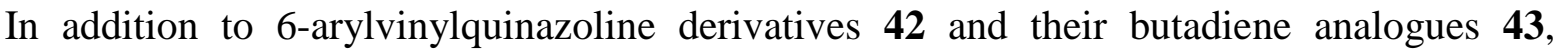
Dhuguru et $\mathrm{al}^{57}$ have designed 6-arylquinazoline chromophores 132a-e. Except dimethylamino 
derivative 132a $\left(\lambda_{\mathrm{em}}=435 \mathrm{~nm}, \Phi_{\mathrm{F}}=0.37\right.$ in $\left.\mathrm{CHCl}_{3}\right)$, these compounds are poorly emissive $\left(\Phi_{\mathrm{F}}<\right.$ 0.03) with blue shifted emission with regards to their vinyl or butadiene analogues 40-42.

Liu and coworkers have designed chromophores 133 and $134 .^{103}$ These compounds can be used for white photoluminescence and electroluminescence combining the blue emitting neutral form and orange-emiting protonated form. Indeed the protonation of the quinazoline ring greatly enhances its electron-withdrawing character and stengthens the ICT leading to bathochromically shifted emission.

Structures 133-135

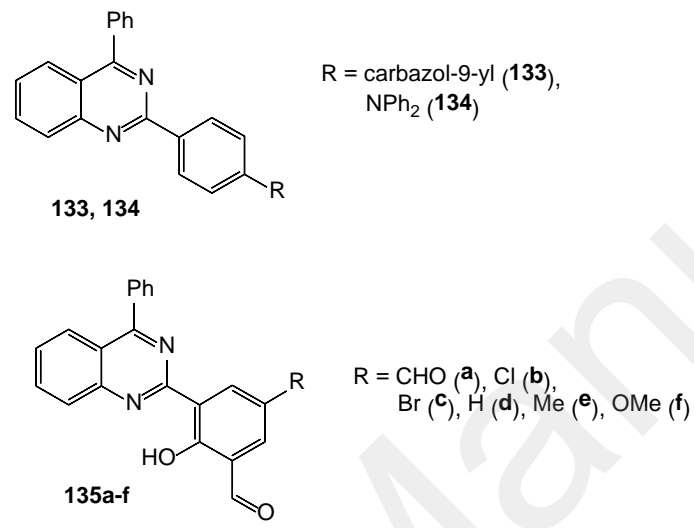

Dwivedi et al have designed a series of quinazoline-based excited state intramolecular proton transfer (ESIPT) active systems 135a-f. ${ }^{104}$ The ESIPT emission, completely quenched in solution, can be restored via aggregation-induced emission. In solid state, these compounds exhibit various emission band corresponding to the enol $\left(\lambda_{\mathrm{em}}=465-513 \mathrm{~nm}\right)$ and keto forms $\left(\lambda_{\mathrm{em}}=\right.$ 560-704 nm). The authors claim that these tunable ESIPT emissive materials have potential applications in optoelectronic devices.

Zhang and coworkers have described a series of 2,4-diarylquinazoline derivatives with benzoimidazole, carbazole and triphenylene substituents 136-139. ${ }^{110}$ These compounds can be used as host material for red phosphorescent organinc light-emitting diodes. The best device was obtained with 136 with external quantum efficiency of $19.2 \%$, current efficiency of $18.3 \mathrm{~cd} / \mathrm{A}$ and $21.3 \mathrm{~lm} / \mathrm{W}$.

Kim and coworkers have designed fluorene-bridged quinazoline derivatives 140. This compound exhibits in DCM solution and thin film. ${ }^{111}$ A blue OLED with external quantum efficiency of $1.58 \%$ at $20 \mathrm{~mA} / \mathrm{cm}^{2}$ has been obtained with this compound. 

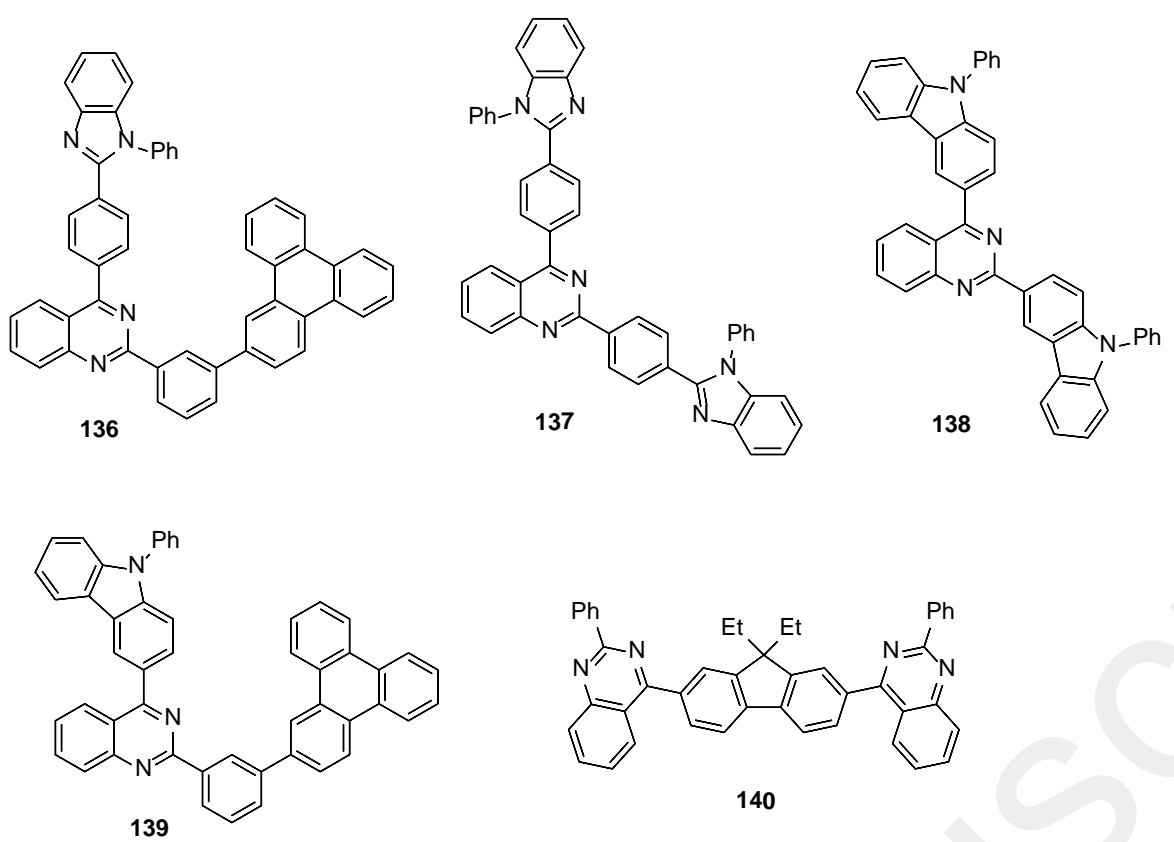

\section{II.2.4. Arylethynylquinazolines}

Arylethynylquinazoline chromophores have been synthesized exclusively by Sonogashira cross coupling reactions. ${ }^{54}$ 4-Arylethynylquinazolines can be obtained from the corresponding chloro derivatives. 6-iodo/bromo- and 6-iodoquinazolines can lead to 6-arylethynyl and 8arylethynylquinazolines. ${ }^{112,113}$ To the best of our knowledge, no 2-ethynylarylquinazoline chromophores have been designed so far.

Achelle and coworkers have proposed 4-arylethynylquiazolines 141a-c. ${ }^{54}$ In DCM solution, these compounds exhibit green emission $\left(\lambda_{\mathrm{em}}=551-565 \mathrm{~nm}\right)$ with low quantum yield, except the diphenylamino derivative 141b $\left(\Phi_{\mathrm{F}}=0.41\right)$, As shown in Table 2, 4-arylethynylquinazolines 141 and 4-arylvinylquinazolines $\mathbf{4 0}$ exhibit red-shifted emission and lower quantum yield than their 4arylquinazoline analogues 122.

Table 2. Comparison of photophysical properties of 4-arylethynylquinazolines 141, 4arylvinylquinazolines $\mathbf{4 0}$ and 4-arylquinazoline analogues 122 in $\mathrm{CH}_{2} \mathrm{Cl}_{2}{ }^{54}$

\begin{tabular}{llll}
\hline Compound & $\lambda_{\text {abs }} / \mathrm{nm}\left(\varepsilon / \mathrm{mM}^{-1} \mathrm{~cm}^{-1}\right)$ & $\lambda_{\mathrm{em}} / \mathrm{nm}$ & $\Phi_{\mathrm{F}}$ \\
\hline 141a & $411(27.5)$ & 560 & 0.03 \\
40a & $433(18.0)$ & 548 & 0.07 \\
122a & $380(16.4)$ & 490 & 0.93 \\
141b & $414(29.2)$ & 565 & 0.41 \\
40b & $429(16.9)$ & 571 & 0.25 \\
122b & $384(16.6)$ & 528 & 0.80 \\
\hline
\end{tabular}


Mphahlele et al have designed a series of 2,6,8-triaryl-4-arylethynylquinazoline derivatives 142. ${ }^{114}$ In $\mathrm{CHCl}_{3}$, these compounds exhibit blue luminescence $\left(\lambda_{\text {em }}=454-480 \mathrm{~nm}\right)$ with low quantum yield $\left(\Phi_{\mathrm{F}}=0.10-0.07\right)$.

Structures 141, 142

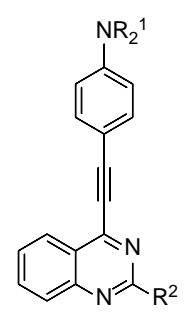

$141 \mathrm{a}^{-\mathrm{c}}$

$\mathrm{R}^{2}=\mathrm{H}: \mathrm{R}^{1}=\mathrm{Me}\left(\mathbf{a}^{\prime}\right) \mathrm{Ph}(\mathbf{b})$ $\mathrm{R}^{1}=\mathrm{Me} \cdot \mathrm{R}^{2}=\mathrm{Ph}(\mathbf{c})$

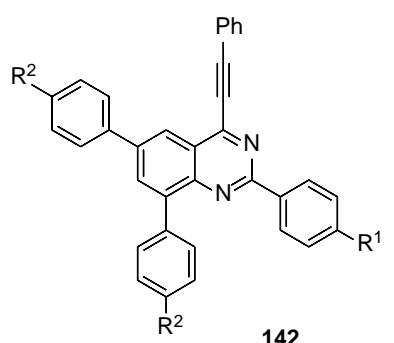

$\mathrm{R}^{1}=\mathrm{H}^{\prime} \mathrm{F}^{\prime} \mathrm{Cl}$, OMe; $\mathrm{R}^{2}=\mathrm{H}^{\prime} \mathrm{F}^{\prime}$ OMe

Mphahlele and coworkers have designed a series of 6-phenylethynylquinazoline derivatives 143-145 and the same teams have also synthesized 8-phenylethynylquinazolines 146, as well as 4,8biarylethynyl- and 4,6,8-triarylethynylquinazolines 147. ${ }^{112,113}$ These compounds exhibit also blue emission in $\mathrm{CHCl}_{3}$ with low to moderate quantum yield.

Structures 143-147
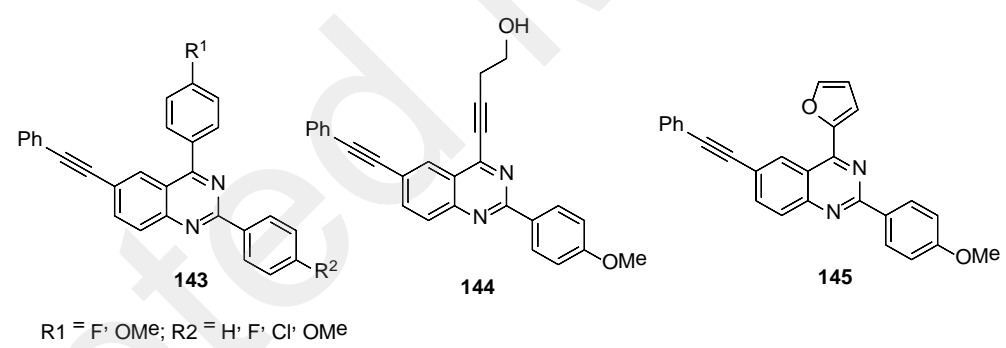

$\mathrm{R} 1=\mathrm{F}^{\prime} \mathrm{OMe} ; \mathrm{R} 2{ }^{\prime} \mathrm{H}^{\prime} \mathrm{F}$ ' Cl' OMe

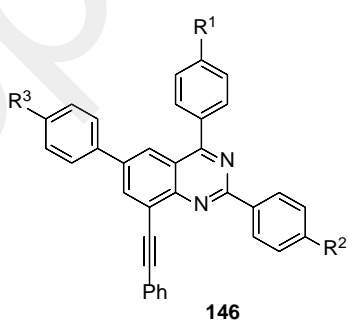

$\mathrm{R}^{1,} \mathrm{R}^{2,} \mathrm{R}^{3}=\mathrm{H}^{\prime} \mathrm{F}, \mathrm{Cl}, \mathrm{OMe}$

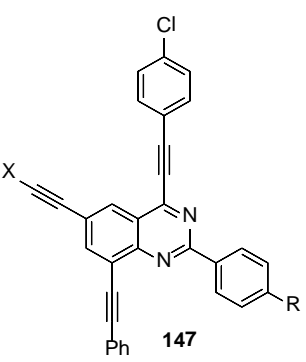

$\mathrm{X}^{=}\left(\mathrm{CH}_{2}\right)_{2} \mathrm{OH}^{\prime} \cdot{ }^{-} \mathrm{Py} ;$

\section{II.2.5. (Het)arylquinoxalines}

2,4-Diarylquinoxalines 150 are generally obtained by condensation of $o$-phenylenediamine 148 and diaryl 1,2-diketone derivatives 149 (Scheme 16,a). ${ }^{115-117}$ 2-Arylquinoxalines 152 can be obtained by condensation reaction between o-phenylenediamine 148 and $\alpha$-bromo-arylketone 
(b), ${ }^{117,118} \alpha$-hydroxy-arylketone (c), ${ }^{119,120}$ phenylethane-1,2-diol $(d \text { or } e)^{121,122}$ or 2-arylethylamines $(f) .{ }^{123}$ Another strategies consist in Suzuki cross-coupling reaction from 2-chloroquinoxaline 151, ${ }^{105}$ as well as nucleophilic substitution of hydrogen in quinoxalin-N-oxides. ${ }^{124}$

Scheme 16

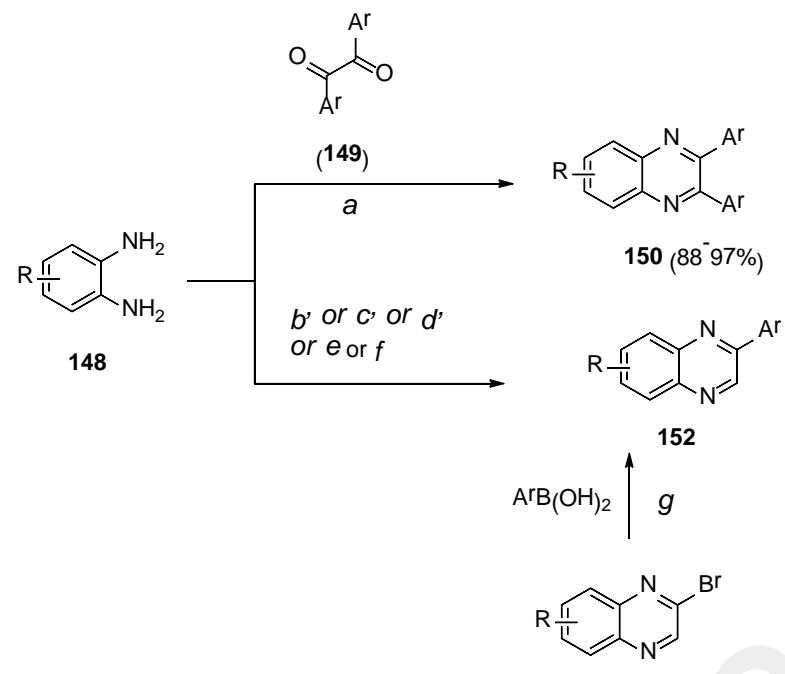

151

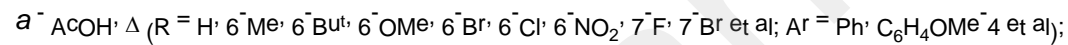

$b^{-} \mathrm{ArC}^{\mathrm{r}}(\mathrm{O}) \mathrm{CH}_{2} \mathrm{~B}^{\mathrm{r}} \cdot \mathrm{K}_{2} \mathrm{CO}_{3}{ }^{\prime} \mathrm{DMF}^{\prime} \mathrm{rt}^{\prime} 2 \mathrm{~h}\left(52^{-} 72 \%\right)\left(\mathrm{R}^{-} \mathrm{H}^{\prime} 4^{-} \mathrm{Me}, 4^{-} \mathrm{Cl}\right.$

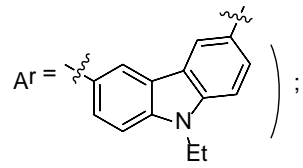

$C^{-} \mathrm{A}^{\mathrm{r}} \mathrm{C}(\mathrm{O}) \mathrm{CH}_{2} \mathrm{OH}^{\prime} \mathrm{Cu}^{-} \mathrm{Mn} / \mathrm{HT}$ ( $\mathrm{HN}^{-}$hydrotalcite), $\mathrm{EtOH}^{\prime} \mathrm{O}_{2}, 70^{\circ} \mathrm{C}^{\prime} 12 \mathrm{~h}\left(65^{-} 90 \%\right) ;$

$\left(\mathrm{R}=\mathrm{H}^{\prime} 4^{-} \mathrm{Cl} ; \mathrm{Ar}^{\mathrm{r}} \mathrm{Ph}^{\prime} \mathrm{C}_{6} \mathrm{H}_{4} \mathrm{Br}^{-}{ }^{\prime}, \mathrm{C}_{6} \mathrm{H}_{4} \mathrm{OMe}_{4}^{-}, \mathrm{C}_{6} \mathrm{H}_{4} \mathrm{Cl}^{-} 3^{\prime} 3^{-} \mathrm{Th}, 2^{-} \mathrm{Naph}\right)$;

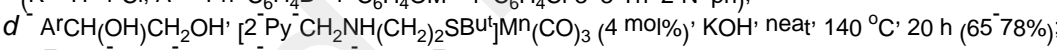

$\mathrm{R}=\mathrm{H}^{\prime} 6 \mathrm{Me}^{-} 7^{-} \mathrm{Me}, 6^{\prime} 7^{-} \mathrm{Me}_{2}, 6^{\prime} 7^{-} \mathrm{Cl}_{2} ; \mathrm{Ar}^{-}=\mathrm{Ph}$;

$e^{-} \mathrm{Ph}^{-} \mathrm{CH}(\mathrm{OH}) \mathrm{CH}_{2} \mathrm{OH}^{\prime}$

$\mathrm{CSOH}^{\circ} \mathrm{H}_{2} \mathrm{O}^{\prime} \mathrm{PhMe} \cdot 150{ }^{\circ} \mathrm{C}$

24 h (85\%);

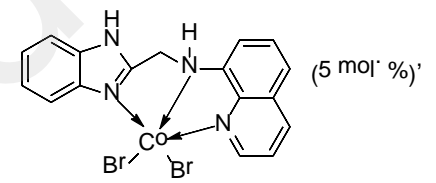

$f^{-} \mathrm{Ar}^{\mathrm{r}}\left(\mathrm{CH}_{2}\right)_{2} \mathrm{NH}_{2} \mathrm{CUBr}^{\prime}$ (10 mol'\%)' PhCl' $\mathrm{O}_{2}$ ' rt' $6 \mathrm{~h}$ (78-97\%); $\left(\mathrm{R}=\mathrm{H} ; \mathrm{Ar}^{-}=\mathrm{Ph}^{\prime} \mathrm{C}_{6} \mathrm{H}_{4} \mathrm{Cl}^{-}{ }^{\prime}, \mathrm{C}_{6} \mathrm{H}_{4} \mathrm{Br}^{-} 4\right.$,

$\mathrm{C}_{6} \mathrm{H}_{4} \mathrm{CF}_{3} 4^{\prime} \mathrm{C}_{6} \mathrm{H}_{4} \mathrm{OMe}^{-}{ }^{\prime}, \mathrm{C}_{6} \mathrm{H}_{4} \mathrm{OMe}^{-}{ }_{3}, \mathrm{C}_{6} \mathrm{H}_{4} \mathrm{OH}^{-} 4^{\prime} 1^{-}$Naph' $^{-} \mathrm{Py}^{\prime} 2^{-} \mathrm{Th}$ et al ;

$g^{-} \mathrm{Pd}(\mathrm{PPh})_{4}{ }^{\prime} \mathrm{Na}_{2} \mathrm{CO}_{3}$ ' EtOH' PhMe' $\mathrm{N}_{2}{ }^{\prime} \Delta^{\prime} 15 \mathrm{~h}\left(93^{-} 95 \%\right)$

$\left(\mathrm{R}^{-} \mathrm{H}^{\prime} \mathrm{Ar}^{\mathrm{r}}=\mathrm{C}_{6} \mathrm{H}_{4}{ }^{-} \mathrm{C}_{6} \mathrm{H}_{4} \mathrm{NMe}_{2}{ }^{-} 4^{\prime} \mathrm{C}_{6} \mathrm{H}_{4} \mathrm{NMe}_{2}^{-}{ }^{-}\right.$)

5-Aryl-, 6-aryl- and 5,8-diarylquinoxalines can be easily obtained by Suzuki or Stille cross coupling reactions from the corresponding bromo or iodo derivatives. ${ }^{111,125,126}$

Nafe and coworkers have synthesized chromophore 153 that exhibits blue luminescence in solution (unspecified solvent, $\left.\lambda_{\text {em }}=467 \mathrm{~nm}, \Phi_{\mathrm{F}}=0.6\right){ }^{127}$

Achelle et al. have synthesized chromophore 154. ${ }^{105}$ This compound exhibits green-yellow luminescence $\left(\lambda_{\text {em }}=539 \mathrm{~nm}\right)$ with high fluorescence quantum yield $\left(\Phi_{\mathrm{F}}=0.90\right)$ in DCM. Design of experiment methodology combined with ANOVA method have shown that compared with diazine fragment the benzodiazine part led to a significant red shift in absorption and emission. 
Telore and coworkers have synthesized carbazole derivatives 155a-c. ${ }^{118}$ These compounds exhibit blue luminescence in DCM and emission solvatochromism attributed to ICT and are therefore potential NLO chromophores.

Lu and coworkers have designed D-A-D chromophore 156. ${ }^{128}$ This compound exhibits yellow-green emission $\left(\lambda_{\mathrm{em}}=557 \mathrm{~nm}\right)$ in DCM due to ICT from diphenylamino groups to the central quinoxaline core. Bulk heterojunction solar cell application has been also proposed for this compound. $^{129}$

Structures 153-156
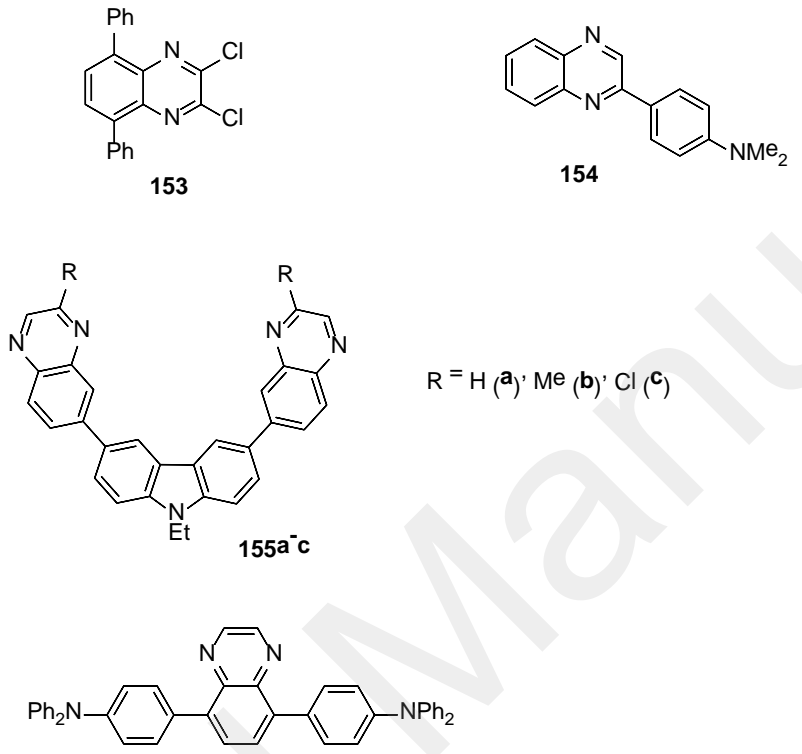

156

Moshkina and coworkers have described a series of V-shaped 2,3-bis(5-arylthiophen-2yl)quinoxaline derivatives 157a-c, 158. ${ }^{115}$ These compounds exhibit blue-green emission $\left(\lambda_{\mathrm{em}}=\right.$ $498-557 \mathrm{~nm})$ in toluene with moderate quantum yield $\left(\Phi_{\mathrm{F}}=0.14-0.07\right)$. The highest quantum yield is observed for the diphenylamino derivative 157b. These compounds exhibit halochromism and the ability of 157a to function as colorimetric and luminescent $\mathrm{pH}$ sensor has been demonstrated. The addition of TFA (up to 135 equiv) led to a blue shifted emission (from $547 \mathrm{~nm}$ to $461 \mathrm{~nm}$ ) attributed to the protonation of the diethylaminophenyl moieties.

Zhang and coworkers have designed chromophores 159a-g. ${ }^{130}$ These compounds exhibit blue-green luminescence in DCM (494-530 nm) as well as emission solvatochromism. 

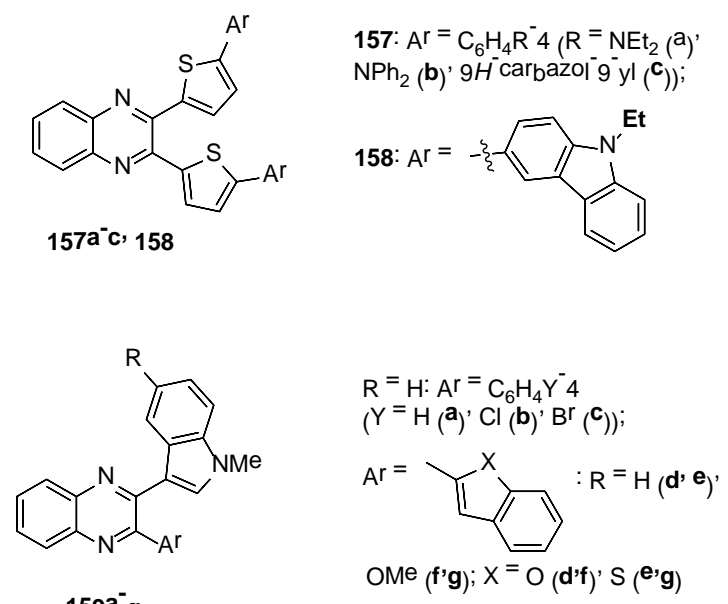

$159 \mathrm{a}^{-} \mathrm{g}$<smiles>[R]c1ccc(-c2nc3ccc([R])cc3nc2-c2nc3cc([R1])c([R1])cc3n2[R])cc1</smiles>

$\mathrm{R}^{1,} \mathrm{R}^{4}=\mathrm{H}^{\prime} \mathrm{Me} ; \mathrm{R}^{2}=\mathrm{H}^{\prime} \mathrm{NO}_{2}$;

160

$\mathrm{R}^{3}=\mathrm{H}^{\prime} \mathrm{F}^{\prime} \mathrm{Cl}$

Burdanov et al designed benzimidazolylquinoxalines 160 as novel fluorophores with tunable sensitivity to solvent effects. ${ }^{131}$ The wavelengths of lowest-energy absorptions in the spectra of various solutions of $\mathbf{1 6 0}$ vary in the range $352-396 \mathrm{~nm}$, whereas the wavelengths of emission maxima vary in the rather broad range $440-519 \mathrm{~nm}\left(\Phi_{\mathrm{F}} 0.03-0.29\right)$. It was found that the addition of small amounts of DMF or DMSO in the solution of $\mathbf{1 6 0}\left(\mathrm{R}^{2}=\mathrm{NO}_{2}, \mathrm{R}^{3}=\mathrm{Cl}, \mathrm{R}^{4}=\mathrm{R}^{1}=\mathrm{H}\right)$ in DCM results in a dramatic quenching of the fluorescence.

Gers-Panters and coworkers have designed a series of 2-aryl-3-aminovinylquinoxalines 161163. These compounds exhibit intense yellow emission in DCM ( $\Phi_{\mathrm{F}}$ up to 0.61 ) with prononced emission solvatochromsim and protochromic fluorescence quenching. ${ }^{132}$

Structures 161-163<smiles></smiles>

161<smiles>[R]c1nc2cc(Cl)c(Cl)cc2nc1/C=C/N1CCCC1</smiles>

162

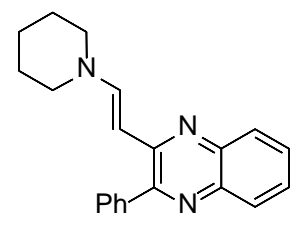

163 
Merkt et al. have described a series of 2-thiophenyl-2-yl-t-ethynylquinoxalines 164-176. These compounds exhibit blue to yellow emission in DCM depending of the substituent with emission quantum yield up to 0.75 for $\mathbf{1 6 4 a}$ and $\mathbf{1 6 4 j} .{ }^{133,134}$ Aggregation induced emission phenomena has been demontrated for compounds 165 and 169: whereas methanol solution of these compounds are non emissive, the addition of water leads to yellow/pink emission. Compounds $\mathbf{1 6 5}$ and $\mathbf{1 7 0}$ are also emissive in solid state (powder and doped thin film of PMMA).

Structures 164-176

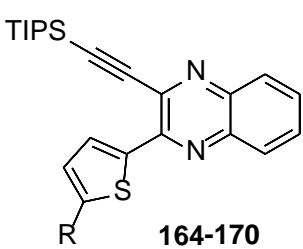

164: $\mathrm{R}=\mathrm{C}_{6} \mathrm{H}_{4} \mathrm{X}_{\mathrm{n}}\left(\mathrm{Xn}=\mathrm{H}\left(\mathbf{a}_{)}, 4-\mathrm{NMe}_{2}\right.\right.$ (b), 4-OMe (c), 4-Me (d) $4-\mathrm{CH}_{2} \mathrm{OH}\left({ }^{\mathbf{e}}\right), 4-\mathrm{Cl}\left({ }^{\mathbf{f}}\right), 4-\mathrm{CN}(\mathbf{g}), 4-\mathrm{NO}_{2}$ (h), 4-CHO (i), 2,6-(OMe) 2 (j);

165: $\mathrm{R}=\mathrm{C}_{6} \mathrm{H}_{4}\left[\mathrm{~N}\left(\mathrm{C}_{6} \mathrm{H}_{4} \mathrm{OMe}-4\right)_{2}\right]-4$

166: $\mathrm{R}=\mathrm{C}_{6} \mathrm{H}_{4}-\mathrm{CH}=\mathrm{Cy}_{2}(\mathrm{Y}=$

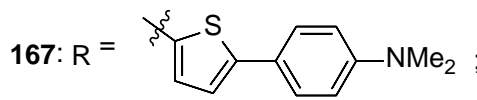
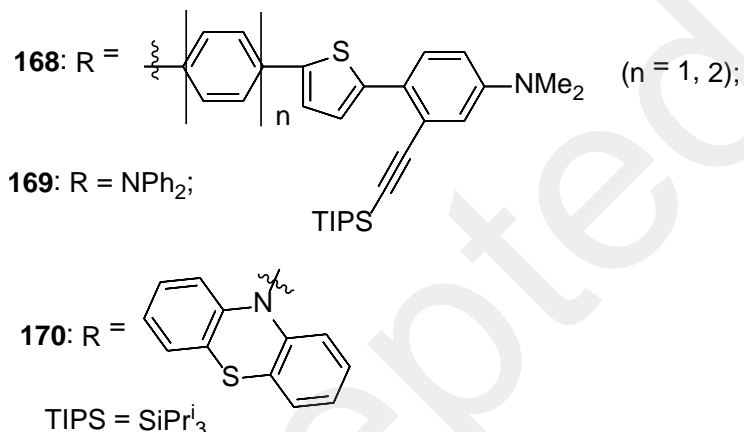

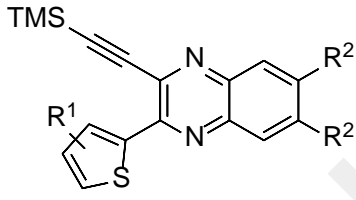

171-173
171: $R^{2}=H, R^{1}=H, M e, \mathrm{Bu}^{\mathrm{t}}, \mathrm{SMe}, \mathrm{OMe}, \mathrm{NMe}_{2}$;

172: $\mathrm{R}^{2}=\mathrm{H}, \mathrm{R}^{1}=\mathrm{O}-\mathrm{C}_{6} \mathrm{H}_{4}$;

173: $\mathrm{R}^{2}=\mathrm{Cl}, \mathrm{R}^{1}=\mathrm{H}$

TMS<smiles>[R]c1cc2nc([R])c(C#C)nc2cc1[R]</smiles>

174-176

174: $R^{2}=H, R^{1}=C_{6} H_{4} X-4\left(X=H, M e, B u^{t}, S M e, O M e, N M e_{2}\right)$; 175: $\mathrm{R}^{1}=\mathrm{C}_{6} \mathrm{H}_{4} \mathrm{NMe}_{2}-4 ; \mathrm{R}^{2}=\mathrm{Cl}, \mathrm{CN}$;

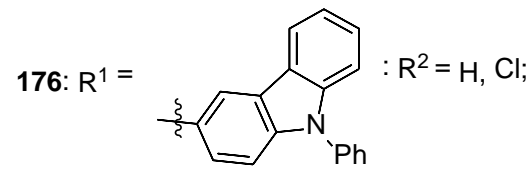

$\mathrm{TMS}=\mathrm{SiMe}_{3}$

Wang et al. have synthesized chromophores 177a,b that exhibit aggregation-enhanced emission in MeCN/water mixture and selective fluorescent quenching toward picric acid. ${ }^{135}$

Lin et al. have designed star-shaped chromophore $178 .{ }^{116}$ This compound exhibits emission at $498 \mathrm{~nm}$ in toluene $\left(\Phi_{\mathrm{F}}=0.42\right)$ and TPA properties with TPA cross section as high as $8950 \mathrm{GM}$ at $790 \mathrm{~nm}$.

Structures 177, 178 


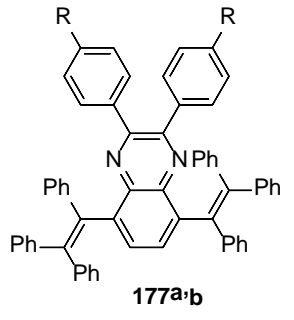

$\left.\mathrm{R}^{\prime} \mathrm{H}_{(\mathbf{a})}\right)^{\prime} \mathrm{OMe}(\mathbf{b})$

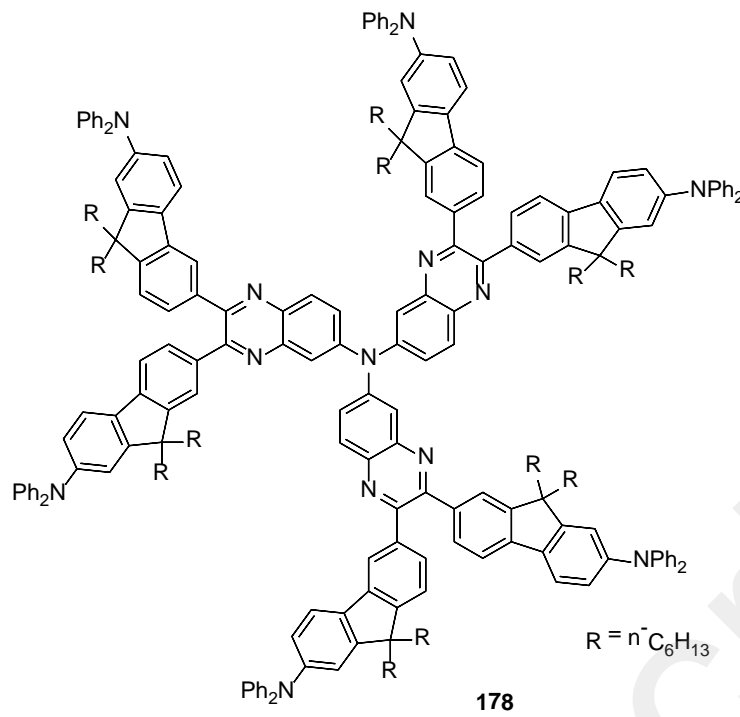

Kim and coworkers have designed fluorene-bridged quinoxaline derivative 179. ${ }^{111}$ As its quinazoline analogue 140, this compound exhibits blue luminescence in DCM solution and thin film. A blue OLED with external quantum efficiency of $1.30 \%$ (slightly lower than with 140) has been obtained with this compound.

Yu et al. have described two fluorine substituted quinoxaline chromophores 180a,b that exhibit aggregation-induced emission (AIE) and thermally activated delayed fluorescence (TADF). ${ }^{136}$ Compound 180a exhibits 23.5\% efficiency (EQE) in doped OLED and 10\% efficiency in non doped orange OLED.

Nowadays much attention is paid to 2,3-diphenylquinoxaline derivatives as electronacceptors for emitters exhibiting TADF effect; such materials are particularly perspective for OLED due to their theoretical ability to reach $100 \%$ of internal quantum efficiency via reverse intersystem crossing (RISC) between singlet and triplet states. Compound 181, which contains a fluorinesubstituted quinoxaline as an electron-acceptor and phenoxazine with good hole-transporting ability as an electron-donor, was described. ${ }^{137}$ Synthesis of $\mathbf{1 8 1}$ was realized by Pd-catalyzed C-N coupling reaction of 6,7-difluoro-2,3-diphenylquinoxaline with phenoxazine. The product $\mathbf{1 8 1}$ demonstrated good thermal stability with a high decomposition temperature of $348{ }^{\circ} \mathrm{C}$ and a broad and weak absorption around 400-500 $\mathrm{nm}$. The neat film of 181 exhibited a bright orange/red emission peak at $606 \mathrm{~nm}$, phosphorescence spectra with a maximum peak at $616 \mathrm{~nm}$ was recorded in the neat film at $77 \mathrm{~K}$. According to the fluorescence and phosphorescence spectra, the energetic gap $\Delta \mathrm{E}_{\mathrm{ST}}$ between first singlet exited state S1 and first triplet exited state T1 of $\mathbf{1 8 1}$ is estimated to be $0.04 \mathrm{eV}$, which is favourable for efficient RISC. Phenoxazine-containing quinoxaline $\mathbf{1 8 1}$ proved to be long-wave TADF emitter, OLED based on $\mathbf{1 8 1}$ achieved a maximum EQE of 13.9\% or 9.0\% depending on the way of its fabrication. 
A series of new butterfly-shaped D-A-D type compounds 182-184 with quinoxaline as an electron acceptor and carbazole or dihydroacridine residues as electron donors was presented by the same Yu's scientific group. ${ }^{138}$ These derivatives were synthesized form 5,8-diphenylquinoxaline using Pd-catalyzed C-N cross-coupling reaction, Suzuki process or copper-catalyzed Ullmann coupling reaction. All compounds exhibit excellent thermal stability with 5\% weight loss decomposition temperatures $\left(\mathrm{T}_{\mathrm{d}}\right)$ in the range of $394-471^{\circ} \mathrm{C}$. Electrochemical and photophysical properties of 182-184 were studied. It was shown that with the increasing electron-donating ability from phenyl to carbazole and dihydroacridine, the ICT absorption bands gradually red-shift from $370 \mathrm{~nm}$ (182) to $482 \mathrm{~nm}$ (184). In films all compounds exhibit luminescence from green to orange with $\lambda_{\text {em }}$ from $502 \mathrm{mn}$ (182) to $603 \mathrm{~nm}$ (184). Phosphorescence spectra were recorded in order to estimate $\Delta \mathrm{E}_{\mathrm{ST}}$ value which ranges form $0.07 \mathrm{eV}$ (184) to $0.33 \mathrm{eV}$ (182) and was found to be in agreement with results of the theoretical analysis. Authors successfully tuned the emission type from local excited-state (LE) to charge-transfer state (CT) transition to acquire a TADF molecule. Although the 184-based orange TADF device exhibited an EQE of only 7.4\%, the contribution from the delayed fluorescence to the overall EQE can reach up to $97 \%$.

Two novel quinoxaline derivatives 185a,b bearing disubstituted carbazole fragment also exhibit TADF emitter properties. ${ }^{139}$ Authors demonstrated that the degree of planarity of emitter molecule has a decisive influence on its electroluminescence properties. The influence of structure of compounds 185 on molecular orientation in films and mixtures containing bis(2(diphenylphosphino)phenyl)ester (DPEPO) and the electroluminescence properties in TADF OLEDs has been studied. Compounds 185 were found to possess green fluorescence in films at room temperature with $\lambda_{\mathrm{em}}=517 \mathrm{~nm}$ (185a) and $546 \mathrm{~nm}$ (185b), luminescence quantum yield $60.4 \%$ and $50.2 \%$ respectively and the value of $\Delta \mathrm{E}_{\mathrm{ST}} 0.10$ (185a), 0.12 (185b). More horizontal molecular orientation of $\mathbf{1 8 5}$ was observed in the mixtures of compounds (in 6 mass\% concentrations) and DPEPO in comparison with neat films that influence positively on OLED performances. The maximum electroluminescence external quantum efficiency measured in the device based on $\mathbf{1 8 5 b}$ was found to be $15.4 \%$.

Kim et al. have incorporated compounds 186, 187 as organic semiconductors in topcontact/bottom-gate organic thin-film transistors (OTFTs). ${ }^{140}$ Thin film of $\mathbf{1 8 7 b}$ showed p-channel characteristics with hole mobilities as high as $2.6 \cdot 10^{-5} \mathrm{~cm}^{2} / \mathrm{Vs}$ and current on/off ratio of $3.5 \cdot 10^{6}$ via vacuum deposition.

Structures 179-187 

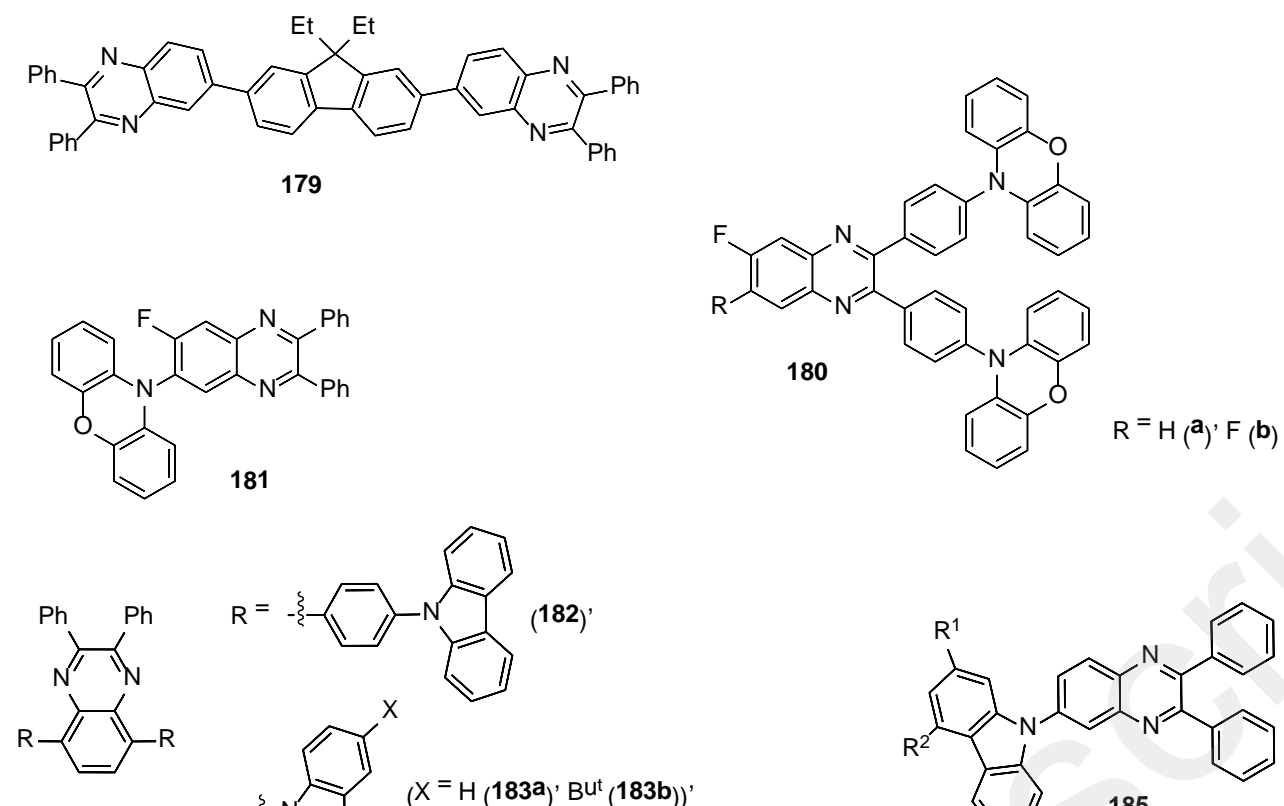

181<smiles>Fc1cc2nc(-c3ccccc3)c(-c3ccccc3)nc2cc1N1c2ccccc2Oc2ccccc21</smiles>

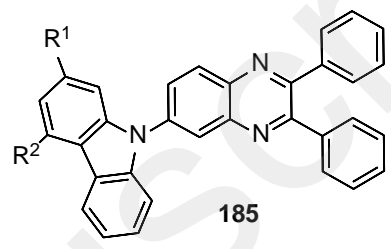

$182^{-} 184$

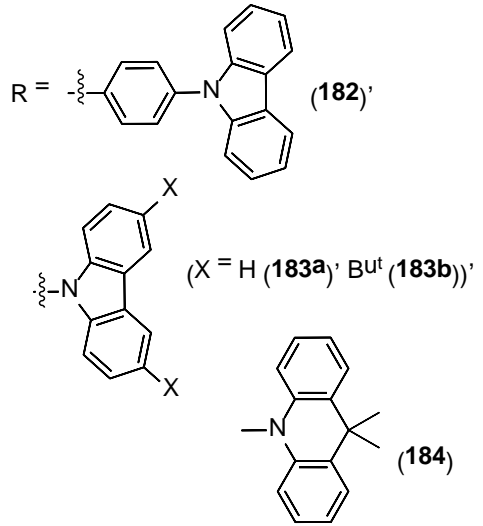

$\mathrm{R}^{1}=\mathrm{H}^{\prime} \mathrm{R}^{2}=$ di(biphen $\left.\mathrm{yl}^{-} 4^{-} \mathrm{yl}\right)^{\text {amine }}\left(\mathrm{a}^{\mathrm{a}}\right.$ $\mathrm{R}^{1}=$ di(biphenyl $4^{-} \mathrm{yl}^{\mathrm{a}}$ amine, $^{2}=\mathrm{H}(\mathbf{b})$

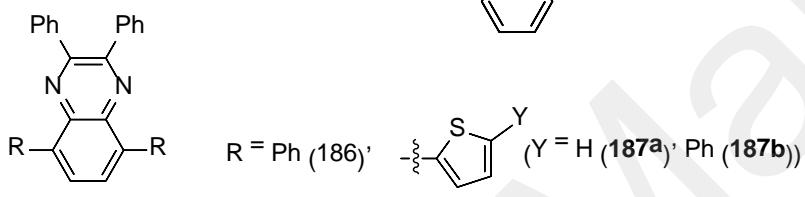

186' $187 a \cdot b$

The quinoxaline fragment has been extensively used in organic photovoltaic (OPV). In particular the diphenylquinoxaline unit has shown a great potential in anti-aggregation and broadening spectra response. ${ }^{141}$ The recent developments of quinoxaline derivatives for photovoltaic have been recently reviewed ${ }^{142-144}$ and structures presented in these reviews will not be discussed here.

Fan and coworkers have designed sensitizers 188 and $189 .{ }^{145}$ In these structures, the 2,3diphenylquinoxaline fragment acts as an auxiliary acceptor. Whereas the incorporation of this fragment between the donor and porphyrin unit (188) has negligible influence on the absorption property, its incorporation between the porphyrin unit and acceptor (189) significantly increases the absorbance for the Soret band and valley between Soret and Q bands. The quasi solid state DSSC with 189 displays a PCE of 6.02\%, 51\% higher than those for $\mathbf{1 8 8}$.

Structures 188, 189 


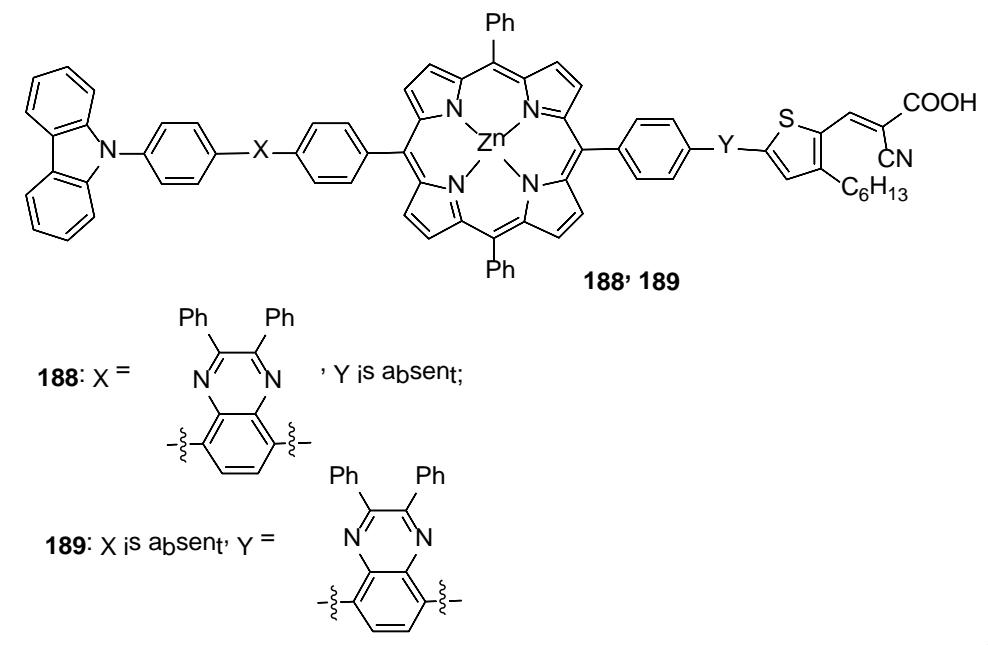

Han et al. have designed phenothiazine chromophore 190. ${ }^{146}$ DSSC based on this compound exhibits an excellent PCE of 10.06\%. Zhang et al. ${ }^{147}$ have designed dye 191 for DSSC application. DSSC device with PCE of $4.63 \%$ was obtained.

Structures 190, 191
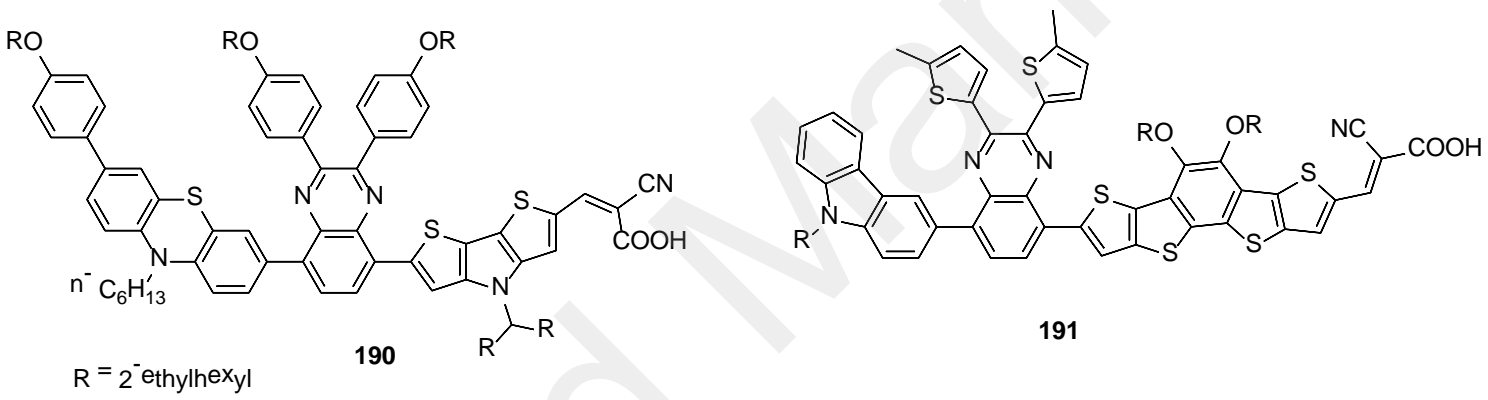

Pei and coworkers and Wang et al. have described D-A- $\pi$-A chromophores 192a,b, 193a as solar cell sensitizers. ${ }^{125,148}$ The two phenyl groups grafted onto the quinoxaline core are demonstrated as efficient building block by improvement of photostability and thermal stability and as antiaggregation functional unit and appear as an alternative to stability deleterious alkyl chain grafted thienyl bridge. Dyes 192b and 193a exhibit conversion efficiency as high as $9.24 \%$ and 8.76\% respectively. Compound 193b with methoxy substituent on the phenyl fragment was designed by Xu et al. ${ }^{149}$ and DSSC with this sensitizer exhibits a PCE of 9.83\%.

Ji and coworkers have shown that the addition of a 2,3-di-n-pentylquinoxaline as auxiliary acceptor in sensitizer 194 significantly enhances photovoltaic performance with PCE of 7.98\%. ${ }^{150}$

Structures 192-196 


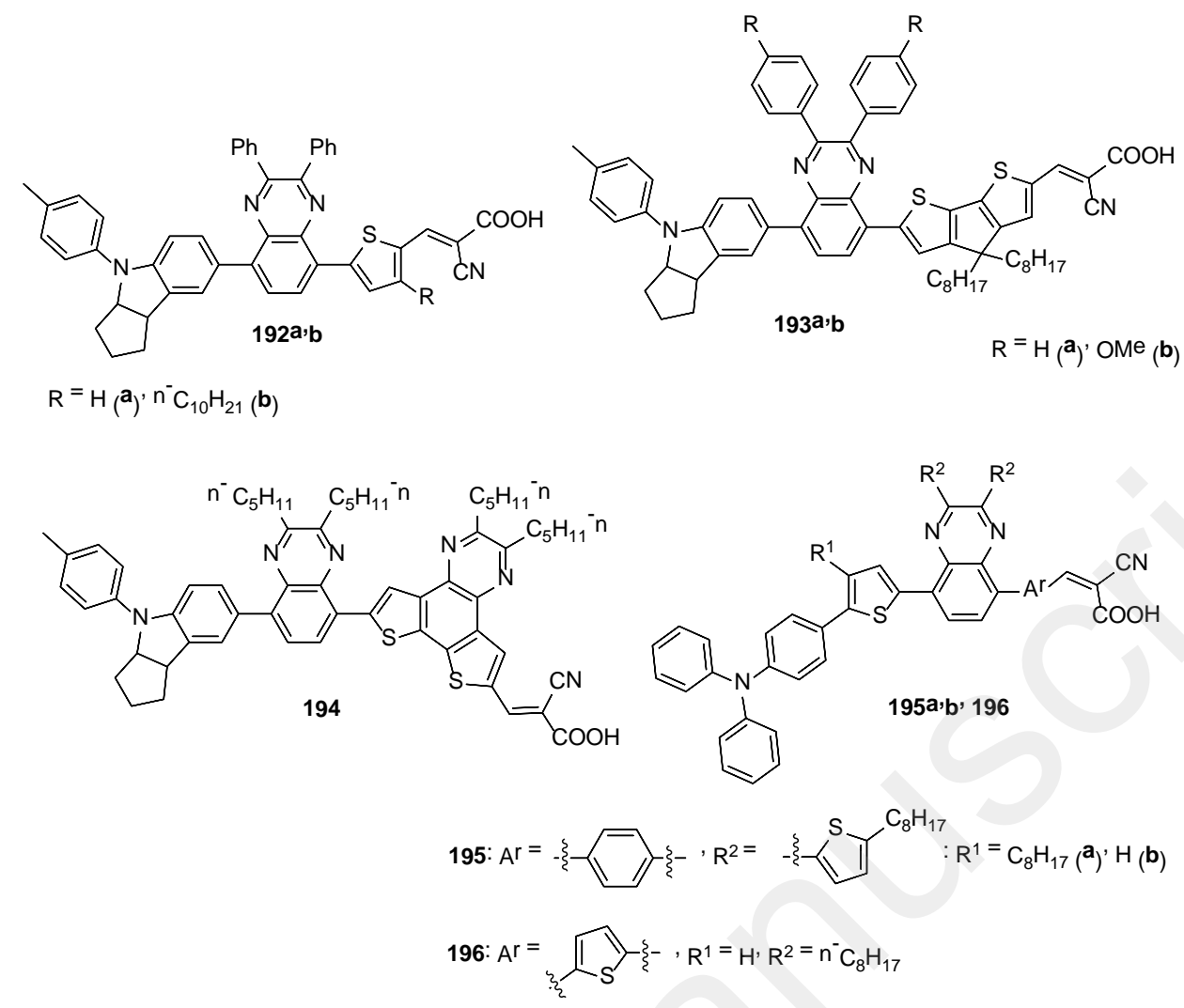

Godfroy and coworkers have synthesized D- $\pi-A-\pi-A$ organic sensitizer 195a. ${ }^{151}$ DSSC based on 195a shows a PCE of 6.36\%. DSSC obtained from similar structures 195b and 196 designed by Ma et al. ${ }^{152}$ exhibit PCE of 7.29 and $7.78 \%$ respectively.

Lu et al. have described a series of quinoxaline chromophores 197a-d for DSSCs. ${ }^{153}$ When the alkyl substituent are removed from the spacer part in 197a to the donor part in 197b and 197c a more conjugated system and a bathochromically shifted maximum absorption band can be realized. Based on 197d quasi solid state DSSC exhibits a power conversion efficiency of $7.14 \%$ (8.27\% with liquid electrolyte). This sensitizer can be combined with another phenazine-based sensitizer with complimentary absorption profile and PCE of $8.04 \%$ in quasi solid state DSSC has been achieved. $^{154}$

The incorporation of fluorine atom has been also tested on similar structures $\mathbf{1 9 8 b}$ and 198c. ${ }^{155}$ When compared with unsubstituted analogue 198a, the quasi-solid state DSSC based on 198c exhibits a 37\% higher efficiency (PCE of 8.2\% for 198a).

Structures 197-200 


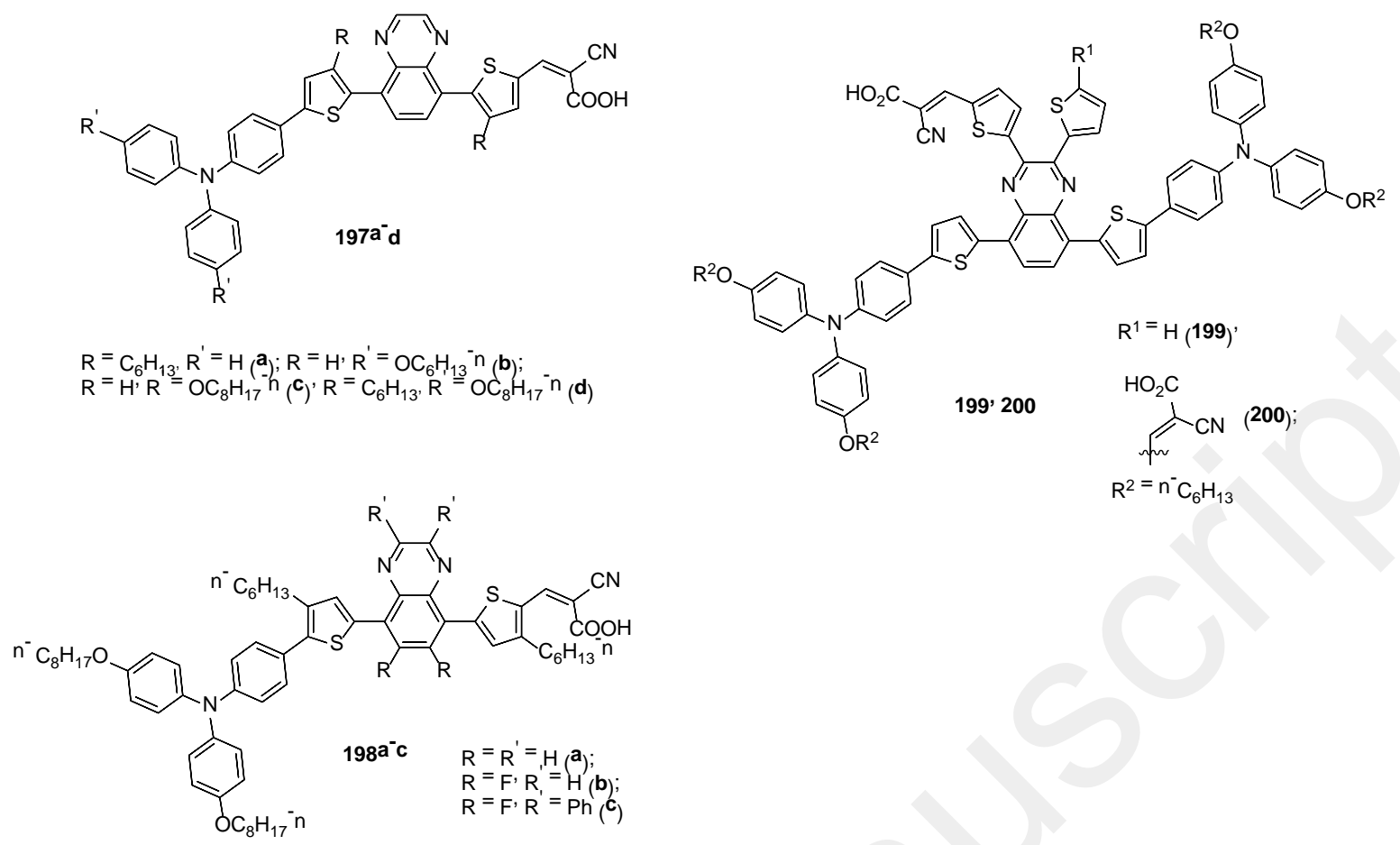

The same team has also designed sensitizers 199 and 200. ${ }^{156}$ A broader and more intense charge transfer band is observed for 199 with a single anchoring group that exhibits a power conversion efficiency of $5.2 \%$ for a quasi-solid-state DSSC (6.2\% with liquid electrolyte) with good stability.

Shen and coworkers have designed sensitizers 201a-c. ${ }^{157}$ They have demonstrated that the incorporation of electron-deficient quinoxaline into the $\pi$-chain significantly enhances the PCE (20\% increase) and DSSC based on 201a exhibits the best performance (PCE of 8.05\%).

$\mathrm{Li}$ et al. have designed two D-A- $\pi$-D sensitizers 202 and 203a employing 3,4ethylenedioxythiophene and cyclopentadithiophene as $\pi$-linker respectively. ${ }^{158}$ Compounds 202, 203a were obtained from 5,8-dibromo-2,3-diphenylquinoxaline via sequenced reactions of Stille cross-coupling, formylation, substitution of second bromine with (diarylaminophenyl)thiophene fragment and condensation with 2-cyanoacetic acid. 2,3-Diphenyl-5,8-dithienylquinoxalines 202, 203a possess intensive absorption in DCM in visible range $\left(\lambda_{\text {abs }}=553 \mathrm{~nm}, \varepsilon=1.75 \cdot 10^{4} \mathrm{M}^{-1} \mathrm{~cm}^{-1}\right.$ for 202 and $\lambda_{\text {abs }}=569 \mathrm{~nm}, \varepsilon=4.12 \cdot 10^{4} \mathrm{M}^{-1} \mathrm{~cm}^{-1}$ for 203a). When grafted on $\mathrm{TiO}_{2}$, blue shift of absorption band was observed with maxima $\lambda_{\text {abs }}=534$ and $537 \mathrm{~nm}$ respectively for 202 and 203a. An all-solid state DSSC with 203a has been obtained with an impressive PCE of 8.0\%.

New blue dye 203b, bearing 2,3-diphenylquinoxaline as acceptor, indeno[1,2-b]thiophenefunctionalyzed triethylamine as donor and cyclopentadithiophene as $\pi$-linker, was synthesized by the same method as quinoxalines 202, 203a. Compound 203b exhibits wide absorption band with $\lambda_{\text {abs }}=600 \mathrm{~nm}$ and high extinction coefficient $\left(\varepsilon=6.3 \cdot 10^{4} \mathrm{M}^{-1} \mathrm{~cm}^{-1}\right)$. DSSC device fabricated on the basis of 203b demonstrated high efficiency $(\mathrm{PCE}=7.81 \%){ }^{159}$ 
Structures 201-203

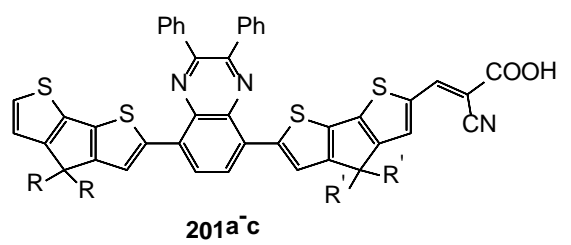

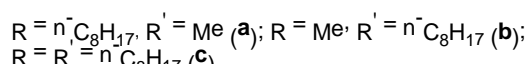
$\mathrm{R}=\mathrm{R}^{\mathrm{C}}=\mathrm{n}^{\mathrm{C}} \mathrm{C}_{8} \mathrm{H}_{17}\left(\mathbf{c}^{\mathrm{C}}\right)$

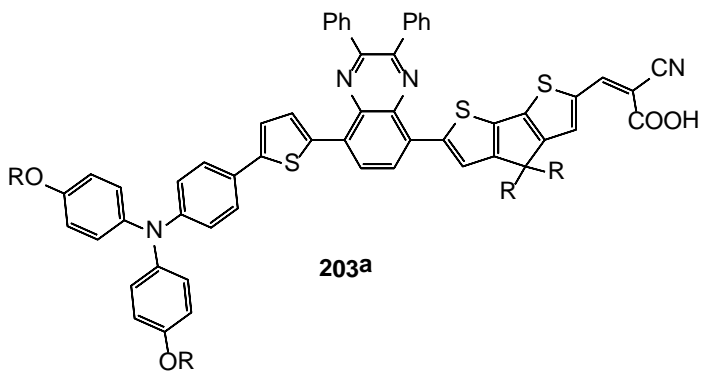

202, 203: $R^{-}{ }^{-}{ }^{-}$ethylhexyl
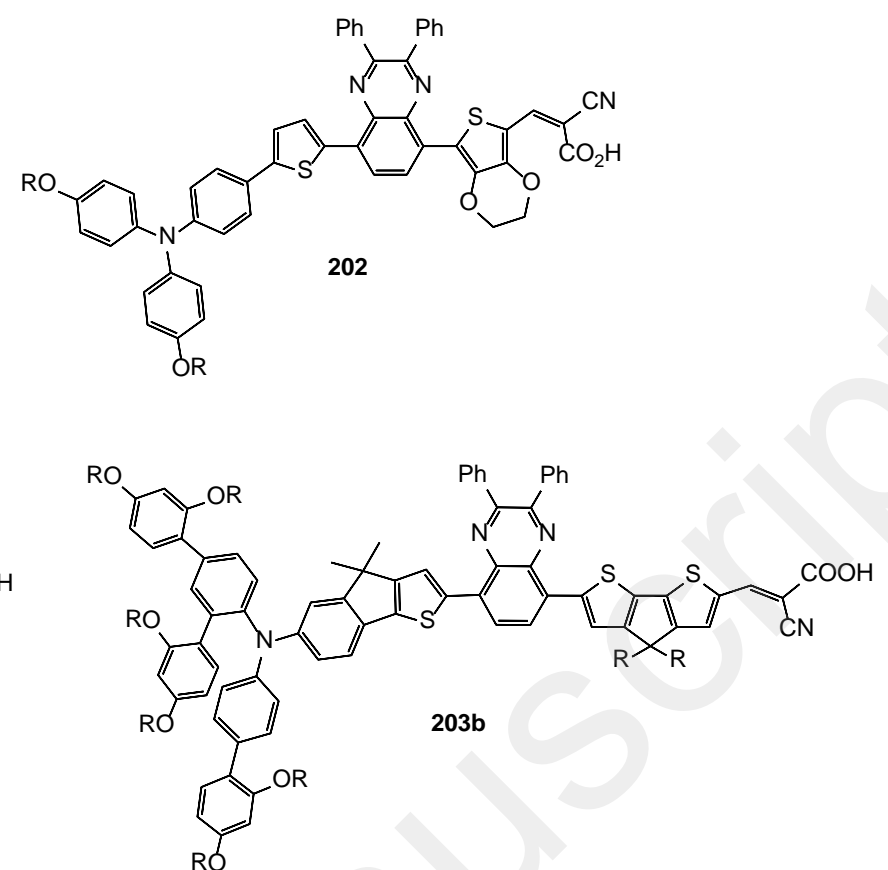

Kono and coworkers have designed sensitizer 204. ${ }^{160}$ DSSCs with 204 showed PCE of $3.2 \%$. To improve the device performances, thienopyrazine analogue was used as a co-adsorbent and PCE of $6.2 \%$ was achieved.

$\mathrm{Yu}$ et al. have designed sensitizer 205 that can be used in solution-processed organic photovoltaic devices with PCE of $1.22 \%{ }^{161}$

Structures 204-208

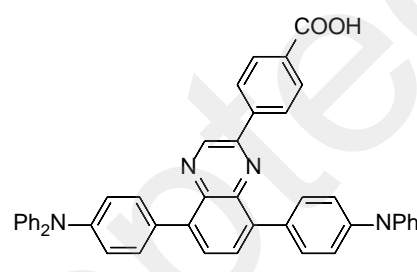

204

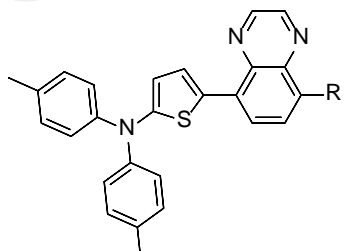

206, 207

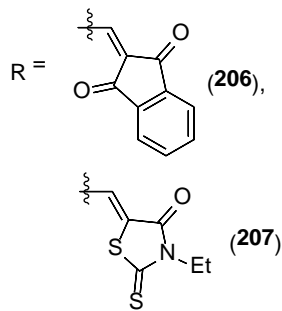

$(207)$

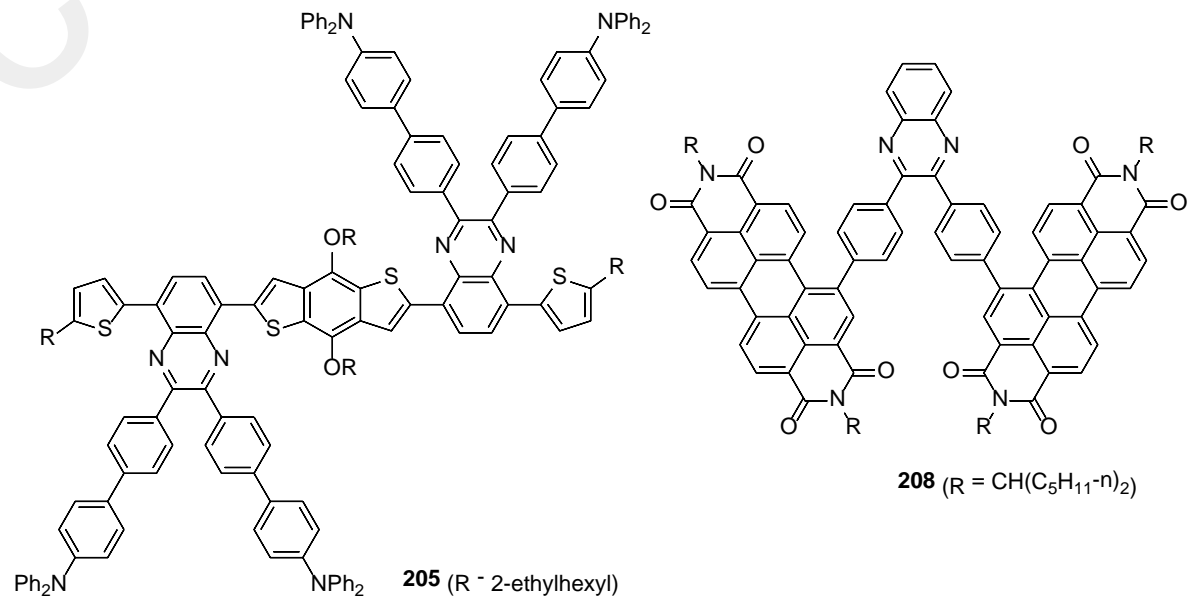


Qi et al. have designed chromophores 206 and 207 as donors for bulk-heterojunction solar cells. ${ }^{162}$ With the configuration $\mathrm{FTO} / \mathrm{c}-\mathrm{TiO}_{2} / 206$ or 207: $\mathrm{C}_{70} / \mathrm{MoO}_{3} / \mathrm{Ag}$, bulk-heterojunction solar cells with PCE of 1.44 and $1.70 \%$ were obtained respectively.

Liu and coworkers have studied perylenediimide acceptor 208. Based on 208 non-fullerene photovoltaic device has been obtained and show PCE of 3.86\%. ${ }^{163}$

Deng and coworkers have designed chromophores 209-212 based on quinoxaline as potential donor for bulk-heterojunction organic solar cells. ${ }^{164}$

Structures 209-216
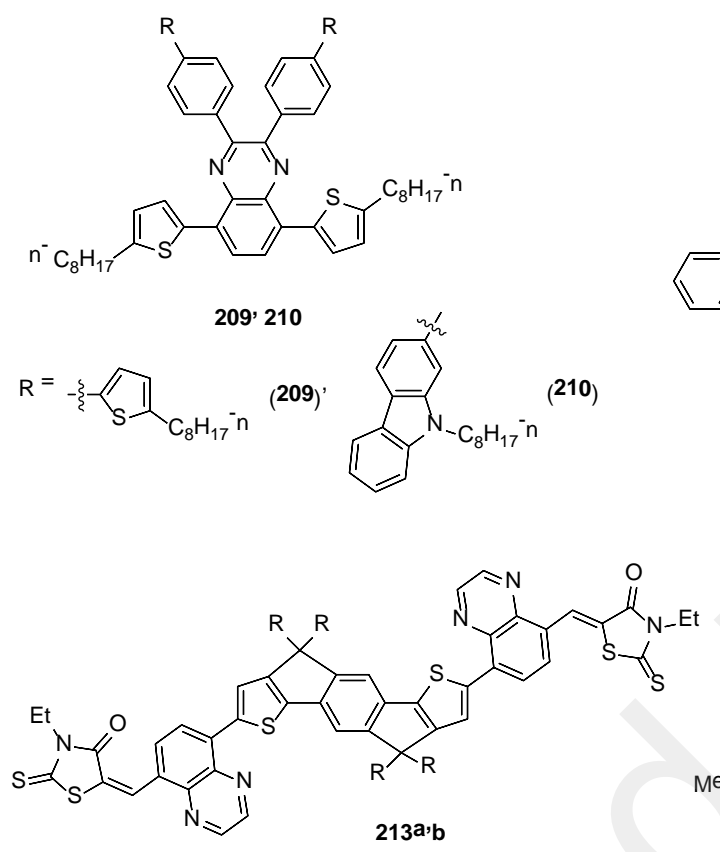
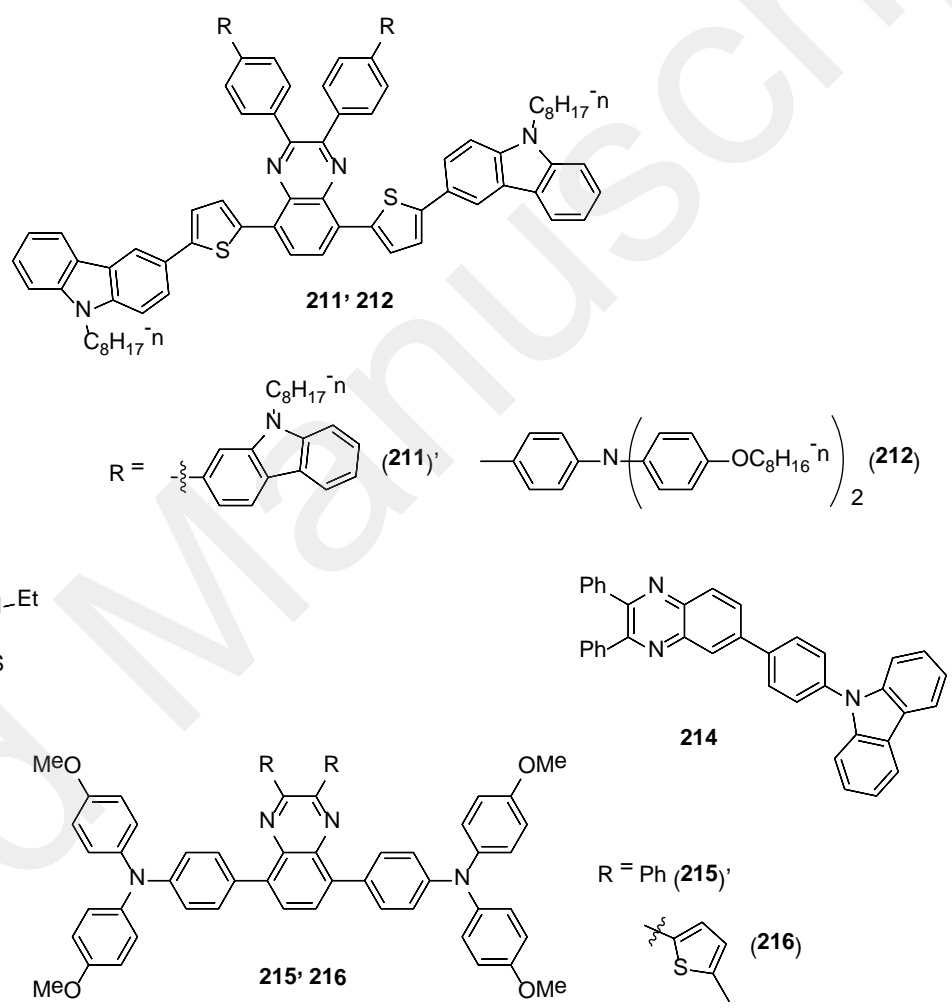

Xiao and coworkers have described $A_{2}-A_{1}-D-A_{1}-A_{2}$ chromophores 213a,b where the quinoxaline is used a bridge acceptor $\left(\mathrm{A}_{1}\right)$ fragment. ${ }^{165}$ These sensitizers exhibit the complimentary absorption spectra with poly(3-hexylthiophene) (P3HT) and polymer solar cells based on P3HT:213a and P3HT:213b showed power conversion efficiency of 4.03 and $4.81 \%$ respectively.

9-(4-(2,3-Diphenylquinoxalin-6-yl)phenyl)-9H-carbazole (214) was designed as host material for red phosphorescence OLED, which demonstrated outstanding electroluminescence performance with maximum current efficiency $21.9 \mathrm{~cd} / \mathrm{A}$, power efficiency $15.4 \mathrm{~lm} / \mathrm{W}$ and external quantum efficiency $12.2 \%{ }^{166}$

Zhang and coworkers have designed D-A-D hole transporting materials 215 and 216 based on quinoxaline central core for perovskite solar cells. ${ }^{167}$ Based on 216, perovskite solar cells exhibit 
a maximum efficiency of $19.62 \%$ outperforming the spirobifluorene derivative generally used as hole transporting material.

\section{II.2.6. Arylethynylquinoxalines}

Arylethynylquinoxalines derivatives are generally obtained by Sonogashira cross coupling reaction. 2-Arylethynylquinoxalines and 2,3-diarylethynylquinoxalines can been obtained from chloro derivatives. ${ }^{168}$ On the other hand, 6-arylethynylquinoxalines and 5,8diarylethynylquinoxalines $\mathbf{2 1 8}$ have been obtained from iodo derivatives 217 (Scheme 17, top reaction). ${ }^{127,169}$ Another strategy to obtain 2-aryl-3-ethynylquinoxaline $\mathbf{2 1 9}$ based on threecomponent activtion/alkynylation/cyclocendensation (AACC) process has been recently proposed (Scheme 17, bottom reaction). ${ }^{134}$

Scheme 17

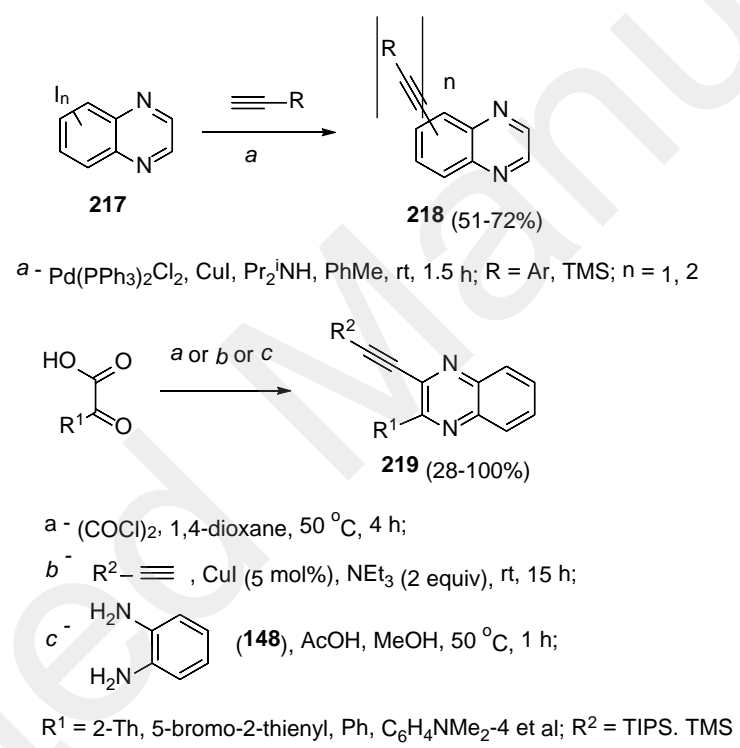

Nafe et al. have synthesized 5,8-di(phenylethynyl)quinoxaline 220. This compound exhibits red-shifted emission $\left(\lambda_{\text {em }}=483 \mathrm{~nm}\right)$ and increased fluorescence quantum yield $\left(\Phi_{\mathrm{F}}=0.85\right)$ with regards to diphenyl analogue $153 .{ }^{127}$

Nguyen et al. have studied the photophysical properties of compounds 221, 222. ${ }^{167}$ Whereas 2-phenylethynylquinoxalines 221a,b exhibit UV-emission $\left(\lambda_{\text {em }}=386-395 \mathrm{~nm}\right)$, disubstituted quinoxalines 222a,b show purple emission ( $\left.\lambda_{\mathrm{em}}=425-445 \mathrm{~nm}\right)$.

Merkt and coworkers have designed 2-aryl-3-arylethynylquinoxalines $\mathbf{2 2 3}^{134}$ These compounds exhibit yellow-orange emission $\left(\Phi_{\mathrm{F}}=0.23-0.42\right)$ in DCM with blue shifted emission when the electron-donating strength of the substituent of the phenylethynyl fragment is increased (223a: $\lambda_{\mathrm{em}}=596 \mathrm{~nm}, 223 \mathrm{~b}: \lambda_{\mathrm{em}}=586 \mathrm{~nm}, 223 \mathrm{c}: \lambda_{\mathrm{em}}=574 \mathrm{~nm}$ ). 

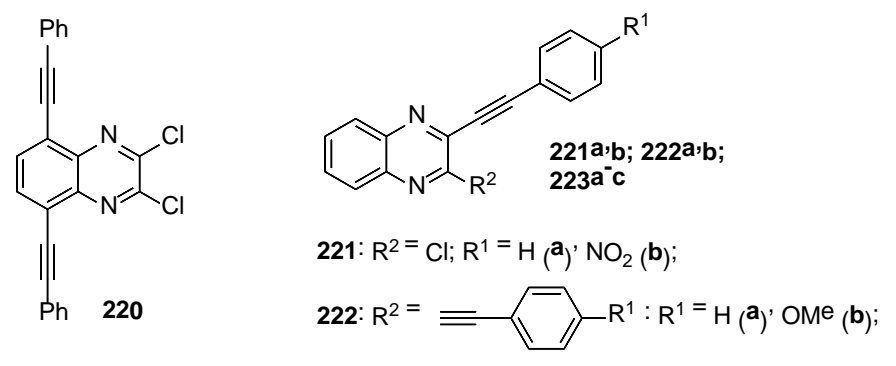

223: $\mathrm{R}^{2}=\mathrm{C}_{6} \mathrm{H}_{4} \mathrm{NMe}_{2}^{-}{ }^{-}:^{1} \mathrm{R}^{1}=\mathrm{H}\left({ }^{\mathbf{a}}\right)^{\prime}$ OMe (b)' $\mathrm{NMe}_{2}\left({ }^{\mathbf{c}}\right)$

Lin and coworkers have designed bisarylacetylene derivative $\mathbf{2 2 4}$ as two-photon absorption chromophore. ${ }^{169}$ A two photon cross section of $2000 \mathrm{GM}$ at $730 \mathrm{~nm}$, higher than that of vinylene analogue 74a, has been observed in toluene.

Structure 224

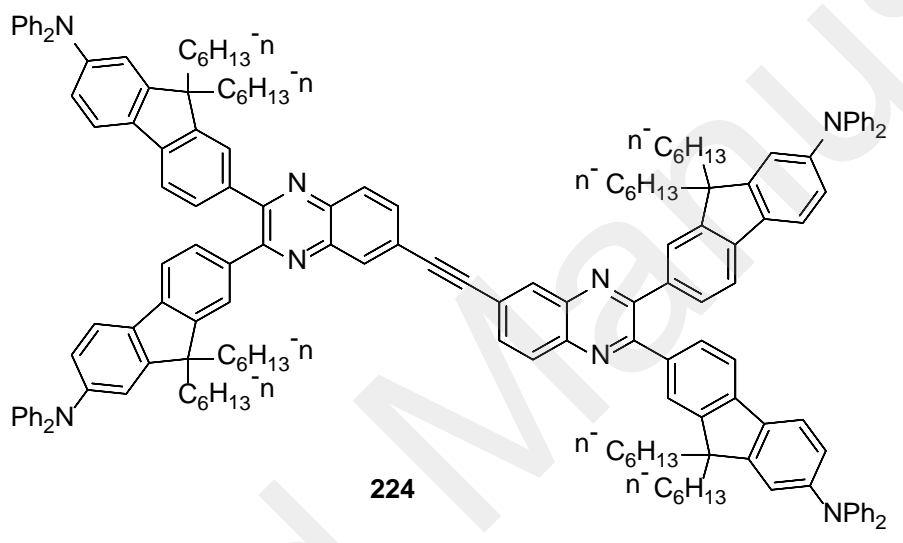

As shown by these numerous examples, the design of (het)aryl- and (het)arylethynylbenzo(di)azine has been a really active field of reseach during the last seven year. These chromophores have found applications in various field such as bioimaging, OLEDs, photovoltaism.

\section{Annelated benzazines}

Different annelated derivatives of quinazolines and quinoxalines are presented in reviews. $^{23,170}$ Many derivatives of annelated benzazines found application as ligands for the synthesis of metalcomplexes. For example, benzo[h]quinoline, ${ }^{171,172}$ and 4-arylthieno[3,2c] quinoline ${ }^{173}$ are used as cyclometallating ligands with expanded $\pi$-conjugated system. Derivatives of dipyrido[3,2-f:2,3-h]quinoxaline (dpq) are applied for the complexation with wide range of metals, ${ }^{174-176}$ in particular, for obtaining complexes with rare-earth elements in which ligand acts as effective antenna. ${ }^{177}$

Wang and co-authors described 6-(2,3-dihydroxyphenyl)-5,6-dihydrobenzimidazo[1,2c]quinoline 225, obtained from 2-(2-aminophenyl)benzimidazole and 2,3-dihydroxybenzaldehyde 
by boiling in methanol for 24 h. ${ }^{178}$ The structure of compound 225 was confirmed by X-ray method. This ligand $\left(\mathrm{H}_{2} \mathrm{~L}^{1}\right)$ exhibited strong emission at $434 \mathrm{~nm}$ in the mixture DMSO/water. Mixing of 225 with different metal ions demonstrated that only addition of $\mathrm{Cu}(\mathrm{II})$ ions lead to luminescence quenching in the ratio $\mathrm{H}_{2} \mathrm{~L}: \mathrm{Cu}(\mathrm{II})=1: 1$. Authors showed that complex 226 forms with azomethine intermediate $\left(\mathrm{H}_{3} \mathrm{~L}^{1}\right)$ into which ligand 225 transformes at $\mathrm{pH}$ below 5 (Scheme 18). The addition of histidine to the complex 226 led to considerable increase of emission at $434 \mathrm{~nm}$ due to ligand substitution. Thus, authors presented compound 225 as fluorescent hemosensor for selective detection of $\mathrm{Cu}$ (II), including in physiological media, and complex $\mathbf{2 2 6}$ can be applied for the detection of histidine.

Scheme 18

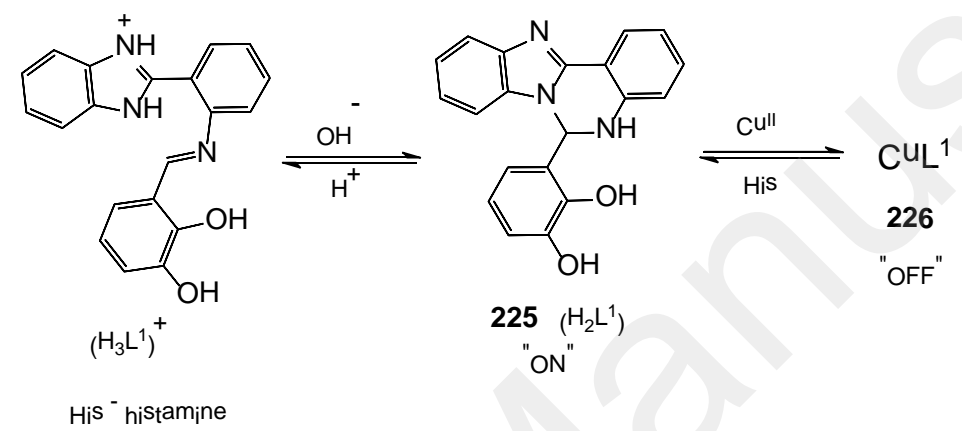

Acosta and co-authors reported the new series of pyrazolo[1,5-c]pyrrolo[1,2-a]quinazolines and pyrazolo[1,5-c]pyrido[1,2-a]quinazolines 229, synthesized by the cascade reaction of anilines 227 and $\omega$-chloroketones 228 (Scheme 19). ${ }^{179}$ These compounds demonstrated mainly blue or green luminescence. Emission spectra of 229 in chloroform exhibited two bands at 358-448 nm and 386-482 nm, attributed to associated and non-associated compounds in non-polar solvent. In ethanol, polar hydrogen-bonding solvent, emission spectra have one band at 382-409 nm, atributed to non-associated compounds. Notably, the luminescence quantum yields for these compounds are rather high $\left(\Phi_{\mathrm{F}}=0.63-0.13\right)$. Studying of electrochemical properties of compounds 229 showed that they can be oxidized chemically into completely $\pi$-conjugated systems.

Scheme 19
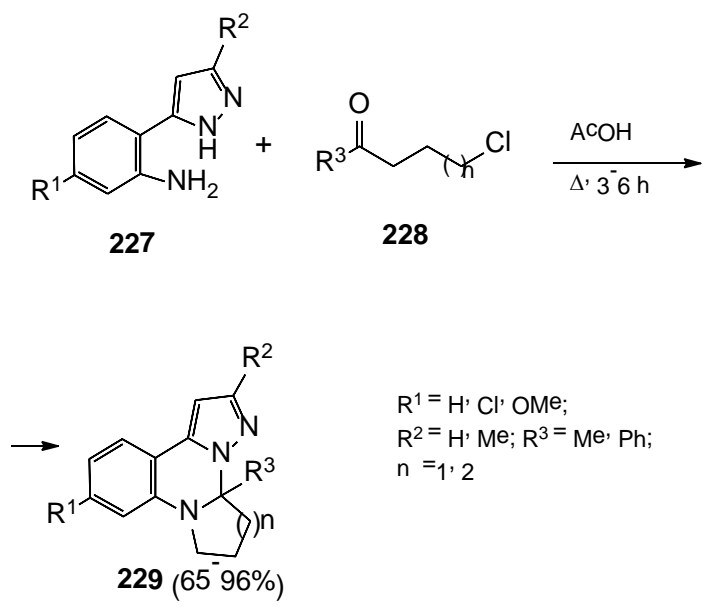

$\mathrm{R}^{1}=\mathrm{H}^{\prime} \mathrm{Cl}$, OMe; $\mathrm{R}^{2}=\mathrm{H}^{\prime} \mathrm{Me} ; \mathrm{R}^{3}=\mathrm{Me}^{\prime} \mathrm{Ph}$; $\mathrm{n}=1,2$ 
Annelated dibenzo- and phenanthroline- quinazoline derivatives were described in patents $^{180,181}$ as emitting, electron-transport and hole-transport layers for OLEDs. Derivative of dibenzo[f,h]quinoxaline were patented as emitting elements in light-emitting materials and devices. $^{182}$

Synthesis and photophysical properties of new dithienylquinazolines 230-233 are described. ${ }^{183,184}$ Compounds were obtained by oxidative cyclization of the correspondent 4,5dithienylpyrimidines, they exhibit blue fluorescence $\left(\lambda_{\mathrm{em}}=388-417 \mathrm{HM}\right)$ with quantum yield in the range of $1.8-4.1 \%$.

Structures 230-233

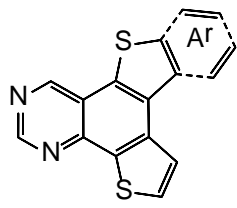

230, 231

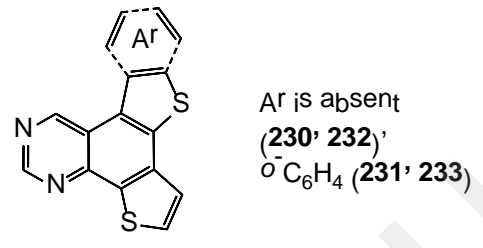

232' 233

Three novel bis(6H-indolo[2,3-b]quinoxalinyl) derivatives 234a-c containing fluorenyl, terphenyl or carbazole bridge were described as emitters for phosphorescent OLEDs. ${ }^{185}$ In toluene solution at room temperature these compounds exhibit fluorescence with $\lambda_{\text {em }}=470-500 \mathrm{~nm}$, in thin film emission maxima were observed at $487-525 \mathrm{~nm}$. At $77 \mathrm{~K}$ in thin film phosphorescence with $\lambda_{\text {em }}=543-594 \mathrm{~nm}$ was noted. Electroluminescent devices based on these materials and iridium additives demonstrated deep red emission and showed EQE > 20\%.

1,3-Diphenyl-1 $H$-benzo[g]pyrazolo[3,4-b]quinoxaline 235, obtained from 2,3diaminonaphthalene and 2,5-diphenylpyrazol-3,4-dione exhibited photoluminescence in THF solution with $\lambda_{\mathrm{em}} \sim 580 \mathrm{~nm}$. ${ }^{186}$ The electronic device fabricated on the basis of 235 demonstrated yellow emission with $\lambda_{\mathrm{em}}=548 \mathrm{~nm}$ and brightness $800 \mathrm{~cd} / \mathrm{m}^{2}$.

Lan and co-authors reported acenaphtho[1,2-b]quinoxalin-diimide 236 as potential nonfullerene component for organic solar cells. ${ }^{187}$ This compound demonstrated relatively wide absorption band (from 300 to $650 \mathrm{~nm}$ ) with moderately low-lying LUMO level (-3.64 eV) and average optical gap $\sim 2 \mathrm{eV}$.

Structures 234-236 

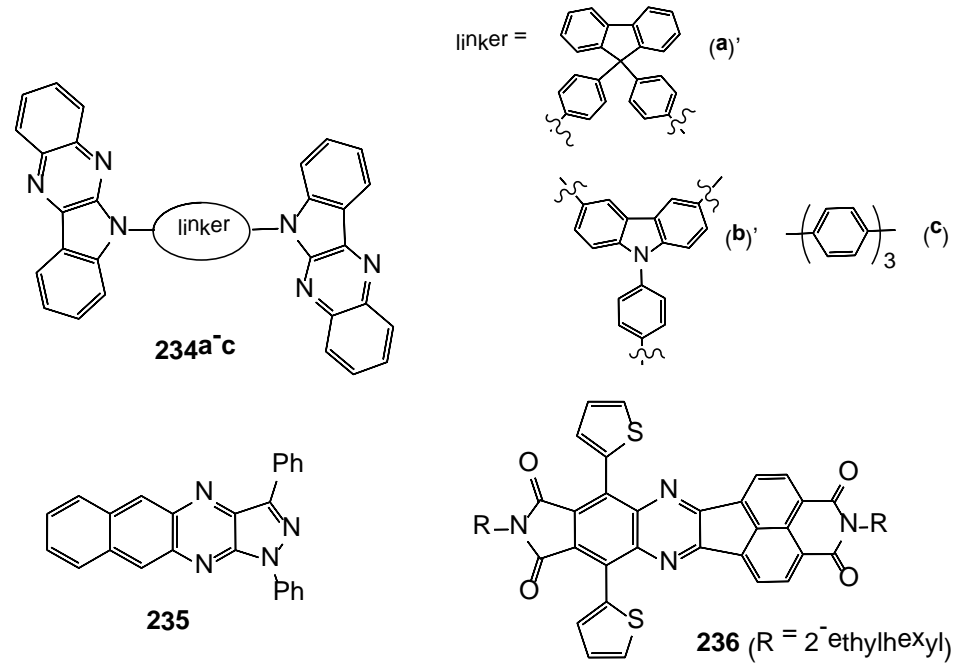

Sakai and co-authors reported quinoxaline[7]carbohelicene derivatives 237, 238 as quinoxaline-conyaining nonplanar molecular systems possessing luminescent properties. ${ }^{188,189}$ Compound 237 and unsubstituted quinoxalin[7]carbohelicene were synthesized from carbohelicene diketone and the corresponding 1,2-diaminobenzene. In order to obtain 1,2-dialkylsubstituted 238 quinoxaline fragment was reduced with dithionite, then reaction with butyllithium and methyl iodide was performed. ${ }^{187}$ Both structures were characterized by spectral methods including X-ray. Compound 237 exhibited fluorescence in THF solution with $\lambda_{\mathrm{em}}=550 \mathrm{~nm}$ and $\Phi_{\mathrm{F}}=0.05 .{ }^{188} \mathrm{In}$ crystals the second band also was observed at $590 \mathrm{~nm}$ which can be attributed, according to authors, to the exumer-like delocalized excited state.

Structures 237-239

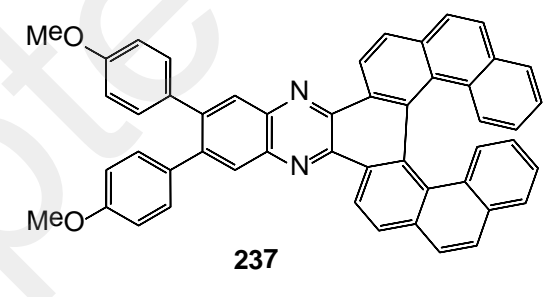

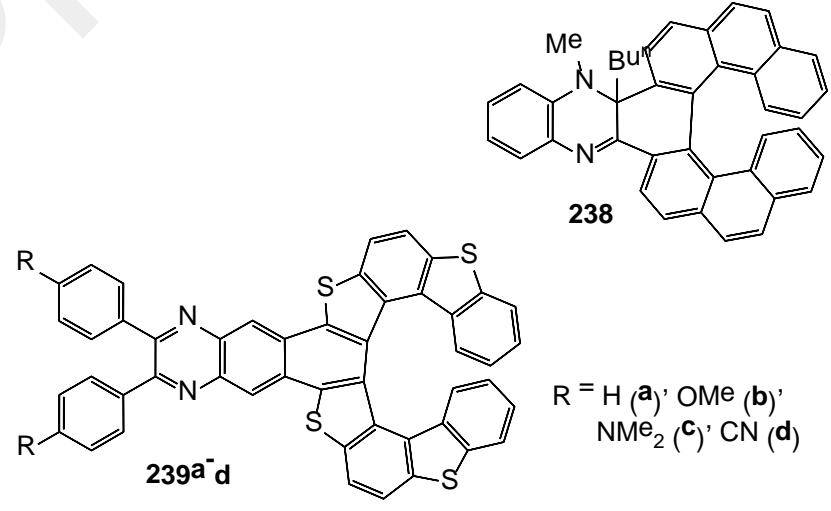

Compound 238 demonstrated red shift of emission band in comparison with quinoxalin[7]carbohelicene approximately at $100 \mathrm{~nm}$ (yellow fluorescence) and five-fold increase 
in quantum yield $\left(\Phi_{\mathrm{F}}=0.25\right)$ relatively to 237 . Circularly polarized luminescent (CPL) properties were studied, OLED based on derivative $\mathbf{2 3 8}$ as emitting layer was successfully fabricated.

The same group of authors ${ }^{190}$ obtained the series of fluorescent «push-pull» tetrathia[9] helicenes 239, bearing quinoxaline as acceptor fragment. Compounds were characterized by NMR ${ }^{1} \mathrm{H}$ and ${ }^{13} \mathrm{C}$ NMR spectroscopy as well as MALDI-TOF and ESI-QTOF massspectrometry data. Compounds 239 exhibit strong fluorescence in THF solution with $\lambda_{\text {em }}=600-660$ nm depending on the nature of substituent $R$, higher quantum yield ( $\Phi_{F}=0.43$ for 239c and 0.30 for 239d) and large Stokes shift. Increased value of $\Phi_{\mathrm{F}}$ for compound 239d allowed to get information on CPL properties, the degree of anisotropic factor was estimated $\left(\mathrm{g}_{\mathrm{CPL}}=3.0 \cdot 10^{-3}\right.$ ). Incorporation of quinoxaline into tetrathio[9]helicene core promotes the «push-pull» nature of thiahelicene derivatives.

New T-shaped tetraphenylethylene-substituted derivatives of acenaphthene- and phenanthrene-quinoxaline 240, 241 with D-A-D structure were reported. ${ }^{191}$ Both luminophores were synthesized by Suzuki cross-coupling reaction from quinoxaline dibromoderivative and boronic acids. Compounds exhibit fluorescence in solution, which is sensitive to solvent polarity: derivative 240 demonstrated blue emission in toluene with $\Phi_{\mathrm{F}}=0.18$ and green emission in dichloromethane with $\Phi_{\mathrm{F}}=0.33$, whereas its counterpart 241 demonstrates green emission in toluene with $\Phi_{\mathrm{F}}=0.21$ and yellow emission in dichloromethane with $\Phi_{\mathrm{F}}=0.55$. Studying of fluorescent properties of these compounds in the THF-water mixture showed that 240, 241 exhibit aggregation induced emission. In solid state luminophores 240, 241 demonstrated reversible mechanochromism with good color contrast due to morphological change from crystal to amorphous state.

Structures 240, 241

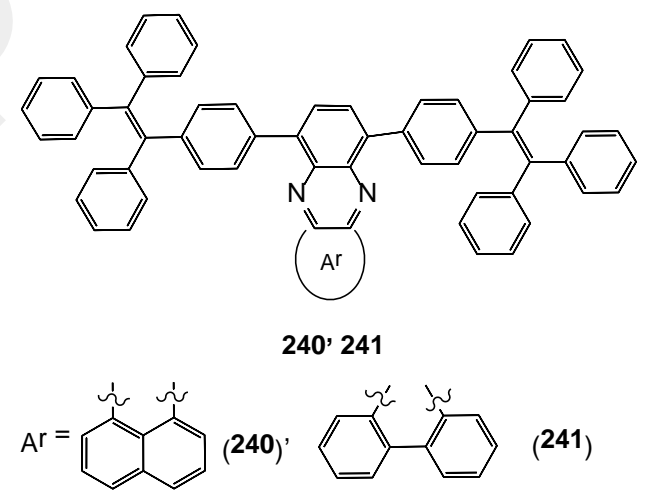

V-shaped fluorescent dyws of D-A type 242-244 bearing bis(thiadiazol)quinoxaline and bis(thiadiazol)phenanthroquinoxaline were described. ${ }^{192}$ In solution, the luminescence and red shift of emission band as well as decrease in intensity were observed with the growth of solvent polarity (for compound $242 \lambda_{\text {em }}$ changed from $474 \mathrm{~nm}$ in cyclohexane to $652 \mathrm{~nm}$ in DCM, $\Phi_{\mathrm{F}}$ from 0.36 to 
0.03; for compound $243 \lambda_{\text {em }}$ changed from $484 \mathrm{~nm}$ to $678 \mathrm{~nm}, \Phi_{\mathrm{F}}$ from 0.51 to 0.11 ). Derivative 244 with lack of donor fragment did not show the dependence of emission on solvent polarity. In solid state orange emission was observed for compound 243 with $\Phi_{\mathrm{F}}=0.17$, for 242 emission was weaker $\left(\Phi_{\mathrm{F}}=0.03\right.$ ) and for $\mathbf{2 4 4}$ it was practically absent. Emission behavior of compounds 242-244 was studied in the mixture THF-water, the most distinct changes were observed for compound 243. At $0 \%$ of water fraction this derivative emitted red light with $\lambda_{\text {em }}=654 \mathrm{~nm}$ and $\Phi_{\mathrm{F}}=0.23$, when increasing the water fraction up to $30 \%$ the intensity considerably decreased, having reached $\Phi_{\mathrm{F}}=$ 0.002. However, beginning from $40 \%$ of water the intensity of emission increased with the final value $\Phi_{\mathrm{F}}=0.18$ at $90 \%$ and hypsochromic shift to orange range is observed. At the high content of water compound $\mathbf{2 4 3}$ formed agregates due to hydrophobic interaction which create the hydrophobic space limiting polarization of the excited state and, as a result, quenching of emission. Transition from initial condition of emission to final through intermediate quenching, reached in Vshaped structure of compound 243, was shown as an example of creation of emission system in the polar water medium. According to authors, unusual double change of emission is caused by the combined aggregation effect and twisted ICT.

Derivatives of bis(thiadiazol)quinoxaline of general formula $\mathbf{2 4 5}$ were patented as organic light emitting elements and materials. ${ }^{193}$ It worth to note that organic dyes emitting in red and near IR range are most important for biovisualization and biological studies.

Structures 242-248
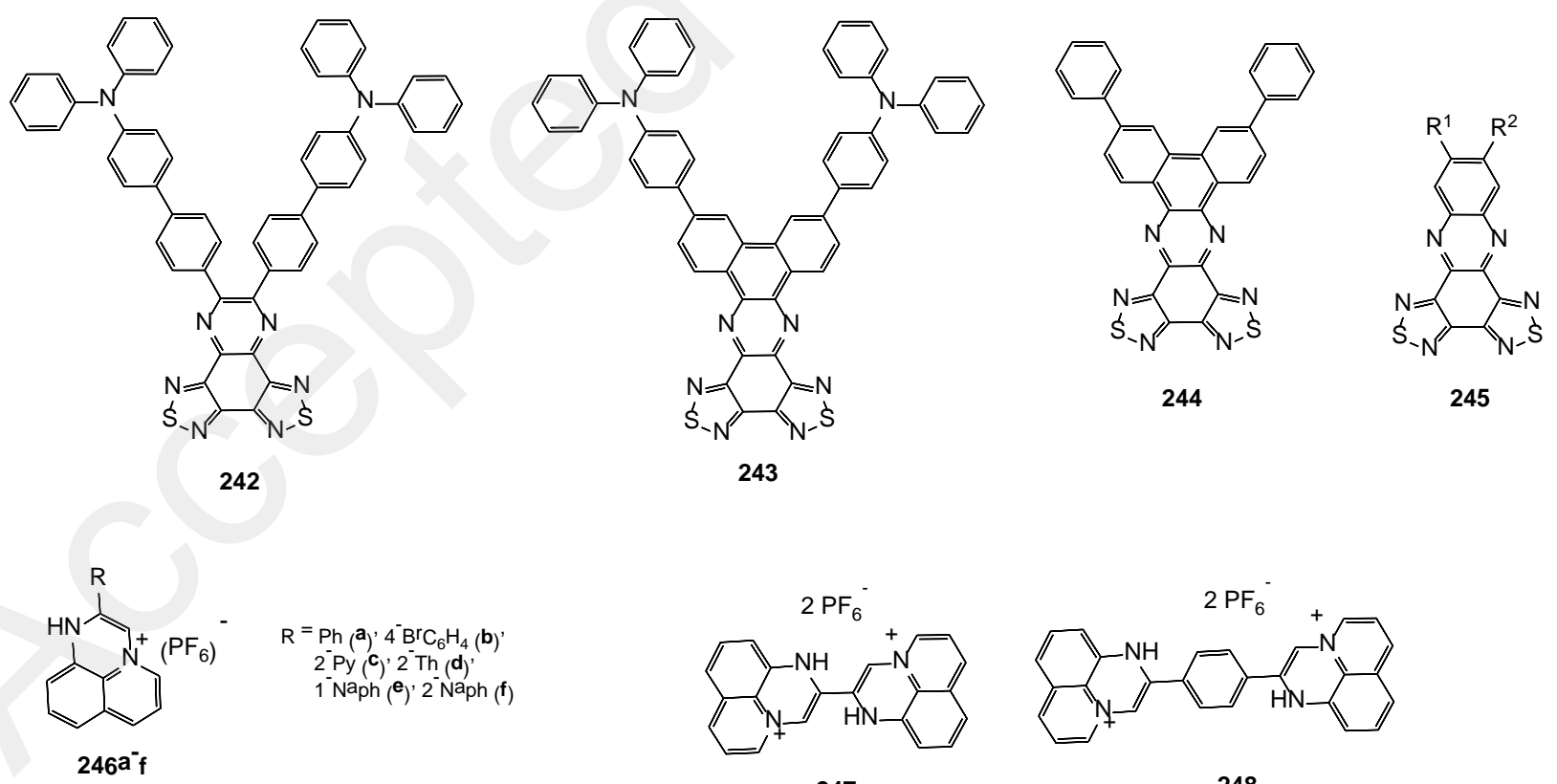

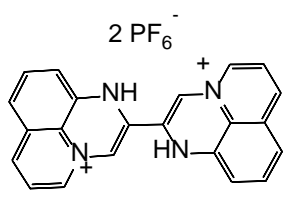

247

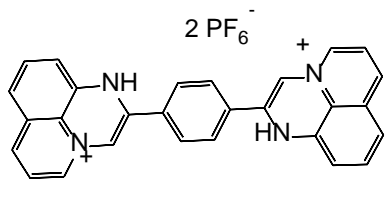

248

Laramee-Milette and co-authors obtained the series of $1 H$-pyrido[1,2,3-de]quinoxaline cationic dyes 246-248 by the reaction of 8-aminoquinoline with $\alpha$-bromoketone. ${ }^{194}$ The structure of compounds 246a,b was confirmed by X-ray data. The majority of derivatives exhibit luminescent 
properties in solution and solid state with $\lambda_{\text {em }}=500-700 \mathrm{~nm}$ and low quantum yield $\left(\Phi_{\mathrm{F}}=\right.$ 0.005-0.017 in $\mathrm{MeOH}$ ). The exception made the compound 247 which proved to be non-emissive in solid state. On the basis of the conducted researches authors came to the conclusion that the observed luminescence in solid state for compounds 246, 248 can be caused by strong intermolecular $\pi-\pi$ interaction leading to aggregation induced emission.

\section{Polymer benzazines}

Functionalised benzazines are included into various $\pi$-conjugated polymers which are perspective for application in different spheres as photoactive materials. Among them quinoxaline and its derivatives have been widely used as building blocks because they can be easily modified by varying the side chains, that promotes the creation of polymeric products. Thus, recent reviews ${ }^{142-}$ 144 are devoted to the development of quinoxaline based polymers for organic photovoltaics (OPV).

Gedefaw and co-authors collected data on the basic structure of monomer qunoxalines and their incorporation into the conjugated polymers of D-A type, special attention was paid to a combination of quinoxaline and benzothiophene fragments in polymeric chain. ${ }^{142} \mathrm{~A}$ broad range of structures and devices considered in this work showed a possibility of precise control of quinoxaline-containing polymers properties for the creation of highly effective OPV devices due to high stability, universality, mild and inexpensive synthesis, peculiar optical, chemical and electronic properties of quinoxaline as acceptor building-block in D-A polymers.

Yuan and co-authors focused on design and synthesis of photovoltaic polymers, including quinoxaline fragment with flexible alkoxy, fluoro and conjugated side chains. ${ }^{143}$ It was shown that incorporation of the last has a positive impact not only on absorption spectra, but also on charge conductivity, energy levels and a microstructure of active layers in polymeric solar cells (PSCs) that leads to considerable improvement of productivity of photovoltaic devices.

Liu and co-authors generalized data on quinoxaline-based D-A conjugated polymers, classifying them by the donor unit incorporated into the quinoxaline moiety. ${ }^{144}$ Variously replaced fluorenes, carbazoles, indacetonodithiophenes, benzodithiophenes, thiophenes and other comonomers were considered as such donor unit. Modifications of chemical structure by twodimensional side chains or fluorine substituents targeted to maximizing the productivity of solar cells were described.

Despite a large number and a variety of synthesized and studied $\pi$-conjugated polymers bearing acceptor quinoxaline fragments as well as some established "structure-properties" correlations, the search of new photoactive polymers with improved characteristics is continued.

Upadhyay and co-authors ${ }^{195,196}$ synthesized novel series of donor-acceptor combined quinoline-carbazol oligomers 249, using Wittig methodology. Compounds were characterized by 
IR, NMR ${ }^{1} \mathrm{H}$ and ${ }^{13} \mathrm{C}$, cyclic voltammetry, atom microscopy and TGA. Oligomers demonstrated thermostability up to $200{ }^{\circ} \mathrm{C}$, good solubility in ordinary organic solvents. Oligomer 249a possesses luminescence with $\lambda_{\mathrm{em}}=420-451 \mathrm{~nm}$ depending on the solvent polarity and $\Phi_{\mathrm{F}}=0.23$ in chloroform. Oligomer $249 \mathrm{~b}$ also exhibited fluorescence with $\lambda_{\mathrm{em}}=385-441 \mathrm{~nm}$ in solution and 473 $\mathrm{nm}$ in film. The luminescence of these compounds can be quenched by the addition of dimethylaniline or dimethyl terephthalate to the solution of oligomer. Optical data allowed to conclude that strong intramolecular $\pi-\pi^{*}$-interaction between carbazole and quinoline takes place in oligomers.

Structures 249, 250

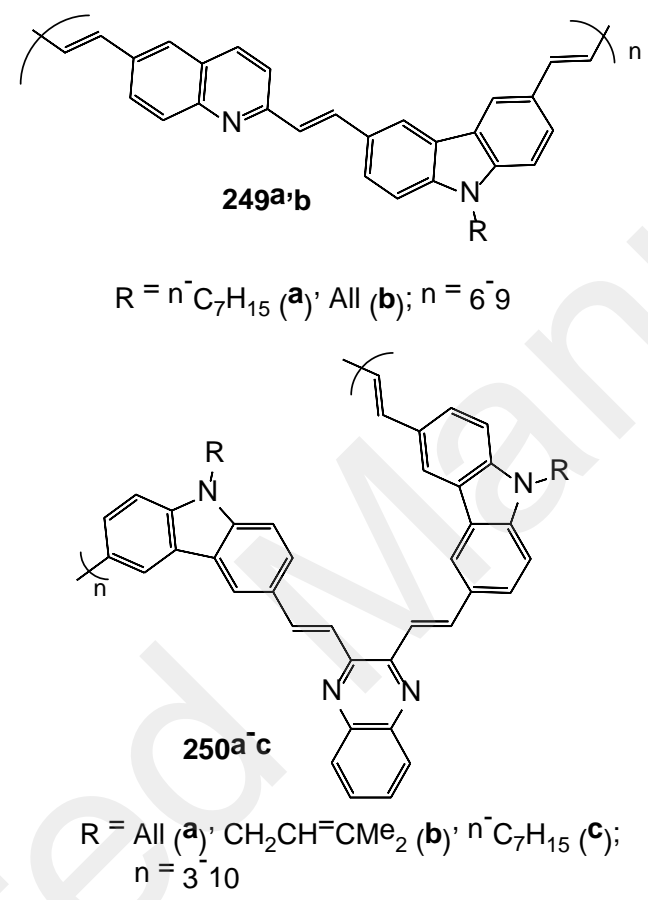

In another work the same authors ${ }^{197}$ described synthesis and properties of oligomers 250a-c, bearing quinoxaline cycle as an acceptor. Compounds are well soluble in organic solvents; decomposition temperatures exceeded $300{ }^{\circ} \mathrm{C}$ with $5 \%$ of weight loss. Oligomers exhibited fluorescence in solution, red shift of emission band is observed with increasing the solvent polarity. Thus, for compound 250a: $\lambda_{\text {em }}=471\left(\mathrm{CHCl}_{3}\right), 521 \mathrm{~nm}(\mathrm{DMF}), \Phi_{\mathrm{F}}=0.41(\mathrm{DMF})$; for $250 \mathrm{~b}: \lambda_{\mathrm{em}}=$ $529 \mathrm{~nm}, \Phi_{\mathrm{F}}=0.49(\mathrm{DMF})$; for 250c: $\lambda_{\mathrm{em}}=545 \mathrm{~nm}, \Phi_{\mathrm{F}}=0.61$ (DMF). In solid state the emission peak underwent red shift up to 550, 562 and $574 \mathrm{~nm}$ for 250a-c correspondently. As in the case of oligomer 249, luminescence of compounds 250 can be quenched by the same quenchers. The behavior of oligomer $\mathbf{2 5 0}$ in relation to a wide range of metal cations was studied and it was shown that only the addition of a $\mathrm{Ni}^{2+}$ cation leads to strong decrease in fluorescence intensity. These compounds can be applied as selective probe on $\mathrm{Ni}^{2+}$ ions in the presence of other metals. According to authors, these oligomers have potential application in OLEDs. 
Guo and co-authors described white light emitting polymers 251 based on polyfluorene derivative, bearing electron-defivient 2,3-biphenyl-6-fluoroquinoxaline in the main chain, and imparted iridium complexes in side chain. ${ }^{198}$ It is shown that the combination of blue fluorescence of the main chain and yellow phosphorescence of iridium complex resulted in effective white emission in this unique polymer.

Structure 251
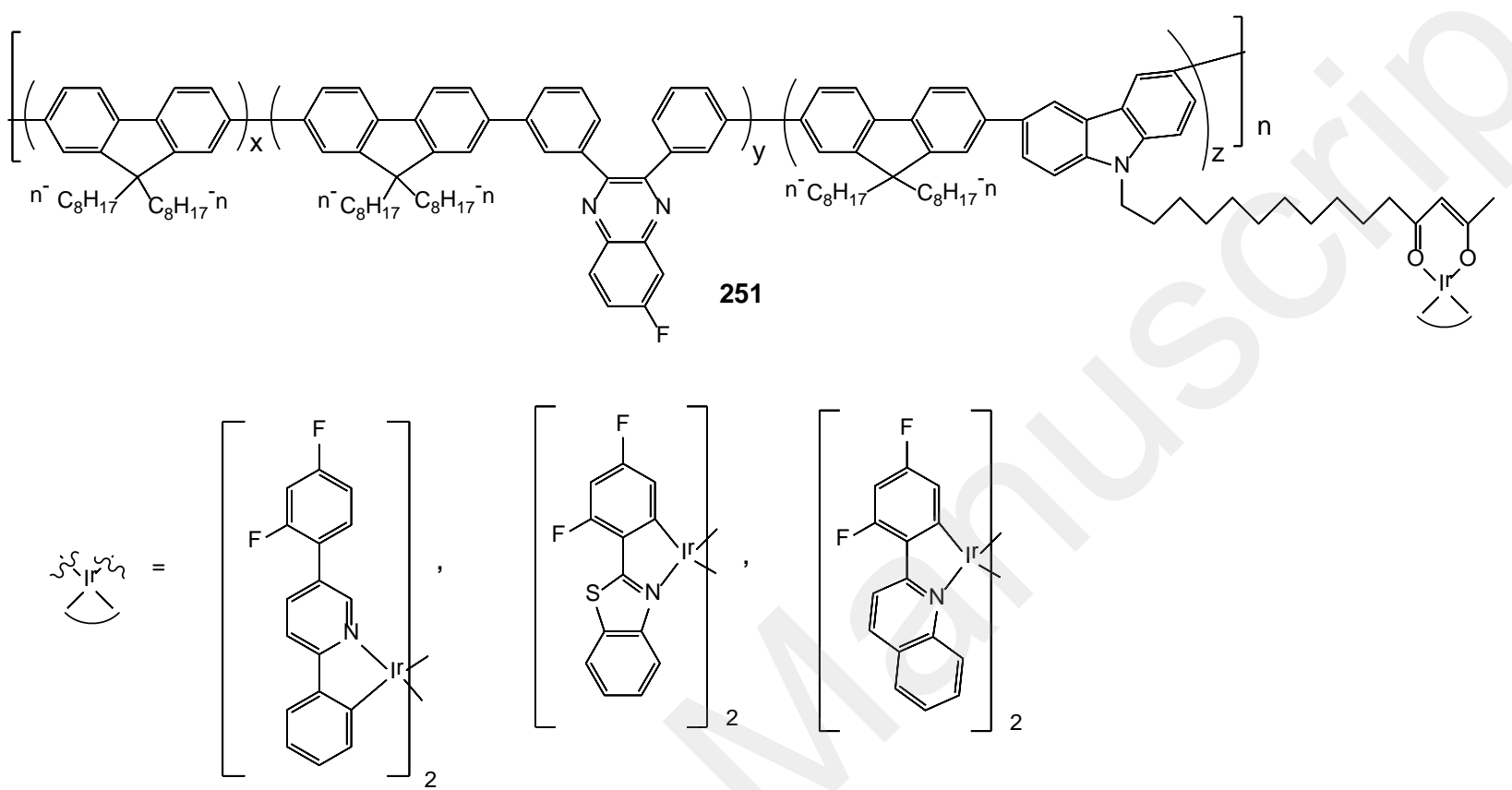

In a number of works the improvement polymers properties was reached by the modification of quinoxaline fragment. Kang and co-authors ${ }^{199}$ prepared five new co-polymers 252, containing 2,3-dialkyl-6,7-difluoroquinoxaline and 9,9-dioctylfluorene with their different ratio in the main chain. All polymers demonstrated high $\mathrm{M}_{\mathrm{w}}$, good solubility in chlorine-containing solvents and high termostability. These copolymers are characterized by rather low value of optical gap (1.93-2.08 $\mathrm{eV}$ ) and deep level of HOMO energy (-5.67--5.59 eV). PSCs based on co-polymers 252 were performed, these devices demonstrated maximum values of PCE in the range $2.91-3.98 \%$.

Structures 252, 253

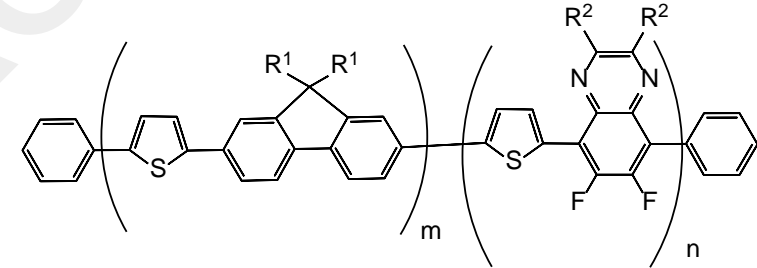

252

$R^{1}=n^{-} C_{8} H_{17}{ }^{\prime 2}{ }^{2}{ }^{-}{ }^{-} C_{12} H_{25}$
Wang and co-authors reported about novel $\pi$-conjugated co-polymer of D-A type 253, including 4-alkyl-3,5-difluorophenyl-substituted quinoxaline as acceptor, disubstituted 
benzodithiophene fragment as donor and thiophene as spacer in the main chain. ${ }^{200}$ Organic solar cells (OSCs) based on 253 exhibited excellent efficiencies both in fullerene (PCE = 9.2\%), and nonfullerene devices $(\mathrm{PCE}=9.6 \%)$. Authors demonstrated that incorporation of two weak electronodonating groups into position 4 of phenyl substituent of quinoxaline led to the improvement of photovoltaic properties.

Yang and co-authors described new polymers 254 for effective non-fullerene для OSCs, containing 3,4-dialkoxyphenyl-substituted quinoxaline and dithiophenearyl fragment. ${ }^{201}$ It was shown that incorporation of 1-4 fluorine atoms into aryl fragment allows effective adjusting levels of polymer frontal molecular orbitals, molecular packing and the morphology of films. According to calculations, polymer $\mathbf{2 5 4 c}$ is characterized by the greatest planarity due to intramolecular noncovalent $\mathrm{S} \cdots \mathrm{F}$ and $\mathrm{H} \cdots \mathrm{F}$ interactions. All polymers showed wide optical gap $\left(\mathrm{E}_{\mathrm{g}}>1.8 \mathrm{eV}\right)$ and the great value of switching voltage $(1.00 \mathrm{~V})$ in non-fullerene OSCs. The device based on polymer 254c exhibited PCE $=9.7 \%$.

Structures 254, 255

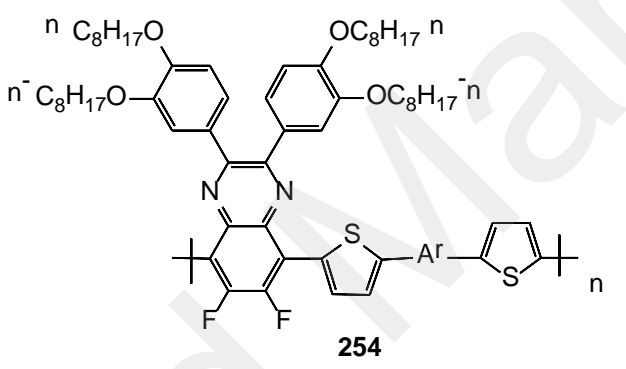

$$
\begin{aligned}
& \mathrm{Ar}^{\mathrm{r}}={ }_{1}, 4^{-} \mathrm{C}_{6} \mathrm{H}_{4}\left({ }^{\mathbf{a}}\right)^{\prime} 1^{\prime} 4^{-}\left(2^{-} \mathrm{FC}_{6} \mathrm{H}_{3}\right)\left(\mathbf{b}^{\prime}\right)^{\prime} 1^{\prime} 4^{-}\left(2^{\prime} 5^{-} \mathrm{F}_{2} \mathrm{C}_{6} \mathrm{H}_{2}\right)\left(\mathbf{c}^{\mathbf{c}}\right)^{\prime} \\
& 2^{\prime} 3^{\prime} 4^{\prime} 5^{\circ} \mathrm{F}_{4} \mathrm{C}_{6}(\mathbf{d})
\end{aligned}
$$

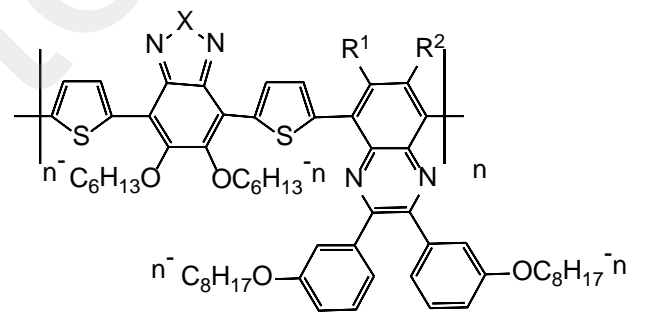

255

$$
R^{1}=R^{2}=H^{\prime} F ; X=O ' S
$$

Wang and co-authors obtained triple co-polymers 255 of $\mathrm{D}-\mathrm{A}_{1}-\mathrm{D}-\mathrm{A}_{2}$ structure by the combination of the simpliest thiophene donor and two simple acceptors: alkoxy-containing benzoxadiazole (benzothiadiazole) and quinoxaline. ${ }^{202}$ Studying of optical, electrochemical properties of these polymers, characteristics of the PSCs samples fabricated on the basis of 255 showed that variation of the structure of A2 moiety allows adjustment of the specified properties of the final polymer. Copolymers absorbed in visible range with maximum at 565-630 nm in solution, 
showed width of an optical gap within 1.70-1.73 eV and the deep level of HOMO energy (-5.60-$5.34 \mathrm{eV}$ ). The maximum value of PCE $=5.84 \%$ was obtained for the device on the basis of copolymer $255\left(X=O, R^{1}=H, R^{2}=F\right)$, and it is much higher than for polymers of D-A or D-A type.

Lin and co-authors described new D-A polymers 256, containing naphtodithiophene as donor and quinoxaline bearing alkylthio and alkylthiophene side chains. ${ }^{203}$ Comparative studying of the influence of flexibility of such chains on polymers properties showed that alkylthio residues lead to the red shift of absorption bands, lowering of the HOMO and LUMO energy level, improvement of intermolecular $\pi \cdots \pi$ interactions and the morphology of films. It was found that PSC based on polymer 256a possessed higher value PCE (5.03 \%), whereas for PSC using 256b PCE was only 1.93\%. Results of researches confirm an important role of substituents in quinoxaline acceptor on the tuning of properties of polymers and devices.

Structures 256, 257

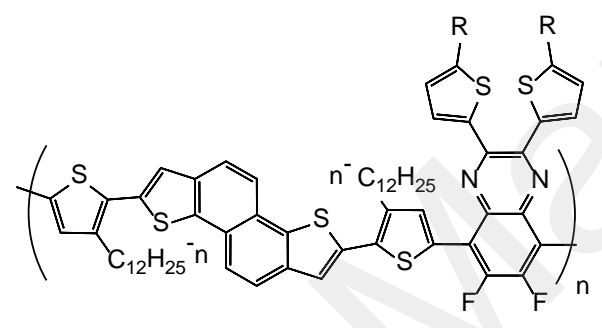

256

$\mathrm{R}^{-} \mathbf{2}^{-}$ethylhexylthio (a)' $2^{-}$ethylhexyl (b)

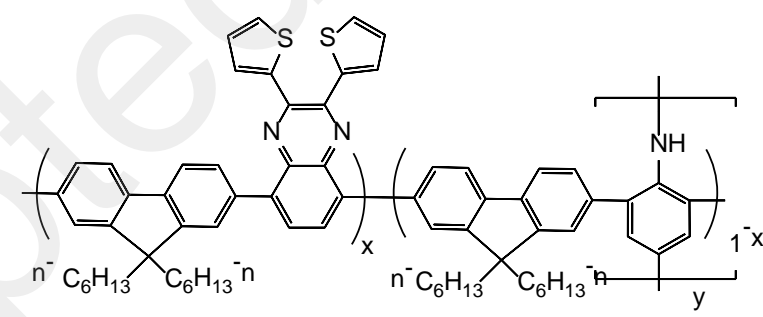

257

In the work of Jessop and co-authors the two-dimensional conjugated polymer 257 based on aniline and 9,9-dihexylfluorene as donor fragments and 2,3-dithienylquinoxaline as acceptor was synthesized. ${ }^{204}$ Comparison of the properties of this polymer with its one-dimensional precursor showed that the effect of perpendicular polyaniline branches resulted, mainly, in considerable reduction of molecular weight, whereas such characteristics as absorption and emission maxima, HOMO and LUMO energy level, size of optical gap practically do not change. OLED fabricated on the basis of polymer 257 as emissive layer, shows the low efficiency of the device, the electroluminescence arises at high value of switching voltage. 
Nagata and co-authors synthesized and studied properties of polymers 258, bearing quinoxalin-2,3-diyl with different chiral side chains. ${ }^{205}$ These compounds were obtained by polymerisation of 1,2-diisocyano-4,5-R-benzenes in the presence of complexes of transitional metals, they possess spiral-like main chain caused by steric pushing of two substituents at positions 5 and 8 of quinoxaline. ${ }^{206}$ Polymers 258 exhibited blue fluorescence in solution, the luminescence intensity for 258c was mich higher than for 258a,b. The dependence of spiral inversion of polymers 258a-c from the solvent was studied and it was shown that all of them possess $M$-spiral structure in $\mathrm{CHCl}_{3}$ and $P$-spiral in 1,1,1-trichloroethane (TCE). Spectra of a circular polarized luminescence (CPL) of polymer 258c in the diluted solutions of several solvents, including $\mathrm{CHCl}_{3}$ and 1,1,1-TCE were registrated, and it was shown that observed signals are obliged to spiral conformation of quinoxaline cycles. CD spactra in $\mathrm{CHCl}_{3}$ and 1,1,1-TCE were almost mirror display of each other. Thus, polymers demonstrated the chiral-switched CPL in the diluted solution and can be considered as the new class of CPL materials.

Structures 258, 259

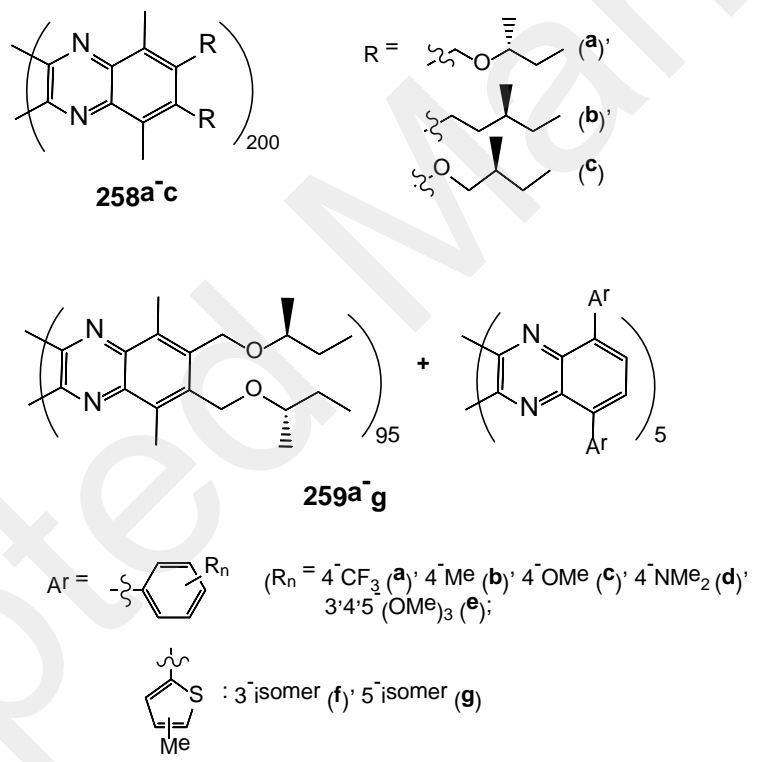

In another work the same group of authors ${ }^{207}$ described co-polymers 259, containing achiral luminescent 5,8-diarylquinoxalines and poly(quinoxalin-2,3-diyl) as main chain with chiral side chains in the ratio 95:5. These co-polymers possess milticolour emission; the colour depends on substituent Ar, red shift of $\lambda_{\text {em }}$ was observed at the increase of electronodonating ability of Ar. Thus, compounds 255a,b exhibit blue emission, 259c,d - green, 259e,f,g - orange or red. Like polymers 258 co-polymers 259 possess $M$-spiral structure in $\mathrm{CHCl}_{3}$. Copolymers 259 showed circular polarized luminescence and CPL spectra in 1,1,1-TCE were almost mirror display of the spectra recorded in $\mathrm{CHCl}_{3}$, demonstrating that in 1,1,1-TCE they get $P$-spiral conformation. Having replaced (S)-2-butoxymethyl of side chain with (S)-3-octyloxymethyl one, authors obtained copolymers exhibiting significant correlation CPL from the nature of solvent ( $n$-octane or 
cyclooctane) while maintaining the wavelength of the CPL. These results showed that in such chiral co-polymers the luminophor and chiral component can be independent from each other. In this case poly(quinoxalin-2,3-diyl) is presented as a multifunctional chiral framework for CPL materials.

Tokoro and co-authors reported the synthesis and optical properties of conjugated polymers 262, including penta-coordinated organosilicon complex based on benzo[h]quinoline. ${ }^{208}$

Scheme 20
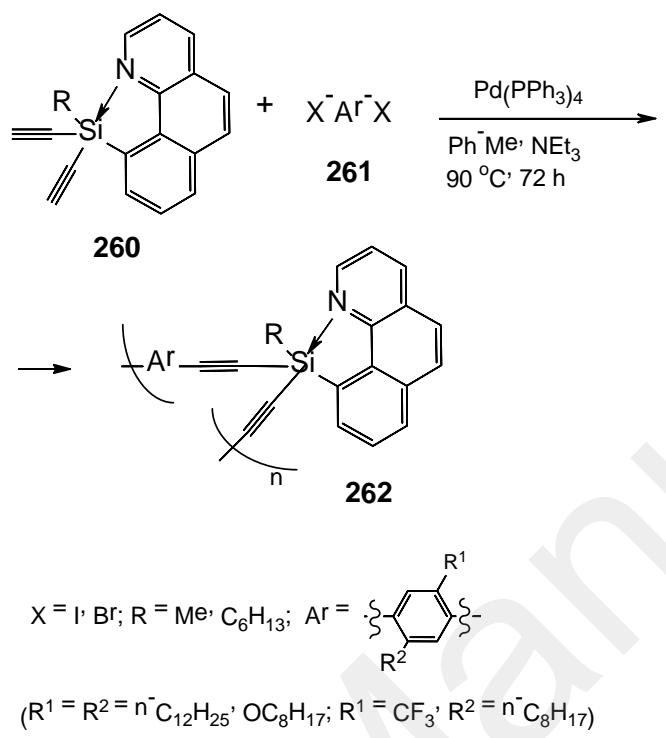

Compounds 262 were obtained from diethynyl monomers 260 and $n$-dihalogenated comonomers 261 by cross-coupling Sonogashira-Hagihara reaction in 75-95\% yield (Scheme 20). Polymers were characterized by NMR ${ }^{1} \mathrm{H},{ }^{13} \mathrm{C},{ }^{29} \mathrm{Si}$ and IR spectra data, possess good solubility in organic solvents. In THF these polymers possess intensive tunable luminescence with $\lambda_{\text {em }}=$ 417-474 nm depending on the nature of aryl substituent and quantum yield up to 0.24 . This is the first example of the luminescent polymers containing pentacoordinate silicon.

\section{Coordination compounds of benzazines}

Since the first data on the OLED based aluminum complex of 8-hydroxyquinoline ( $\mathrm{Alq}_{3}$ ) possessing green fluorescence have been published, ${ }^{24}$ this compound has been widely studied as an electron-transport and luminescent material. Numerous researches were also focused on optimization of $\mathrm{Alq}_{3}$ structure for achievement of blue emission. Thus, authors of work ${ }^{209}$ were synthesized derivatives 263 bearing electron-donor or electron acceptor groups at quinoline core in order to tune the value of HOMO-LUMO gap. Complexes 263 were obtained through the reaction of tri(isopropoxide)aluminium with 4-methyl-6-R-quinolines (Scheme 21), the structure of 263a was confirmed by X-ray. In DCM solution complexes 263 exhibit blue fluorescence with $\lambda_{\max }$ 478-482 nm and $\Phi_{\mathrm{F}}=0.46-0.57$, which exceeds the value for $\mathrm{Alq}_{3}\left(\Phi_{\mathrm{F}}=0.15\right)$. Simple devices 
using compounds $\mathbf{2 6 3}$ as an electron-transport and emitting material were created, the best value EQE (4.6\%) was observed for OLED based on 263a.

Scheme 21

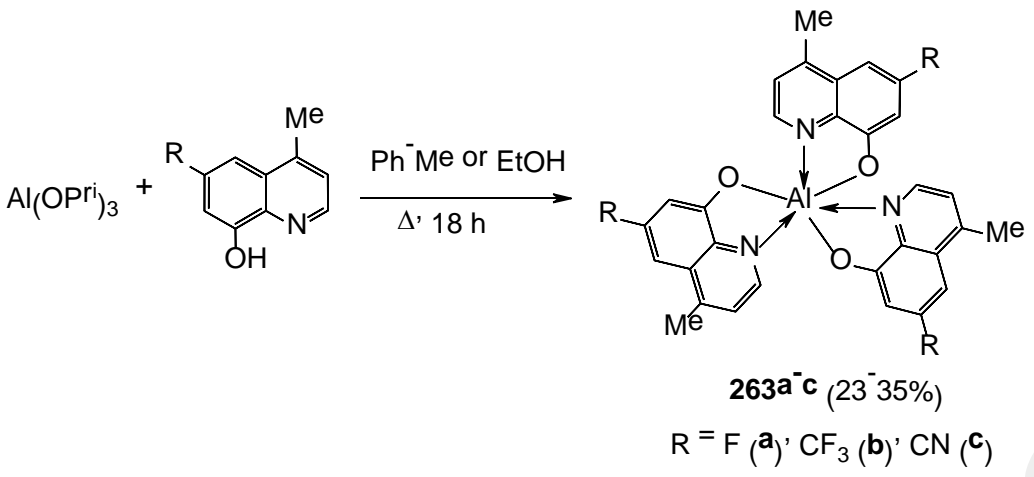

Triplet energies of derivatives $\mathbf{2 6 3}$ were determined from the phosphorescence spectra recorded at $77 \mathrm{~K}$, these data also showed blue shift in comparison with $\mathrm{Alq}_{3}$ and higher values in comparison with the Ir complexes on the basis of quinoline derivatives. Such characteristics allowed applying compounds $\mathbf{2 6 3}$ for the creation of OLEDs emitting white light (WOLEDs). The device based on the derivative 263a showed EQE up to 19\% and high purity of white light (color rendering index, CRI) $\sim 80 .^{209}$

Another approach for increasing the intensity of fluorescence of $\mathrm{Alq}_{3}$ was developed. ${ }^{210}$ Authors obtained organo-inorganic hybrid material in which $\mathrm{Alq}_{3}$ chromophore is intercalated into zirconium phosphate modified with butylamine (BAZrP). This hybrid ( $\left.\mathrm{Alq}_{3} / \mathrm{BAZrP}\right)$ showed very intensive green-blue fluorescence with shift of $\lambda_{\mathrm{em}}$ up to $505 \mathrm{~nm}\left(\lambda_{\mathrm{em}}=515 \mathrm{~nm}\right.$ for $\left.\mathrm{Alq}_{3}\right)$. Besides, the hybrid showed prolonged lifetime of the excited state that allows applying it in other areas, such as conversion and storage of solar energy.

In the last decades, many researches on coordination compounds of benzazines for optoelectronic materials have been directed to application of wide range of transitional elements, in which electronic structures d- and f-sublevels are filled. Transitional elements are divided into delements, lanthanides (4f-elements) and actinides (5f-elements), there are significant differences between these groups. $d$-Elements have a filling of nd-orbitals: $3 d-4 d-$, 5d- (three rows or three decades), d-elements of which differ in chemical properties from each other. Examples of 3d-metals are $\mathrm{Mn}, \mathrm{Fe}, \mathrm{Co}, \mathrm{Ni}, \mathrm{Cu}, \mathrm{Zn}$; 4d-metals include Ru, Pd, Ag, Cd; and 5d-metals are Os, Ir, Pt. Any dorbitals in space leave far beyond the atom or an ion; therefore electrons on them are exposed to strong influence of a coordination environment. At the same time d-electrons strongly influence the next atoms and ions. Existence of incomplete configurations of d-orbitals of transitional metals atoms provides features of magnetic behavior of their compounds. The main feature of almost any d-element is the variable valency of its atoms. 
The review published by Katkova et $a l^{9}$ is devoted to complexes of rare-earth elements with quinoline ligands, and a number of Os, Ir, Pt complexes with azine ligands are presented. ${ }^{8,211}$

\section{V.1. Complexes of benzazines with d-metals}

\section{V.1.1. Complexes with Zn ${ }^{\mathrm{II}}, \mathrm{Cd}^{\mathrm{II}}$, Co ${ }^{\mathrm{II}}, \mathrm{Cu}^{\mathrm{I}}, \mathrm{AgI}^{\mathrm{I}} \mathrm{Pd}^{\mathrm{II}}$}

Quinoline derivatives containing coordinating group at positions 8 or 2 remain the most promissing ligands for obtaining complexes with luminescent properties. Photophysical, thermal and electronic properties of polyaniline (PA) composite with zinc bis(8-hydroxyquinolate) 264, obtained by oxidative polymerization, are compared with properties of free $\mathrm{Zn}$ complex. ${ }^{212}$ It is shown that doping of PA with zinc complex led to the increase in termostability and conductivity. The intensity of fluorescence of composite increased considerably, and it can show purple emission with $\lambda_{\text {em }}=423 \mathrm{~nm}$ under excitation at $\lambda_{\text {exc }}=340 \mathrm{~nm}$, or blue emission with $\lambda_{\mathrm{em}}=468 \mathrm{~nm}$ under exitation at $\lambda_{\text {exc }}=360 \mathrm{~nm}$. This polymeric composite represents potential material for electronic and optoelectronic application.

Structures 264-270
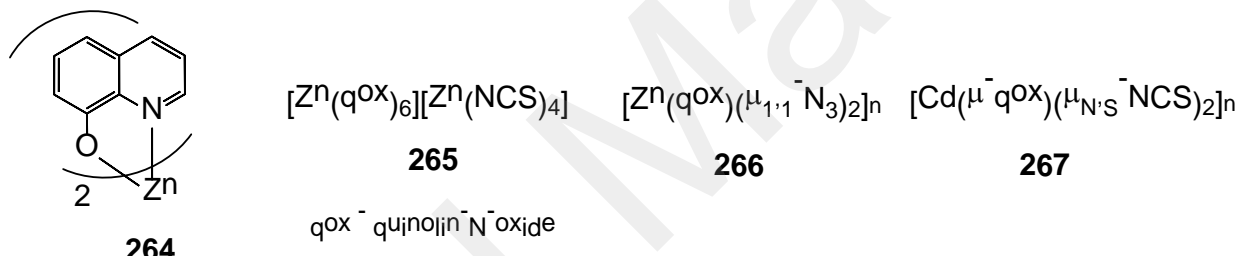

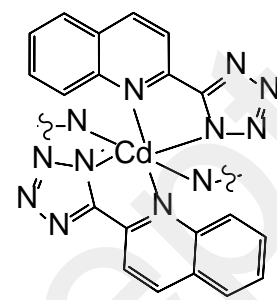

268

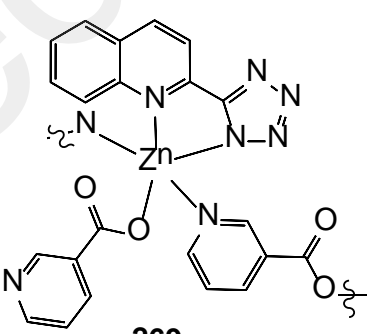

269

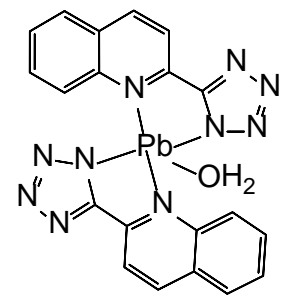

270

Quinoline-N-oxide (qox) was used as O-ligand for the synthesis of $\mathrm{Zn}^{\mathrm{II}}$ and $\mathrm{Cd}^{\mathrm{II}}$ complexes 265-267. ${ }^{213}$ The structures of these compounds were determined by X-ray method. Complex 265 consists of octahedral cation $\left[\mathrm{Zn}(\mathrm{qox})_{6}\right]^{2+}$ and tetrahedral anion [Zn(NCS) $\left.)_{4}\right]^{2-}$. In complex 266 the $\mathrm{Zn}^{\mathrm{II}}$ centers with coordination number 5 are connected with azide groups in a polymeric chain. Octahedral $\mathrm{Cd}^{\mathrm{II}}$ centers in complex 267 are connected in a polymeric chain with ligand molecules and isothiocyanate-anions. In solid state, Zn complexes 265 and 266 exhibit luminescence with broad emission band, aligned at 621 and $614 \mathrm{~nm}$ respectively, whereas complex 267 shows two emission maxima - at 618 and $654 \mathrm{~nm}$. 
Complexes $\mathrm{Cd}^{\mathrm{II}}$ (268), $\mathrm{Zn}^{\mathrm{II}}$ (269) and $\mathrm{Pb}^{\mathrm{II}}$ (270), synthesized by solvothermal reaction of quinoline-2-carbonitrile, sodium azide and metal chloride in the presence of $\mathrm{NH}_{4} \mathrm{Cl}$ (for 268) or nicotinic acid (for 269), were presented. ${ }^{214}$ According to X-ray data, complex 268 represents linear polymer in which $\mathrm{Cd}$ ion has an octahedral environment formed by six nitrogen atoms of four quinoline-tetrazole ligands. Zinc atom in complex 269 also surrounded in octahedral way with four nitrogen atoms and two oxygen atoms of nicotinic acid. In compound 270, the square-pyramidal environment of $\mathrm{Pb}$ ion takes place. All complexes possess strong luminescence in solid state. Compound 268 exhibited blue emission with $\lambda_{\mathrm{em}}=494 \mathrm{~nm}$, the spectrum of complex 269 contains two bands with maximum at $464 \mathrm{~nm}$ and $580 \mathrm{~nm}$, in both cases emission is short-lived (10-12 nsec). Unlike them the $\mathrm{Pb}$ complex 270 showed yellow emission with $\lambda_{\mathrm{em}}=550 \mathrm{~nm}$ and longer lifetime (125 $\mu \mathrm{sec})$.

Binuclear $\mathrm{Zn}^{\mathrm{II}}$ complexes (272) were obtained on the basis of tetrakis-quinoline ligands 271 (Scheme 22), compounds 272 were investigated for fluorescent sounding of phosphate anions. ${ }^{215}$ The formation of complexes 272 with composition ligand: $\mathrm{Zn}^{2+}=(1: 2)$ in solutions was controlled by monitoring of changes in absorption and fluorescence spectra under addition of $\mathrm{Zn}^{2+}$ ions to a ligand. The composition and structure of complexes $\left[(272 \mathrm{c}-\mathbf{e})\left(\mathrm{AcO}^{-}\right)\left(\mathrm{ClO}_{4}^{-}\right)_{2}\right]$, obtained from ligands 271c,d,e and acetate or perchlorate, were confirmed by X-ray method. Each zinc ion in these complexes is pentacoordinated with three nitrogen atoms, one oxygen atom from a ligand and another oxygen atom from acetateanion. Complexes 272a,c,e demonstrated week fluorescence with $\lambda_{\text {em }}=450 \mathrm{~nm}$, addition of pyrophosphate (PPi) up to 1 equiv. led to the increase of intensity, and futher addition of PPi resulted in the decrease. Such changes are due to the formation of triple complex ligand- $\mathrm{Zn}^{2+}$-PPi (1:2:1) corresponding to the emission maximum, and then removal of $\mathrm{Zn}$ under the excess of pyrophosphate takes place. $\mathrm{Zn}_{2}$-Complex 272a showed the best results in experiments with pyrophosphates and was used for determination of enzymatic activity of pyrophosphatase.

Scheme 22
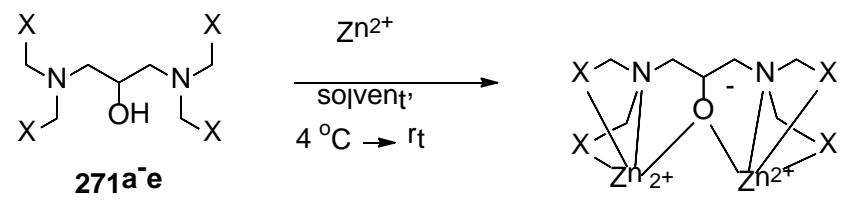

$272 \mathrm{a}^{-\mathrm{e}}\left(27^{-} 78 \%\right)$

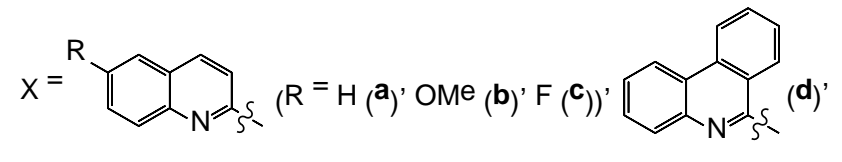

$\overbrace{N}^{(e)}$ 
Complex 273, obtained on the basis of 2-(benzimidazol-2-yl)quinoline and tri( $o$ tolyl)phosphine also contains tricoordinated $\mathrm{Cu}^{\mathrm{I}}$ atom, according to X-ray data. ${ }^{216}$ Compound 273 possesses strong yellow phosphorescence proved to be perspective for OLED.

Structures 273, 274

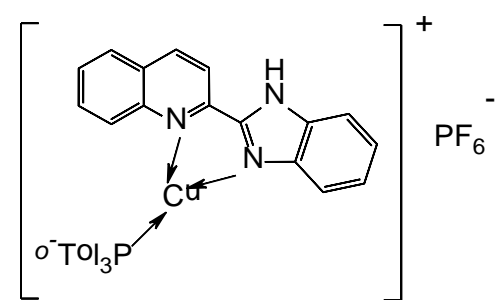

273

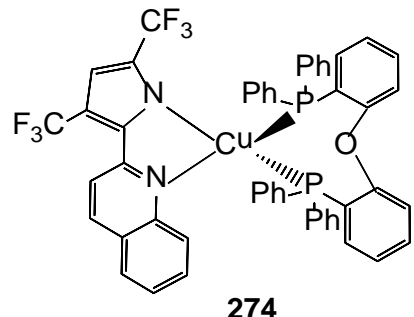

274

Neutral complex Cu'274 was synthesized using 3,5-bis(trifluoromethyl)-2-(quinolin-2yl)pyrrole as $N, N$-ligand and bidentate phosphine auxiliary ligand. ${ }^{217}$ In DCM solution at room temperature compound 274 possesses orange-red luminescence with $\lambda_{\mathrm{em}}=603 \mathrm{~nm}$ and $\Phi_{\mathrm{F}}=0.12$. In a firm matrix (77K) the blue shift of a maximum of emission $>50 \mathrm{~nm}$ and the increase in $\Phi_{\mathrm{F}}$ up to $51 \%$ (total on fluorescence and phosphorescence bands) take place, thus, the complex shows rigidochromism.

The design of coordination polymers drew special attention due to their some interesting physical and optical properties and the possibility of use as multifunctional materials. Polymeric $\mathrm{Zn}^{\mathrm{II}}, \mathrm{Cd}^{\mathrm{II}}$ and $\mathrm{Hg}^{\mathrm{II}}$ complexes with general formula $\left[\mathrm{M}(\mathrm{dca})_{2}(\text { quin })_{2}\right]_{\mathrm{n}}(\mathbf{2 7 5 a}-\mathbf{c})$ were obtained by the reaction of quinoxaline (quin), metal acetate and subsequent addition of dicyanamide (dca) in the ratio 1:1:2 in methanol. ${ }^{218}$ According to X-ray data, complexes are isostructural and represent 1D coordination polymers. Complexes exhibit strong blue fluorescence both in methanol and solid state $\left(\lambda_{\mathrm{em}}=407-445 \mathrm{~nm}, \Phi_{\mathrm{F}}=0.21-0.70\right)$. Zinc complex 275a possesses the highest intensity with $\Phi_{\mathrm{F}}=$ 0.70 , possibly, because of stronger $\pi \ldots \pi$ interactions between quinoxaline fragments.

Mixed $\mathrm{Cd}^{\mathrm{II}}$ complexes on the basis of quinazoline (qnz) and second co-ligand with compositions $\left[\mathrm{Cd}(\mathrm{qnz})_{2}(\mathrm{SCN})_{2}\right]_{\mathrm{n}}(\mathbf{2 7 6 a}),\left[\mathrm{Cd}(\mathrm{qnz})_{2}(\mathrm{dca})_{2}\right]_{\mathrm{n}}(\mathbf{2 7 6 b}),\left[\mathrm{Cd}(\mathrm{qnz})_{2}\left(\mathrm{~N}_{3}\right)_{2}\right]_{\mathrm{n}}$ (276c) were synthesized and characterized in work. ${ }^{219}$ Polymeric structures of compounds 276a,b were confirmed by X-ray method. All three complexes exhibit strong fluorescence in solid state with $\lambda_{\text {em }}$ $=397 \mathrm{~nm}$ and the type of spectra is close to a spectrum of initial quinazoline ligand.

Coordination $\mathrm{Cu}^{\mathrm{I}}, \mathrm{Ag}^{\mathrm{I}}$ polymers with some azine ligands exhibit interesting luminescent properties and already find application for obtaining the emitting layers in polymeric LED. ${ }^{220}$ Complexes of $\mathrm{Ag}^{\mathrm{I}}(\mathbf{2 7 8}, \mathbf{2 7 9})$ and $\mathrm{Cu}^{\mathrm{I}} \mathbf{( 2 8 0 )}$, synthesized on the basis of 2,3-quinolinedicarboxylic acid $\left(\mathrm{H}_{2} \mathrm{qldc}\right)$ (277) in the conditions of hydrothermal reaction, were presented. ${ }^{221}$ It is established that temperature has an impact on the structure of final product (Scheme 23). Thus, at $80{ }^{\circ} \mathrm{C}$ complex 278 with preservation of both carboxyl groups is formed, and at $120^{\circ} \mathrm{C}$ decarboxylation 
takes place, and complexes of both silver, and copper $(\mathbf{2 7 9}, \mathbf{2 8 0})$ are formed on the basis of 3quinolinecarboxylic acid (3-Hqlc). According to X-ray data, in structures 278, 279 silver atom is coordinated with one nitrogen atom and two oxygen atoms from other quinoline molecules; copper atom in the structure $\mathbf{2 8 0}$ is coordinated with three iodine atoms and one nitrogen atom.

Scheme 23

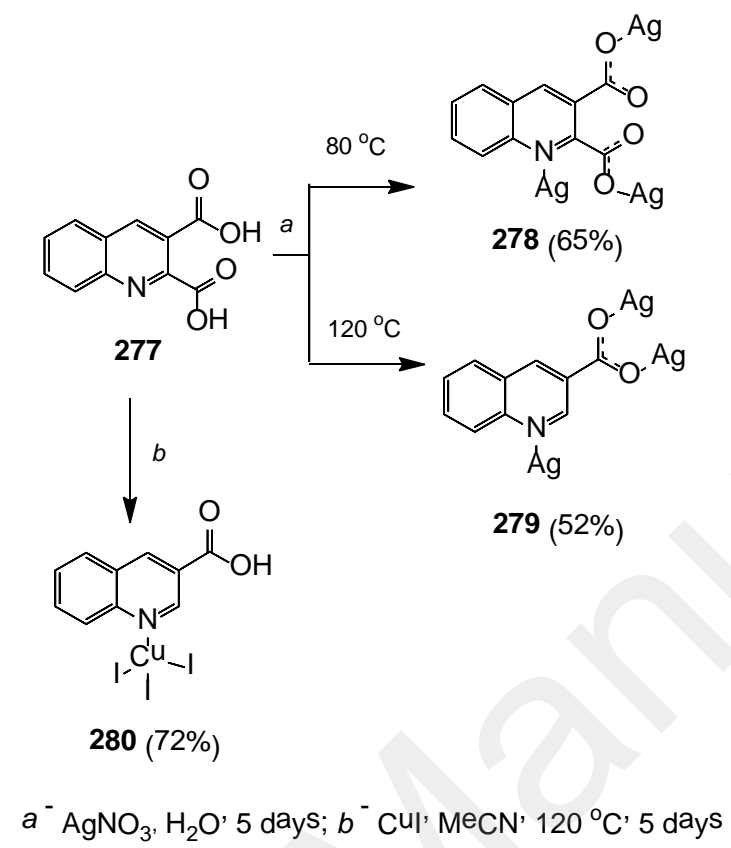

Both $\mathrm{Ag}^{\mathrm{I}}$ complexes exhibit stable blue luminescemce in solid state and solution with intensive emission band at $404-427 \mathrm{~nm}$ depending on solvent nature at $298 \mathrm{~K}$, at $77 \mathrm{~K}$ red shift of emission band was observed. $\mathrm{Cu}^{\mathrm{I}}$ complex demonstrates tunable luminescence at $298 \mathrm{~K}$ and $77 \mathrm{~K}$ from yellow to red, demonstrating thermochromic behavior. Polymethyl methacrylate doped by complex 280 shows higher intensity of yellow luminescence, improved thermostability and longer lifetime of the excited state than initial coordination polymer $\mathbf{2 8 0}{ }^{221}$

Coordination polymer based on $\mathrm{Ag}^{\mathrm{I}}$ with composition $\left[\mathrm{Ag}(\right.$ quin) $)\left(\mathrm{ReO}_{4}\right)$ (281) was obtained by reaction of $\mathrm{AgReO}_{4}$ with quinoxaline (quin) in acetonitrile at room temperature. ${ }^{22}$ According to X-ray data, structure $\mathbf{2 8 1}$ includes cationic polymer chains built from [Ag(quin)] ${ }^{+}$, in wich silver ion possesses almost linear geometry. Two oxygen atoms of anion $\left(\mathrm{ReO}_{4}\right)^{-}$act as bidentate bridges, connecting chains in 3D supramolecular structure. The obtained complex showed luminescence with emission bands at $\sim 615 \mathrm{~nm}, 550 \mathrm{~nm}$ (as in initial quinoxaline) and an additional band at 445 $\mathrm{nm}$.

New one-dimentional coordination polymer based on $\mathrm{Co}^{\mathrm{I}}$ with composition $[\mathrm{Co}(\mathrm{SCN})(\mathrm{gl})]_{\mathrm{n}}$ (282) was synthesized by reaction of $\mathrm{Co}\left(\mathrm{NO}_{3}\right)_{2} \cdot 6 \mathrm{H}_{2} \mathrm{O}$ c KSCN with quinoline (gl) in the mixture water/MeCN at room temperature. ${ }^{223}$ According to X-ray data, $\mathrm{Co}^{\mathrm{I}}$ atom possesses distorted trigonal-pyramidal environment $\mathrm{N}_{2} \mathrm{~S}_{2}$ with two $\mathrm{S}$ atoms and one $\mathrm{N}$ atom from the third thiocyanate 
anion as well as $\mathrm{N}$ atom from quinoline ligand. Polymer shows blue luminescence with $\lambda_{\mathrm{em}}=415$ and $435 \mathrm{~nm}$ in solid state at ambient temperature.

Structures 281-285

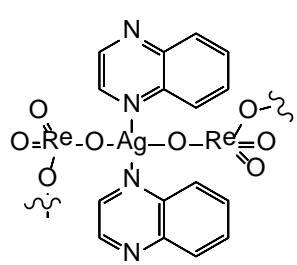

281
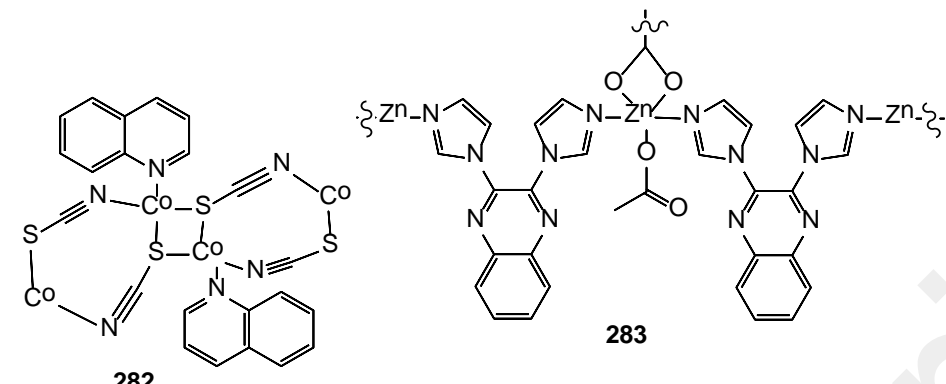

283
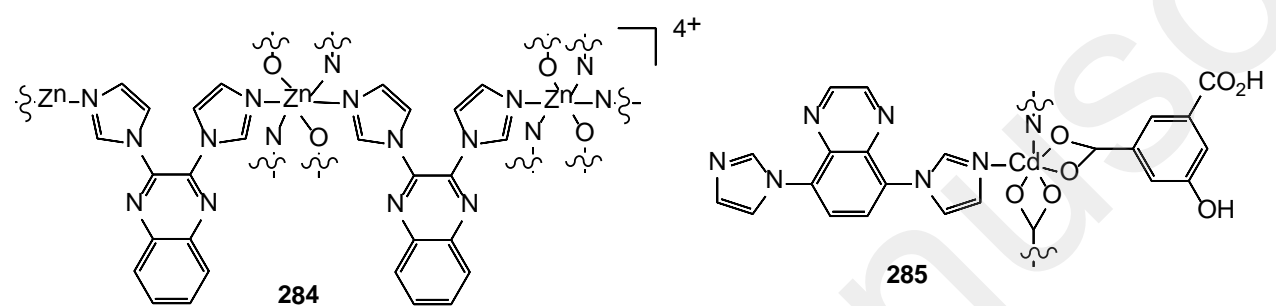

Quinoxaline derivatives including annelated ones also often act as ligands for metal complexes. Thus reaction of 2,3-bis(imidazol-1-yl)quinoxaline (biimquin) with zinc acetate led to polymeric complex $\left[\mathrm{Zn}\left(\mu_{2}\right.\right.$-biimquin $\left.)(\mathrm{OAc})_{2}\right] \cdot \mathrm{H}_{2} \mathrm{O}$ (283), whereas in the case of zinc chloride $\left[\mathrm{Zn}\left(\mu_{2} \text {-biimquin }\right)_{2}\left(\mathrm{H}_{2} \mathrm{O}\right)_{2}\right] \cdot 4 \mathrm{Cl}^{-} \cdot \mathrm{H}_{2} \mathrm{O}$ (284) was formed. ${ }^{224}$ Composition and structure of complexes were determined by X-ray method. In a one-dimensional zigzag chain of complex $283 \mathrm{Zn}^{\mathrm{II}}$ atoms are connected with ligands by the bridge through imidazole nitrogen atoms. In the complex 284 ligands are connected in the same way, but the structure is presented by a one-dimensional spherelike double chain. Both complexes in solid state at room temperature show an intensive blue luminescence with $\lambda_{\mathrm{em}}=387 \mathrm{~nm}$ (283) and $426 \mathrm{~nm}$ (284).

$\mathrm{Cd}^{\mathrm{II}}$ complex on the basis of 5,8-di(1H-imidazol-1-yl)quinoxaline (biimquix) (285) was obtained by solvotermal reaction, and ligand was formed in situ from 3,6-di(4H-imidazol-4yl)benzene-1,2-diamine and glyoxal. ${ }^{225}$ According to X-ray data, the composition of 285 is $\left\{[\mathrm{Cd} \text { (biimquix)(hip) }] \cdot 2 \mathrm{H}_{2} \mathrm{O}\right\}_{\mathrm{n}}$, where hip is deprotonated 5-hydroxyisophthalic acid. Each $\mathrm{Cd}^{\mathrm{II}}$ center is hexacoordinated with two nitrogen atoms from different biimquix ligands and with four carboxylate oxygene atoms from two different hip. In solid state at room temperature complex exhibited intense wide emission band at $\lambda_{\mathrm{em}}=454 \mathrm{~nm}$. The sensitivity of this complex towards different metal ions was studied and it was shown that under addition of Fe( $\left.\mathrm{NO}_{3}\right)_{3}$ solution in DMF the intensity of emission of complex is quenched by $82.5 \%$, what considerably surpasses the sensitivity to other ions. It allowed recommending the complex $\mathbf{2 8 5}$ for luminescent detecting of $\mathrm{Fe}^{3+}$. 
New $(N, N, N)$-tridentate ligand 286, bearing 2-aminomethylpyridyl group at enaminopyrrolo[2,3-b]quinoxalin-2-one, formed complex 287 under reaction with $\mathrm{Zn}^{\mathrm{II}}$ acetylacetonate and complex 288 under the treatment with Cd(acac) ${ }_{2}$ (Scheme 24). ${ }^{226}$ Structure and composition of complexes were determined by X-ray method. Both complexes in solid state exhibit green luminescence with emission maximum at $472 \mathrm{~nm}$ (287) and $473 \mathrm{~nm}$ (288).

Scheme 24

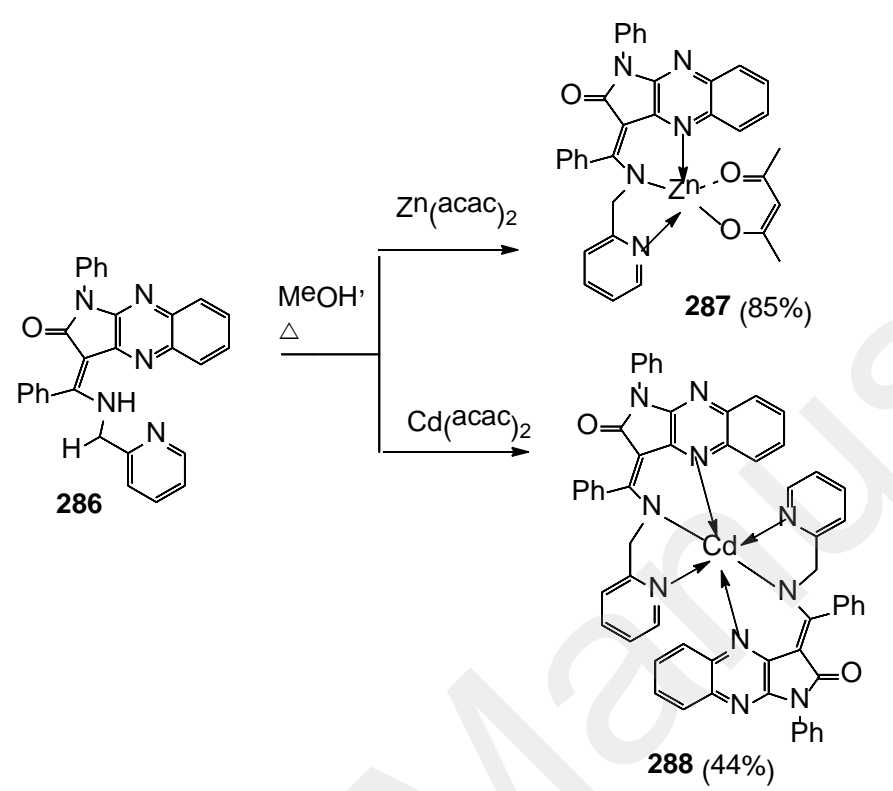

$\mathrm{Cu}^{\mathrm{I}}$ complexes 289a,b were synthesized on the basis of dipyrido[3,2-f:2,3-h]quinoxaline (dpquin) and triphenylphosphine. ${ }^{227}$ According to X-ray data, complexes are polynuclear and isostructural; and in crystals favorable paired $\pi \ldots \pi$-stacking takes place. These complexes possess an intensive luminescence in ethanol solution at room temperature with $\lambda_{\mathrm{em}}$ at $451,470 \mathrm{~nm}$, the observed red shift relative to $\mathrm{dpq}\left(\lambda_{\mathrm{em}}=419 \mathrm{~nm}\right)$ is caused by the coordination of ligand with copper atom.

$\mathrm{CN}$-substituted complex 289c in DMF solution demonstrates blue luminescence with $\lambda_{\text {em }}=$ $417 \mathrm{~nm}$, hypsochromic shift relative to ligand's emission band $\left(\lambda_{\mathrm{em}}=430 \mathrm{~nm}\right)$ takes place. $^{228}$

Structures 289, 290
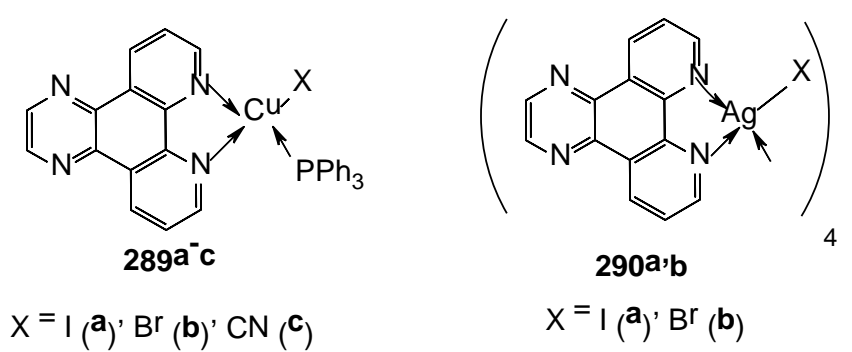

Complexes of $\mathrm{Ag}^{\mathrm{I}} \mathbf{2 9 0 a , b}$ with composition $[\mathrm{AgX}(\mathrm{dpquin})]_{4}$, were obtained by slow diffusion method for the first time. ${ }^{229}$ According to X-ray data, 290a,b are isostructural and tetranuclear. Structure 290a includes four symmetrically equivalent cations $[\mathrm{Ag}(\mathrm{dpquin})]^{+}$ 
connected in a square with four $\mu$-bridged iodine anions. Ag atom is in tetrahedral environment

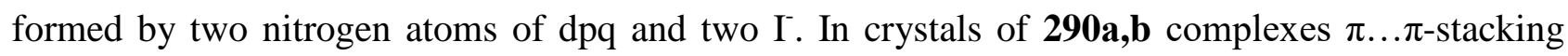
interaction and Ag-Ag interaction take place. Both complexes possess an intensive photoluminescence in ethanol solution at room temperature with emission maxima at 450, 470 and $480 \mathrm{~nm}$.

Ability of numerous benzazine derivatives to coordinate easily with metal ions is often used for their studying as sensors on metal ions. So, in work $^{230}$ the Schiff base obtained from 8aminoquinoline and 2-imidazolcarboxaldexyde was investigated as the selective and reversible luminescent hemosensor for $\mathrm{Zn}^{2+}$ ions in the mixture water/methanol with a limit of detection $5.81 \times 10^{-6} \mathrm{M}$. Another Schiff base synthesized from 1-aminopyrene and 8-hydroxyquinoline-2carboxaldehyde proved to be selective reversible luminescent chemosensor for $\mathrm{Fe}^{3+}$ ions in aqueous medium with a limit of detection $2.52 \times 10^{-8} \mathrm{M}^{231}$

\section{V.1.2. Complexes with $\mathrm{Ru}^{\mathrm{II}}$}

Among the transitional metals $\mathrm{Ru}^{\mathrm{II}}$ drew close attention in coordination chemistry due to its stability, structural novelty and a number of interesting photophysical and photochemical properties, including ability to adjust color scale of luminescence in a wide spectral interval. Complexes of $\mathrm{Ru}^{\mathrm{II}}$ represent one of the most studied classes of phosphorescent materials as they often emit in red region, though with a small quantum yield, such as complexes of $\mathrm{Ru}^{\mathrm{II}}$ with azine ligands. ${ }^{232} \mathrm{Ru}^{\mathrm{II}}$ complexes of general formula cis/trans-[Ru( $\left.\left.\mathrm{PPh}_{3}\right)_{2}(2-\mathrm{Hqlc})_{2}\right](\mathbf{2 9 1}, \mathbf{2 9 2})$ with 2quinolinarboxylic acid (2-Hqlc) as co-ligand (Scheme 25) were synthesized and studied. ${ }^{233}$ trans- $^{-}$ Isomer 291 was obtained in DCM at room temperature, whereas cis-isomer 292 - unter reflux in methanol. The structure of complexes was confirmed by X-ray method, the ruthenium atom geometry in both isomers represents the distorted octahedron. Interesting that cis-isomer 292 exhimited strong luminescence in DCM with $\lambda_{\mathrm{em}}=324 \mathrm{~nm}$ and low-intensive emission in methanol $\left(\lambda_{\mathrm{em}}=343 \mathrm{~nm}\right)$ under irradiation at $\lambda=281 \mathrm{~nm}$, at the same time trans-isomer 291 is non-emissive. For these complexes the property is defined by both metal environment geometry, and polarity of solvent.

Scheme 25
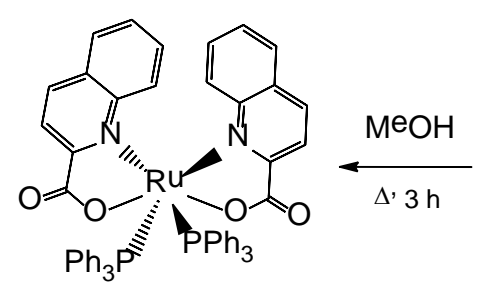

$292(78 \%)$

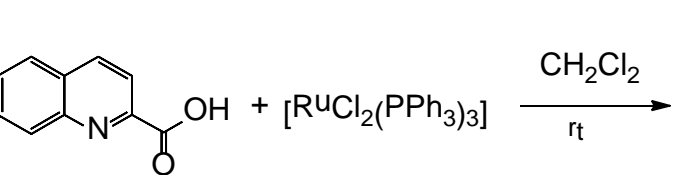

$2^{-} \mathrm{Hq} \mid \mathrm{C}$

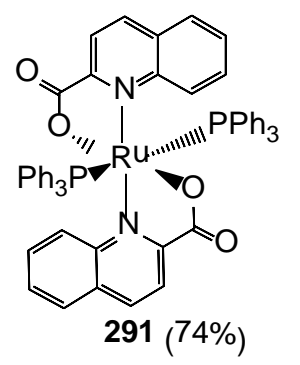


Three novel $\mathrm{Ru}^{\mathrm{II}}$ complexes 293a-c with expanded $\pi$-conjugated system in the second ligand (imidazoquinoline) were obtained and studied by spectral methods. ${ }^{234}$ Solutions of complexes in DMF demonstrate red or orange luminescence with emission maxima at $621 \mathrm{~nm}$ (293a), $607 \mathrm{~nm}$ (293b) and $603 \mathrm{~nm}$ (293c). Authors demonstrated that substitution of anthracene with pyrene or perylene in auxiliary ligand allows tuning the quantum yield and lifetime of emission.

Structures 293a-c
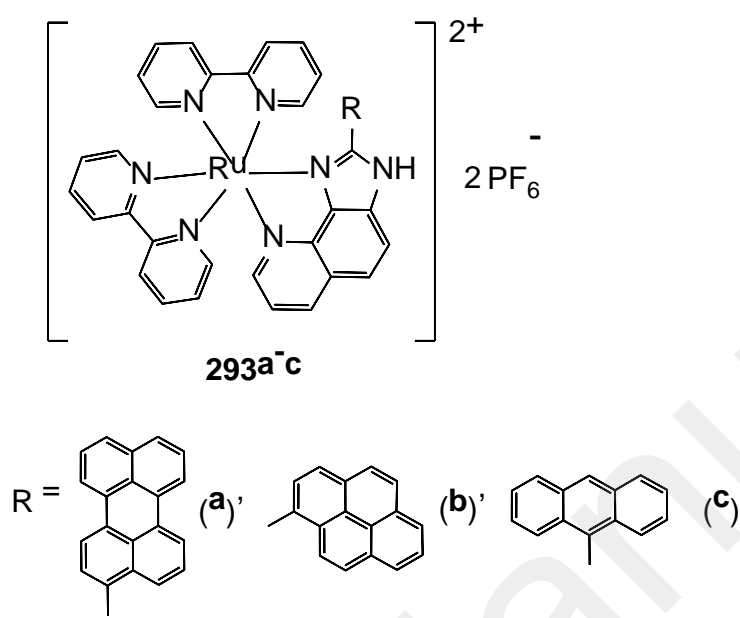

$\mathrm{Ru}^{\mathrm{II}}$ complexes with dipyrido[3,2-f:2,3- $h$ ]quinoxaline (dpq) derivatives as main ligand were described. ${ }^{174,175}$ Thus, complexes with composition $\left\{\mathrm{Ru}\left[\mathrm{dpquin}(\mathrm{COOH})_{2}\right]_{\mathrm{x}}(\mathrm{L})_{3-\mathrm{x}}\right\}^{2+}(\mathbf{2 9 4})$, where dpquin $(\mathrm{COOH})_{2}$ is 6,7-dicarboxydipyrido[3,2-f:2,3-h]quinoxaline, $\mathrm{L}=$ bpy or phen, were synthesized. ${ }^{174}$ 6,7-Dicyanoderivative dpquin was used as starting compound, its refluxing with [Ru(bpy $)_{2} \mathrm{Cl}_{2}$ ] in the ratio $1: 1$ in acetonitrile and subsequent addition of $\mathrm{NaBF}_{4}$ led to the formation of complex $\left\{\mathrm{Ru}\left[\mathrm{dpquin}(\mathrm{COOH})_{2}\right](\mathrm{bpy})_{2}\right\}\left(\mathrm{BF}_{4}\right)_{2}$ (294a). Varying conditions, type of an auxiliary ligand and a ratio of ligands, authors obtained complexes with composition $\left\{\mathrm{Ru}\left[\mathrm{dpquin}(\mathrm{COOH})_{2}\right]_{2}(\mathrm{bpy})\right\}\left(\mathrm{BF}_{4}\right)_{2} \quad$ (294b), $\quad\left\{\mathrm{Ru}\left[\mathrm{dpquin}(\mathrm{COOH})_{2}\right](\text { phen })_{2}\right\}\left(\mathrm{BF}_{4}\right)_{2} \quad$ (294c), $\left\{\mathrm{Ru}\left[\text { dpquin }(\mathrm{COOH})_{2}\right]_{2}(\right.$ phen $\left.)\right\}\left(\mathrm{BF}_{4}\right)_{2} \quad(\mathbf{2 9 4 d}), \quad\left\{\mathrm{Ru}\left[\mathrm{dpquin}(\mathrm{COOH})_{2}\right]_{3}\right\}\left(\mathrm{BF}_{4}\right)_{2} \quad(\mathbf{2 9 4 e}) . \quad$ All compounds 294 exhibit luminescent properties with red shift of emission maximum in acetonitrile from $513 \mathrm{~nm}$ (294a) to $646 \mathrm{~nm}$ (294e). LEDs created on the basis of these complexes demonstrated a possibility of tuning of electroluminescence color from blue-green to orange through the close to white ( $\lambda_{\text {em }}$ changed from $485 \mathrm{~nm}$ (294a) up to $572 \mathrm{~nm}$ (294e)). The best characteristics were shown by the device on the basis of complex 294a.

Structures 294-296 

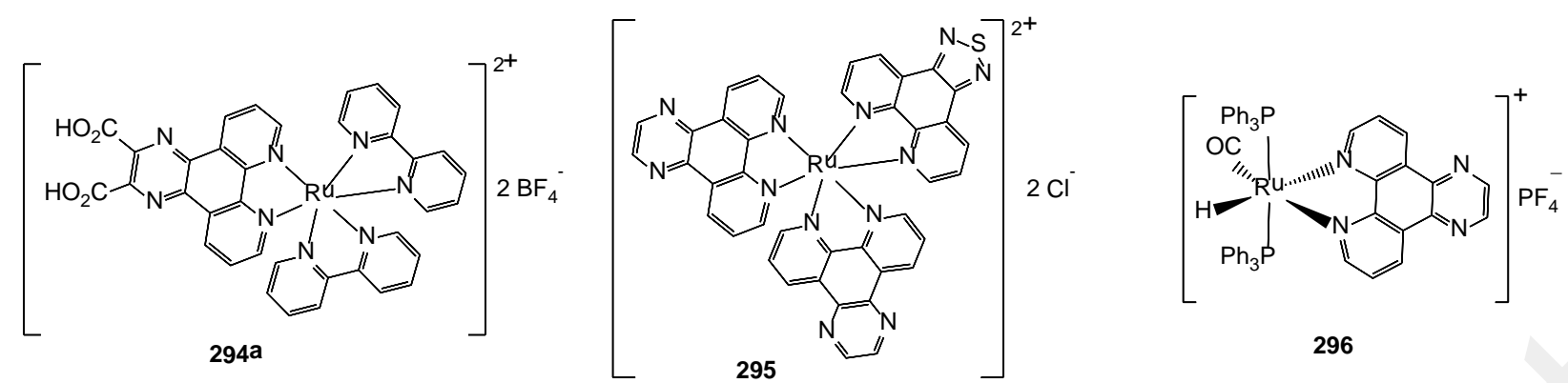

$\mathrm{Ru}^{\mathrm{II}}$ complex 295, containing two dpquin ligands and [1,2,5]-thiadiazolo-[3,4-f][1,10]phenantrolin as auxiliary ligand, was presented. ${ }^{175}$ Compound exhibits intensive red luminescence with wide emission band with maximum at $637 \mathrm{~nm}$ (in DMF and water).

The new family of the luminophores based on $\mathrm{Ru}^{\mathrm{II}}$ complexes is represented by compound 296 in which only one diimine ligand (dpquin) and four different auxiliary ligands are present. ${ }^{176}$ Complex was synthesized by ligand-substitution reaction of precursor $\left[\mathrm{Ru}(\mathrm{CO})(\mathrm{H})_{2}\left(\mathrm{PPh}_{3}\right)_{3}\right]$ with dpquin in ethanol under reflux. The structure 296 was confirmed by X-ray method. This complex exhibits orange luminescence with emission maximum at $592 \mathrm{~nm}$ in DCM at room temperature. In the vitrified environment at $77 \mathrm{~K}$, blue shifted emission ( $\lambda_{\text {em }}$ up to $531 \mathrm{~nm}$ ) and increase in excited state lifetime from $2.16 \mu$ s (in solution) up to $188.3 \mu$ s take place. Comparison of characteristics of complex 296 with other compounds of this group allows authors to conclude that the strengthening in a rigidity and $\pi$-conjugation in diimine ligand leads to the increase in luminescence effectiveness.

\section{V.1.3. Complexes with $\mathbf{P t}^{\mathrm{II}}$}

Cyclometallated $\mathrm{Pt}^{\mathrm{II}}$ complexes represent cjmpounds containing five-membered metallocycle with covalent C-Pt bond. Such complexes attracted considerable interest in the last decades and already found various applications due to tunability of their photophysical properties and possibility to apply of both singlet and triplet excitons for the increase of electroluminescence effectiveness. $^{209}$ Complexes of such type are mixed liganded, and along with a bidentate cyclometallating $\left(\mathrm{C}^{\wedge} \mathrm{N}\right)$ ligand N,O-, N,S-, O,O-, N,X- and other bi- and monodentate ligands are used as co-ligands.

For tuning the emission of platinum complexes the introduction of chromophore groups in the structure of $\left(\mathrm{C}^{\wedge} \mathrm{N}\right)$ ligand or changing the nature of co-ligand are used. The functionalized complexes 297, containing $N$-octylcarboxamide residue with chromophore group $\mathrm{R}$ in quinoline fragment and acetylacetonate (acac) as co-ligand, were synthesized. ${ }^{235}$ The structure of compounds 297c,d was confirmed by X-ray data. Studying of luminescence of these complexes in aerobic and degased solutions at ambient temperature and at $77 \mathrm{~K}$ showed that chromophore-containing compounds 297b-d exhibit double emission: fluorescence due to chromophore with $\lambda_{\mathrm{em}}<500 \mathrm{~nm}$ 
and phosphorescence with $\lambda_{\text {em }} \sim 605 \mathrm{~nm}$. In case of a pyrenyl derivative 297d, sharp increase in emission lifetime ${ }^{3}$ MLCT (up to $42 \mu$ s) was noticed, that could be due to a proximity of energies ${ }^{3}$ MLCT and ${ }^{3}$ LC in excited states and a possibility of energy transmission process between them.

Structures 297, 298

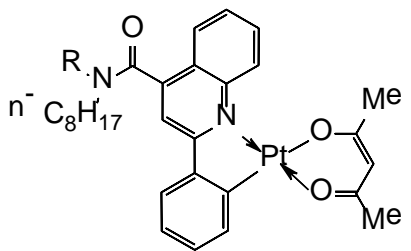

$297 a^{-} d$

$\mathrm{R}=\mathrm{H}\left(\mathbf{a}^{\prime}\right.$<smiles>c1ccc2ccccc2c1</smiles>

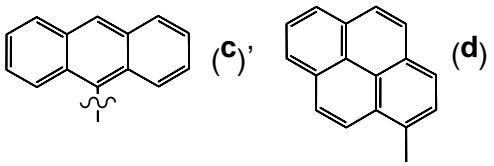

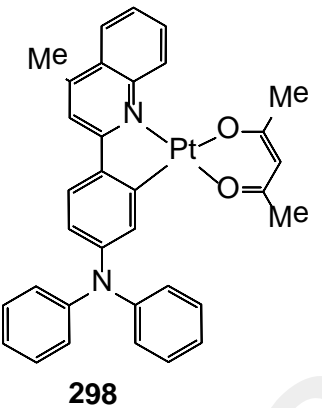

298

On the basis of quinoline $\left(\mathrm{C}^{\wedge} \mathrm{N}\right)$ ligand, bearing a strong electrondonating substituent such as triphenylamine and acac as co-ligand, cyclometallated complex 298 was obtained. ${ }^{211}$ Compound 298 demonstrated red phosphorescence with $\lambda_{\mathrm{em}}=593 \mathrm{~nm}$ and high quantum yield (0.99), it was used as a dopant for the creation of highly effective OLED.

New $\mathrm{Pt}^{\mathrm{II}}$ complexes of dendrimer structure 299-301, in which emitting base (ppq)Pt(acac/dmp) (ppq is 2,4-diphenylquinoline, acac is acetylacetone and dmp is dipyvaloylmethane) and carbazole dendron are connected with flexible $n$-butylene chain $(\mathbf{3 0 0 , 3 0 1 )}$ or rigid $n$-phenylene bridge (299) were synthesized. ${ }^{236}$ All compounds were characterized by ${ }^{1} \mathrm{H}$, ${ }^{13} \mathrm{C}$ NMR and mass-spectrometry analysis, and the structures of complexes 299b, 301a were confirmed by X-ray method. The influence of dendrons and the linker on photophysical properties and the packing of complexes were studied. The intensive bands in absorption spectra at 409-415 $\mathrm{nm}$ coresponding to $\mathrm{d} \pi(\mathrm{Pt})-\pi^{*}(\mathrm{~L})$ metal-ligand charge transfer (MLCT) mixed with the triplet LC transition were noted. All complexes exhibit bright red phosphorescence in DCM at room temperature with $\lambda_{\mathrm{em}} \sim 608 \mathrm{~nm}$. In films, emission spectra are widened and shifted to the long-wave range. It is shown that flexible $N$-butylene linker practically does not affect photoluminescent properties, but change the molecular packing that leads to the emergence of material guest function. Compounds 299-301 possess also electroluminescence, OLED devices were created on the basis of them, and the device based on the complex 301a demonstrated the best characteristics.

Structures 299-304 

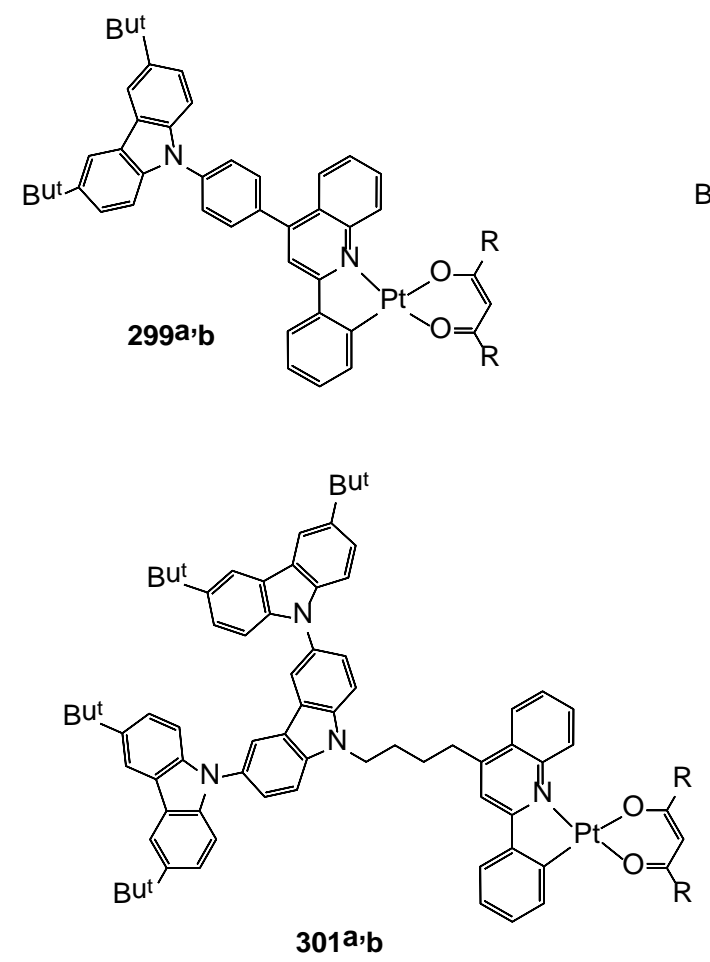

299-301: R = Me (a)' But (b)
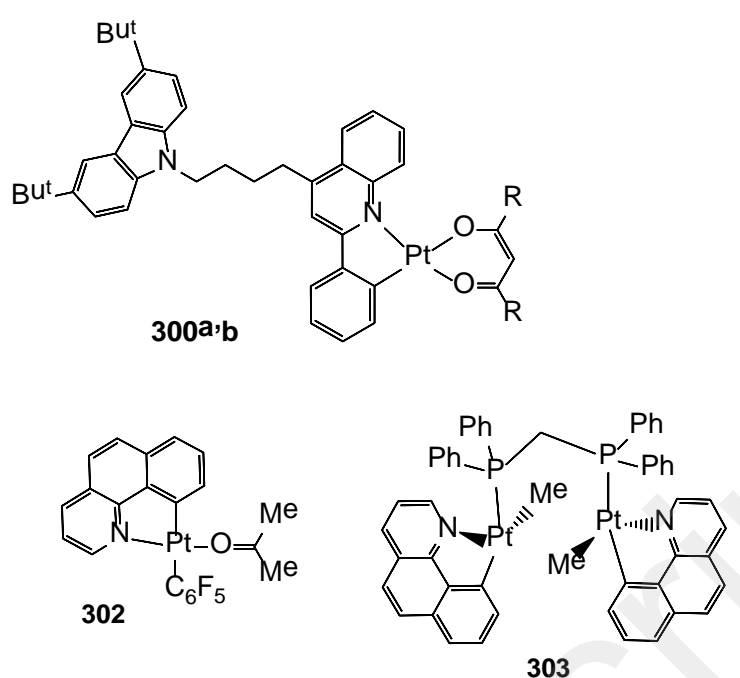

303

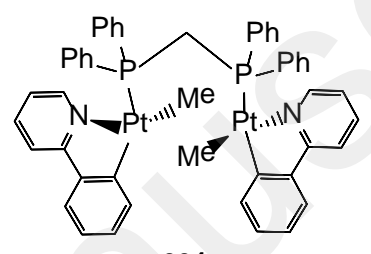

304

In some works ${ }^{171,172,237}$ benzo[h]quinoline was used as $\left(\mathrm{C}^{\wedge} \mathrm{N}\right)$ ligand for the synthesis of cyclometallated $\mathrm{Pt}^{\mathrm{II}}$ complexes 302, 303.

Complex $\mathrm{Pt}^{\mathrm{II}}$ with benzo[h]quinoline (bzql) (302) was synthesized by the reaction of activating precursor $\left[\right.$ cis- $\mathrm{Pt}(\mathrm{Ph})_{2}(\text { thf })_{2}$ ] with benzoquinoline in boiling acetone during $2.5 \mathrm{~h} .{ }^{171}$ This compound was characterized with only spectral data. Interaction of complex $\mathbf{3 0 2}$ with equimolar amount of terminal alkynes or diphenylacetylene led to the formation of the correspomding $\dot{\eta}^{2}$ alkyn-containing complexes $\left[\mathrm{Pt}(\mathrm{bzq})\left(\mathrm{C}_{6} \mathrm{~F}_{5}\right)\left(\dot{\eta}^{2}-\mathrm{HC} \equiv \mathrm{CR}\right)\right] \quad\left(\mathrm{R}=\mathrm{Ph}, \mathrm{Bu}^{\mathrm{t}}\right.$, ferrocenyl $)$ or $\left[\mathrm{Pt}(\mathrm{bzq})\left(\mathrm{C}_{6} \mathrm{~F}_{5}\right)\left(\dot{\eta}^{2}-\mathrm{PhC} \equiv \mathrm{CPh}\right)\right]$. Complex 302 exhibit luminescence in solid state and solution at room temperature and $77 \mathrm{~K}$, arising mainly from intraligand (bzq) excited state with some mixing with ${ }^{3}$ MLCT. In emission spectra bands at 477-482 $\mathrm{nm}$ and 553-595 $\mathrm{nm}$ are observed, their ratio depends on exitation wavelength, temperature and aggregate state. It should be noted that this complex demonstrates the considerable luminescent thermochromism (green at $77 \mathrm{~K}$, orange at 298 $\mathrm{K})$. The alkyne-containing complexes obtained from $\mathbf{3 0 2}$ also possess luminescent properties.

Binuclear cyclometallated complexes of methylplatinum(II), containing benzo[h]quinoline (303) or 2-phenylpyridine (304) as $\left(\mathrm{C}^{\wedge} \mathrm{N}\right)$ ligand, were described. ${ }^{237}$ Compounds were obtained by the substitution of $\mathrm{SMe}_{2}$ co-ligands in the complex $\left[\mathrm{PtMe}\left(\mathrm{SMe}_{2}\right)\left(\mathrm{C}^{\wedge} \mathrm{N}\right)\right]$ with bis(diphenylphosphino)methane in acetone at room temperature. The structures of 303 and 304 were confirmed by X-ray method. Both complexes exhibit bright red luminescence in solid state with $\lambda_{\mathrm{em}}=638 \mathrm{~nm}$ (303) and $655 \mathrm{~nm}$ (304). Authors demonstrated that complex 304 easily transfoms into binuclear $\mathrm{Pt}^{\mathrm{IV}}$ complex with composition $\left[\mathrm{Pt}_{2} \mathrm{Me}_{4}(\text { bzql })_{2}(\mu-\mathrm{I})_{2}\right]$ under the action of 
the excess of MeI in acetone at $0{ }^{\circ} \mathrm{C}$ during $1 \mathrm{~h}$, the structure of obtained product was confirmed by X-ray data.

Novel cyclometallated $\mathrm{Pt}^{\mathrm{II}}$ complexes 306-308, bearing the same $\left(\mathrm{C}^{\wedge} \mathrm{N}\right)$ ligand, бензо[h]хинолин were synthesized, and impact of modification of an auxiliary ligand on phosphorescence efficiency in comparison with the earlier synthesized complex $\mathbf{3 0 5}$ was described. ${ }^{172}$ The structure of compound $\mathbf{3 0 5}$ was confirmed by X-ray analysis, ${ }^{238}$ it exhibits an intensive luminescence with $\lambda_{\text {em }}=550 \mathrm{~nm}$ in hexane at room temperature. It was shown that the complex emits from metal-perturbed ligand-centered triplet state with a speed constant $1.4 \cdot 10^{5} \mathrm{c}^{-1}$.

Structures 305-308

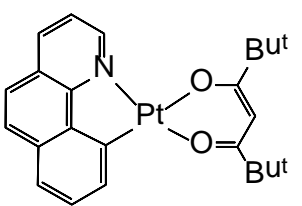

305

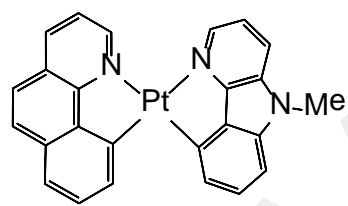

307

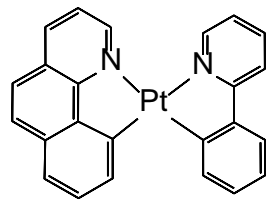

306

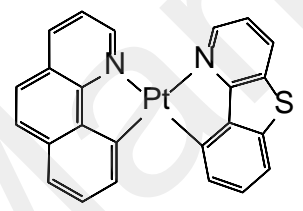

308

Authors performed calculations for structures 306-308 by means of DFT and TDDFT methods: geometry in the basic and the low-lying triplet excited state, frontal molecular orbitals, charge transfer, phosphorescence, speed constants of radiation and non-radiation processes. ${ }^{172}$ The obtained results allowed to conclude that the replacement of dipivaloylmethane with other ligands in these structures led to the improvement of rigidity which can weaken non-emissive ways. Complex 307 showed the balanced electronic and hole conductivity that is important for OLED materials. Complexes 306 and $\mathbf{3 0 8}$ could be regarded as excellent phosphorescent materials for devices with high phosphorescence quantum efficiency.

2,3-Diphenylquinoxaline represents a convenient $\mathrm{C}^{\wedge} \mathrm{N}$-ligand for the synthesis of mono and the binuclear cyclometallated $\mathrm{Pt}^{\mathrm{II}}$ complexes. ${ }^{239}$ So, the reaction of this ligand with $\mathrm{K}_{2} \mathrm{PtCl}_{4}(1.5$ equiv) in acetic acid led to the mixture of dichlorinated mono- and binuclear intermediates, which under the action of dipivaloylmethane transformed into the mixture of mono- (309) and binuclear (310) complexes. $^{237}$ Products were separated by column chromatography and characterized by NMR ${ }^{1} \mathrm{H}$ and mass spectra data. Both complexes possess fluorescence in degasated DCM at room temperature with $\lambda_{\mathrm{em}}=668 \mathrm{~nm}\left(\Phi_{\mathrm{F}}=0.14\right)(\mathbf{3 0 9})$ and $\lambda_{\mathrm{em}}=749 \mathrm{~nm}\left(\Phi_{\mathrm{F}}=0.025\right)(310)$. At $77 \mathrm{~K}$ emission spectra are structured and exhibit maxima in red or near IR range at 625, 677, 747sh nm (309), 694, $760 \mathrm{~nm}$ (310). Authors noted that binuclear complexes on the basis of 2,3- 
diphenylquinoxaline are potential phosphorescent materials which strongly absorb and brightly emit with extraordinary low energy.

Structures 309-313

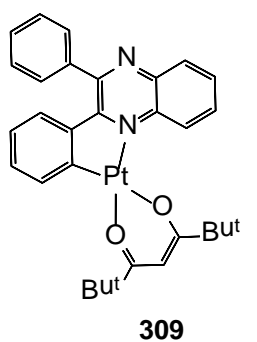

309
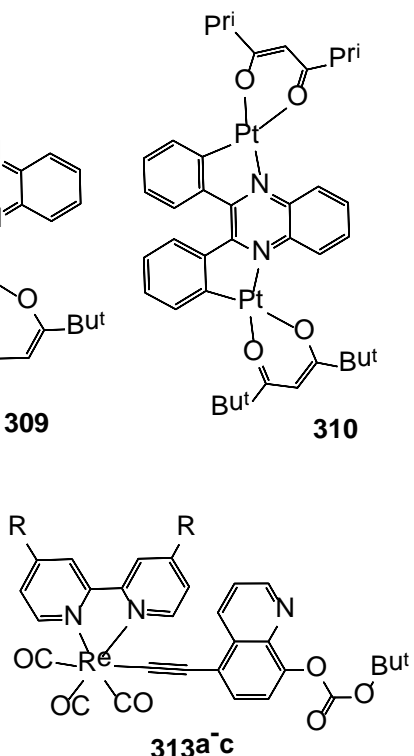

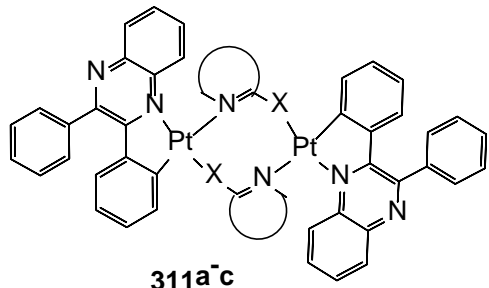

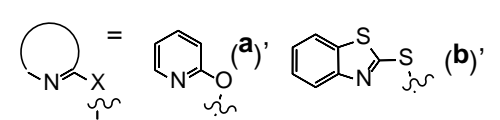

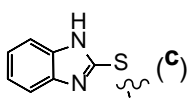

$R=H\left(a^{\prime}\right) M e(b)$

$\mathrm{But}^{\mathrm{t}}(\mathbf{c})$

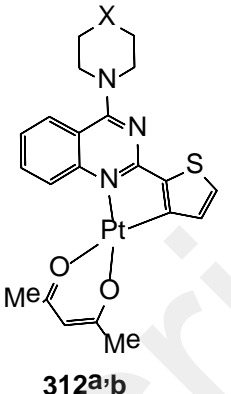

$\mathrm{X}=\mathrm{O}(\mathbf{a})^{\prime} \mathrm{CH}_{2}(\mathbf{b})$

2,3-Diphenylquinoxaline was used for the synthesis of $\mathrm{Pt}^{\mathrm{II}}$ complexes 311a-c with other structure. $^{240}$ The method includes the formation of dichloro-containing intermediate (2,3$\mathrm{Ph}_{2}$ quin) ${ }_{2} \mathrm{Pt}_{2} \mathrm{Cl}_{2}$, which interacts with auxillary ligand (2-hydroxypyridine, 2-mercaptothiazole, 2mercaptobenzimidazole) in THF in the presence of sodium hydride leading to complexes $\mathbf{3 1 1}$. The structure of 311a was confirmed by X-ray method. Complexes 311b,c exhibit luminescence in $\mathrm{DCM}$ at $25{ }^{\circ} \mathrm{C}$ in red range c $\lambda_{\mathrm{em}}=744 \mathrm{~nm}$ and $745 \mathrm{~nm}$ correspondently. At $77 \mathrm{~K}$ the blue shift of emission band took place at $37 \mathrm{~nm}$ (311b) and $17 \mathrm{~nm}$ (311c). A larger shift was observed in the PMMA film (up to $665 \mathrm{~nm}$ and $626 \mathrm{~nm}$ respectively). Authors reported that emission spectra of complex 311a could not be measured.

We synthesized complexes 312a,b on the basis of 2-(thiophen-2-yl)-4-(morpholin-4-yl) and 2-(thiophen-2-yl)-4-(piperidin-1-yl)quinazolines as $\left(\mathrm{C}^{\wedge} \mathrm{N}\right)$ ligands. ${ }^{241}$ The structure of 312a was confirmed by X-ray method. Both complexes exhibit orange luminescence in acetonitrile with emission maximum at $584 \mathrm{~nm}$ (312a) and $579 \mathrm{~nm}$ (312b).

Unlike to well-known $\mathrm{Pt}^{\mathrm{II}}$ complexes, exhibiting luminescent properties and widely presented in scientific literature, there are only few compounds of other d-element such as Re, tricarbonyl-diimine complexes of the last, containing azine or benzazine fragment with the formation of Re-C bond, also possess luminescence. So, in recent work ${ }^{242}$ the new class of complexes $\mathrm{Re}^{\mathrm{I}}$ 313a-c including 5-alkynyl-8-hydroxyquinoline derivative in the structure was presented. Compounds were obtained by the reaction of $\left[\mathrm{Re}(\mathrm{CO})_{3}(\mathrm{bpy}) \mathrm{Cl}\right]$ with 8-tbutyloxycarbonyloxy-5-ethynylquinoline in THF in the presence of AgOTf and TEA under reflux 
in nitrogen atmosphere in the dark during $24 \mathrm{~h}$. Structures of compounds were determined by ${ }^{1} \mathrm{H}$ NMR, IR and mass-spectra data as well as by X-ray data for the complex 313c.

Complexes 313 demonstrated red luminescence in DCM, in emission spectra wide bands with maxima at $643-632 \mathrm{~nm}$ were observed; in solid state the bands were blue-shifted to $595-575$ $\mathrm{nm}$. Rather long luminescence lifetime measured at low and ambient temperature allows to assume the triplet nature of emission.

\section{V.1.4. Complexes with Ir ${ }^{\text {III }}$}

Cyclometallated Ir ${ }^{\mathrm{III}}$ complexes represent the most studied class of the compounds used for the creation of the phosphorescent materials emitting in red or near IR range that was outlined in recent reviews. ${ }^{211,243}$ In work $^{243}$ a number of Ir $^{\text {III }}$ complexes on the basis of 2-phenylquinoline and 2,4-diphenylquinoline were presented. 2-Thienylquinoline was used as one more C,N-ligand for the synthesis of the Ir ${ }^{\mathrm{III}}$ complex (314), acetylacetone acts as an auxiliary ligand. ${ }^{244}$ Compound exhibits red photoluminescence with $\lambda_{\mathrm{em}}=629 \mathrm{~nm}$ in DCM. Values of HOMO and LUMO levels and energy gap were calculated from the data of cyclic voltammetry. OLED fabricated on the basis of the complex 314 demonstrated clear red phosphorescence with narrow value of the complete width on a half of height $(46 \mathrm{~nm})$, the maximum brightness of $24.000 \mathrm{~cd} / \mathrm{m}^{2}$ and $\mathrm{EQE}=11.1 \%$.

Structures 314-316

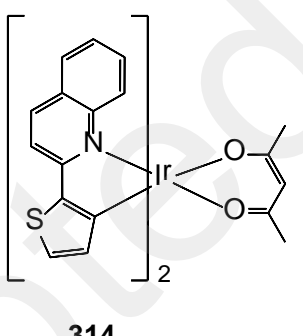

314

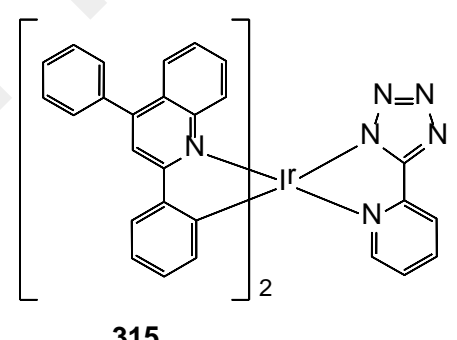

315

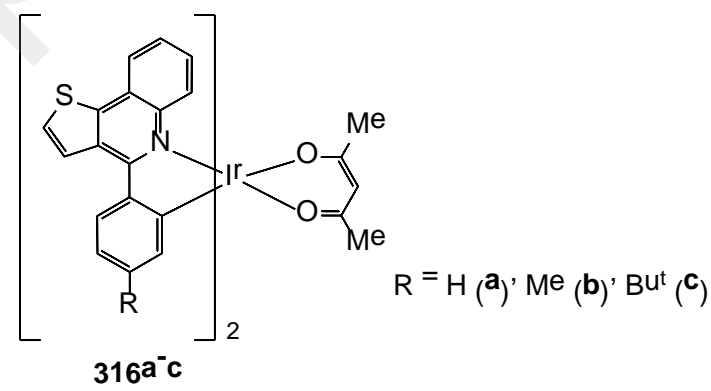

The incorporation of 2-(1H-tetrazol-5-yl)pyridine as an auxiliary ligand into iridium complex 315 based on 2,4-diphenylquinoline allowed to obtain new thermostable phosphorescent emitter. ${ }^{245}$ Photophysical characteristics demonstrated the mixing of singlet and triplet excited states. This complex exhibits orange luminescence in DCM with $\lambda_{\text {em }}=578 \mathrm{~nm}$, quantum yield 0.87 . 
Phosphorescence lifetime at room temperature is $1.34 \mu$ s. OLED fabricated with complex 315 as dopant-emitter possessed high high efficiency, brightness and a yellow-orange emission.

4-Arylthieno[3,2-c]quinoline was used as cyclometallating ligand with expanded $\pi$ conjugation system for the synthesis of $\mathrm{Ir}^{\mathrm{III}}$ complexes $316 .{ }^{173}$ The obtained complexes are thermostable ( $5 \%$ of weight lose was observed at a temperature more than $340{ }^{\circ} \mathrm{C}$ ). All complexes demonstrated red luminescence in DCM solution $\left(\lambda_{\mathrm{em}}=612-617 \mathrm{~nm}\right)$. Photoluminescence quantum yields for complexes 316 doped into 4,4'-N,N'-dicarbazolebiphenyl films at concentration of 4 weight $\%$ on air proved to be $0.46-0.47$. The luminescence lifetime of compounds 316 measured in degased DCM at ambient temperature is within 1.58-1.71 $\mu$ s that confirms their triplet- emitting nature. Red phosphorescent OLEDs were fabricated on the basis of these complexes, the device based on the complex 316a demonstrated the best characteristics with EQE $=22.9 \%$.

Quinoline containing benzimidazole at position 2 was used as an auxiliary $\mathrm{N}^{\wedge} \mathrm{N}$-лиганд in the synthesis of Ir ${ }^{\mathrm{III}}$ complexes 317, 318. ${ }^{246}$ The structure of compounds was confirmed by X-ray. It is shown that in complexes $\mathbf{3 1 7}$ the cyclometallated fragment $\left[\operatorname{Ir}(\mathrm{dfppy})_{2}\right]^{+}$(dfppy is difluorophenylpyridine) is coordinated with neutral benzimidazole molecule, forming the cationic $\mathrm{Ir}^{\mathrm{III}}$ complex. In the compound 318, the fragment $\left[\operatorname{Ir}(\mathrm{dfppy})_{2}\right]^{+}$is coordinated with benzimidazole anion forming neutral Ir ${ }^{\mathrm{III}}$ complex. All complexes differ with their molecular packing. Both types of complexes exhibited luminescence in DCM at ambient temperature; while compounds 317a-c demonstrated strong emission bands with $\lambda_{\text {em }}=558,572$ and $573 \mathrm{~nm}$ respectively and wide shoulder at $585 \mathrm{~nm}$ (317a), $600 \mathrm{~nm}$ (317b,c), complex 318 exhibited rather weak emission at 546 $\mathrm{nm}$. The luminescence quantum yields in DCM are 0.14-0.18 (317a-c) and 0.032 (318). At $77 \mathrm{~K}$ all complexes demonstrated rigidochromism with the shift of emission bands to the short-wave range. In solid state at ambient temperature all complexes demonstrate intensive luminescence, compounds 317a-c - yellow, complex 318 - orange with the red-shifted emission maxima in comparison with solutions, and the degree of shift is various for compounds 317 and $\mathbf{3 1 8}$. Authors noted distinct influence of molecular structure of these complexes on their photophysical properties. It is interesting to note that complexes 317a and 318, which differ in nitrogen atom of imidazole cycle involved in the complexation, are able to switch the luminescence between the strong $\left(\lambda_{\mathrm{em}}=558\right.$ $\mathrm{nm})$ and weak $\left(\lambda_{\mathrm{em}}=546 \mathrm{~nm}\right.$ ) luminescent state under addition of $\mathrm{NEt}_{3} / \mathrm{TFA}$ that is attributed to their structural interconversion.

Structures 317-319 

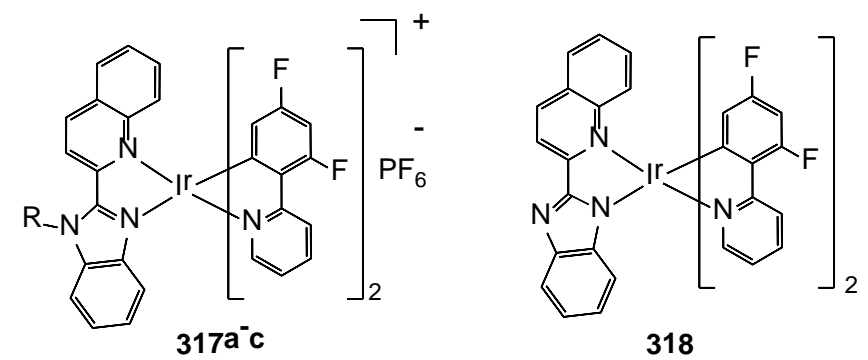

317: $\mathrm{R}=\mathrm{H}(\mathbf{a})^{\prime} \mathrm{Me}(\mathbf{b}), \mathrm{n}^{-} \mathrm{C}_{8} \mathrm{H}_{17}\left(\mathbf{c}^{\mathbf{c}}\right)$

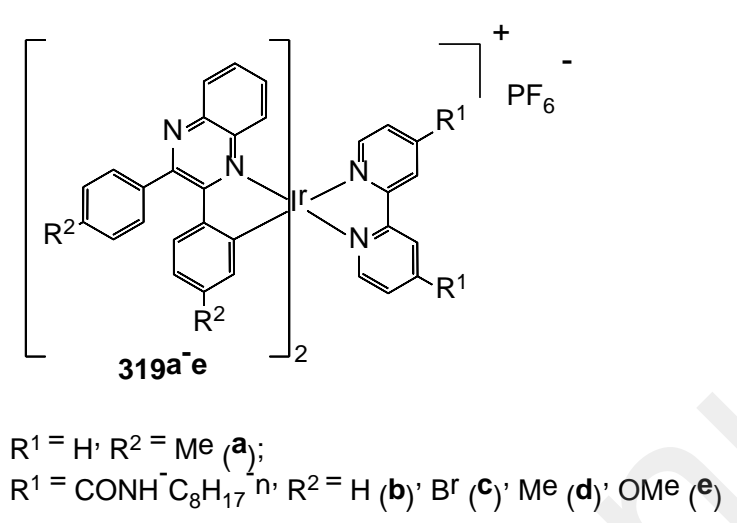

Substituted quinoxalines are also used as cyclomatellating ligands in the synthesis of Ir $^{\text {III }}$ complexes, for example, for precise tuning of luminescent properties. So, in work $^{247}$ a number of $\mathrm{Ir}^{\mathrm{III}}$ complexes (319a-e). on the basis of the $p$-substituted 2,3-diphenylquinoxalines as $\left(\mathrm{C}^{\wedge} \mathrm{N}\right)$ ligands and 2,2'-bipyridine or its 4,4'-dioctylamidoderivatives as an auxiliary ligands were synthesized Structures of compounds are characterized by spectral data and X-ray for complexes 319a and 319d. These complexes demonstrated luminescence with emission maximum at 619-640 $\mathrm{nm}$ depending on the nature of substituents and solvent, quantum yields are low (0.018-0.027). On the basis of experimental and theoretical studies of complexes $\mathbf{3 1 9}$ authors came to the conclusion that the impact of ${ }^{3} \mathrm{MLCT}$ in excited state is significant, and mixing ${ }^{3} \mathrm{MLCT} /{ }^{3} \mathrm{LLCT}$ in the most low-energy absorption and emission bands takes place.

As it was already mentioned, quinazoline derivatives are actively used as ligands for the synthesis of metalocomplexes including cyclometallated ones. ${ }^{23}$ Incorporation into the position 4 of quinazoline of 2,6-bis(trifluoromethyl)pyridyl substituent, capable to affect on molecular packing and electronic mobility due to $\mathrm{CF}_{3}$ groups, allowed to obtain $\mathrm{Ir}^{\mathrm{III}}$ complexes 320, 321 demonstrating highly effective orange-red electroluminescence. ${ }^{248,249}$ Compounds include different auxiliary ligands, they were characterized by spectral data, and the structure of complex 321 was confirmed by X-ray data. Thermal, electrochemical and photophysical properties of these compounds were studied. 

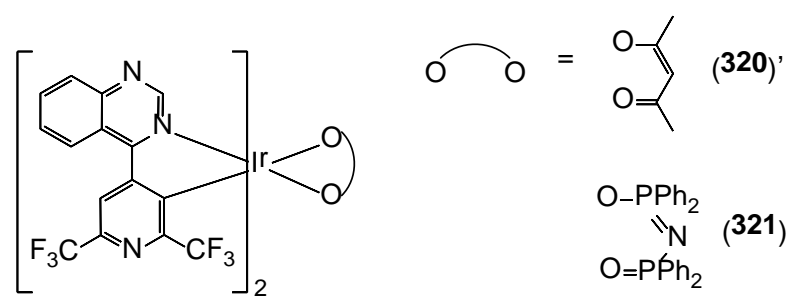

$320^{\prime} 321$

Both complexes possess strong phosphorescence in DCM solution with emission maximum at $588 \mathrm{~nm}$ and quantum yield 0.91 (320), 0.98 (321). Using these complexes as emitters, devices with one and two emitting layers (EML) were created. Comparison of their characteristics showed that for double-EML devices they were much better one-EML. Also the nature of auxiliary ligand, the replacement of acetylacetonate with tetraphenylimidodiphosphinate (complex 321) has great influence on electroluminescent efficiency. Higher characteristics were obtained for double-EML devices based on emitter 321 with addition of $\mathrm{Eu}^{\mathrm{III}}$ complex [Eu(dbm) $)_{3}$ phen] as sensitizer: the maximum brightness is $129466 \mathrm{~cd} \mathrm{~m}^{-2}$, maximum energy efficiency is $62.96 \mathrm{~cd} \mathrm{~A}^{-1}, 53.43 \mathrm{~lm} \mathrm{~W}^{-1}$ and EQE 20.2\%. The obtained results demonstrate that $\mathrm{Ir}^{\mathrm{III}}$ complexes with qunazoline $\mathrm{C}^{\wedge} \mathrm{N}$ ligand represent perspective orange-red phosphorescent materials for OLEDs.

\section{V.2. Complexes with rare earth elements}

Luminescent complexes of rare earths (REE) with organic ligands are well-known and found rather broad application due to excellent optical properties owing to the specificities of the electronic structure of these metals, to effective intramolecular energy transfer from ligand to metal atom (antenna effect), adjustable structure of complexes. ${ }^{9}$ However REE complexes have also the drawbacks, related to low chemical, optical and thermal stability. For the improvement of properties of complexes research of new organic ligands continues.

Bisamides of diethylenetriamino- $N, N$ ', $N$ '’-pentaacetic acid (DTPA), containing quinoline derivatives as amino component functioning as light harvesting fluorophore antenna, were used as polidentate ligands of $\mathrm{H}_{3} \mathrm{~L}^{2}$ and $\mathrm{H}_{3} \mathrm{~L}^{3}$ types for the synthesis of complexes with a number of $\mathrm{Ln}^{\text {III }}$ ions. ${ }^{250,251}$ Complexes with composition $\mathrm{LnL}^{2}$ (322a-h) were obtained on the basis of ligands $\mathrm{H}_{3} \mathrm{~L}^{2}$ (Scheme 26) and is was shown that 6-aminoquinoline acts as a remote sensitizer for Ln-ions. ${ }^{250}$ All compounds were characterized by mass spectra, and diamagnetic complex 322a was studied by ${ }^{1} \mathrm{H}$ NMR spectroscopy. The photophysical analysis of complexes showed that compounds Eu (322b) and Sm (322c) possess red emission, complexes Er, Yb, Nd (322e-g) emitted in near IR range (900-1500 nm) in powders and solutions. It should be noted that among compounds 322 the 
complex Eu showed the considerable quantum yield (0.04) with emission in the visible range, and complex $\mathrm{Yb}$ demonstrated the most intensive emission in IR range in non-deuterated solvent.

Scheme 26

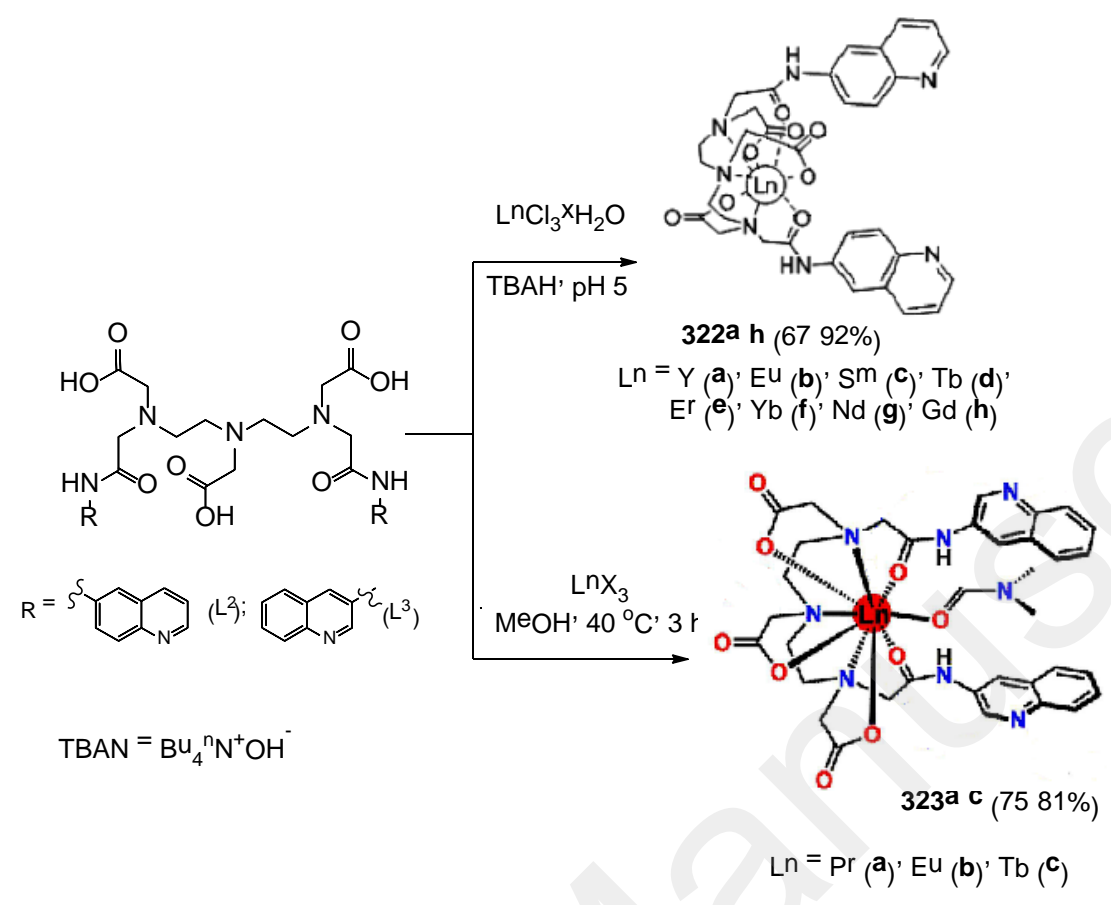

Lanthanide complexes 323 with ions of $\operatorname{Pr}(\mathbf{a}), \mathrm{Eu}(\mathbf{b}), \mathrm{Tb}$ (c) were synthesized on the basis of ligand $\mathrm{H}_{3} \mathrm{~L}^{3}{ }^{251}$ The structures were confirmed by X-ray method, nine-coordinated geometry of $\mathrm{Ln}^{3+}$ ion $\left(\mathrm{LnN}_{3} \mathrm{O}_{6}\right)$ was revealed. Complexes $\mathrm{Eu}^{\mathrm{III}}$ and $\mathrm{Tb}^{\mathrm{III}}$ exhibit strong red and green emission in solvent under excitation with light at the absorption peak of quinoline chromophore. The experiments on DNA- and a protein binding, DNA-splitting and cytotoxic study showed that complexes 323b,c have potential applications in biomedicine as the probing, therapeutic agents or potential transporters of chemotherapeutic drugs.

One more polydentate ligand containing quinoline fragments connected by O-bridge and carboxyl groups $\left(\mathrm{L}^{4}\right)$ was synthesized and stable lanthanide complexes 324a,b [ $\mathrm{Ln}=\mathrm{Eu}(\mathbf{a})$, Tb (b)] of structure $\mathrm{LnL}^{4}\left(\mathrm{H}_{2} \mathrm{O}\right)$ were obtained on its basis in aqueous medium (Scheme 27). ${ }^{252}$ The presence of water molecule in the coordination sphere was shown by mass-spectrometry method. Compounds exhibited red and green emission in water with rather high quantum yield: 0.095 for Eu of complex 324a and 0.02 for Tb complex 324b.

Scheme 27 

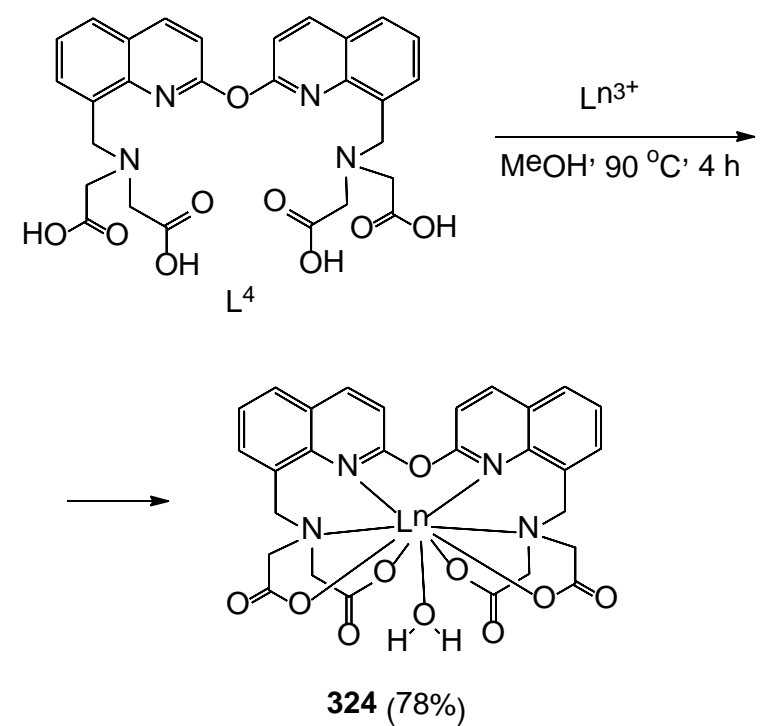

Lanthanide complexes 325, 326 with new chiral ligands containing two quinoline fragments connected with rigid 1,2-cyclohexandiamine fragment were synthesized (Scheme 28). ${ }^{253}$ According to X-ray data, the composition of complex 325a is $\left(\mathrm{L}^{5}\right) \mathrm{La}\left(\mathrm{NO}_{3}\right)_{3}$, the similarity of X-ray diffractions in powder for all complexes allows to attribute such structure for all series. Reflection and emission spectra of compounds 325, 326 at ambient temperature in powders were analysed and the possibility to obtain three different color emissions (blue, green and red) depending on the nature of chelatated ion was shown. According to authors, the obtained complexes have potential application in the field of luminescent devices.

\section{Scheme 28}

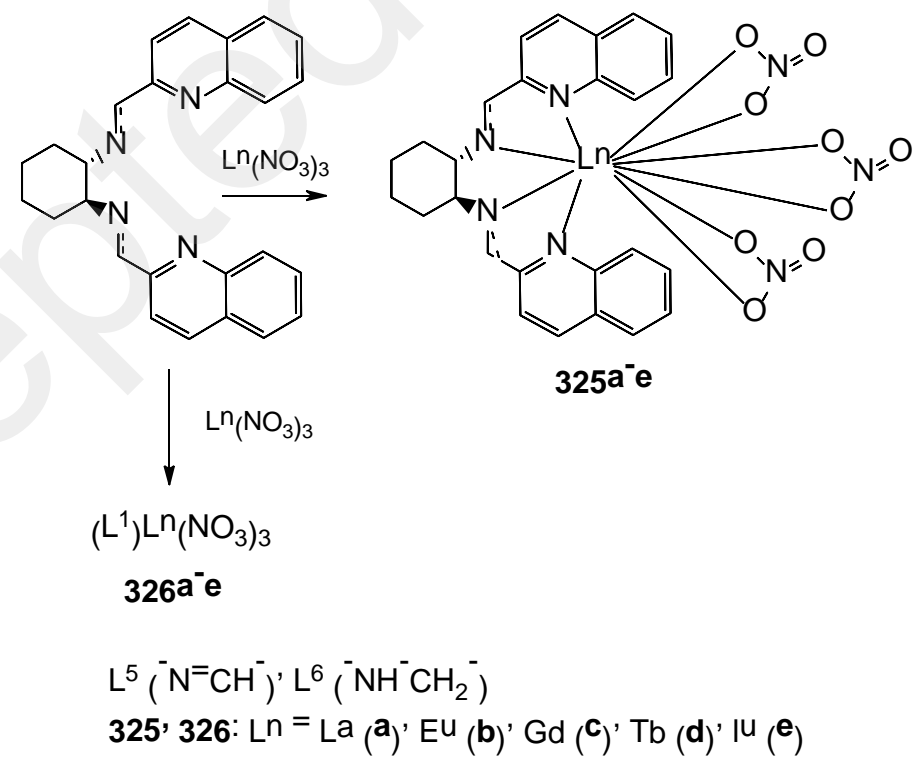

Complexes $\mathrm{Yb}$ 327, 328 were obtained on the basis of N-(2-(8hydroxyquinolinyl)methane(2-(4-imidazolyl)ethanamine) (Hnma) (Scheme 29). ${ }^{254}$ It should be noted that ligand Hnma was formed in situ through the reaction of 8-hydroxyquinolin-2-aldehyde, histamine and ytterbium salt in the mixture $\mathrm{MeOH} / \mathrm{CH}_{2} \mathrm{Cl}_{2}$ in the case of perchlorate and 
$\mathrm{MeOH} / \mathrm{CH}_{2} \mathrm{Cl}_{2} / \mathrm{DMSO}$ in the case of nitrate. The structures of complexes were determined by X-ray method, it was showm that the anion plays an important role in the type of complexation. In the complex 327, the $\mathrm{Yb}^{3+}$ ion is completely encapsulated by two ligand molecules, and perchlorate anion is not coordinated, counterbalancing the positive charge, whereas in the complex $\mathbf{3 2 8}$ the $\mathrm{Yb}^{3+}$ ion is coordinated by one ligand molecule as well as oxygen atoms nitrate anion and DMSO. The ligand nma works as antenna in complexes, activating luminescence in near IR range (900-1100 nm) with the bands characteristic for $\mathrm{Yb}^{3+}$ (Figure 2).

Scheme 29
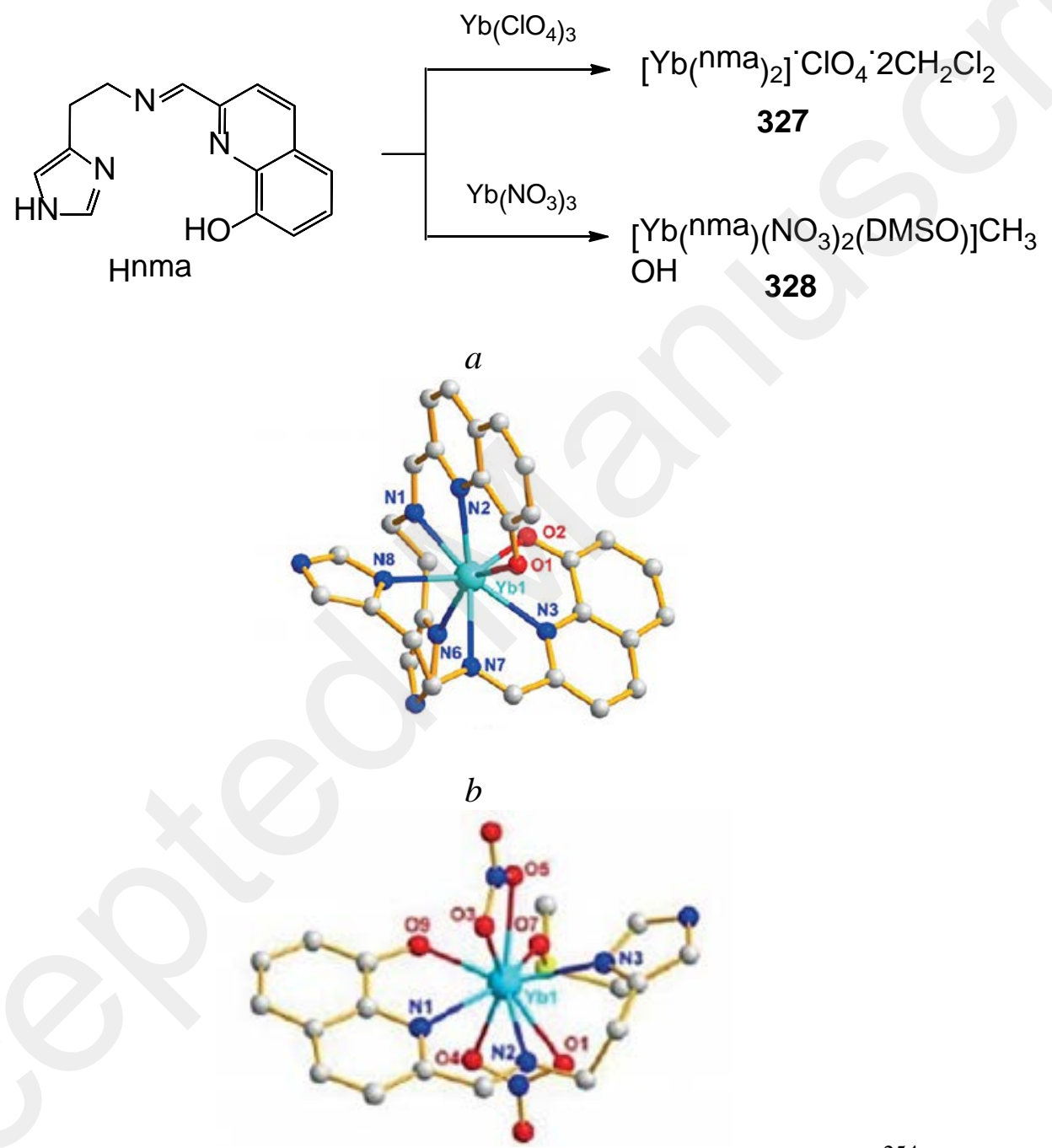

Figure 2. Molecular structure of complexes 327 (a), 328 (b). ${ }^{254}$

Complexes of some lanthanides with organic ligands continue to draw much attention also as single molecular magnets (SMM) demonstrating superparamagnetic behavior lower particular blocking temperature in molecular scale. Thus, new binuclear lanthanide complexes with composition [ $\left.\mathrm{Ln}_{2}(\mathrm{dbm})_{4} \mathrm{q}_{2}(\mathrm{MeOH})_{2}\right]$ (329: $\mathrm{Ln}=\mathrm{Nd}$ (a), Tb (b), Dy (c), Ho (d)) and $\left.\left[\mathrm{Er}_{2}(\mathrm{dbm})_{4} \mathrm{q}_{2}(\mathrm{MeOH})\right] \cdot \mathrm{MeCOMe}(\mathbf{3 3 0})\right)$, containing 8-hydroxyquinoline (q) and dibenzoylmethane (dbm) ligands were synthesized. ${ }^{255}$ The structures of compounds 329, 330 were confirmed by X-ray 
data; it was shown that $\mathrm{Ln}^{3+}$ ions ate connected with $\mu$-phenol bridges of quinoline ligads. In complexes 329 each $\mathrm{Ln}^{3+}$ ion is coordinated with two bidentate dbm molecules, two q ligands and one $\mathrm{MeOH}$ molecule. Luminescent properties of obtained compounds were studied. Complex 329a in solid stare exhibits the typical emission of $\mathrm{Nd}^{3}$ ion in near IR range with the most intensive band at $1060 \mathrm{~nm}$. Magnetic properties of polycrystalline samples of complexes 329, 330 in the temperature range 300-2 K were studied. The research of magnetism dynamics allowed revealing that complex 329c (with $\mathrm{Dy}^{3+}$ ) demonstrated single molecular magnet behavior.

Coordination polymer 331 was synthesized by reaction of 2-(pyridin-2-yl)quinolin-4carboxylic acid with europium nitrate in solvothermal conditions (Scheme 30). ${ }^{256}$ The structure of polymer as confirmed by X-ray method; europium ion proved to be octacoordinated with four oxygen atoms from two nitrate ions and four oxygen atoms from four ligands. Each ligand in binded two $\mathrm{Eu}^{3+}$ centers with a brige, as a result 1D structure forms. All nitrogen atoms are not coordinated. Polymer 331 exhibited luminescence typical for $\mathrm{Eu}^{3+}$ ion with emission bands at 592, 616, 652 and $696 \mathrm{~nm}$, the most intensive was one at $616 \mathrm{~nm}$. Under the action of $\mathrm{HCl}$ vapours on polymer the luminescence quenched more than for $90 \%$ during 120 sec. After the action of $\mathrm{NH}_{3}$ vapours the luminescence quickly returned (within $\sim 90 \mathrm{sec}$ ). After 5 cycles polymer keeped about $50 \%$ of luminescent intensity that testifies a possibility of its application as the sensor for fast visual detection of $\mathrm{HCl}$. It was shown that protonation proceeds at pyridine nitrogen atom, changes energy of ligand excited state and makes it incapable to act as the antenna for $\mathrm{Eu}^{3+}$ ion.

Scheme 30

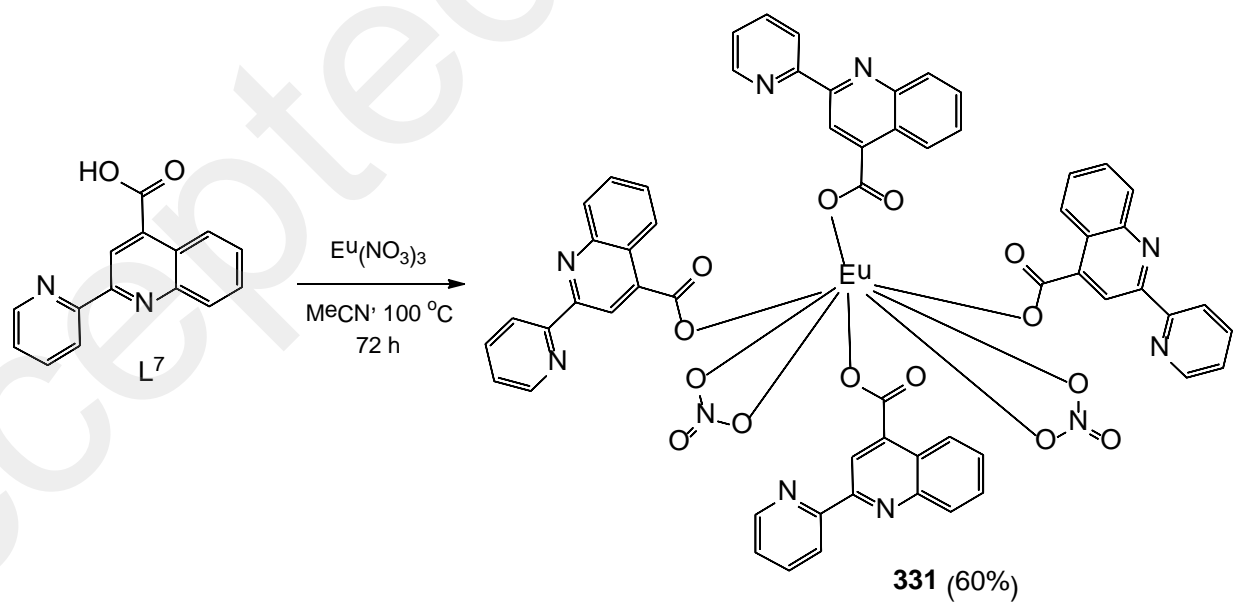

The series of lanthanide complexes 332-340, obtained on the basis of 2,3quinolinedicarboxylic acid ( $\mathrm{H}_{2}$ gldc) in solvo(hydro)thermal conditions was presented (Scheme 31). ${ }^{257}$ As it was mentioned, this acid decarboxylizes into 3-Hglc under heating above $120{ }^{\circ} \mathrm{C}$ and participates in the formation of complexes. ${ }^{221}$ All complexes were characterized by IR spectra and X-ray diffraction in powders. In the structure $332 \mathrm{~K}^{+}$ions act as structure-directing agents, implemented into the resulting crystal material. Incorporation of phenantroline (phen) led to the 
increase of system rigidity, dimer structures of complexes 333-335 are different, and complexes 335-340 are isostructural. Luminescent properties of all compounds were studied in solid state at $298 \mathrm{~K}$ or $77 \mathrm{~K}$. Compounds 332-335 exhibit red emission typical for $\mathrm{Eu}^{3+}$ with the most intensive band at $613 \mathrm{~nm}$. Complexes 333, 334, containing phen, possess higher values of luminescence lifetime than 332 due to sensibilisation not only Hglc, but also phen. Other complexes (336-340) exhibited luminescence typical for Ln ion. Hybrid materials, demonstrating strong red luminescence at concentration of 8\%, were obtained by doping of complexes 333, 334 in PMMA.

Scheme 31

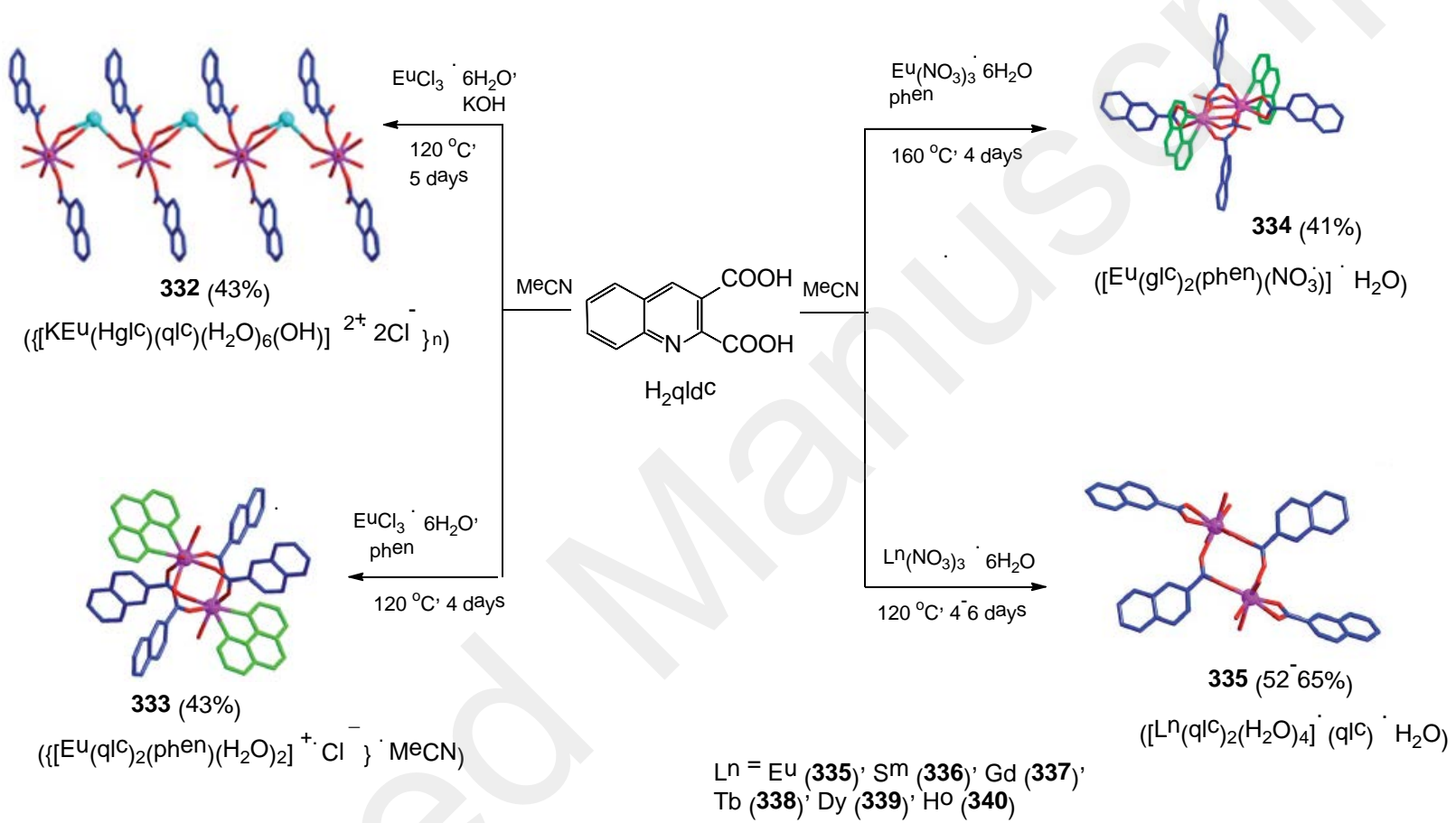

Luminescent complexes of $\mathrm{Eu}$ and $\mathrm{Tb}$ (341), (342) were obtained on the basis of dipyridoquinoxaline (dpquin). ${ }^{177}$ According to X-ray data, complexes are mononuclear. Eu ion is located in dodecaedric surroundment in the structure 341, coordinated with nitrogen atoms of dpquin ligand, two DMF molecules and three $\mathrm{NO}_{3}{ }^{-}$anions. Tb complex has heptacoordinated structure of octaedric type; nitrogen atoms of dpquin ligand, two DMF molecules and three $\mathrm{Cl}^{-}$ anions paeticipate in the coordination of metal. Both complexes are high emissive, dpquin ligand act as effective antenna; in emission spectra narrow intensive bands typical for $\mathrm{Eu}$ and $\mathrm{Tb}$ ions are observed. Authors showed prospects in application of these compounds for biomedicine.

Structures 341, 342 

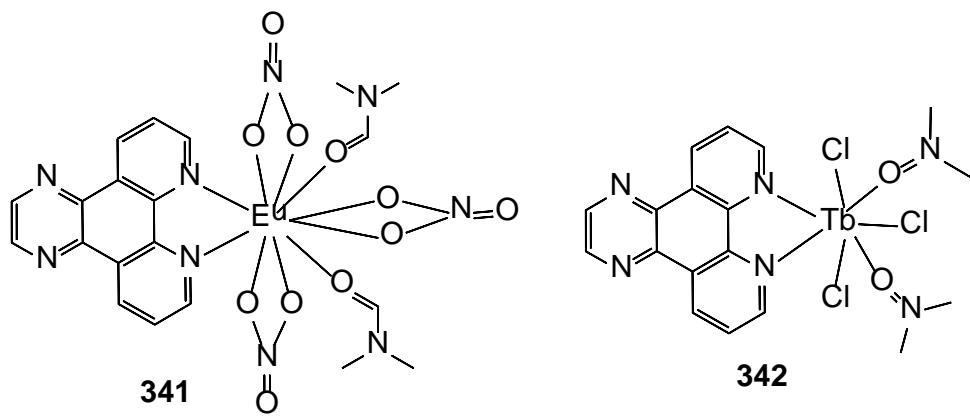

342

\section{V.3. Complexes with boron (III)}

Tetracoordinated $\mathrm{B}^{\mathrm{III}}$ complexes with $N, N$ - and $N, O$-heterocyclic ligands continue to draw much attention as bright emitting materials with a blue, green and orange luminescence. Some benzazines derivatives we reviewed ${ }^{253}$ as such ligands.

The series of $\mathrm{BF}_{2}$-complexes 343a-e was synthesized on the basis of bis(6-bromoquinolin-2yl)amine as $N, N$-ligand with subsequent substitution od bromine with $N$-aryl residue. ${ }^{259}$ All compounds were characterized by multinuclear spectroscopy, X-ray data were obtained for the complexes 343b,c,e. Complexes 343 proved to be thermostable, they exhibit intensive luminescence in DCM solution and solid state in visible range. Depending on the nature of $N$-aryl substituent the emission maximum was observed at 440-505 nm, the quantum yield was rather high (0.24-0.78), complex 343b possessing the highest quantum yield. The influence of protonation on luminescence of complex 343c was studied and it was shown that both in solution and solid state (on filter paper) the luminescence changed from green to red and back at change $\mathrm{pH}$ from 1 to 12. The obtained results demonstrated that these complexes able of emission tuning by protonation and could be regarded as good candidates for $\mathrm{pH}$ sensors, biological tests and OLED.

Structures 343-347 

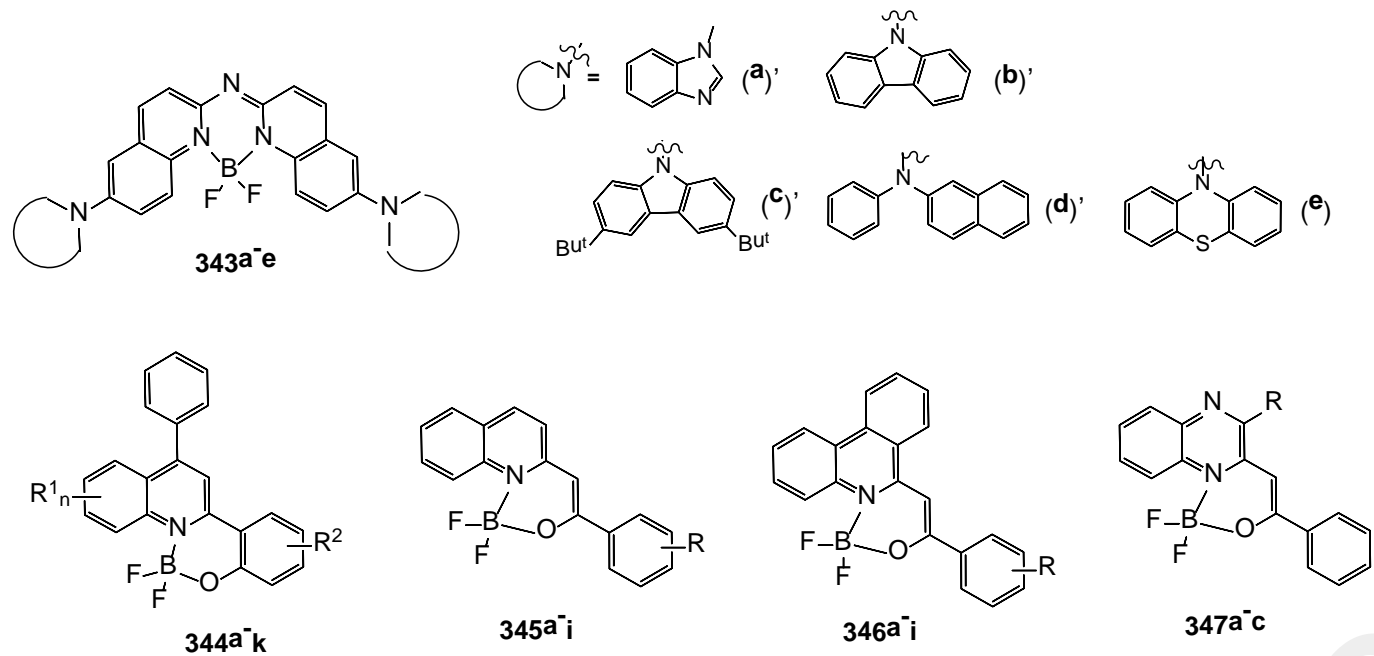

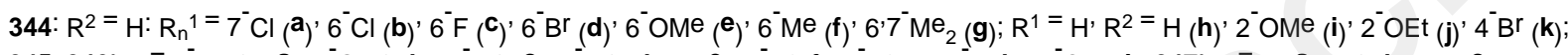

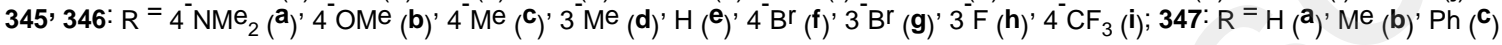

Quinoline derivatives were used as $\mathrm{N}$, $\mathrm{O}$-ligands for the synthesis of $\mathrm{BF}_{2}$-complexes 344 , 345. $^{260-262}$ Compounds 344 were synthesized on the basis of 2-(4-phenylquinolin-2-yl)phenols. ${ }^{260}$ Incorporation of phenyl residue at the position 4 of quinoline could lead to the improvement of luminescent properties in solid state due to the decrease of $\pi \ldots \pi$-interaction between chromophores. The structure of complexes was confirmed by ${ }^{1} \mathrm{H},{ }^{13} \mathrm{C},{ }^{19} \mathrm{~F}$ and ${ }^{11} \mathrm{~B}$ NMR, massspectrometry data and by X-ray for compound 344i. All complexes exhibited luminescence in chloroform solution with emission maximum at 467-538 nm and large Stokes shift (up to 10231 $\mathrm{cm}^{-1}$ for $\mathbf{3 4 4 j}$ ) and low quantum yield (0.03-0.12). Emission maxima of complexes in solid state are bathochromically shifted relative to solution (5-20 nm shift), luminescence is more intensive. Electrochemical properties of complexes were studied by CV method. Values of HOMO (-5.32-$6.10 \mathrm{eV})$ and LUMO (-2.64--3.46 eV) energies as well as energetic gap (2.14-2.77 eV) were calculated, they were found to be close to values $\mathrm{Alq}_{3}$ complex. ${ }^{260}$ The obtained results demonstrate the existence an electron-transport properties of $\mathrm{BF}_{2}$ complexes 344 .

Difluoriborates, obtained on the basis of 2-benzoylmethylenequinolines 345a-i, were characterized by ${ }^{1} \mathrm{H},{ }^{13} \mathrm{C},{ }^{15} \mathrm{~N},{ }^{19} \mathrm{~F}$ and ${ }^{11} \mathrm{~B}$ NMR, X-ray difraction, quantum chemistry, and X-ray analysis for compounds 345b-f,i. ${ }^{261}$ In solutions of these complexes through space spin-spin interaction constants $\left({ }^{\mathrm{TS}} \mathrm{J}\right.$ ) between ${ }^{19} \mathrm{~F}$ and ${ }^{1} \mathrm{H}(8)$ or ${ }^{13} \mathrm{C}(8)$, nuclei were observed. The nature of bond in $\mathrm{NBF}_{2} \mathrm{O}$ fragment was studied, it was shown that $\mathrm{B}-\mathrm{N}$ interaction is dative while bonds $\mathrm{B}-\mathrm{O}$ and B-F are polar covalent. The clear dependence between the nature of the substituent $\mathrm{R}$ and the constant ${ }^{1} J\left({ }^{11} \mathrm{~B},{ }^{19} \mathrm{~F}\right)$ was revealed. Complexes 345a-i exhibit strong luminescence in chloroform with $\lambda_{\text {em }}=435-520 \mathrm{~nm}$ and quantum yield $0.37-0.94$ depending on the nature of substituent. ${ }^{262}$ The highest quantum yields were registrated for compounds 345a,b $(0.86,0.94)$ with electron donor substituent $\mathrm{R}$, the largest bathochromic shift in absorption and emission spectra was observed for 
compound 345a (with 4-NMe 2 ). Authors demonstrated that absorption and emission spectra of such complexes can be well simulated by quantum chemistry methods.

In recent work, ${ }^{263} \mathrm{BF}_{2}$-complexes $346 \mathbf{a}-\mathbf{i}$ were obtained on the basis of phenacylphenantridine with the same substituents $\mathrm{R}$ as in compounds $\mathbf{3 4 5}$. Phenantridine can be regarded as analog of benzoannelated quinoline or isoquinoline. Authors studied the effect of substituent and double benzoannelation on photophysical properties of complexes 346 in comparison with quinoline complexes 345 obtained earlier ${ }^{262}$ by experimental and quantum methods. It was shown that the substituent $\mathrm{R}$ has the same impact, as in compounds $\mathbf{3 4 5}$. Due to 4$\mathrm{NMe}_{2}$ groups present in 346a, the considerable bathochromic shift in absorption and emission spectrum takes place that is due to charge transfer in exited state for this compound. Quinoid structure, arising in the course of this process, limits the mobility in exited state and explains high fluorescence quantum yield for complex 346a (0.81). However, in general complexes 346 possess less intensive luminescence $\left(\Phi_{\mathrm{F}}\right.$ for $\left.\mathbf{3 4 6 b}-\mathbf{i}=0.67-0.09\right)$ than analogs 345 ( $\Phi_{\mathrm{F}}$ for $\mathbf{3 4 5 b} \mathbf{b} \mathbf{i}=0.94-$ $0.37)$.

New quinoxaline- $\beta$-ketoiminate boron difluoride complexes 347a-c possessing tunable and fascinating photophysical properties $\left(\lambda_{\text {em }}=467-482 \mathrm{~nm}, \Phi_{\mathrm{F}}=0.78-0.92\right)$ have been developed. ${ }^{264}$ Compounds 347 demonstrated unusual acidochromic behavior triggered by acid vapor.

We synthesized $\mathrm{BF}_{2}$ and $\mathrm{BPh}_{2}$ complexes 348a-d, 349a-d with five-membered chelate cycle on the basis of 2-methyl-8-oxyquinoline and its 6,7-difluoroderivative. ${ }^{265}$ Another ligand, 2-(2hydroxyphenyl)-3H-quinazolin-4-one was used for the preparation of complexes 350a,b, 351 with six-membered boron-containing cycle.

Structures 348-351

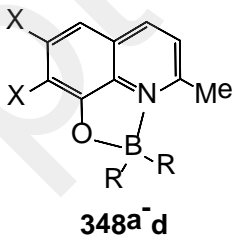

$R=P h: X=H(a), F(b) ;$
$R=F, X=H(c), F(d)$

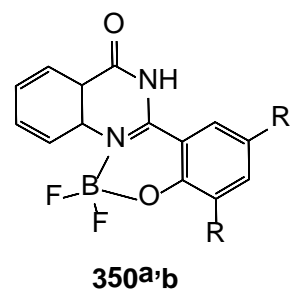

$R^{=} H\left(a^{\prime} B^{u^{t}}(\mathbf{b})\right.$

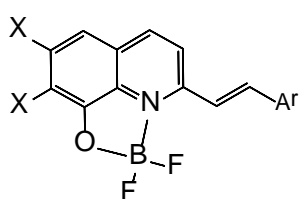

$349 a^{-} d$

$\mathrm{R}=\mathrm{Ph}: \mathrm{X}=\mathrm{H}(\mathbf{a}){ }^{\prime} \mathrm{F}(\mathbf{b})$;

$R=F^{\prime} X=H_{(c)}{ }^{\prime} F(d)$;

$\mathrm{Ar}^{\mathrm{r}}={ }^{-} \mathrm{MeOC}_{6} \mathrm{H}_{4}$

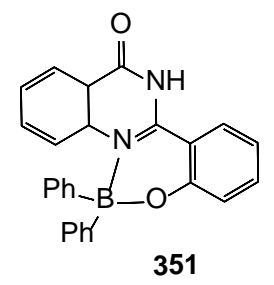


All complexes were characterized by NMR ${ }^{1} \mathrm{H},{ }^{19} \mathrm{~F}$ and ${ }^{11} \mathrm{~B}$ spectroscopy, mass-spectrometry data; X-ray analysis was performed for compound 349a. Compounds exhibit luminescent properties with emission maximum at 390-502 $\mathrm{nm}$ and large Stokes shift, the colour and intensity are dependent on the nature of substituent both in ligand and boron atom. Thus, the presence of fluorine atoms in benzene ring of complexes 348 led to significant red shift of emission band and to increase in quantum yield from 0.005 to 0.025 . Diphenylboron complexes 349a,b exhibit higher quantum yield relative to difluoroboron ones ( 0.18 and 0.29 correspondently). The incorporation of $t$-butyl group into phenol fragment of compound 350b led to long-wave shift of emission band and the

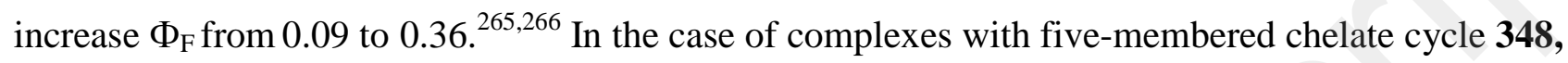
349 the luminescence of diphenylboron derivatives (348a,b, 349a,b) exceedes the luminescence of difluoroboron complexes (348c,d, 349c,d).

\section{Conclusion}

During the last years there has been a growing interest to investigation of organic and organometallic push-pull chromophores fro their futher application in luminescent, photovoltaic and other optoelectronic devices. Indeed, in the context of "green" energy and reducing energy consumption, the development of new solar storage materials and the creation of energy-efficient lighting devices play a key role. In the field of new technologies, data storage and optical processing are important, and highly efficient materials with nonlinear optical properties are required. With respect to these applications, more preference is now given to organic and organometallic materials containing $\pi$-conjugated core than to inorganic materials due to lower cost, easier tunability and low toxicity.

In this context, the incorporation of benzazine fragments into the structure of benzazine fragments is interesting: as electron-deficient heterocycles, benzazines exhibit electron-acceptor character and can be used as acceptor part in push-pull structures, leading to ICT. Benzazine derivatives have a stronger electron-acceptor effect on the system than their pyridine and diazine counterparts. Benzazines can also be used as $\pi$-conjugated linkers. A lone electron pair of nitrogen atom can easily interact with a proton or metal cation, allowing for tuning of photophysical and electronic properties of target compound.

Analysis of the literature shows that various quinoline derivatives and their aza-analogs continue to attract attention as promising luminescent materials and components for optoelectronics. The review presents the main approaches to the synthesis and functionalization of $\pi$-conjugated benzazine chromophores. Traditional methodologies include the formation of benzazine ring using different condensation reactions. More modern methods consist in functionalization of already 
formed benzazine core with application of Knoevenagel condensation and cross-coopling of different types from commercially available methyl- and halogen-substituted benzazines.

Many quinoline chromophores have found widespread use or appear promising. For example, ways of modifying structure 19 to provide a molecular switch and logic gates for processing information are discussed. ${ }^{267}$ This review does not reveal any clear trends in the main uses of quinoline dyes. While for many quinoxaline chromophores, especially for 5,8diarylquinoxaline derivatives, there is a clear trend - their design is implemented for photovoltaic devices as small molecules or polymers. The quinoxaline backbone is commonly used in systems such as the $\pi$-conjugated linker or the auxiliary electron acceptor group. Quinoxaline-containing polymers with different chiral side chains demonstrate a new class of materials with circularly polarized luminescence. According to our knowledge, such dyes are not yet used in industry; they are closest to commercial adoption from all the structures mentioned in this review. Another promising application of quinoxaline chromophores is related to nonlinear optical properties: recently interesting structures with $2^{\text {nd }}$ order nonlinear optical properties, in which the quinoxaline fragment acts as $\pi$-conjugated linker or electron-acceptor part, have been obtained.

The development of quinazoline chromophores has started relatively recently, and so far a limited number of molecules have been developed, possibly due to the small amount of commercially available quinazoline-type reagents. However, recently such a promising direction for the application of these heterocycles, as the creation of pure organic chromophores for white OLEDs by partially protonating one of several nitrogen atoms of heterocyclic molecule and selecting a certain ratio of protonated to untonated forms of the benzazine derivative, has been proposed.

Annelation of benzazines with various fragments leads to new properties and applications. Dibenzo- and phenanthrolinquinazoline derivatives already find use as electron-transport, holetransport layers, bis(indoloquinoxalinyl) derivatives with various bridges represent promising emitters for phosphorescence OLEDs, derivatives of acenaphthoquinoxalinediimide are of interest as non-mullerene components for organic solar cells.

New properties of annelated benzazines were also revealed. The modification of quinoxaline with carbohelicene or tetrathiagelicene allowed the creation of non-planar molecular systems exhibiting circular-polarized luminescence (CPL). The V-shaped thiadiazole annelated quinoxaline molecules demonstrated an example of creating an emission system in a polar aqueous environment with double emission change. The novel T-shaped tetraphenylethylene substituted derivatives of acenaphthene- and phenanthrenquinoxaline showed aggregation-induced emission and mechanochromism as cyclomellating ligands with an extended $\pi$-conjugated system. 
Much attention is paid to obtaining coordination compounds of benzazines with various metals: mono-, binuclear, cyclometallated, possessing dendrimer or polymer structure, exhibiting luminescent properties in a wide spectral range. Pure organic benzazine derivatives are used in promising directions associated with the design of fluorophores for controlled molecular photo switches; emitters exhibiting white emission; fluorophores with aggregation-induced emission in the red and near IR regions, which is important for biovisualization and biological research. Complexes of benzazines with such metals as Pt, Ir are already used or presented as promising high-performance phosphorescence emitters for OLED with tunable emission. Complexes of benzazine ligands with rare-earth elements possess unique chemical and photophysical properties, these structures are promising for biomedicine as probing and therapeutic agents. Compounds of lanthanides with functionalized benzazines also attracted attention as single-molecule magnets showing superparamagnetic behavior.

Despite the progress made in synthesizing and investigating functionalized benzazines, there are still challenges to be solved. One of them is related to the development of atom-economic and low-stage synthetic approaches using metal-non-catalyzed reactions, which will bring the processes closer to the basic principles of "green chemistry", reduce the negative impact on the environment and economic costs.

Another problem is related to the design of highly rigid benzazine ligand structures to produce metal complexes capable of exhibiting the effect of thermally activated delayed fluorescence (TADF). In such compounds, the energy of both singlet and triplet excitons can be realized as emission through the singlet state, resulting in high quantum yields. TADF materials present an alternative to triplet emitters in OLEDs, which are characterized by low quantum phosphorescence yield.

The work was carried out with financial support from the Russian Foundation for Basic Research (grant number 18-03-00112), Program of Ural Division of RAS (project № 18-3-3-16) and State Contract (№ AAAA-A19-119012290117-6).

Figure 1 is published with permission of The Royal Society of Chemistry Publishing, and figure 2 - with the permission of Wiley Publishing.

\section{REFERENCES}

1. Highly Efficient OLEDs with Phosphorescent Materials (Ed. H. Yersin). Wiley-VCH, Weinheim, 2008

2. Lanthanide Luminescence, Photophysical, Analytical and Biological Aspects. Vol. 7 (Eds. P. Hannienen, H. Harma). Springer, Heidelberg, 2011

3. Luminescence: from Theory to Applications (Ed. C. Ronda). Wiley-VCH, Weinheim, 2008 
4. Organic Light Emitting Diode (Ed. M. Mazzeo). Sciyo, Rijeka, 2010

5. M.N.Bochkarev, A.G.Vitukhnovsky, M.A. Katkova. Organic Light Emitting Diode (OLED). Dekom, Nizhny Novgorod, 2011

6. W.Hu, Z.Bao, K.Muellen. J. Mater. Chem., 22, 4134 (2012)

7. P.P.Zak, V.A.Lapina, T.A.Pavich, A.V.Trovimov, N.N.Trofimova, Yu.B.Tsaplev. Russ. Chem. Rev., 86, 831 (2017)

8. A.P.Pushkarev, M.N.Bochkarev. Russ. Chem. Rev., 85, 1338 (2016)

9. M.A.Katkova, A.G.Vitukhnovsii, M.N.Bochkarev. Russ. Chem. Rev., 74, 1089 (2005)

10. J.Liang, L.Ying, F.Huang, Y.Cao. J. Mater. Chem. C, 4, 10993 (2016)

11. S.Mukherjee, P.Thilagar. Dyes Pigm., 110, 2 (2014)

12. E.Zhang, W.Xia, X.Yan. Molecules, 21, 1615 (2016)

13. D.Chen, S-J.Su, Y.Cao. J. Mater. Chem. C, 2, 9565 (2014)

14. D.Dini, M.J.F.Calvete, M.Hanack. Chem. Rev., 116, 13043 (2016)

15. G.J.Hedley, A.Ruseckas, I.D.W.Samuel. Chem. Rev., 117, 796 (2017)

16. O.Ostroverkhova. Chem. Rev., 116, 13279 (2016)

17. S.Achelle, N. Plé. Curr. Org. Synth., 9, 163 (2012)

18. S.Achelle, C.Baudequin. Targets Heterocycl. Systems, 17, 1 (2013)

19. S.Achelle, J.Rodríguez-López. ChemistrySelect, 3, 1852 (2018)

20. S.Achelle, C.Baudequin, N. Plé. Dyes Pigm., 98, 575 (2013)

21. S.Achelle, N. Plé, A.Turck. RSC Adv., 1, 364 (2011)

22. G.N.Lipunova, E.V.Nosova, T.V.Trashakhova, V.N.Charushin. Russ. Chem. Rev., 80, 1115 (2011)

23. G.N.Lipunova, E.V.Nosova, V.N.Charushin, O.N.Chupakhin. Curr. Org. Synth., 15, 793 (2018)

24. C.W.Tang, S.A.Van Slyke. Appl. Phys. Lett., 51, 913 (1987)

25. S.Yuan, R.Tan, H.Lan, S.Xiao. Chem. Lett., 43, 1130 (2017)

26. J.Xiong, Z.Li, J.Tan, S.Ji, J.Sun, X.Li, Y.Huo. Analyst, 143, 4870 (2018)

27. S.Zhu, W.Lin, L.Yuan. Dyes Pigm., 99, 465 (2013)

28. L.Li, P.Wang, Y.Zhang, Y.Wu, Z.Chen, C.He. J. Mol. Struct., 1051, 23 (2013)

29. S.Fu, L.Wang, H.Dong, J.Yu, L.Xu, J.Xiao. Tetrahedron Lett., 57, 4633 (2016)

30. R.Flores-Noria, R.Vázquez, E.Arias, I.Moggio, M.Rodríguez, R.F.Ziolo, O.Rodríguez, D.R.Evans, C.Liebig. New J. Chem., 38, 974 (2014)

31. R.Cinar, J.Nordmann, E.Dirksen, T.J.J. Müller. Org. Biomol. Chem., 11, 2597 (2013)

32. M.J.Mphahlele, A.O.Adeloye. Molecules, 18, 15769 (2013)

33. M.F.Budyka, V.M. Li, N.I.Potashova. High Energy Chem., 47, 107 (2013)

34. M.F.Budyka, N.I.Potashova, T.N.Gavrishova, V.M.Li. High Energy Chem., 48, 185 (2014)

35. M.F.Budyka, V.M.Li. High Energy Chem., 52, 103 (2018) 
36. O.Kharchenko, V.Smokal, A.Krupka, A.Kolendo. Mol. Cryst. Liq. Cryst., 640, 71 (2016)

37. V.Smokal, A.Krupka, O.Kharchenko, O.Krupka, B.Derkowska-Zielinska, A.Kolendo. Mol. Cryst. Liq. Cryst., 661, 38 (2018)

38. M.F.Budyka, K.F.Sadykova, T.N.Gavrishova. J. Photochem. Photobiol A: Chem., 241, 38 (2012)

39. M.F.Budyka, N.I.Potashova, T.N.Gavrishova, V.M.Lee. High Energy Chem., 46, 309 (2012)

40. M.F.Budyka, T.N.Gavrishova, N.I.Potashova, O.V.Chashchikhin. High Energy Chem., 49, 237 (2015)

41. M.F.Budyka, V.M.Lee, T.N.Gavrishova. J. Photochem. Photobiol. A: Chem., 279, 59 (2014)

42. M.F.Budyka, V.M.Li. Mendeleev Commun., 24, 140 (2014)

43. M.F.Budyka, V.M.Li, T.N.Gavrishova. High Energy Chem., 48, 376 (2014)

44. O.V.Chashchikhin, M.F.Budyka. Photochem. Photobiol. Sci., 16, 1252 (2017)

45. O.V.Chashchikhin, M.F.Budyka, T.N.Gavrishova, V.M.Li. RSC Adv., 7, 2236 (2017)

46. G.Wu, Q.Cao, M.Li, X.Tang, K.Chiu, W.Lai, Q.Tong. J. Photochem. Photobiol. A, 355, 487 (2018)

47. L.Li, P.Wang, Y.Hu, G.Lin, Y.Wu, W.Huang, Q.Zhao. Spectrochimica Acta A, 139, 243 (2015)

48. D.Tzeli, I.D.Petsalakis, G.Theodorakopoulos. Phys. Chem. Chem. Phys., 18, 32132 (2016)

49. R.P.Zanocco, S.Valdebenito, Y.Gidi, G.Zapata-Torres, E.Lemp, S.Nonell, A.L.Zanocco. Photochem. Photobiol., 94, 1092 (2018)

50. Z.Guo, A.Shao, W-H.Zhu. J. Mater. Chem. C, 4, 2640 (2016)

51. O.V.Serdyuk, I.V.Evseenko, G.A.Dushenko, Yu.V.Revinskii, I.E.Mikhailov. Russ. J. Org. Chem., 48, 78 (2012)

52. I.E.Mikhailov, D.A.Svetlichnyi, O.N.Burov, Yu.V.Revinskii, G.A.Dushenko, V.I.Minkin. Russ. J. Gen. Chem., 85, 1074 (2015)

53. I.E.Mikhailov, D.A.Svetlichnyi, O.N.Burov, G.A.Dushenko, Yu.V.Revinskii, S.V.Kurbatov. Russ.

J. Gen. Chem., 86, 989 (2016)

54. S.Achelle, J.Rodríguez-López, F.Robin-le Guen. J. Org. Chem., 79, 7564 (2014)

55. I.Mangalagiu, T.Benneche, K.Undheim. Tetrahedron Lett., 37, 1309 (1996)

56. C.Huang, Y.Fu, H.Fu, Y.Jiang, Y.Zhao. Chem. Commun., 6333 (2008)

57. J.Dhuguru, W.Liu, W.G.Gonzalez, W.M.Babinchak, J.Miksovska, R.Landgraf, J.N.Wilson. J. Org. Chem., 79, 4940 (2014)

58. M.A.Kravchenko, E.V.Verbitskiy, I.D.Medvinskiy, G.L.Rusinov, V.N.Charushin. Bioorg. Med. Chem. Lett., 24, 3118 (2014)

59. S.Achelle, A.Barsella, C.Baudequin, B.Caro, F.Robin-le Guen. J. Org. Chem., 77, 4087 (2012)

60. J.Zhao, J.Sun, O.Simalou, H.Wang, J.Peng, L.Zhai, P.Xue, R.Lu. Dyes Pigm., 151, 296 (2018)

61. S.Achelle, J.Rodríguez-López, F.Bureš, F.Robin-le Guen. Dyes Pigm., 121, 305 (2015) 
62. P.Thirumurugan, D.Muralidharan, P.T.Perumal. Dyes Pigm., 81, 245 (2009)

63. Z.Zhang, C.Pi, H.Tong, X.Cui, Y.Wu. Org. Lett., 19, 440 (2017)

64. M.S.F.Franco, M.H.dePaula, P.C.Glowacka, F.Fumagalli, G.C.Clososki, F.daSilva Emery. Tetrahedron Lett., 59, 2562 (2018)

65. N.A.Kazin, Y.A.Kvashnin, R.A.Irgashev, W.D.Dehaen, G.L.Rusinov, V.N.Charushin. Tetrahedron Lett., 56, 1865 (2015)

66. E.V.Verbitskiy, P.A.Slepukhin, M.A.Kravchenko, S.N.Skornyakov, N.P.Evstigneeva, N.V.Kungurov, N.V.Zil'berberg, G.L.Rusinov, O.N.Chupakhin, V.N.Charushin. Bioorg. Med. Chem. Lett., 25, 524 (2015)

67. A.A.Kalinin, S.M.Sharipova, T.I.Burganov, A.I.Levitskaya, Y.B.Dudkina, A.R.Khamatgalimov, S.A.Katyuba, Y.H.Budnikova, M.Y.Balakina. Dyes Pigm., 156, 175 (2018)

68. D.W.Chang, S.-J.Ko, J.Y.Kim, L.Dai, J.-B.Baek. Synth. Met., 162, 1169 (2012)

69. S.Achelle, A.Barsella, B.Caro, F.Robin-le Guen. RSC Adv., 5, 39218 (2015)

70. S.Achelle, J.Rodríguez-López, C.Katan, F.Robin-le Guen. J. Phys. Chem. C, 120, 26986 (2016)

71. F.Castet, A.Pic, B.Champagne. Dyes Pigm., 110, 256 (2014)

72. B.Zhu, T.Zhang, Q.Jiang, Y.Li, Y.Fu, J.Dai, G.Li, Q.Qi, Y.Cheng. Chem. Commun., 54, 11558 (2018)

73. R.Chauhan, M.Shahid, M.Trivedi, D.P.Amalnerkar, A.Kumar. Eur. J. Inorg. Chem., 3700 (2015)

74. K.Senthilkumar, K.Thirumoorthy, C.Dragonetti, D.Marinotto, S.Righetto, A.Colombo, M.Haukka, N.Palanisami. Dalton Trans., 45, 11939 (2016)

75. D.Cvejn, S.Achelle, O.Pytela, J.-P.Malval, A.Spangenberg, N.Cabon, F.Bureš, F.Robin-le Guen. Dyes Pigm., 124, 101 (2016)

76. S.Achelle, S.Kahlal, J.-Y.Saillard, N.Cabon, B.Caro, F.Robin-le Guen. Tetrahedron, 70, 2804 (2014)

77. T.-C.Lin, W.Chien, C.-Y.Liu, M.-Y.Tsai, Y.-J.Huang. Eur. J. Org. Chem., 4262 (2013)

78. H.-J.Lee, H.Xin, S.-M.Park, S.-I.L.Park, T.Ahn, D.-K.Park, S.A.Jenekhe, T.-W.Kwon. Bull. Korean Chem. Soc., 33, 1627 (2012)

79. A.Slodek, M.Filapek, G.Szafraniec, I.Grudzka, W.A.Pisarki, J.G.Malecki, L.Zur, M.Grela, W.Danikiewicz, S.Krompiec. Eur. J. Org. Chem., 5256 (2014)

80. G.C.dos Santos, A.de Andrade Bartolomeu, V.Farias Ximenes, L.C.da Silva-Filho. J. Fluoresc., 27, 271 (2017)

81. X.Cao, Q.Ding, A.Gao, Y.Li, X.Chang, Y.Wu. New J. Chem., 42, 6305 (2018)

82. C.Tran, N.Berqouch, H.Dhimane, G.Clermont, M.Blanchard-Desce, D.Ogden, P.I.Dalko. Chem. Eur. J., 23, 1860 (2017) 
83. G.C.dos Santos, R.Oliveira Servilha, E.F.de Oliveira, F.C.Lavarda, V.F.Ximenes, L.C.da SilvaFilho. J. Fluoresc., 27, 1709 (2017)

84. V.Kumar, M.Gohain, J.H.VanTonder, S.Ponra, B.C.B.Bezuindenhoudt, O.M.Ntwaeabrowa, H.C. Swart. Optical Mater., 50, 275 (2015)

85. M.Ghate, H.K.Dahule, N.T.Kalyani, S.J.Dhoble. Lumiescence, 33, 297 (2018)

86. P.A.More, G.S.Shankarling. Sens. Actuators B-Chem., 241, 552 (2017)

87. J.Han, X.Tang, Y.Wang, R.Liu, L.Wang, L.Ni. Spectrochimica Acta A, 205, 597 (2018)

88. Q.Wu, M.Mao, W.Liang, F.J.Stadler. Talanta, 186, 110 (2018)

89. H.G.Bonacorso, M.B.Rodrigues, B.A.Iglesias, C.H.da Silveira, S.C.Feitosa, W.C.Rosa, M.A.P.Martins, C.P.Frizzo, N.Zapatta. New J. Chem., 42, 10024 (2018)

90. S.Kotowicz, M.Siwy, M.Filapek, J.G.Malecki, K.Smolarek, J.Grzelak, S.Mackoski, A.Slodek, E.Schab-Balcerzak. J. Lumin., 183, 458 (2017)

91. B.Czaplinska, A.Maron, J.G. Malecki, G.Szafraniec-Gorol, M.Matussek, K.Malarz, A.MrozekWilczkiewicz, W.Danikiewicz, R.Musiol, A.Slodek. Dyes Pigm., 144, 119 (2017)

92. A.Slodek, M.Matussek, M.Filapek, G.Szafraniec, AQ.Szlapa, I.Grudzka-Flak, M.Szczurek, J.G.Malecki, A.Maron, E.Schab-Balcerzak, E.M.Nowak, J.Sanetra, M.Olejnik, W.Danikiewicz, S.Krompiec. Eur. J. Org. Chem., 2500 (2016)

93. C.-H.Chen, L.-C.Hsu, P.Rajamalli, Y.-W.Chang, F.-ly.Wu, C.-Y.Liao, M.-J.Chiu, P.-Y.Chou, M.J.Huang, L.-K.Chu, C.H.Cheng. J. Mater. Chem. C, 2, 6183 (2014)

94. I.Bhattacharjee, N.Acharya, H.Bhatia, D.Ray. J. Phys. Chem. Lett., 9, 2733 (2018)

95. S.Picard, E.Genin, G.Clermont, V.Hugues, O.Mongin, M.Blanchard-Desce, New. J. Chem., 37, 3899 (2013)

96. S.Alapour, S.J.Zamisa, J.R.A.Silva, C.N.Alves, B.Omondi, D.Ramjugernath, N.A.Koorbanally. CrysEngComm, 20, 2316 (2018)

97. S.Picard, G.Clermont, E.Genin, M.Blanchard-Desce. Tetrahedron, 71, 1088 (2015)

98. J.G.Croissant, S.Picard, D.Aggad, M.Klausen, C.M.Jimenez, M.Maynadier, O.Mongin, G.Clermont, E.Genin, X.Cattoën, M.Wong Chi Man, L.Raehm, M.Garcia, M.Gary-Bobo, M.Blanchard-Desce, J.-O.Durand. J. Mater. Chem. B, 4, 5567 (2016)

99. P.Ning, P.Dong, Q.Geng, L.Bai, Y.Ding, X.Tian, R.Shao, L.Li, X.Meng, J. Mater. Chem. B, 5, 2743 (2017)

100. H.Yang, G.Fang, M.Guo, P.Ning, Y.Feng, H.Yu, X.Meng. Sensors Actuators B, 270, 318 (2018) 101. H.K.Paumo, M.J.Mphahlele, L.Rhyman, P.Ramasami. Tetrahedron, 72, 123 (2016) 102. Y.Yan, Y.Zhang, C.Feng, Z.Zha, Z.Wang, Angew. Chem. Int. Ed., 51, 8077 (2012) 103. D.Liu, Z.Zhang, H.Zhang, Y.Wang. Chem. Commun., 49, 10001 (2013) 104. B.K.Dwivedi, V.D.Singh, R.P.Paitandi, D.S.Pandey. ChemPhysChem, 19, 2672 (2018) 
105. S.Achelle, F.Robin-le Guen. J. Photochem. Photobiol. A, 348, 281 (2017)

106. E.V.Nosova, T.N.Moshkina, G.N.Lipunova, D.S.Kopchuk, P.A.Slepukhin, I.V.Baklanova, V.N. Charushin. Eur. J. Org. Chem., 2876 (2016)

107. E.V.Nosova, T.N.Moshkina, G.N.Lipunova, I.V.Baklanova, D.S.Kopchuk, P.A.Slepukhin, V.N.Charushin. Mendeleev Commun., 28, 14 (2018)

108. E.V.Nosova, T.N.Moshkina, G.N.Lipunova, E.S.Kelbysheva, N.M.Loim, P.A.Slepukhin, V.N.Charushin, I.V.Baklanova. Mendeleev Commun., 28, 33 (2018)

109. X.Wang, J.Li, Y.Huang, J.Zhu, R.Hu, W.Wu, H.Jiang. J. Org. Chem., 83, 10453 (2018)

110. Z.Zhang, J.Xie, H.Wang, B.Shen, J.Zhang, J.Hao, J.Cao, Z.Wang. Dyes Pigm., 125, 299 (2016)

111. D.Y.Kim, J.Kang, S.E.Lee, Y.K.Kim, S.S.Yoon. Luminescence, 32, 1180 (2017)

112. M.J.Mphahlele, H.K.Paumo, L.Rhyman, P.Ramasami. Molecules, 20, 14656 (2015)

113. H.K.Paumo, M.J.Mphahlele, L.Rhyman, P.Ramasami. Tetrahedron, 72, 123 (2016)

114. M.J.Mphahlele, H.K.Paumo, A.M.El-Nahas, M.M.El-Hendawy. Molecules, 19, 795 (2014)

115. T.N.Moshkina, E.V.Nosova, G.N.Lipunova, M.S.Valova, V.N.Charushin. Asian J. Org. Chem., 7, $1080(2018)$

116. T.-C. Lin, Y.-H. Lee, C.-Y. Liu, B.-R. Huang, M.-Y. Tsai, Y.-J. Huang, J.-H. Lin, Y.-K. Shen, C.-Y. Wu Chem. Eur. J., 19, 749 (2013)

117. K.B.Harsha, S.Rangappa, H.D.Preethem, T.R.Swaroop, M.Gilandoust, K.S.Rakesh, K.S.Rangappa, Chem. Select, 3, 5228 (2018)

118. R.D.Telore, A.G.Jadhav, N.Sekar. J. Fluoresc., 27, 1531 (2017)

119. X.Meng, X.Bi, C.Chaoying, G.Chen, B.Chen, Z.Jing, P.Zhao. Green Chem., 20, 4638 (2018)

120. M.Mio, T.Rie, U.Yuu, Y.Mizuki, M.Yuki, K.Naoki, Y.Shuji. Heterocycles, 93, 75 (2016)

121. K.Das, A.Mondai, D.Srimani. Chem. Commun., 54, 10582 (2018)

122. S.Shee, K.Ganguli, K.Jana, S.Kundu. Chem. Commun., 54, 6883 (2018)

123. K.Gopalaiah, A.Saini, S.N.Chandrudu, D.C.Rao, H.Yadav, B.Kumar. Org. Biomol. Chem., 15, 2259 (2017)

124. I.A.Utepova, A.A.Musikhina, O.N.Chupakhin. Rus. Chem. Bull., 65, 2523 (2016)

125. K.Pei, Y.Wu, A.Islam, Q.Zhang, L.Han, H.Tian, W.Zhu. ACS Appl. Mater. Interfaces, 5, 4986 (2013)

126. S.Xu, L.Feng, J.Yuan, Z.-G.Zhang, Y.Li, H.Peng, Y.Zou. ACS Appl. Mater. Interfaces, 9, 18816 (2017)

127. J.Nafe, S.Herbert, F.Auras, K.Karaghiosoff, T.Bein, P.Knochel. Chem. Eur. J., 21, 1102 (2015)

128. X.Lu, S.Fan, J.Wu, X.Jia, Z.-S.Wang, G.Zhou. J. Org. Chem., 79, 6480 (2014)

129. M.Bourass, A.T.Benjelloun, M.Benzakour, M.Mcharfi, F.Jhilal, M.Hamidi, M.Bouachrine. New J. Chem., 41, 13336 (2017) 
130. Z.Zhang, Z.Dai, X.Jiang. Asian J. Org. Chem., 4, 1370 (2015)

131. T.I.Burdanov, N.A.Zhukova, V.A.Mamedov, C.Bannwarth, S.Grimme, S.A.Katsuba. Phys. Chem. Chem. Phys., 19, 6095 (2017)

132. C.F.Gers-Panther, H.Fischer, J.Nordmann, T.Seiler, T.Behnke, C.Würth, W.Frank, U.ReschGenger, T.J.J.Müller. J. Org. Chem., 82, 567 (2017)

133. F.K.Merkt, T.J.J.Müller. Sci. China Chem., 61, 909 (2018)

134. F.K.Merkt, S.P.Höwedes, C.F.Gers-Panther, I.Gruber, C.Janiak, T.J.J.Müller. Chem. Eur. J., 24, 8114 (2018)

135. L.Wang, M.Cui, H.Tang, D.Cao. Dyes Pigm., 155, 107 (2018)

136. L.Yu, Z.Wu, G.Xie, C.Zhong, Z.Zhu, D.Ma, C.Yang. Chem. Commun., 54, 1379 (2018)

137. L.Yu, Z.Wu, G.Xie, C.Zhong, Z.Zhu, H.Cong, D.Ma, C.Yang. Chem. Commun., 52, 11012 (2016)

138. L.Yu, Z.Wu, C.Zhong, G.Xie, K.Wu, D.Ma, C.Yang. Dyes Pigm., 141, 325 (2017)

139. D.H.Kim, K.Inada, L.Zhao, T.Komino, N.Matsumoto, J.C.Ribierre, C.Adachi. J. Mater. Chem. C, 5, 1216 (2017)

140. H.Kim, M.R.Reddy, S.-S.Hong, C.Kim, S.-Y.Seo. J. Nanosci. Nanotechnol., 17, 5530 (2017)

141. L.-N.Yang, S.-C.Li, Z.-S.Li, Q.-S.Li. RSC Adv., 5, 25079 (2015)

142. D.Gedefaw, M.Prosa, M.Bolognesi, M.Seri, M.R.Andersson. Adv. Energy Mater., 1700575 (2017)

143. J.Yuan, J.Ouyang, V.Cimrová, M.Leclerc, A.Najari, Y.Zou. J. Mater. Chem. C, 5, 1858 (2017)

144. M.Liu, Y.Gao, Y.Zhang, Z.Liu, L.Zhao. Polym. Chem., 8, 4613 (2017)

145. S.Fan, K.Lv, H.Sun, G.Zhou, Z.-S.Wang. J. Power Sources, 279, 36, (2015)

146. M.-L.Han, Y.-Z.Zhu, S.Liu, Q.-L.Liu, D.Ye, B.Wang, J.-Y.Zheng. J. Power Sources, 387, 117 (2018)

147. K.Zhang, W.Zhang, J.Huang, A.Pang, M.S.Wong. Org. Electron., 42, 275 (2017)

148. Y.Wang, Z.Zheng, T.Li, N.Robertson, H.Xiang, W.Wu, J.Hua, W.-H.Zhu, H.Tian. ACS Appl. Mater. Interfaces, 8, 31016 (2016)

149. L.Xu, C.Xin, C.Li, W.Wu, J.Hua, W.Zhu. Solar Energy, 169, 450 (2018)

150. H.-X.Ji, Z-S.Huang, L.Wang, D.Cao. Dyes Pigm., 159, 8 (2018)

151. M.Godfroy, C.Aumaitre, F.Caffy, Y.Kervella, L.Cabau, L.Pellejà, P.Maldivi, S.Narbey,

F.Oswald, E.Palomares, D.Joly, R.Demadrille. Dyes Pigm., 146, 352 (2017)

152. L.-W.Ma, Z.-S.Huang, S.Wang, H.Meier, D.Cao. Dyes Pigm., 145, 126 (2017)

153. X.Lu, Q.Feng, T.Lan, G.Zhou, Z.-S.Wang. Chem. Mater., 24, 3179 (2012)

154. X.Lu, T.Lan, Z.Qin, Z.-S.Wang, G.Zhou. ACS Appl. Mater. Interfaces, 6, 19308 (2014)

155. X.Jia, W.Zhang, X.Lu, Z.-S.Wang, G.Zhou. J. Mater. Chem. A, 2, 19515 (2014) 
156. X.Lu, X.Jia, Z.-S.Wang, G.Zhou. J. Mater. Chem. A, 1, 9697 (2013)

157. C.Shen, Y.Wu, W.Zhang, H.Jiang, H.Zhang, E.Li, B.Chen, X.Duan, W.-H.Zhu. Dyes Pigm., 149, 65 (2018)

158. X.Li, B.Xu, P.Liu, Y.Hu, L.Kloo, J.Hua, L.Sun, H.Tian. J. Mater. Chem. A, 5, 3157 (2017)

159. Z.Shen, B.Xu, P.Liu, Y.Hu, Y.Yu, H.Ding, L.Kloo, J.Hua, L.Sun, H.Tian. J. Mater. Chem. A, 5, 1242 (2017)

160. T.Kono, T.N.Murakami, J.-I.Nishida, Y.Yoshida, K.Hara, Y.Yamashita. Org. Electron., 13, 3097 (2012)

161. J.Yu, W.Zhu, H.Tan, Q.Peng. Chem. Phys. Lett., 667, 254 (2017)

162. X.Qi, Y.-C.Lo, Y.Zhao, L.Xuan, H.-C.Ting, K.-T.Wong, M.Rahaman, Z.Chen, L.Xiao, B.Qu. Frontiers Chem., 6, 260 (2018)

163. X.Liu, T.Liu, C.Duan, J.Wang, S.Pang, W.Xiong, Y.Sun, F.Huang, Y.Cao. J. Mater. Chem. A, 5, 1713 (2017)

164. J.Deng, Q.Tao, D.Yan, X.Huang, Y.Liao. Mater. Sci. Poland, 36, 167 (2018)

165. B.Xiao, A.Tang, J.Yang, A.Mahmood, X.Sun, E.Zhou. ACS Appl. Mater. Interfaces, 10, 10254 (2018)

166. M.Hu, Q.Xu, Y.Jiang, H.Mu, L.Gao, P.Hu, J.Huang, J.Su. Dyes Pigm., 150, 185 (2018)

167. H.Zhang, Y.Wu, W.Zhang, E.Li, C.Shen, H.Jiang, H.Tian, W-H.Zhu. Chem. Sci., 9, 5919 (2018)

168. T.-D.Nguyen, V.-S.Dang, V.-H.Nguyen, T.M.-T.Nguyen, C.-H.Dang. Polycycl. Aromatic

Compds, 38, 42 (2018)

169. T.-C.Lin, Y.-Y.Liu, M.-H.Li, Y.-H.Lee. Dyes Pigm., 109, 72 (2014)

170. E.V.Verbitskiy, G.L.Rusinov, O.N.Chupakhin. Arkivoc, i, 356 (2017)

171. J.R.Berenguer, E.Lalinde, M.T.Moreno, S.Sanchez, J.Torroba. Inorg. Chem., 51, 11665 (2012)

172. H-W.Fan, F-Q.Bai, Z-X.Zhang, Y.Wang, Z-X.Qu, R-L.Zhong, H-X.Zhang. RSC Adv., 7, 17368 (2017)

173. B.Jiang, X.Ning, S.Gong, N.Jiang, C.Zhong, Z-H.Lu, C.Yang. J. Mater. Chem. C, 5, 10220 (2017)

174. H.Shahroosvand, S.Resaei, E.Mohajerani, M.Mahmoidi, M.A.Kamyabi, S.Nasiri. New J. Chem.,

38, 5312 (2014)

175. S.S.Bhat, V.K.Revankar, A.Khan, R.J.Buther, K.Thatipamula. New J. Chem., 39, 3646 (2015)

176. F.Yu, W-K.Chu, C.Shen, Y.Luo, J.Xiang, S-Q.Chen, C-C.Ko, T-C.Lau. Eur. J. Inorg. Chem., 3892 (2016)

177. S.Dasari, A.K.Patra. Dalton Trans., 44, 19844 (2015)

178. D.Wang, J-D.Zheng, X-J.Zheng, D-C.Fang, D-Q.Yuan, L-P.Jin. Sens. Actuat.. B: Chemical, 228, 387 (2016) 
179. P.Acosta, A.Ortiz, B.Insuasty, R.Abonia, J.Quiroga. Monatsh. Chem., 148, 237 (2017)

180. Patent WO2017160905A1 (2017)

181. Patent US20170373257A1 (2017)

182. Patent US2014/0034925A1 (2014)

183. E.V.Verbitskiy, G.L.Rusinov, O.N.Chupakhin, V.N.Charushin ARKIVOC, (iv), 204 (2016)

184. E.V.Verbitskiy. Dissertation doctor of chemical sciences. UrFU, Ekaterinburg, 2019

185. T-H.Su, C-H.Fan, Y-H.Ou-Yang, L-C.Hsu, C-H.Cheng. J. Mater. Chem. C, 1, 5084 (2013)

186. A.Danel, B.Jarosz, P.Karasinski, B.Sahraoui, P.Armatys. Mater. Lett., 138, 9 (2015)

187. L.Lan, Z.Chen, L.Ying, F.Huang, Y.Cao. Org. Electronics, 30, 176 (2016)

188. H.Sakai, S.Shinto, Y.Araki, T.Wada, T.Sakanoue, T.Takenobu, T.Hasobe. Chem. Eur. J., 20, 10099 (2014)

189. H.Sakai, S.Shinto, J.Kumar, Y.Araki, T.Sakanoue, T.Takenobu, T.Wada, T.Kawai, T.Hasobe. J.

Phys. Chem., 119, 13937 (2015)

190. Y.Yamamoto, H.Sakai, J.Yuasa, Y.Araki, T.Wada, T.Sakanoue, T.Takenobu, T.Kawai,

T.Hasobe. Chem. Eur. J., 22, 4263 (2016)

191. A.Ekbote, T.Jadhav, R.Misra. New J. Chem., 41, 9346 (2017)

192. T.Ishi, I.Y.Moriyama. Tetrahedron, 73, 1157 (2017)

193. Patent JPWO2015137244 (2017)

194. B.Laramee-Milette, J.G.Ferreira, G.S.Hanan. ChemistrySelect, 2, 3952 (2017)

195. A.Upadhyay, S.Karpagam. J. Photopolym. Sci. Technol., 28, 755 (2015)

196. A.Upadhyay, S.Karpagam. J. Fluoresc. 26, 439 (2016)

197. A.Upadhyay, S.Karpagam. Dyes Pigm., 139, 50 (2017)

198. T.Guo, W.Zhong, J.Zou, L.Zing, W.Yang, J.Peng. RSC Adv., 5, 89888 (2015)

199. Y.Kang, R.Agneewari, J.Lee, J.H.Kwon, V.Tamilavan, S.S.Park, S.H.Park, Y.Jin. Macromol. Chem. Phys., 1800117 (2018)

200. T.Wang, T-K.Lau, X.Lu, J.Yuan, L.Feng, LJiang, W.Deng, H.Peng, Y.Li, Y.Zou. Macromolecules, 51, 2838 (2018)

201. J.Yang, M.A.Uddin, Y.Tang, Y.Wang, Y.Wang, H.Su, R.Gao, Z-K.Chen, J.Dai, H.Y.Woo,

X.Guo. ACS Appl. Mater. Interfaces, 10, 23235 (2018)

202. L.Wang, H.Liu, Z.Huai, Y.Li, S.Yang. Dyes Pigm., 148, 72 (2018)

203. Y.Lin, X.Chen, C.Jiang, M.Zhao, Y.Li, H.Wang. Org. Electron., 61, 197 (2018)

204. I.A.Jessop, F.R.Diaz, C.A.Terraza, A.Tundidor-Camba, A.Leiva, L.Cattin, J-C.Bernede.

Polymers, 10, 553 (2018)

205. Y.Nagata, T.Nishikawa, M.Suginome. Chem. Commun., 50, 9951 (2014) 
206. Y.Nagata, T.Yamada, T.Adachi, Y.Akai, T.Yamamoto, M.Suginome. J. Am. Chem. Soc., 135, 10104 (2013)

207. T.Nishikawa, Y.Nagata, M.Suginome. ACS Macro Lett., 6, 431 (2017)

208. Y.Tokoro, H.Yeo, K.Tanaka, Y.Chujo. Pol. Chem., 4, 5237 (2013)

209. C.Perez-Bolivar, S.Takizawa, G.Nishimura, V.A.Montes, P.Anzenbacher Jr. Chem. -Eur. J., 17, 9076 (2011)

210. X.Zhang, S.Shi, Q.Liu, J.Zhou, J.Ye, C.Yu. Chem. Commun., 47, 6359 (2011)

211. X.Yang, G.Zhou, W-Y.Wong. Chem. Soc. Rev., 44, 8484 (2015)

212. F.A.Rafiqi, K.Majid. RSC. Adv., 6, 22016 (2016)

213. F.A.Mautner, C.Berger, R.C.Fischer, S.S.Massoud. Inorg. Chim. Acta, 439, 69 (2016)

214. X-X.Jin, B.Ye, L-L.Xu, A-B.Wu, J.Xiang. Z. Anorg. Allg. Chem., 643, 1195 (2017)

215. Y.Mikata, R.Ohnishi, R.Nishijima, A.Matsumoto, H.Konno. Inorg. Chem., 57, 7724 (2018)

216. Patent CN 104829636 (2015)

217. C-W.Hsu, C-C.Lin, M-W.Chung, Y.Chi, G-H.Lee, P-T.Chou, C-H.Chang, P-Y.Chen. J. Am. Chem. Soc., 44, 12085 (2011)

218. P.Chakraborty, S.Mondal, S.Das, A.D.Jana, D.Das. Polyhedron, 70, 11 (2014)

219. B.Machura, I.Nawrot, R.Kruszynski, M.Dulski. Polyhedron, 54, 272 (2013)

220. S.Y.Liu, X.L.Qi, R.B.Lin, X.N.Cheng, P.Q.Liao, J.P.Zhang, X.M.Chen. Adv. Funct. Mater., 24, 5866 (2014)

221. Y.Song, R-Q.Fan, H-J.Zhang, Z-W.Liu, X-T.Wang, C-T.Tan, Y-L.Yang, Y-L.Wang. RSC Adv., 5, $17343(2015)$

222. Yu.V.Kokunov, Yu.E.Gorbunova,V.V.Kovalev, S.A.Kozyukhin. Russ. J. Coord. Chem., 41, 747 (2015)

223. L.Li, S.Chen, R-M.Zhou,Y.Bai,D-B.Dang. Spectrochim. Acta. A : Mol. Biomol. Spectroscopy. 120, 401 (2014)

224. W.Zhu, C-K.Xia, Y-L.Wu, J-M.Xie. Z. Anorg. Allg. Chem., 640, 1518 (2014)

225. X.Zhang, Z-J.Wang, S-G.Chen, Z-Z.Shi, J-X.Chen, H-G.Zheng. Dalton Trans., 46, 2332 (2017)

226. K.Ostrowska, K.Stadnicka, M.Gryl, B.Musielak, L.J.Witek, O.Bochenska. Polyhedron, 133, 294 (2017)

227. A.Chen, S.Meng, J.Zhang, C.Zhang. J. Mol. Struct., 1050, 15 (2013)

228. A.Chen, S.Meng, J.Zhang, C.Zhang. Mol. Cryst. Liq. Cryst., 605, 187 (2014)

229. A.Chen, S.Meng, J.Zhang, C.Zhang. Inorg. Chem. Commun., 35, 276 (2013)

230. S.Mukherjee, S.Talukder. J. Lumin., 177, 40 (2016)

231. S.Mukherjee, S.Talukder. J. Fluoresc., 26, 1021 (2016)

232. K.Ocakoglu, E.Harputlu, P.Guloglu, S.Erten-Ela, Inorg. Chem. Commun. 24, 118 (2012) 
233. J.G.Malecki, A.Maron, I.Gryca, A.Mori, T.Suzuki. Polyhedron, 62, 188 (2013)

234. J.Wang, Y.Shang. J. Korean Chem. Soc. 56, 313 (2012)

235. O.J.Stacey, B.D.Ward, S.J.Coles, P.N.Horton, S.J.A.Pope. Dalton Trans., 45, 10297 (2016)

236. H.Li, W.Yuan, X.Wang, H.Zhan, Z.Xie, Y.Cheng. J. Mater. Chem. C. 3, 2744 (2015)

237. S.Jamali, R.Czerwieniec, R.Kia, Z.Jamshidi, M.Zabel. Dalton Trans., 40, 9123 (2011)

238. A.Bossi, A.F.Rausch, M.J.Leitl, R.Czerwieniec, M.T.Whited, P.I.Djurovich, H.Yersin, M.E.Thompson. Inorg. Chem., 52, 12403 (2013)

239. S.Culham, P-H.Lanoe, V.L.Whittle, M.C.Durrant, J.A.GaretzWilliams. Inorg. Chem., 52, 10992 (2013)

240. Y.Zhu, K.Luo, L.Zhao, H.Ni, Q.Li. Dyes Pigm., 145, 144 (2017)

241. E.V.Nosova, T.N.Moshkina, D.S.Kopchuk, G.N.Lipunova, P.A.Slepukhin, V.N.Charushin. Mendeleev Commun., 26, 129 (2016)

242. W-K.Chung, M.Ng, N.Zhu, S.K-L.Siu, V.W-W.Yam. J. Organomet. Chem., 847, 278 (2017)

243. C-L.Ho, H.Li, W-Y.Wong. J. Organomet. Chem., 751, 261 (2015)

244. J.M.Lim, J-Y.Kwon, F.Xu, H.U.Kim, D-H.Hwang. J. Nanosci. Nanotech., 13, 8007 (2013)

245. B.Umamahesh, N.S.Karthikeyan, K.I.Sathiyanarayanan, J.M.Malicka, M.Cocchi. J. Mater. Chem. C, 4, 10053 (2016)

246. D-P.Gong, T-B.Gao, D-K.Cao, M.D.Ward. Dalton Trans., 46, 275 (2017)

247. E.E.Langdon-Jones, A.J.Hallett, J.D.Routledge, D.A.Crole, B.D.Ward, J.A.Platts, S.J.A.Pope. Inorg. Chem., 52, 448 (2013)

248. H-B.Han, R-Z.Cui, G-Z.Lu, Z-G.Wu, Y-X.Zheng, L.Zhou, H.Zhang. Dalton Trans., 46, 14916 (2017)

249. H-B.Han, R-Z.Cui, Y-M.Jing, G-Z.Lu, Y-X.Zheng, L.Zhou, J-L.Zuo, H.Zhang. J. Mater. Chem. C, 5, 8150 (2017)

250. D.J.Lewis, F.Moretta, A.T.Holloway, Z.Pikramenou. Dalton Trans., 41, 13138 (2012)

251. K.Singh, S.Banerjee, A.K.Patra. RSC Adv., 5, 107503 (2015)

252. H.Hammoud, A.deBettencourt-Dias, M.Schmitt, J.H.S.K.Montriro, J.S.Rossini, A.Lecointre,

S.Gallet, J-J.Bourguignon, S.Mameri. ChemistrySelect, 1, 6618 (2016)

253. M.Mihorianu, M.Leonzio, M.Monari, L.Ravotto, P.Ceroni, M.Bettinelli, F.Piccinelli. ChemistrySelect, 1, 1996 (2016)

254. J.Wang, H.Li, P.Chen, M.Zhang, W.Sun, P.Yan. Z. Anorg. Allg. Chem., 642, 368 (2016)

255. H-Y.Shen, W-M.Wang, H-L.Gao, J-Z.Cui. RSC Adv., 6, 34165 (2016)

256. J.Zhang, W-B.Yang, C-Z.Lu. Dalton Trans., 44, 13586 (2015)

257. H.Zhang, R.Fan, P.Wang, X.Wang, S.Gao, Y.Dong, Y.Wang, Y.Yang. RSC Adv., 5, 38254 (2015) 
258. G.N.Lipunova, E.V.Nosova, V.N.Charushin, O.N.Chupakhin. Comments Inorg. Chem., 36, 245 (2016)

259. X.Zhu, H.Huang, R.Liu, X.Jin. Y.Li, D.Wang, Q.Wang, H.Zhu. J. Mater. Chem. C. 3, 3774 (2015)

260. U.Balijapalli, S.K.Iyer. Eur. J. Org. Chem., 5089 (2015)

261. A.Zakrzewska, E.Kolehmainen,A.Valkonen, E.Haapaniemi, K.Rissanen, L.Checinska, B.Osmialowska. J. Phys. Chem. A. 117, 252 (2013)

262. A.Zakrzewska, R.Zalesny, E.Kolehmainen, B.Osmialowska, B.Jedrzejewska, H.Agren, M.Pietrzak. Dyes Pigm., 99, 957 (2013)

263. A.M.Grabarz, B.Jedrzejewska, A.Zakrzewska, R.Zalesny, A.D.Laurent, D.Jacquemin, B.Osmialowska. J. Org. Chem., 82, 1529 (2017)

264. C.W.Liao, R.M.Rao, S.-S.Sun. Chem. Comm., 51, 2656 (2015)

265. E.V.Nosova, T.N.Moshkina, G.N.Lipunova, I.V.Baklanova, P.A.Slepukhin, V.N.Charushin. J. Fluorine Chem., 175, 145 (2015)

266. T.N.Moshkina, E.V.Nosova, G.N.Lipunova, M.S.Valova, O.S.Taniya, P.A.Slepukhin, V. N.Charushin. J. Fluorine Chem., 221, 17 (2019)

267. M.F.Budyka. Russ. Chem. Rev., 86, 181 (2017)

\section{Data for front page}

E.V.Nosova. Doctor of chemical sciences, Professor at Organic and biomolecular chemistry department of Chemical Technology Institute UrFU; senior researcher at Laboratory of heterocyclic compounds, IOS Ural Branch of RAS

E-mail: emilia.nosova@yandex.ru

Scientific interests: benzazines, antitubercular agents, luminophores

S.Achelle. $\mathrm{Ph} \mathrm{D}$, Habilitation to direct research, Associate Professor in the Institut des sciences Chimiques de Rennes, Université de Rennes 1

E-mail: sylvain.achelle@univ-rennes1.fr

Scientific interests: functionalized $\pi$-conjugated materials, diazine chromophores, structure-property relationships, applications as fluorescent sensors, white light emission and nonlinear optics.

G.N.Lipunova. Doctor of chemical sciences, Professor

Leading researcher at laboratory of coordination compounds IOS Ural Branch of RAS, researcher at Organic and biomolecular chemistry department of Chemical Technology Institute UrFU Scientific interests: azaheterocycles, coordination compounds, luminophores. 
V.N.Charushin. Academician of RAS, doctor of chemical sciences, Professor RAS. Director of IOS Ural Branch of RAS, Professor at Organic and biomolecular chemistry department, Chemical Technology Institute UrFU.

E-mail: Valery-Charushin-562@yandex.ru

Scientific interests: uncatalyzed by transition metal nucleophilic substitution of hydrogen in arenes and hetarenes, PASE methods in the synthesis of azaheterocycles, biologically active compounds, luminophores.

O.N.Chupakhin. Academician of RAS, doctor of chemical sciences, Professor RAS. Professor at Organic and biomolecular chemistry department, Chemical Technology Institute UrFU, General researcher of IOS Ural Branch of RAS

Scientific interests: nucleophilic substitution of hydrogen, uncatalyzed by transition metal nucleophilic substitution of hydrogen in arenes and hetarenes, one-stage regioselective approaches to complicated heterocyclic structures, including bridged, alkaloid-like, supramolecular compounds; chemistry of fluorine-containing compounds, including heterocyclic ones; chemical aspects of environmental protection; biologically active compounds (antibacterial, antiviral, cardiotropic, antineoplastic agents). 